\title{
Masculinities and gender-based violence in South Africa: a study of a masculinities-focused intervention programme
}

\author{
by \\ Karen De Villiers Graaff
}
Dissertation presented for the degree of
Doctor of Philosophy in the
Faculty of Arts and Social Sciences
at Stellenbosch University

Supervisor: Prof L.P.T. Heinecken 


\section{DECLARATION}

By submitting this dissertation electronically, I declare that the entirety of the work contained therein is my own, original work, that I am the sole author thereof (save to the extent explicitly otherwise stated), that reproduction and publication thereof by Stellenbosch University will not infringe any third party rights and that I have not previously in its entirety or in part submitted it for obtaining any qualification.

March 2017

Copyright @ 2017 Stellenbosch University All rights reserved 


\section{ABSTRACT}

South Africa as a country experiences extremely high rates of violence and gender-based violence (GBV). A wide range of interventions have been implemented as a means to respond to these, including legislative changes from government, and women-focused reactive interventions which act as support for survivors of incidents of violence. However, these have had not a significant impact on reducing levels of GBV in the country, and this suggests that alternative methods need to be investigated. This research therefore focuses on a specific alternative - masculinities-focused interventions - in the hope of understanding how to improve the effect of these as a GBV reduction strategy.

A review of the literature focusing on causes of GBV point to a number of different opinions, ranging from individual aspects (such as substance abuse, or witnessed or experienced abuse) to more societal-level aspects (such as culture, and strain theories). However, few of these focus on the fact that it is overwhelmingly men who perpetrate violence in all regions and cultures. I therefore argue that an important aspect to understand when looking at GBV is the impact of hegemonic masculinities on men. Certain versions of masculinity, such as hypermasculinities and those associated with the military, have a specific emphasis on violence as a means of achievement, and societies where these forms of masculinity are prevalent and praised are therefore likely to display high levels of GBV.

The majority of GBV interventions in South Africa are reactive and survivor-focused. However, the literature suggests that these are not effective at reducing levels of GBV, resulting in attempts to focus specifically on men and masculinities in order to do so. While masculinities-focused interventions have a number of positive effects, little attention has thus far been paid to the way in which these effects are achieved. This research therefore aims to help understand how such interventions influence participants, and also those factors which motivate them to join and remain involved in the intervention, in order to contribute to the knowledge on how to improve these interventions in the future.

These questions were investigated through participant observation of workshops, focus group discussions with workshop participants, and one-on-one interviews with workshop participants, facilitators and practitioners in the field of GBV. Four focus groups were conducted, and one-on-one interviews with seven workshop participants and nine workshop facilitators and practitioners.

This study showed that the primary reason for participants joining is through a desire to be involved in community improvement, rather than a specific interest in GBV prevention. Supporting the notion that socialisation is heavily influenced by a person's peers, the 
aspects which were noted as having the biggest effect both during and after the intervention were the presence of a supportive peer group, and facilitators who acted as positive role models. These aspects motivated participants to want to shift their behaviour and become role models themselves. This study therefore highlights issues to consider in the improvement of GBV interventions as well as the implications for addressing GBV more broadly. 


\section{OPSOMMING}

As ' $n$ land het Suid-Afrika besonder höe vlakke van geweld en geslagsgebaseerde geweld (GGG). ' $n$ Wye spectrum van ingrypings is al toegepas om hierdie verskynsels aan te pak, hierby ingesluit wetsveranderings van regeringskant, en vrou-georienteerde reaktiewe ingrypings wat ondersteuning verskaf aan die oorlewendes van GGG. Maar hierdie ingrypings het nie 'n noemenswaardinge impak op GGG vlakke gehad nie, en dit wil voorkom asof alternatiewe middele ondersoek moet word. Hierdie navorsing fokus dan op ' $n$ spesifieke alternatief - manlikheids georienteerde ingrypings - met die doel om te verstaan hoe die impak van hierdie ingrypings as GGG verminderingstrategieë verbeter kan word.

'n Oorsig van die literatuur aangaande die oorsake van GGG dui op 'n aantal verskillende opinies, vanaf indiwiduele oorsake (soos dwelm misbruik, of waargenome of ervaarde mishandeling) na meer maatskaplike oorsake (soos kultuur en teorieë van spanning). Maar baie min van hierdie teorieë focus op die feit dat dit oorweldigend mans is wat verantwoordelik is vir hierdie geweld in alle gebiede en kulture. Ek argumenteer derhalwe dat ' $n$ belangrike aspek om in ag te neem met GGG is die impak van hegemoniese manlikhede op mans. Verskeie vorms van manlikheid, soos hipermanlikhede en daardie manlikhede wat met die militêr geassosieer word, het 'n spesifieke fokus op geweld as prestasiemiddel, en samelewings waar hierdie vorms van manlikheid sterk voorkom en geprys word is derhalwe geneig om hoë vlakke van GGG te openbaar.

Die meerderheid van GGG ingrypings in Suid-Afrika is reaktief en gefokus op die oorlewendes. Maar die literatuur wil voorgee dat hierdie ingrypings nie effektief is in die vermindering van GGG-vlakke nie, wat veroorsaak dat meer manlikhede-gefokuste ingrypings voorkom om hierdie doel te bereik. Terwyl manlikhede-gefokuste ingrypings ' $n$ aantal positiewe resultate vertoon, is daar tot dusver maar min aandag geskenk aan die maniere waarop hierdie resultate bereik word. Hierdie navorsing wil dan verstaan hoe sulke ingrypings deelnemers beinvloed, asook daardie faktore wat deelnemers motiveer om by die ingryping aan te sluit en betrokke te bly, met die doel om by te dra tot die kennis van hoe hierdie ingrypings in die toekoms verbeter kan word.

Hierdie vrae is deur middel van deelnemed waarneming van werkswinkels, fogus groep besprekings met werkswinkel deelnemers, en aangesig-tot-aangesig onderhoude met werkswinkel deelnemers, bemiddelaars en GGG praktisyns, ondersoek. Vier fokus groepe, aangesig-tot-aangesig onderhoude met sewe werkswinkel deelnemers en nege werkswinkel bemiddelaars en prakisyns, is gevoer. 
Hierdie studie het bewys dat die vernaamste rede waarom deelnemers aansluit is ' $n$ begeerte om betrokke te raak in gemeenskapsverbetering, eerder as ' $n$ spesifieke belangstelling in die voorkoming van GGG. In ondersteuning van die gedagte dat sosialisering noemenswaardig beïnvloed word deur 'n persoon se eweknieë, is die aspekte wat die grootste impak beide gedurende en na die ingryping gehad het die aanwesigheid van 'n ondersteunende ewekniegroep, en bemiddelaars wat as positiewe rolmodelle opgetree het. Hierdie aspekte het deelnemers gemotiveer om hulle gedrag te verander, en dus om hulleself rolmodelle te word. Hierdie studie onderstreep dus belangrike aspekte in die verbetering van GGG ingrypings sowel as die implikasies vir GGG ingrypings in die algemeen gesien. 


\section{ACKNOWLEDGEMENTS}

First thanks go to my supervisor, Prof Lindy Heinecken, who helped me find an actual topic out of all the vague ideas that I started out with. Thank you for the support and encouragement at times when I lost motivation, for regular reality checks, and for committing so much of your time and energy to help me get this dissertation in by deadline.

This research was made possible by a scholarship from the Graduate School of Arts and Social Sciences, which enabled me to commit to a full-time PhD, and ensured that I submitted on time to prove that I deserved it. Thank you to those who administrated the funding and provided invaluable skills-development and advice to make this goal achievable.

Thank you to all those at Sonke Gender Justice who made this research possible by being so generous with their time, help and patience. I was also constantly grateful for positive responses from those at organisations around Cape Town and South Africa, who took time out of their day to answer the questions of a student when they were busy implementing the theory.

Thank you to all the workshop participants who allowed me to observe their groups, and gave me so much time and honesty in focus groups and interviews.

To all the friends who helped keep me sane through a long and emotional process - thank you for taking me swimming, running and surfing to get me away from my desk, for dinners and lunchtime treats, and for believing that l'd finish when the light at the end of the tunnel was a long way off.

Thank you to my family for not complaining when I monopolised dinners with endless thesis talk, and to my brother Simon for setting the bar so high.

Finally, to my parents, Anna and Johann, thank you for mentorship, advice, support, editing, translation, contacts, and writing retreats throughout this entire process. Most importantly, thank you for sharing your love of learning so that I keep going back for more. 


\section{TABLE OF CONTENTS}

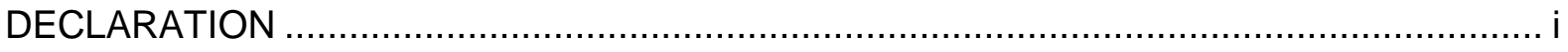

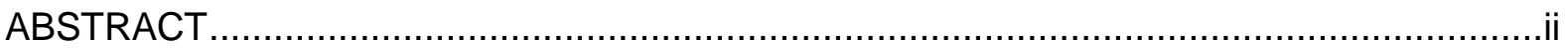

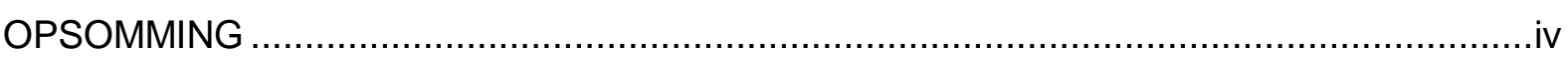

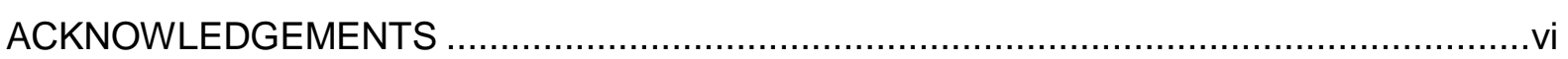

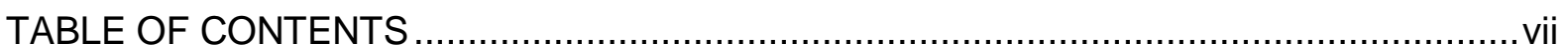

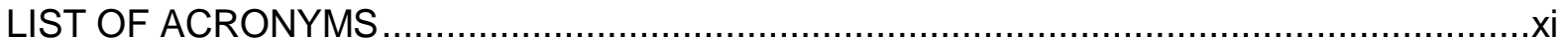

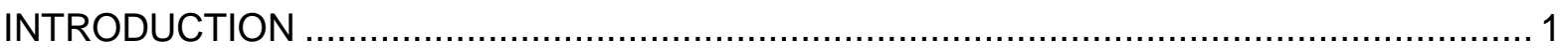

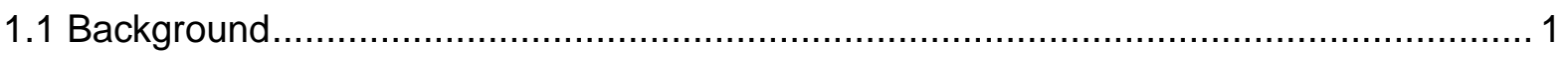

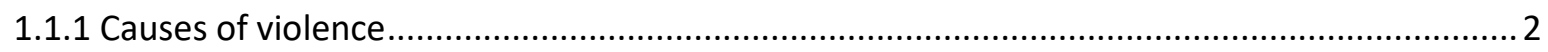

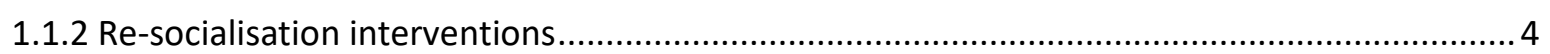

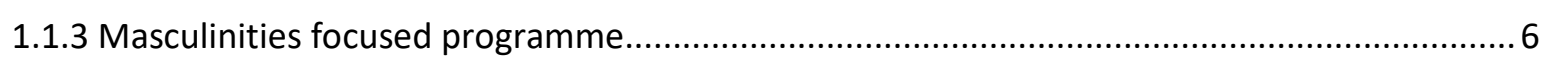

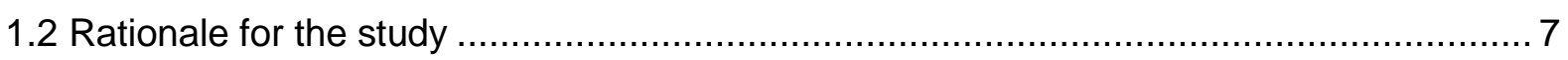

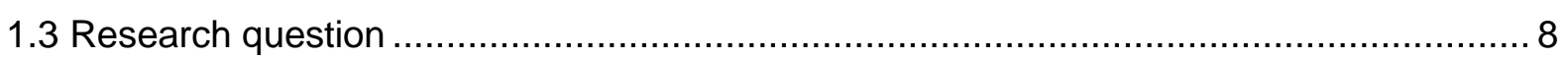

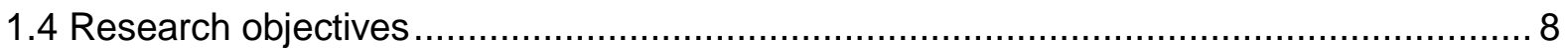

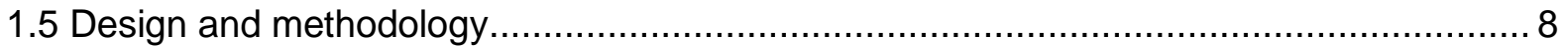

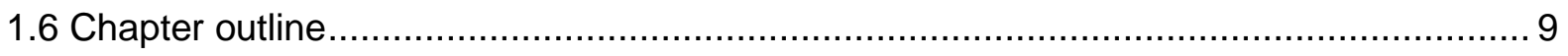

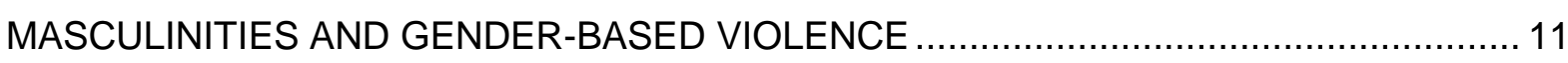

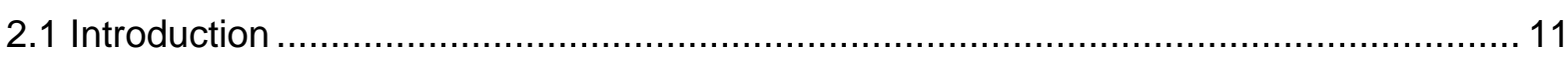

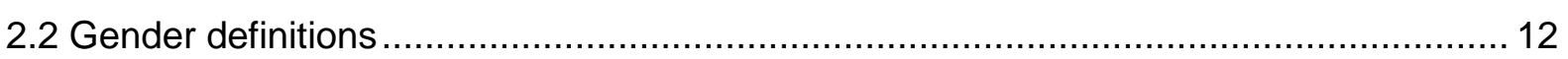

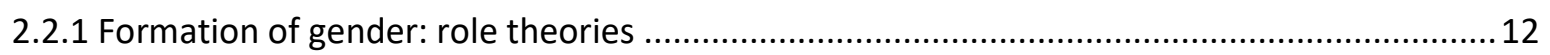

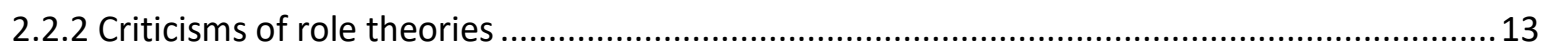

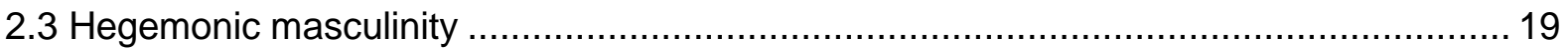

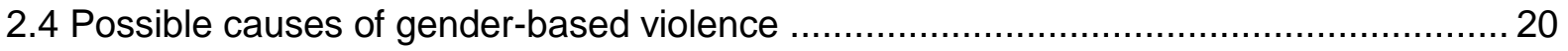

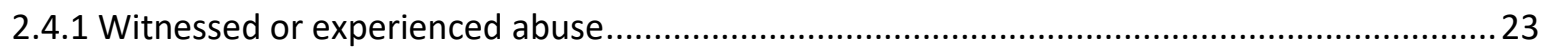

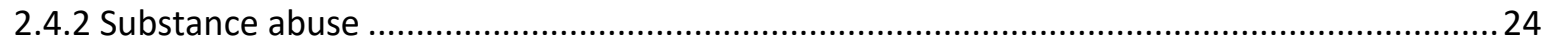

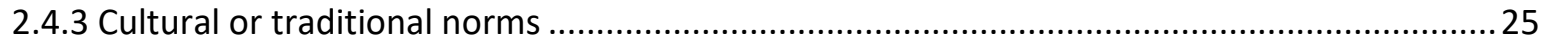

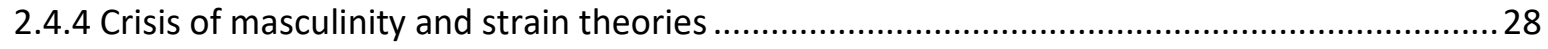

2.5 Militarised masculinities and hypermasculinities.................................................. 33

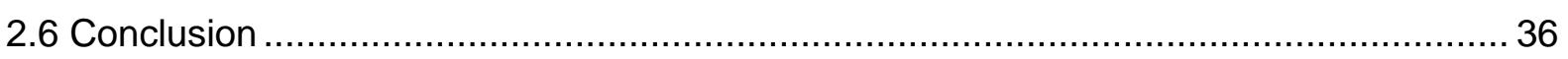

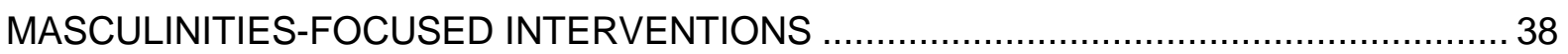

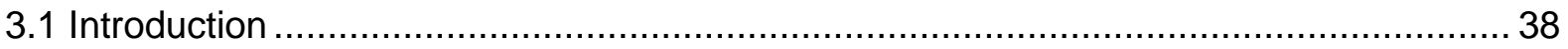

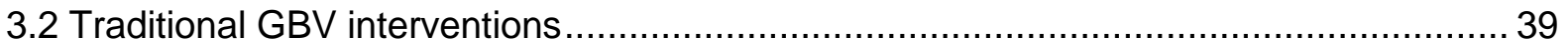

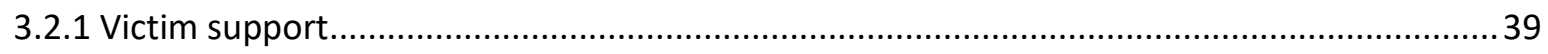

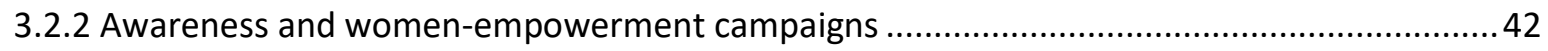




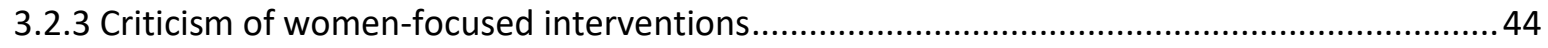

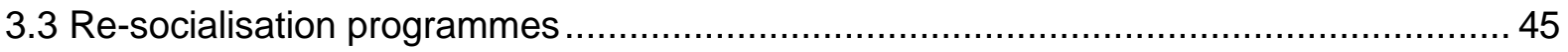

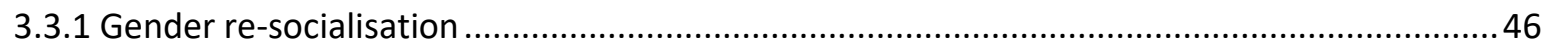

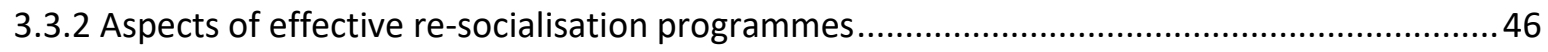

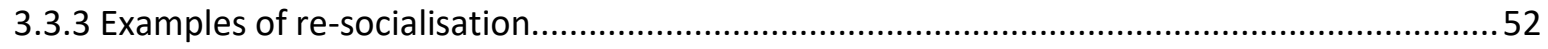

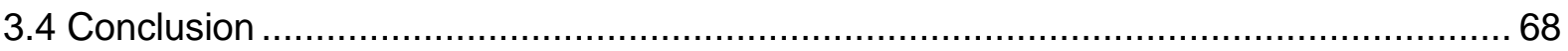

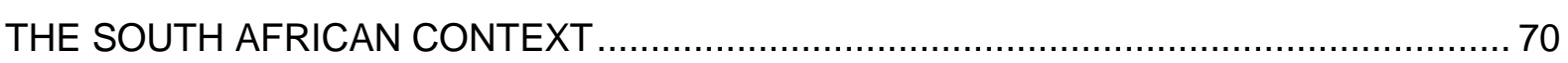

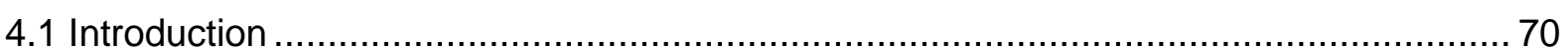

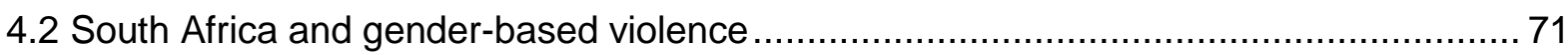

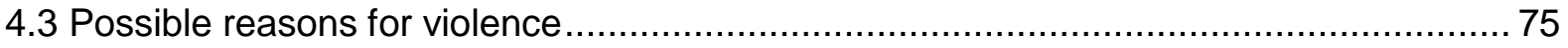

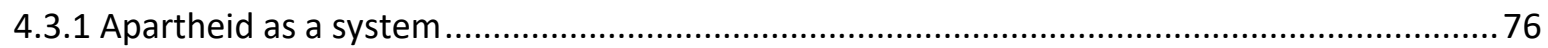

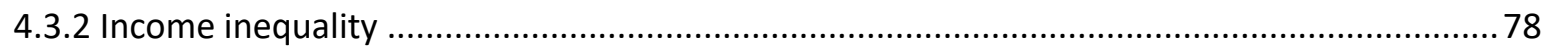

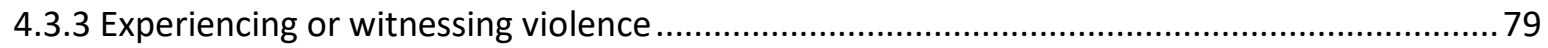

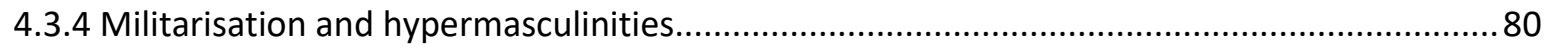

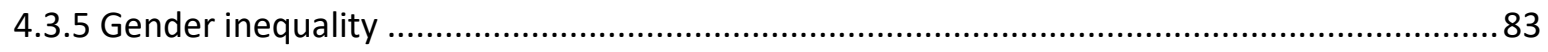

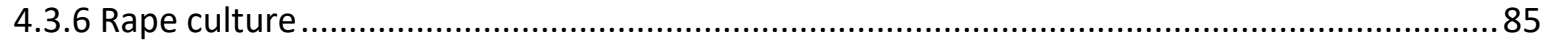

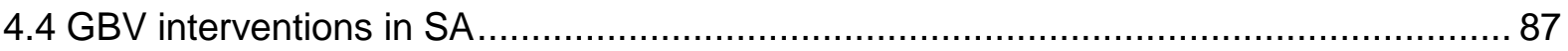

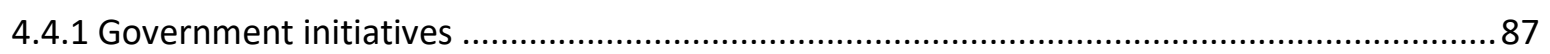

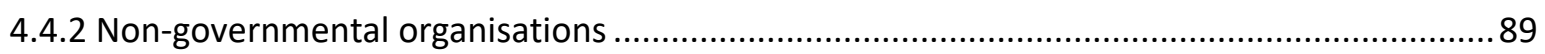

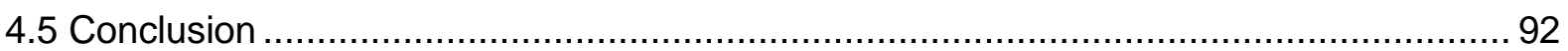

SONKE GENDER JUSTICE AND 'ONE MAN CAN': A CASE STUDY OF A

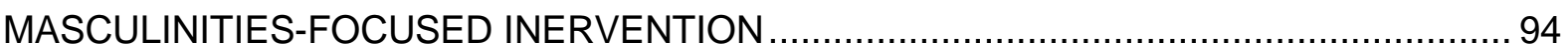

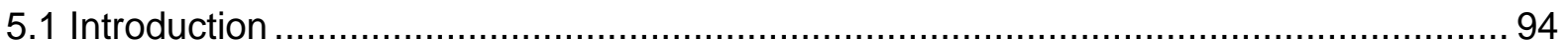

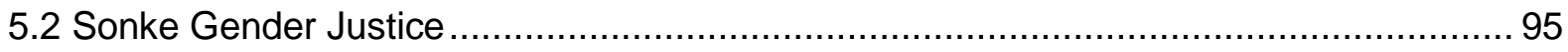

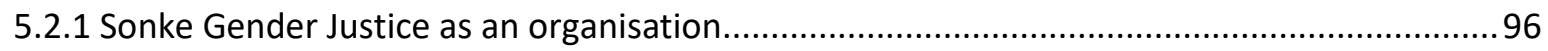

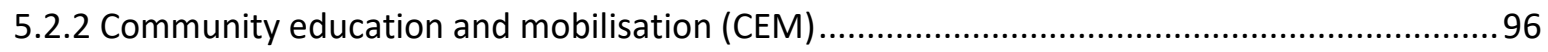

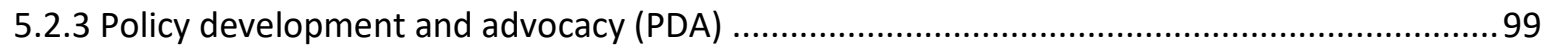

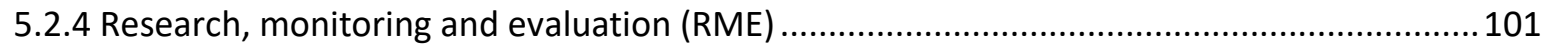

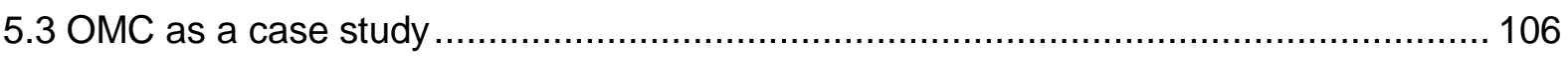

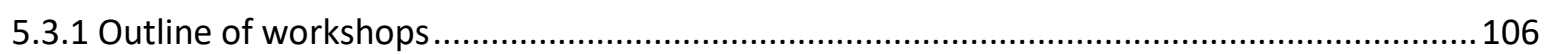

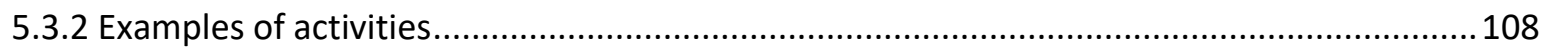

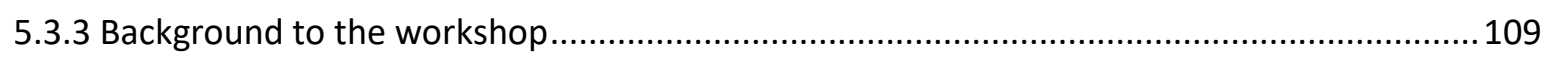

5.3.4 OMC in context of masculinities-focused re-socialisation interventions ..............................111

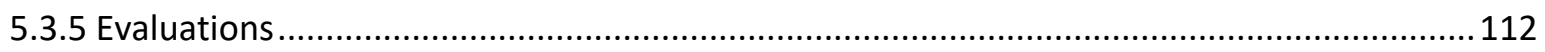

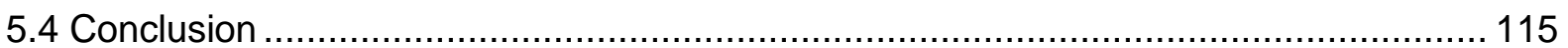

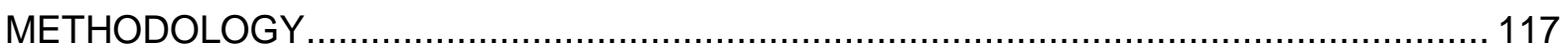

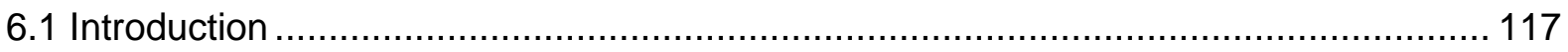




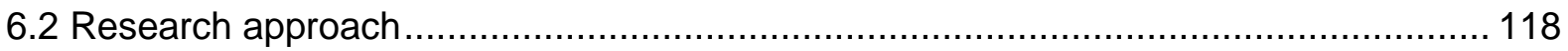

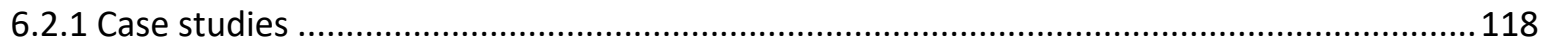

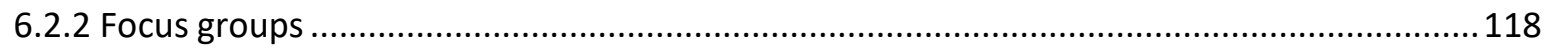

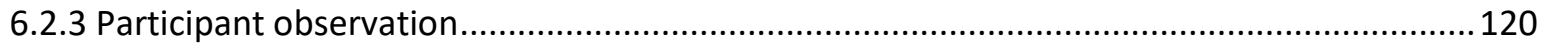

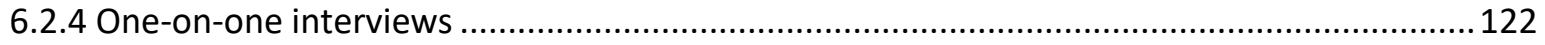

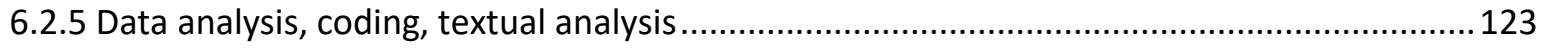

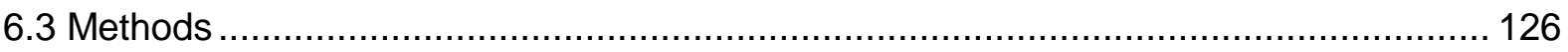

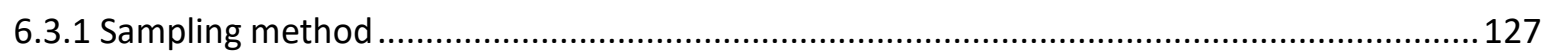

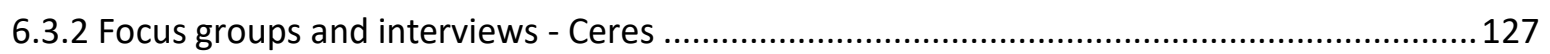

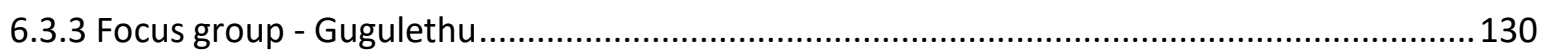

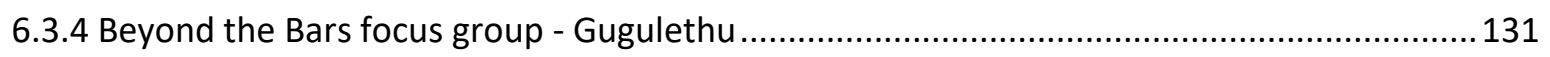

6.3.5 Interviews with facilitators and practitioners................................................................ 132

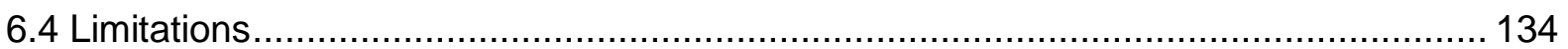

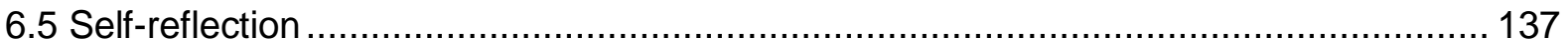

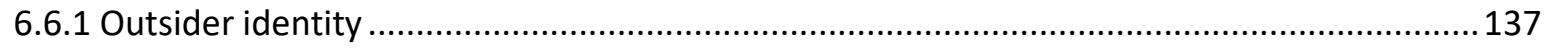

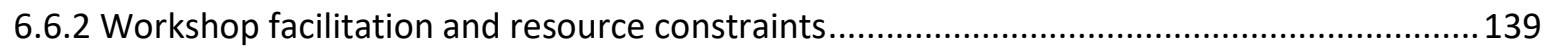

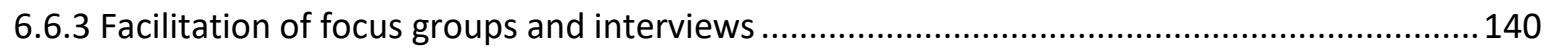

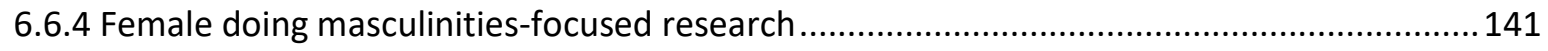

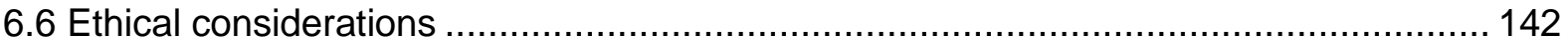

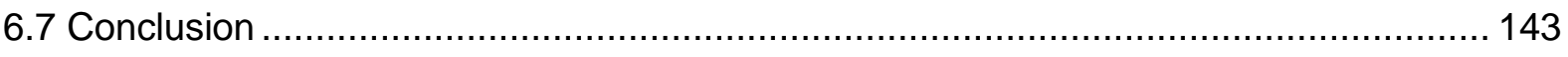

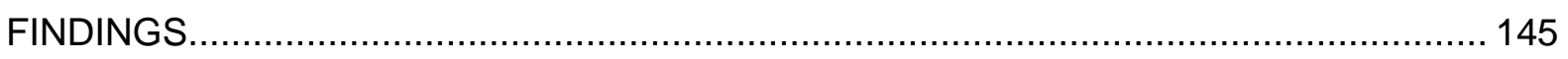

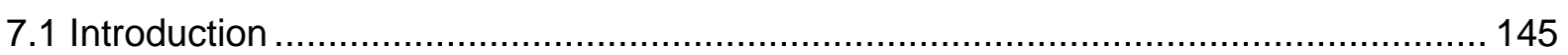

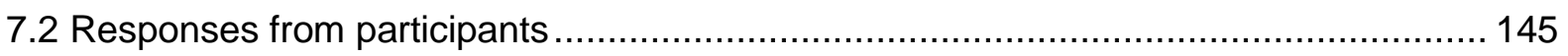

7.2.1 Participants' reasons for involvement in the workshops .................................................. 146

7.2.2 Workshop activities that had a lasting impact................................................................... 149

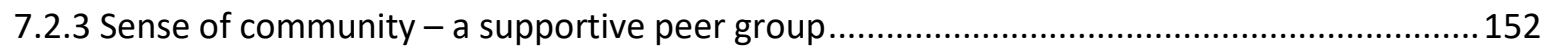

7.2.4 Role models - the importance of having and of being role models ..................................... 154

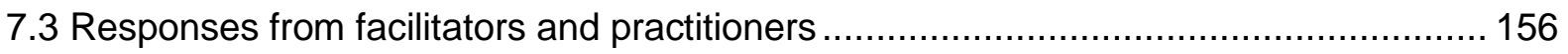

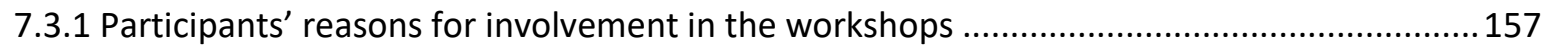

7.3.2 Workshop activities that facilitators see having an impact ................................................. 158

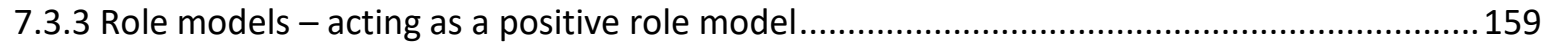

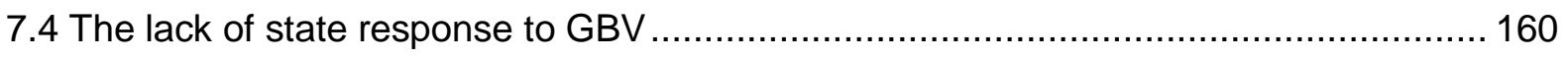

7.5 'Gender-based violence in our communities... it's normal' ...................................... 163

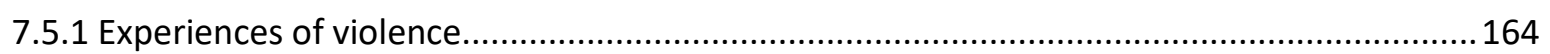

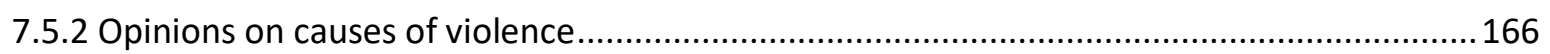

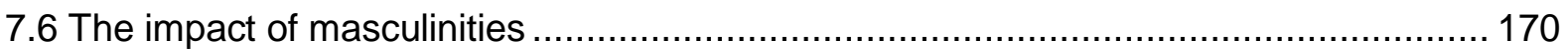




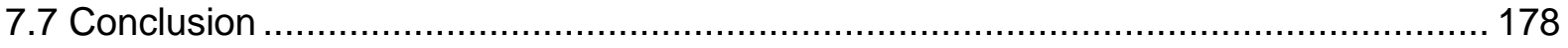

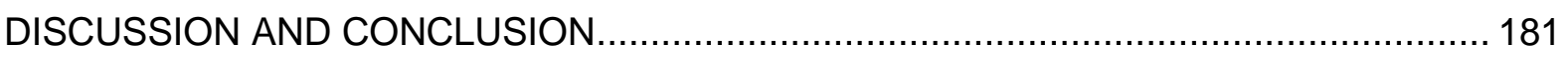

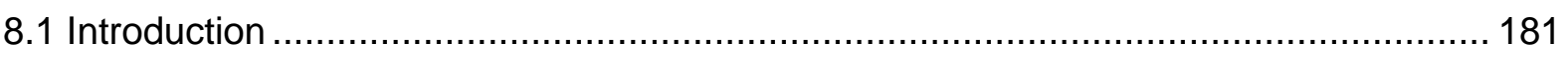

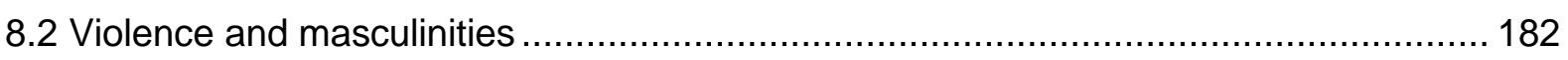

8.3 Current intervention as a way to address violence ........................................... 187

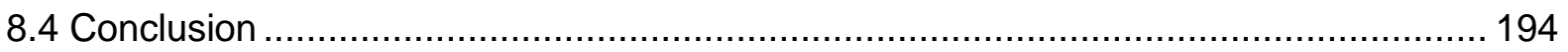

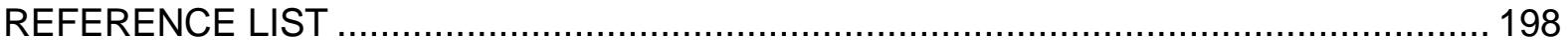

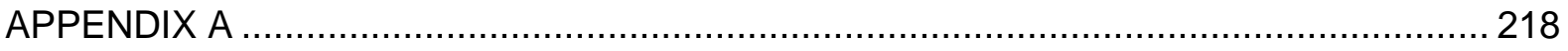

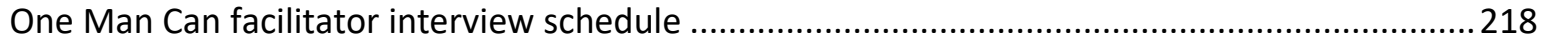

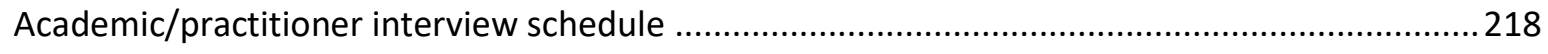

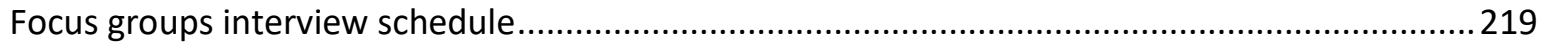

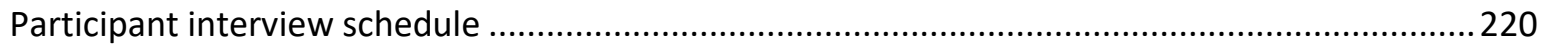




\section{LIST OF ACRONYMS}

ANC - African National Congress

APLA - Azanian People's Liberation Organisation

BIP - Batterer Intervention Programme

CEDAW - Convention on the Elimination of all forms of Discrimination Against Women

DDR - Disarmament, Demobilisation and Reintegration

DJCD - Department of Justice and Constitutional Development

DOH - Department of Health

EFF - Economic Freedom Fighters

EMAP - Engaging Men through Accountable Practice

FGM - Female Genital Mutilation

GBV - Gender-Based Violence

IFP - Inkatha Freedom Party

IPV - Intimate Partner Violence

MAP - Men as Partners

MASVAW - Men's Action for Stopping Violence Against Women

MK - umKhonto weSizwe

MRC - Medical Research Council

NP - National Party

NSP - National Strategic Plan

OECD - Organisation for Economic Co-operation and Development

OMC - One Man Can

PAC - Pan-African Congress

PPASA - Planned Parenthood Association of South Africa

SADF - South African Defence Force

SAP - South African Police

SAPS - South African Police Service

SDU - Self-Defence Units

SGBV - Sexual and Gender-Based Violence

SPU - Self-Protection Units

SSR - Security Sector Reform

STI - Sexually-Transmitted Infection

TB - Tuberculosis

VAW - Violence Against Women

VAWG - Violence Against Women and Girls

VCT - Voluntary Counselling and Testing 
WHO - World Health Organisation 


\section{CHAPTER 1}

\section{INTRODUCTION}

\subsection{Background}

Violence and gender-based violence (GBV) have become a major concern in many countries around the world, and this is particularly true in the case of South Africa, which has some of the highest rates of violence outside of a conflict zone (Moffett, 2006; Peacock, 2012). Numerous organisations and writers have highlighted this fact, drawing attention to the high levels of rape (Tshwaranang Legal Advocacy Centre, 2012), intimate partner violence (Mathews, Abrahams, Martin, Vetten, van der Merwe, \& Jewkes, 2004), and violence against women (Jewkes, Sikweyiya, Morrell \& Dunkle, 2009).

A number of reasons have been suggested for these high levels of violence, with many analyses focusing on the system of Apartheid that officially existed in the country from the 1940s until the 1990s. Thus, some have suggested that Apartheid 'normalised' certain forms of violence, such as violence by or against the state (Anderson, 1999/2000). As violence becomes normalised, it can easily become adopted as a marker of masculinity, suggesting that men will feel they need to use violence in order to prove their masculinity, and this can contribute to increased levels of violence going forward. Another explanation which is often provided for violence in South Africa is the high level of income inequality, with a number of studies noting the link between income inequality and violence in the country (Seedat, Van Niekerk, Jewkes, Suffla \& Ratele, 2009).

Along with this, the presence of militarised masculinities and hypermasculinities in South Africa is an additional factor which has been noted as creating a 'culture of violence' in the country (Hamber, 2000). As will be discussed below, militarised masculinities and hypermasculinities often emphasise violence and aggression, while hypermasculinities in particular tend to contribute to gender inequality and the presence of a 'rape culture'. Gender inequality has been noted as a factor which perpetuates cultures of violence, and particularly gender-based violence (Buscher, 2005), and South Africa is a profoundly gender unequal society. Along with this, a number of writers (such as Gqola, 2015) have highlighted the presence of a rape culture in South Africa.

Thus, there are numerous factors which contribute to the high levels of violence in the country today, but I argue that chief among these is the existence of masculinities which encourage the use of violence by men, while the extreme levels of gender inequality and presence of a rape culture in South Africa further enable this violence. While numerous interventions in the country focus on providing support to female victims of violence, the lack 
of reduction in the rates of GBV suggests that alternative methods are required, and the literature below proposes that masculinities-focused interventions can play a role in this.

Thus, different bodies of literature were consulted for this study, starting with the causes of violence, with an emphasis on the effect of masculinities, followed by an overview of different ways of addressing this violence. Due to the focus on masculinities as a cause of violence, interventions which work specifically with men are then discussed in more detail, including a case study of a South African masculinities-focused intervention.

\subsubsection{Causes of violence}

There is a substantial amount of literature that focuses on individuals who perpetrate violence, arguing that there are certain factors which cause some people to respond violently (eg. Malinosky-Rummell \& Hansen, 1993; Goldstein, 2004; Lau, 2009). In this regard, a factor which is often mentioned is that of witnessed or experienced abuse in childhood. A number of writers argue that such experiences may contribute to a person's likelihood of perpetrating violence themselves later in life (Malinosky-Rummell \& Hansen, 1993; Paolucci, Genuis \& Violato, 2001; Lau, 2009). However, the link between the two is not always as absolute or as strong as has been assumed (Stith, Rosen, Middleton, Busch, Lundeberg \& Carlton, 2000).

Additionally, focusing on witnessed or experienced abuse does not help to explain why it is overwhelmingly men who perpetrate almost all forms of violence worldwide, which suggests that alternative explanations are required. Another possible explanation is the causal relationship between substance abuse and violence with a number of studies showing a strong connection between the two (Fals-Stewart \& Kennedy, 2005), although the direction or causality of the relationship is unclear. Along with this, substance abuse seems to impact differently on men than on women (El-Bassel, Witte, Wada, Gilbert \& Wallace, 2001). Thus, substance abuse also does not help us to understand why it is that men are more likely to perpetrate violence than women.

The two factors outlined above do little to explain broader patterns of violence, and why certain regions are more violent than others, which has led to a focus on societal or cultural factors which may impact on violence. For example, some literature has highlighted a link between GBV and more traditional or conservative norms, particularly those which are predominantly patriarchal (Saffitz, 2010). Additionally, a number of writers have noted that 'tradition' or 'norms' are often used as a way of justifying or excusing violence or gender inequality (Cock, 1991; Usdin, Scheepers, Goldstein \& Japhet, 2005). Despite literature supporting the link between conservative gender norms and GBV, the focus on 'cultural practices' runs the risk of demonising or othering specific cultures while normalising 
practices in Western cultures. This then implies that the 'cultural practice' in question is the reason for GBV, or that GBV only occurs in countries which implement them (Armstrong, 1994; Adelman, 2003; Greig, 2004). However, research has consistently shown that GBV is a worldwide phenomenon, no matter what the culture is of the country being investigated (Walby, 1990; Lau, 2009). The fact that men perpetrate violence in all societies implies that the expectations of masculinities are more of a factor in enabling violence than any particular cultural practice, and the link between these masculinities and violence needs to be investigated.

In order to understand the expectations of masculinities and how they can impact on violence, it is important to outline how gender and masculinities develop. Gender is generally understood as the expectations and norms about how men and women should behave and interact with others (Barker, Contreras, Heilman, Singh, Verma \& Nascimento, 2011). In other words, gender is a socially constructed aspect of a person's identity, which means that gender is something that is learned, taught and reinforced by society. While individuals have a significant amount of agency in choosing how to perform their gender, the circumstances and context in which they live will heavily impact on this agency (Butler, 1988).

Masculinities are those aspects of behaviour which men are expected to display or achieve in order to prove their manhood, and a significant amount of literature has been generated on the pressure that men face to achieve these masculinities. Connell (1987) first coined the term 'hegemonic masculinity', which is the version of masculinity considered most desirable within a specific society or group (Messerschmidt, 1993:82). While hegemonic masculinities are context-specific, certain aspects tend to be relatively consistent, with four main factors appearing in many versions of hegemonic masculinities. These factors are being the economic breadwinner or provider (Muntingh \& Gould, 2010; Dworkin, Colvin, Hatcher \& Peacock, 2012), physical strength (Lindegger \& Maxwell, 2007), sexual prowess including an 'uncontrollable' sexual appetite and sexual risk-taking (Mankayi, 2008), and heterosexuality (Connell, 2005).

Due to the pressures on men to achieve these factors, it is sometimes assumed that if men are not able to achieve certain norms, they will compensate by over-emphasising other aspects of masculinity (Messerschmidt, 1993; Dolan, 2002; Harders, 2011). For example, if men are unable to act as the financial providers for their family, they will compensate by turning to other ways to 'prove' their masculinity (Walby, 1990), and these alternative markers may include the use of violence, or risky sexual practices such as multiple partners or not using condoms (Mankayi, 2008). Thus, it is often assumed that those who are unemployed or living in poverty are more likely to perpetrate violence, and this has been 
supported in some studies (e.g. Peralta \& Tuttle, 2013). However, these theories tend to be less helpful in explaining middle- and upper-class violence, and imply that only those who live in poverty will perpetrate violence, which has been shown not to be the case. In addition, such theories risk ignoring that some versions of masculinity specifically condone or expect violence against women as a means of achievement (Gibson \& Rosenkrantz Lindegaard, 2007), rather than being an abnormal response to perceived strain. Thus, masculinities which emphasise violence may play a powerful role in encouraging men's use of violence.

Two particular versions of masculinity specifically encourage aggression or violence, and these are militarised masculinities and hypermasculinities. While militarised masculinities tend to emphasise weapon-use, hypermasculinities are more closely linked to calloused sexual attitudes towards women (Hamburger, Hogben, McGowan \& Dawson, 1996). Given these characteristics, there is a growing body of literature looking at the link between hypermasculine traits and GBV, both internationally and in South Africa (Smeaton \& Byrne, 1987; Lau, 2009; Barker et al., 2011). This suggests that the presence of hypermasculinities in South Africa could be a key factor impacting on the levels of violence in the country. Similarly, the fact that masculinities contribute to violence suggests that focusing specifically on masculinities could play an important role in helping to address this violence.

A drawback of using concepts such as hypermasculinities and militarised masculinities to explain violence is that these perpetuate the notion that only certain masculinities encourage violence. This then suggests that only these 'problematic' masculinities need to be addressed to lower the levels of violence in a specific context. Along with this, using these terms ignores the fact that the use of violence has been normalised for almost all men across wide-ranging contexts, rather than only being used by those enacting militarised or hypermasculinities. Thus, militarised and hypermasculinities refer more to a type of culture that develops because of the effect that militarisation has on society and behaviour through its normalisation of violence. It does not necessarily refer to a specific group of men, such as those who have served in the military. Hence, these terms have limitations. However, for the purposes of this study, the terms are helpful to highlight the emphasis on violence which has remained pervasive in the South African context.

\subsubsection{Re-socialisation interventions}

The fact that masculinities are socialised rather than inherent suggests that one means of addressing the high levels of violence perpetrated by men is through re-socialisation interventions, which problematize gender norms and can contribute to the development of alternative less violent and patriarchal versions of masculinities. However, traditionally this has not been the primary method of responding to GBV, with many interventions primarily 
providing support services for survivors of violence (Ellsberg, Arango, Morton, Gennari, Kiplesund, Contreras \& Watts, 2015). There are a number of aspects that tend to be included in these survivor-focused interventions, such as counselling, medical treatment, legal and court support, support groups, and places of shelter, with the intention being to provide support to survivors of violence in order to facilitate their recovery, and to partner them during the judicial process if they choose to press charges. However, despite acknowledgement that these are important to survivors, there is little evidence to show that these interventions help to reduce the violence (Ellsberg et al., 2015). Along with the more recent research focusing on masculinities as a possible cause of a wide range of forms of GBV, the lack of impact on levels of violence of women-focused programmes has led to an increase in interventions that work with men (Jewkes, Flood \& Lang, 2015).

Gender socialisation is strongly influenced by important people in an individual's life (such as peers and family members), and institutions in the community (such as schools and churches), and this implies that the people surrounding the individual play a large role in any further socialisation or re-socialisation process, and specifically in its success or failure (Davidson \& Gordon, 1979). This suggests that factors such as supportive peer groups, and positive models of hoped-for norms can play a powerful role in successful re-socialisation.

A number of studies have suggested aspects of re-socialisation interventions which can produce the most significant impact, including the intervention being voluntary rather than compulsory (Goffman, 1961; Scott, 2010), the presence of positive role models (Barker, 2003), and a supportive peer group (Davidson \& Gordon, 1979; Silvergleid \& Mankowski, 2006). Along with this, interventions seem to have a greater impact when they are gendertransformative (Ricardo \& Virani, 2010; Dworkin, Hatcher, Colvin \& Peacock, 2013), and when they are part of a multi-sectoral and multiple strategy programme (Ellsberg et al., 2015).

Different versions of re-socialisation interventions have been implemented, ranging from those which involve an extreme level of interruption of participants' lives (total institutions and disarmament, demobilisation and reintegration programmes [DDR]) through to those which involve minimal disruption (batterer intervention programmes [BIPs], and masculinities-focused interventions). The most significant impacts tend to arise from total institutions such as prison or the military (Davidson \& Gordon, 1979; Henslin, 2010), which can result in relatively major changes in a person's behaviour and attitudes. In a similar vein, DDR processes tend to be relatively intensive, in terms of participants spending extended periods of time involved in these, yet there is little evidence to prove whether these work (Muggah, 2006), and some have argued that their lack of effectiveness is partly because 
there is little focus on masculinities during the demobilisation process (Clarke, 2008; Theidon, 2009; UN-IAWG, 2012).

A less-invasive form of re-socialisation are BIPs, in which men who have been convicted of domestic violence attend compulsory workshops as a means of reducing their future use of violence. However, evaluations of BIPs tend to be relatively pessimistic, often showing minimal impact on participants' future use of violence or on their attitudes in relation to the use of violence (Rosenfeld, 1992; Arias, Arce \& Vilariño, 2013). This therefore leads to a focus on the final version of re-socialisation intervention discussed in this research, which is masculinities-focused interventions. These are voluntary programmes which work with men as a means of preventing GBV, often with the intention of specifically problematizing gender, with a World Health Organisation (WHO, 2010) review finding that these kinds of programmes can result in a number of positive outcomes. This supports the thesis underpinning this research which suggests that masculinities-focused interventions can have a positive impact on levels of GBV in the communities in which they are implemented.

A number of these interventions have been implemented in a variety of contexts, including Program $\mathrm{H}$ in Brazil, MASVAW in India, and Stepping Stones in South Africa, all three of which have been positively evaluated by a number of authors (Pulerwitz, Barker \& Segundo, 2004; Hu \& Salie-Kagee, 2007). These often show a positive impact on specific behaviours, as well as contributing to improvements in participants' attitudes towards gender equality (Das, Mogford, Singh, Barbhuiya, Chandra \& Wahl, 2012). This suggests that these masculinities-focused interventions can have a positive effect on beliefs and behaviours linked to GBV. However, despite these positive results, a number of evaluations found that this effect tended to be predominantly behavioural, with little influence on patriarchal attitudes (Jewkes et al., 2010; Roy \& Das, 2014). This suggests that these interventions lead to only limited shifts in the social norms that maintain inequality. However, despite these limitations, I argue that masculinities-focused interventions can play a more effective role in reducing violence than women-focused interventions. This is explained with reference to a South African example of a masculinities-focused programme.

\subsubsection{Masculinities focused programme}

The case study intervention used for this research is the One Man Can (OMC) initiative implemented by Sonke Gender Justice, a South African NGO. South Africa provides a particularly good context in which to investigate the impact of this form of intervention because of its extremely high rates of violence and GBV. Along with this, despite significant rhetoric from government, and a large number of women-focused interventions, there has 
thus far been little reduction in these levels of violence, suggesting that alternative approaches need to be investigated.

The OMC intervention is similar in design to the masculinities-focused programmes mentioned above, and is relatively well aligned with the literature on how to create effective re-socialisation interventions in that it is voluntary, has a gender-transformative focus, uses facilitators as positive role models, and helps to create supportive peer groups for participants. Along with this, OMC is one aspect of Sonke's broader work programme, which includes numerous different strategies and sectors of focus, and the use of a multi-sectoral approach has also been highlighted as an aspect which improves the effectiveness of these kinds of intervention. This would suggest that the impact of OMC on participants should be relatively positive and sustainable.

A number of evaluations have been conducted on the intervention, generally reporting positive results (Dworkin et al., 2013; Hossain et al., 2014). However, in a similar fashion to the evaluations of Program H, MASVAW and Stepping Stones, the evaluations of OMC also raised questions about the depth of the impact that the intervention had. The evaluations tended to point to the intervention having a predominantly behavioural change, as the participants now view a specific behaviour (violence) as problematic, but do not question the gender norms behind it.

Studies have also noted that there has been little attention paid to the fact that some men's attitudes and behaviours are changing without the impact of interventions, and that more attention should therefore be paid to the factors that are influencing these shifts (Dworkin et al., 2012, 2013). In other words, men are voluntarily joining these kinds of interventions, implying that their attitudes towards gender equality and masculinities may already have begun to shift, yet there has been little research thus far on why men choose to join such initiatives, or on what initiated their attitudinal shift. Along with this, the understanding of how these interventions do impact on men is limited (Dworkin et al., 2013). Thus, highlighting the factors that are contributing to the behavioural or attitudinal shifts which participants experience can allow those working in the field of masculinities to better adapt interventions to encourage and enable these shifts.

\subsection{Rationale for the study}

Much of the literature has quantitatively investigated what the impact of these interventions are on men, but there has been little focus to date on uncovering how this impact is achieved and sustained (Dworkin et al., 2013). Along with this, not many studies have looked at why participants choose to engage in a voluntary masculinities-focused intervention, or at the factors which support or hinder this engagement over time (Dworkin et al., 2012, 2013). To a 
large extent, this means that it is difficult to know how to address the current shortcomings in masculinities-focused interventions as there is little understanding of the ways in which the content and process are received by participants. Accordingly, the rationale for this study is to provide a more complete picture of how these interventions impact on participants, including the factors which initially attract them to join an intervention, and those which enable them to sustain the impacts that they feel they gained. This knowledge will hopefully contribute to helping design interventions which can have a more sustainable attitudinal impact on participants.

\subsection{Research question}

The aim of this study is to examine how a masculinities-focused intervention programme which aims to address gender inequality and GBV is being implemented and the effect the programme has on men taking part in the programme. Accordingly, the research question is, how does a masculinities-focused intervention like OMC impact on those who take part, and which factors enable participation and the sustainability of the impact?

\subsection{Research objectives}

1. To examine the literature on the causes of GBV in societies, with a particular focus on South Africa.

2. To analyse various theories of masculinities, as well as how masculinities are shaped through socialisation and environmental influences, and the link between hypermasculinities and GBV.

3. To discuss the different methods used to respond to GBV, including reactive and preventative interventions, and women-focused and masculinities-focused programmes. 3. To examine the use of masculinities-focused programmes as a tool to address gender inequality and GBV, as well as their effectiveness.

4. To study participants of a specific masculinities-focused intervention, the Sonke One Man Can programme, to establish:

- why men volunteer to take part in the programme;

- how they define their masculinities and what shaped this;

- how the intervention impacts on them; and

- the factors that either enable or undermine their efforts to sustain its impact.

\subsection{Design and methodology}

The research for this study was qualitative, aiming to understand the ways in which the intervention impacts on participants. As there are so few masculinities-focused interventions currently being implemented in South Africa, this research aimed to generate rich data on a single case study through the use of participant observation, focus groups and one-on-one 
interviews. The primary reason for choosing qualitative research was that the sample size was small, meaning that medium- to large-scale survey-type research was inappropriate. Along with this, the focus in this research was more on the meanings and understandings of participants, rather than on quantifying any aspect of the experience. Thus, qualitative methods were more appropriate in gathering this type of data.

The fieldwork involved participant observation of two workshops and a support group, four focus groups of workshop participants, seven follow-up interviews with workshop participants, and nine one-on-one interviews with workshop facilitators and practitioners involved in the field of GBV. Interviews and focus groups were semi-structured with openended questions, allowing participants to supply their own meanings on the topics, rather than providing pre-decided themes. Interviews were audio-recorded and transcribed, and the transcriptions were coded to assist in data analysis.

\subsection{Chapter outline}

Chapter One has introduced the study, providing the context, rationale and a brief overview of the research methodology, which will be discussed in more detail in Chapter Six.

Chapter Two reviews the literature on gender-based violence and its possible causes, with a primary focus on masculinities as a contributing factor to GBV. The chapter therefore discusses how gender and masculinities are socialised, and highlights different versions of masculinities including hegemonic, militarised and hypermasculinities.

Chapter Three discusses different approaches to addressing GBV, beginning with an outline of 'traditional' women-focused interventions before moving onto re-socialisation programmes which specifically focus on men. The aspects which improve the effectiveness of these interventions are discussed, along with examples of different kinds of re-socialisation programmes.

Chapter Four provides some geographic context for this study, looking at South Africa, the levels of GBV experienced here, and possible explanations for this violence, before focusing on ways in which different groups have tried to address this violence.

Chapter Five describes the specific case study which was used for this research, looking at both the organisation which implements it and the design and background of the intervention.

Chapter Six outlines the research design, explaining the different methods used, and the data collection and analysis, before describing some limitations of the study and providing some reflection on the research process. 
Chapter Seven presents the findings of the research, with key areas of interest highlighted. Chapter Eight discusses the research findings in the context of the broader literature on masculinities-focused interventions and GBV-prevention, with suggestions on the ways in which these interventions impact on participants. The chapter concludes with some recommendations for improving their impact, and for future research. 


\section{CHAPTER 2}

\section{MASCULINITIES AND GENDER-BASED VIOLENCE}

\subsection{Introduction}

Violence is a significant social issue in contemporary South Africa. The country is often listed as one of the most dangerous in the world and as having some of the highest levels of violence outside of conflict zones (Moffett, 2006; Peacock, 2012:10). As in many other countries, the vast majority of violence is perpetrated by men (Jules-Macquet, 2014), suggesting that a potential means of addressing violence is through a focus on men and the reasons behind their use of violence. For this reason, the predominant focus of this research is on masculinities and their contribution to violence. This chapter therefore begins by outlining the definitions of gender and masculinities and how they are constructed or socialised, in order to frame the debates on this issue. I then move on to a discussion of the factors thought to cause or enable violence. While these factors impact on both genders, the fact that violence is seen as an acceptable response for men but not for women requires an investigation of different versions of masculinities and their potential links to violence. Addressing these issues provides the background for the later discussion of ways to begin addressing violence in different contexts, and to point out that masculinities-focused interventions could be a way to address the normalisation of violent behaviour.

Given the widespread nature of violence and particularly sexual violence, there is a substantial amount of literature that focuses on individuals who perpetrate violence, arguing that there are certain factors which cause some people to respond violently (eg. MalinoskyRummell \& Hansen, 1993; Goldstein, 2004; Lau, 2009). Addressing these factors could therefore play a significant role in reducing the violence perpetrated by these individuals. However, the literature tends not to address why these factors have diverse impacts on different groups, or why certain regions tend to have higher levels of violence than others. This gap in the literature has led to a focus on larger societal-level factors to explain violence, including culture and the difficulties people can face in achieving certain aspired-to statuses (eg. Cock, 1991; Buscher, 2005; Peralta \& Tuttle, 2013). While societal-level factors have more general applicability to understanding violence than theories which focus on individuals, they tend to overlook the fact that most perpetrators are male. This is not to say that all men are violent, or are expected to be violent, but the vast majority of violence is perpetrated by men, in all regions and countries around the world. The question therefore needs to be asked: why this is the case, and how it can be addressed to reduce the incidence of GBV? Accordingly, the aim of this chapter is to discuss the norms which condone or expect violence from men. 


\subsection{Gender definitions}

An important starting point is defining the way certain core concepts are used in this study, and the primary definition is of the difference between sex and gender. While a person's sex refers to their biological make-up, '[g]ender refers to the widely shared expectations and norms within a society about appropriate male and female roles, responsibilities and behaviours, and the ways in which women and men interact with each other' (Barker, Contreras, Heilman, Singh, Verma \& Nascimento, 2011:14). In other words, gender is a socially-constructed aspect of a person's identity, which means that gender is something learned, taught and reinforced by the society in which a person lives. Although 'gender' is often used to imply a focus only on women, this uses the term to mean both men and women. While a person's gender and sex can coincide, this is not always necessarily the case, and a person's gender can be influenced by numerous other factors, such as race, class, language, religion and geographic region. Hence, a person's gender is something that is acquired rather than inherent, and can be shaped and re-shaped through different societal forces. Numerous theories have arisen to explain how this occurs, with an important initial contribution being gender role theories.

\subsubsection{Formation of gender: role theories}

Initially, many scholars focused on socialisation theories, which assume that people learn their gender roles through social interaction and positive or negative reinforcement from influential people in their lives, such as peers, parents, teachers etc. For example, Oakley's gender role theory (1972) describes the process of how children are socialised into their expected gender roles, beginning with modelling the behaviour of their same-sex parent, meaning girls will model their mothers, while boys model their fathers. Through this, children learn their socially-expected role. To reinforce this, children are given gender-specific toys and clothes, and encouraged to conform to gender-specific activities and behaviours. Girls may be given dolls or kitchen sets as toys in order to enforce their assumed future role as a mother with an interest in childcare and housework. Alternatively, boys may be given sports equipment, building blocks and toy weapons, encouraging an interest in sports, engineering or building, and violent games. Added to this, the toys tend to be given specific colours, with girls' toys and clothes being predominantly pink or purple, and boys' toys and clothing in primary colours such as red and blue. Societal approval or disapproval reinforces these expected norms, with girls in pink being complimented, while boys wearing pink would be frowned upon.

Linked to this, children are encouraged to behave in certain ways which are thought to arise from their gender. For example, 'little girls are more likely to be told to be quiet and not to make a noise in circumstances where little boys would be expected to be boisterous' (Walby, 
1990:91). Thus, girls who are noisy or enjoy sports will be labelled 'tomboys' or 'butch', while boys who are quiet or prefer to play indoors will be called 'sissies'. These sanctions can come from numerous sources and institutions including family, schools, the media, and social norms (Butler, 1988; Thomson, 2002). Girls may be praised for taking an interest in dolls and childcare, while boys may face 'penalties' for showing interest in the same things, in the form of ostracism, ridicule, and social isolation (Anderson, 2008; Moleketi \& Motsoane, 2013). Through these steps, children are generally thought to learn their accepted gender role, and to begin to behave accordingly.

However, these assumptions have been criticised on a number of fronts, primarily relating to the fact that they ignore a child's agency in choosing how they perform their role, but also because they take little account of the fact that there are numerous aspects to a child's identity beyond just gender, and that these have a profound impact on gender roles in a given context. Related to this is the fact that there are always multiple versions of each gender in a society or community, and these versions are afforded different levels of status depending on the context. The following section therefore discusses the main criticisms regarding role theories, alongside the more recent literature which aims to update and expand on the original theories.

\subsubsection{Criticisms of role theories}

The primary criticisms of role theories relate to their explanation of gender as the only important aspect of a person's identity (Martino, 2008), and the assumption that men and women each only have the option of one possible gender role, rather than recognising the multiple variations of gender which are available in any given context (Connell, 2005), and the changing nature of gender roles across time and geographical space. Similarly, gender role theories describe gender as a relatively neutral identity, ignoring the power differentials which exist between and within genders (Messerschmidt, 2001). Finally, gender role theories portray children as 'empty vessels' with little agency in creating their own identity (Butler, 1998), and gender role socialisation as a static once-off process which occurs when a child is young, and does not alter again (Chafetz, 1997). These criticisms have therefore led to the development of more nuanced theories of gender socialisation.

The assumption that there is only one gender role available for men and one for women has led a number of writers to focus on how gender roles evolve, within both cultures and individuals. For example, Messerschmidt (2001) discussed the variations that occur in gender norms between eras and regions, and within individuals over their lifetime, explaining how the definitions and norms of masculinity and femininity can vary widely in different eras (Connell \& Messerschmidt, 2005; Myrttinen, 2009). In certain times, masculinities would 
have been tied to working in jobs that required physical strength or manual labour, while at others, symbols of masculinity may have included business suits and wealth, and being able to employ someone else to do manual labour for you. A person living in an urban setting would be expected to live up to different standards of masculinity than a person living in an agricultural setting, while those in secular regions would be expected to behave differently to those living in areas with a strong religious influence.

Along with the fact that gender roles differ over time and region, an individual's expected gender role changes during their lifetime. The roles that boys and girls are expected to perform can be quite different from those they have to take on as adults (Barker \& Ricardo, 2005), and while children may be expected to mimic the behaviour of adults of the same sex, the expectations of their achievements of these roles may be different. Thus, a six-year-old boy is not likely to be expected to financially support his family, although he may be expected to begin thinking about possible careers in order to achieve this, while an adult man is very likely to be expected to provide financial support to others. Thus, the expectations on a single person vary greatly during their lifetime, suggesting that the socialisation process is not static or once-off, but is constantly changing.

The shifts in a person's gender role during their lifetime also points to their agency in choosing specific aspects of this role, and Connell $(1993,2005)$ has noted the agency that both children and adults have in choosing or rejecting aspects of their role. People are expected to present different 'versions' of their identity depending on the context and are able to choose which versions to present at different times (Butler, 1988). Butler therefore emphasises the active role that individuals play in their gender, through the notion of 'performativity', noting that, '[g]ender reality is performative which means, quite simply, that it is only real to the extent that it is performed' (Butler, 1988:7). In other words, gender is not something that a person is, but rather something that they do - it is a performance, and can be adapted for different contexts and life stages, with different settings requiring different versions of these roles to be presented in order to be appropriate. Messerschmidt notes, 'all individuals engage in purposive behaviour and monitor their own action reflexively' (1993:77), reinforcing the notion that individuals have ongoing agency in choosing how to portray their gender role.

An individual is therefore likely to behave differently in different contexts, such as a professional environment, in a religious or a social setting, or with friends or family. Each person will also have varying levels of power or prestige in different settings, meaning that their gender role is fluid with regards to their context. In her own home, a woman may have considerable power as a mother to her children, yet her role in relation to her husband may 
be much more subordinate. A man who works in a relatively menial job may have very little prestige in the workplace, but wield a large amount of power in an athletic setting where he is a star player on a team. Thus, each person's gender performance is a result of all the different identities they have, and the context in which they find themselves.

Gender role theory therefore, 'fails to address the emotional investments that compel individuals to embrace particular normative identities and the conflict that can result as one attempts to live these roles' (Martino, 2008:194). In other words, despite the agency that individuals have in choosing the version of their gender that they present, '[t]hese possibilities are necessarily constrained by available historical conventions' (Butler, 1988:2), meaning that the societal norms at play in the individual's context impact heavily on the options that they feel are available to them. Strong sanctions may be experienced if a person acts outside of the 'acceptable' gender norms of their community, which implies that even though a person could theoretically choose to perform a wide variety of roles, the stigma or negative associations attached to certain behaviours makes this unlikely. Even something as mild as a boy wearing pink, as mentioned above, is likely to result in him being mocked or reprimanded for doing so, and therefore quickly learning that this is something he should only do if he is willing to endure the negative responses he will receive for it.

The fact that it is often considered unacceptable for men to take on typically feminine traits (and vice versa) highlights the relational nature of gender, an aspect which gender role theories tended to ignore. Relationality refers to the fact that genders are defined through a process of comparison with an 'other'. In other words, the definitions of genders are often specifically developed as the opposite of a perceived 'other', with characteristics which are complementary but assumed to be mutually exclusive. For example, as Buscher states, "'[m]asculinity" does not exist except in contrast to "femininity"' (2005:9), with men typically being described as rational, logical and independent, which are all considered to be positive characteristics, while women are stereotyped as emotional, irrational and dependent on others, all of which are considered to be negative traits (Cock, 1991; Clarke, 2008). The concept of relationality therefore highlights the fact that even though masculinities would not exist if they were not in contrast to femininities, masculinities are typically considered to be the norm, or have positive traits, while femininities are defined in terms which are thought to be negative and the opposite of those which are linked to masculinities (Patel \& Tripodi, 2007).

This results in gender roles often being constructed as a binary, in opposition to something else, and some writers have critiqued the concept of a binary as too limited, in that it implies that there is only one version of each gender, in opposition to one other gender. Similarly, 
seeing gender as binary ignores the fact that each person has a much broader range of identities than just their gender, including their race, religion, sexuality, socio-economic status and language, and all of these will impact on a person's gender. Thus, gender roles are heavily influenced by the context in which they are developed. For example, white masculinities do not exist except in contrast to black masculinities; middle-class masculinities only exist in contrast to lower- or upper-class masculinities, and so on. This means that while there are multiple versions of each gender, they are each predominantly constructed in opposition to something else (Butler, 1988).

The favouring of certain gender roles over others has been the focus of a significant amount of more recent research. Initially, the male/female gender roles were seen as relatively neutral opposites, with neither being favoured over the other (Walby, 1990), but this is increasingly being critiqued by those who work in the field of gender. For example, Connell (2005) focuses on issues of power and the fact that certain gender roles (specifically hegemonic masculinities, which will be discussed in more detail below) are favoured in different areas. The gender norms which become favoured or considered 'normal' are often a result of the context in which the identities are being formed, meaning that the socioeconomic, ethnic, regional, religious and political contexts impact on which gender roles are considered to be the 'norm'. Thus, instead of gender roles being 'neutral', Walby states that masculinities are typically, 'the mode of the oppressor and femininity that of the oppressed' (1990:93).

However, gender inequality is not the only way in which a certain role is favoured over another, and power differentials come into play in relation to many different identities. To explain this, Kimberlé Cranshaw coined the term 'intersectionality' which refers to the fact that all people have multiple identities - gender, race, economic status, religion etc - and these different identities can combine to form different or additional levels of oppression or difficulty (1991). For example, black women tend to be disadvantaged both by being women and by being black, thus suffering 'double' oppression in relation to men, and to higherstatus (typically white) women (Cranshaw, 1991). Intersectionality has largely been used in black feminism as a way to problematise the assumption that all women face similar burdens and that the best-known (white, middle-class, heterosexual) scholars can speak for those from different identity groups (e.g. black, lower- or working-class, lesbian) (Cranshaw, 1991). While many women do share the burden of patriarchy and sexism, and particularly sexual violence, some women do still retain a position of privilege at the expense of other women and men, resulting in a situation of partial privilege. 
The concept of 'partial privilege' has more recently been used in the context of literature on masculinities, with McGinley and Cooper (2013) and Mutua (2012/2013) employing it to explain how certain men (eg. Gay men, black men, poor men) occupy a position of some privilege by being a man, yet are also in a position of a relative lack of power in relation to white educated heterosexual men (Mutua, 2012/2013). Thus, 'partial privilege' refers to the idea of being at the intersection of a privileged and a subordinated category, with the position of power or subordination being context specific (Mutua, 2012/2013). For example, in the South African context, white homosexual men retained status over white women and African men, yet they were seen as inferior to white heterosexual men (Conway, 2008), and this is true in many contexts around the world, with "heterosexuality... a fundamental indication of "maleness"' (Messerschmidt, 1993:74). Connell therefore argues that this results in, 'a gender politics within masculinity' (1995:37), an aspect which will be elaborated on in the discussion on hegemonic masculinities.

However, Mutua notes that there is little discussion of 'partial privilege' in the intersectionality literature, and the term 'intersectionality' has become closely associated with black feminism, leading some writers (such as McGinley and Cooper, 2013) to prefer the term 'multidimensionality' in the context of work on masculinities. Mutua agrees, titling her work: 'Multidimensionality is to masculinities what intersectionality is to feminism' (2012/2013). She further explains that multidimensionality is context-specific, in a similar manner to partial privilege. For example, the idea of white supremacy over black people is an issue in a country like South Africa, but less so in a country like China, with a much more racially homogenous population (2012/2013:355). Following from this, there is a body of literature which focuses specifically on the situation facing black men in countries which had either colonial or white rule.

Historical and geographical contexts have led to certain race, class, religious or sexual identity norms being considered positive, while others are negatively defined in opposition to them (Mooney, 1998; Morrell, 1998). For example, middle- to upper-class men tend to be typified as educated, successful and controlled, while lower- and working-class men are described as uneducated, coarse and often violent. A particular gender stereotype - in this case, middle- and upper-class men - is taken as the norm, and is typified by positive characteristics, while others are defined in opposition to it. As a result of this, there has been a substantial amount written about the fact that white, usually middle- to upper-class gender norms tend to be privileged above those of other races and classes (Messerschmidt, 1993; Buscher, 2005). 
This is particularly relevant in countries which have a colonial or racialized history. In colonial times, white masculinities were usually seen as rational, in control and educated, while African (or Indian or Asian) masculinities were seen as impulsive, irrational, and more animal-like (Segal, 1993; Dolan, 2002; Buscher, 2005). Colonial or racial governments, such as in Apartheid South Africa, infantilised African men who were often called 'boys' by white men, and were employed in menial or low-ranking jobs reporting to white men (Breckenridge, 1998; Kandirikirira, 2002; Langa \& Eagle, 2008). This created a situation of African men not being able to achieve many of the normal 'requirements' of masculinity, such as land ownership or being able to financially support a family, and therefore having to find other means to do so (Suttner, 2007). Men's efforts to use other means to achieve masculinity are discussed in more detail below, but the result of this was often that African men were in a subordinate position to white men and women, while still being in a position of authority over African women.

However, Mutua argues that in some cases the identity of 'blackmen' actually functions as a double oppression, rather than as partial privilege (2012/2013:347). In other words, the combination of the two identities creates a third, 'multidimensional whole' identity, which is viewed even more negatively than the two other identities separately (2012/2013:347). Thus, African men's identity, 'sits at the intersection of a privileged category or a subordinated category, the meaning of which turns on context and whether his assumed gender privilege actually may be an additional source of oppression' (2012/2013:361). For example, African men were considered to be more dangerous than white men, especially to white women (Moffett, 2006), which meant that African men were more likely to be arrested, convicted and jailed (Cranshaw, 1991; Messner, 1997). Despite their partial privilege in relation to African women, they faced a double subordination in relation to white men and women.

The development of gender socialisation theories has created a body of literature which is much more useful for understanding gender roles and how they are developed. In the context of this study, the fact that gender roles are socialised is significant, as it contradicts previous thinking which viewed them as inherent and unchangeable. Since the focus of this study is on ways to address GBV through problematizing and potentially shifting masculinities towards more positive norms, the fact that gender roles are fluid and constantly changing is positive. However, the impact of social norms and status hierarchies means the roles that people are willing to adopt may be limited, with many people being unlikely to want to take on a role with a lower status than the one they currently perform. The 'ranking' of gender, and specifically the favouring of certain versions of masculinity, has resulted in the notion of 'hegemonic masculinities', as discussed below. 


\subsection{Hegemonic masculinity}

Hegemonic masculinity is the version of masculinity which is considered most desirable or prevalent within a specific society or group, and which other masculinities (and genders) are measured against (Connell, 1987). It is therefore the version of masculinity that enjoys the highest status in its context, and is seen as 'the idealised form of masculinity in a given historical setting' (Messerschmidt, 1993:82). Despite the fact that a hegemonic masculinity is considered the norm within a certain community, it may be relatively unattainable, and it is likely that very few, if any, men will be able to achieve it (Nagel, 1998; Kimmel, 2006). However, it remains the 'benchmark' against which most men are measured, and is usually the version most prevalent in the media and pop culture (Donaldson, 1993).

Hegemonic masculinities are context specific, meaning that there may be differences between masculinities in different cultures, but certain aspects tend to be relatively consistent. The feature which occurs most commonly relates to men being the economic breadwinners or providers within a family or household (Muntingh \& Gould, 2010; Dworkin, Colvin, Hatcher \& Peacock, 2012), which is often linked to being employed, or having land or livestock (Morrell, 1998; Lwambo, 2011). A second aspect relates to physical strength or 'toughness', which can involve using violence as a means to control others (Lindegger \& Maxwell, 2007), including sexual dominance of women (Lopes, 2011). Linked to sexual dominance of women is an expectation of sexual prowess, with the implication that men have an 'uncontrollable' sexual appetite (Mankayi, 2008), resulting in sexual risk-taking, such as multiple sexual partners and not using condoms. Finally, the majority of hegemonic masculinities assume heterosexuality on the part of men (Connell, 2005). Men who do not or cannot achieve these standards (such as unemployed, gay or non-violent men) may be afforded less status in society, or not considered 'masculine' at all (Farr, 2002; Conway, 2008; Langa \& Eagle, 2008).

The concept of 'hegemonic masculinities' is now widely used in much of the literature around gender and masculinities, but it has begun to be problematized by a number of scholars, including Connell herself. For example, Connell (1995) has noted that it is often taken for granted that certain aspects of hegemonic masculinities are constant, yet there has been little questioning of how or when these aspects became considered the norm. As Connell asks, '[t]he male role literature took it for granted that being a breadwinner was a core part of being masculine. But where did this connection come from?' (1995:28-29). In addition, Connell and Messerschmidt (2005) note that the term 'hegemonic masculinities' has begun to imply something static, suggesting that it has become an identity which is constant and unchanging. However, the concept of hegemonic masculinities specifically points to the notion that masculinities are fluid and constantly changing (Ratele, 2012). Thus, the 
'fundamental feature of the concept remains the combination of the plurality of masculinities and the hierarchy of masculinities' (Connell \& Messerschmidt, 2005:846).

Even though the specific construction of hegemonic masculinities differs across contexts, the existence in all cultures of versions of masculinity which are considered hegemonic places pressure on men in these cultures to achieve the norms associated with it. The pressure to achieve these norms, and the societal disapproval if they are not achieved, is what makes hegemonic masculinities such a powerful concept in work on men. Hegemonic masculinities are taken to be 'normal', and the specific aspects attached to it are assumed to be 'how men are', implying that anyone who is not able to achieve these aspects is abnormal or problematic. Attempting to behave in ways outside of the norms of hegemonic masculinities will therefore entail disapproval or stigma, and is not something many people would voluntarily choose to do. This suggests that re-socialisation into an alternative set of norms will likely be difficult for many individuals. However, the fact that hegemonic masculinities are fluid and constantly changing also provides some hope that it is possible to shift these norms towards something more positive, and this process will be discussed in more detail in the following chapter.

The focus of this research is on masculinities and its links with GBV, and I argue that men's attempts to achieve the norms of masculinities play a significant role in their use of violence. However, there is a large body of literature which suggests alternative causes of violence, as discussed below.

\subsection{Possible causes of gender-based violence}

As was stated above, the majority of violence worldwide is perpetrated by men, yet the causes of violence have long been a source of debate. While the fact that men are the primary perpetrators is true of almost all forms of violence, the focus of this research is specifically on GBV. GBV is violence that is directed against a person on the basis of their gender (European Institute for Gender Equality, n.d.), meaning that although it is often equated only with sexual violence or violence against women (e.g. rape, domestic violence), it encompasses a much wider range of acts. The concept of GBV and what it constitutes has shifted over time, and this shift has largely been due to the writing of feminist theorists (Robert, 1993/94). Initially, violence against women was seldom recognised as a crime, with only physical violence outside the home or perpetrated by those unknown to the victim being included. Problematically, this tended to suggest that domestic violence or rape within a marriage was a 'private' affair, and did not classify as violence that needed to be criminalised or prosecuted (DeKeseredy, 2011). Physical or sexual violence by men against their female 
partners was often condoned or encouraged, and seen as an acceptable way for men to maintain control in their relationships.

However, this began to be contested as writers argued that acts such as rape, marital rape or domestic violence are a manifestation of systemic inequality between genders, rather than personal issues suffered by individual women (Simpson, 1989). For example, Brownmiller (1975) described rape as a tool used by all men to control all women. Thus, rather than being a sexual crime, it is an expression of control and power. As DeKeseredy notes, 'there is something about broader structural and cultural forces, such as patriarchy, that allows for so very many women to be victimized' (2011:298). Thus, these forms of violence need to be addressed systemically, rather than on a case-by-case basis.

Given that GBV is based on a person's gender, it can be targeted at those who do not conform to gender stereotypes, as in the case of gay-bashing or 'corrective rape', where it is intended as a form of punishment for transgressing societal norms. Alternatively, GBV can also include violence that is permitted because of the favouring of certain genders over others. An example of this is female infanticide, where female babies are aborted or killed because boys are considered to have more 'worth'.

Despite the fact that GBV covers such a wide range of acts, violence between men tends to be excluded, even though men and boys are overwhelmingly the most common victims of violence (Ratele, 2012; Peacock, 2013). For example, a United Nations Office of Drugs and Crime [UNODC] study in 2013 found that, 'the global male homicide rate is almost four times that of females' (2013:13), and roughly 79\% of homicide victims are men (2013:28). Growing awareness of this fact has led to a shift from the overwhelming focus on women in literature on GBV, towards research including much broader aspects of GBV, and particularly the fact that men can also be victims of GBV. For example, Jones (2000) discusses how men are disproportionately likely to be killed in conflict, both as combatants and as civilians, and that armies are made up almost exclusively of men who are expected to fight, and potentially die, in order to protect their country, community or family. Men's involvement in a military group can become an essential part of the performance of their masculinity, an issue which is discussed in more detail in later chapters. In these contexts, women are expected to be removed from the fighting, and the killing of women by armies is seen as a much more serious crime than the killing of men (Jones, 2000), yet this is seldom recognised as a form of GBV against men.

As another example of ways in which GBV affects men, some authors (e.g. Kaufman, 2012; Peacock, 2012) have highlighted the rape of men which, while potentially less common than the rape of women, is still occurring worldwide. The rape of both women and men is severely 
under-reported in South Africa and elsewhere, and it is estimated that anything from one in four to only one in nine rapes are reported to the police. The heavy stigma attached to the rape of men means that this is even more likely to be under-reported, and support services for male victims are hard to find (Peacock, 2012). The stigma arises because of the expectations of strength and heterosexuality attached to hegemonic masculinities, meaning that a man being raped suggests both weakness and homosexuality on his part. In being unable to physically fight off an attacker, and engaging in homosexual sex (albeit unwillingly), men may fear that their ability to achieve the required norms of hegemonic masculinities could be permanently damaged. Thus, it is easier if they do not report the violence, to avoid the shame and stigma attached to it.

These are just two examples of the ways that GBV can apply to acts where men are victims, and this broader definition is important to keep in mind in the context of masculinitiesfocused work which aims to reduce GBV. Maintaining a discourse in which men are always perpetrators and women are always victims risks alienating men, by implying that they are only problematic, and not able to be part of efforts to reduce violence (Pease, 2008). Additionally, focusing on men only as perpetrators of violence misses the many forms of violence that men themselves experience (Peacock, 2012). If the aim of masculinitiesfocused work is to involve men in working to prevent GBV in their communities, the discourse needs to be as inclusive as possible. This research therefore uses the broader definition of GBV explained above, which includes violence against and between men.

When looking at the causes of violence, much of the focus in the literature has been on the individuals who commit violent acts, with factors such as experienced abuse or substance abuse highlighted as contributing to the likelihood that an individual would perpetrate violence themselves. However, recently a broader approach has been used, which focuses more on the societal-level factors which can contribute to violence, including aspects such as traditional or cultural norms and different versions of masculinity. These works include strain theories, and work on the so-called 'crisis of masculinity'.

While examining the causes of a particular individual's use of violence can provide information on a specific case, theories which focus only on individuals risk missing the broader influences which play a role in enabling violence to be perpetrated on a large scale, particularly in a country like South Africa with its very high rates of violence. Crucially, the theories also do not allow us to answer the question of why it is that almost all violence is perpetrated by men. Although ascribing all violence to one cause, such as masculinities, risks ignoring numerous other factors that can play a role, I argue that the presence and privileging of certain versions of masculinities can go a long way to explaining much of the 
violence that is currently taking place. This section therefore looks at the different theories behind what causes men in particular to perpetrate GBV, beginning with those which focus on the factors causing specific individuals to turn to violence, and moving on to those which have a broader societal-level approach.

\subsubsection{Witnessed or experienced abuse}

One of the variables most likely to be associated with interpersonal violence by men is whether they witnessed or experienced physical or sexual abuse themselves as a child (Lau, 2009). In a 2001 meta-analysis of published research on the effects of childhood sexual abuse, Paolucci, Genuis and Violato found that those who had experienced childhood sexual abuse were more likely to become a part of the victim-perpetrator cycle, suggesting that such individuals are more likely to perpetrate abuse after having been a victim of abuse themselves. Similarly, Malinosky-Rummell and Hansen (1993) found that there is a link between childhood experience of physical abuse and later perpetration of dating violence and violence towards spouses, with men who had been physically abused showing twice the rates of violence towards spouses than non-abused men. In addition, the study found that approximately $30 \%$ of physically abused or neglected individuals abuse their own children suggesting that, 'spouse abusers report higher rates of physical abuse than do nonabusive spouses, and physically abused persons abuse their spouse more often than do nonabused persons' (Malinosky-Rummell \& Hansen, 1993:75). Despite this, a meta-analysis of the intergenerational transmission of spouse abuse found that the link is not as absolute or as strong as has been assumed (Stith, Rosen, Middleton, Busch, Lundeberg \& Carlton, 2000). While some who have been abused later become abusers themselves, this is not always the case, and not everyone who is abusive was once abused themselves.

The study by Stith et al. raised a number of additional questions about the correlation between witnessed or experienced abuse and later perpetration of violence, with a primary issue being that the direction of causation can be unclear. Along with this, it is difficult to establish whether witnessing abuse has the same effect as experiencing it, and whether abuse in childhood makes a person more likely to be a victim or a perpetrator of violence. Finally, the study questioned whether men or women are more likely to be involved in spousal abuse. The meta-analysis found that growing up in an abusive family is positively linked to becoming involved in a violent marital relation, but that it affects men and women differently, with men being more likely to become perpetrators of violence, while women are more likely to become victims. 'Thus, cultural socialization practices may interact with modelling of same-sex parent behaviour, leading to differential effects for boys and girls growing up in violent homes.' (Stith et al., 2000:648). It therefore seems that having grown 
up in an abusive family interacts with gender norms to result in different outcomes for men and women.

Witnessed or experienced abuse does appear to be linked to later violence, indicating that interventions which focus on an individual (such as psychotherapy) could be effective in reducing their future use of violence. However, the fact that men and women express this violence differently suggests that societal gender norms also play a significant role in how and why the violence is perpetuated. Thus, interventions which focus on problematizing gender norms could be a more useful strategy in addressing how and why these norms play a role, as will be discussed in Chapter Three.

\subsubsection{Substance abuse}

Another factor related to an individual's perpetration of GBV is substance abuse (Goldstein, 2004; Barker et al., 2011), and studies suggest that, 'the strength of association between substance abuse and IPV [Intimate Partner Violence] appears to be very robust' (FalsStewart \& Kennedy, 2005:7). Fals-Stewart and Kennedy found that $40-60 \%$ of married or cohabiting couples entering treatment for substance abuse reported one or more episodes of IPV in the year prior to entering the programme (2005:5), and that over $80 \%$ of all IPV episodes occurred within four hours of the male partner drinking (2005:8). The link between substance abuse and violence therefore seems to be strong for both genders (Fals-Stewart \& Kennedy, 2005), but in a similar fashion to witnessed or experienced abuse, this may manifest differently for men and women. Thus, while substance abuse is linked to being either a victim or perpetrator of such violence (Wong, Huang, DiGangi, Thompson \& Smith, 2008), a 2001 study found that drug-involved women are at an increased risk of being a victim of partner abuse, rather than a perpetrator (El-Bassel, Witte, Wada, Gilbert \& Wallace, 2001:42).

Nonetheless, as with experienced or witnessed abuse, the direction or causality of the relationship is less clear. In other words, it is hard to determine if substance abuse causes violence, or if violence causes individuals to abuse substances. As noted by Liebschutz, Savetsky, Saitz, Horton, Lloyd-Travaglini and Samet, 'the nature of the association appears to be complex, in that a history of interpersonal trauma increases the risk for substance abuse, and substance abuse increases the risk for interpersonal trauma' (2002:121). Along with this, it is hard to prove if alcohol and other drug-use facilitates or contributes to violence, simply co-varies with violence, or is used as an 'excuse' for violence (Fals-Stewart \& Kennedy, 2005). In some cases, it may be that substance abuse causes a person to perpetrate violence, while in others the person uses substance abuse as an explanation for committing violence - being drunk or high could be used as a viable excuse for having acted 
violently. Finally, it may just be a coincidence that episodes of violence tend to occur at the same time as episodes of substance abuse. Despite the difficulty in tracing the direction of causation, the connection seems robust.

The findings linking substance abuse to violence support those relating to witnessed or experienced abuse in suggesting that working with individuals could help to reduce a person's later perpetration or experience of violence. This also suggests that the strong link between substance abuse and violence could be included and problematized in interventions which aim to reduce GBV. Links between experienced abuse or substance abuse and GBV have been found in numerous studies, yet the reasons why these factors impact on different people in different ways is less clear. For example, it is hard to explain why substance abuse may make a man more likely to perpetrate violence, while it makes a woman more likely to be a victim. As a result of this, the focus in trying to understand the causes of violence has begun to turn to cultural or societal factors.

\subsubsection{Cultural or traditional norms}

Looking at the context in which people find themselves may provide some explanation of why individuals respond in such different ways, as these contexts could contain norms which allow, condone or even encourage GBV. As a first example, GBV is often blamed on (or excused by) culture or tradition, with cultural practices such as polygamy, female circumcision or female genital mutilation, and bride price all believed to increase the likelihood of GBV, especially against women (Buscher, 2005). While not all of these are necessarily practised in South Africa, there is generally a strong culture of patriarchy and relatively conservative gender norms, which are discussed in more detail in Chapter Four. Thus, the impact of these kinds of norms on GBV could provide some clues as to why the levels of violence are so high in the country.

As an example, the practice of bride price is thought to increase a woman's chances of experiencing GBV because the husband may assume it implies that he 'owns' his wife (Kim \& Motsei, 2002; Saffitz, 2010:88). This sense of ownership can then lead the husband to feel justified in treating her poorly, or becoming angry if she does not fulfil her expected role, which can include aspects such as cleaning, cooking, childcare or providing sex. Another practice which is thought to increase the likelihood of GBV in a marriage is polygamy, with a study in Zimbabwe showing that women who were in polygamous marriages were 1.77 times more likely to suffer spousal physical violence than those in monogamous marriages (Wekwete, Sanhokwe, Murenjekwa, Takavarasha \& Madzingira, 2014:1422). Although this study did not suggest reasons for why this is the case, it could arise from a similar mindset to that surrounding bride price, meaning that polygamous marriages may be based on the 
notion of the husband having possession of his wives, which may lead him to use violence against them, as explained above.

The link between GBV and more traditional or conservative norms about the position of women seems to be supported by the literature, with Saffitz stating that 'GBV is more prevalent in societies with rigid gender roles or in patriarchal communities in which male dominance is engrained in a masculine identity' (2010:85). Cock agrees that, 'tradition is often invoked to justify gender inequality' (1991:129) and this seems to be especially true in areas where there is a belief that domestic violence is a 'private affair' (Usdin, Scheepers, Goldstein \& Japhet, 2005:2435). Additional norms which may contribute to the acceptance of GBV include thinking that a man is the authority in a household, that a husband 'owns' his wife, or that a woman is not able to refuse to have sex with a man who provides for her financially, and these can then provide 'justifications' for the use of violence (Heise, Ellsberg \& Gottmoeller, 2002:S8).

Due to the fact that conservative gender roles contribute to violence against women, it would seem logical that patriarchal beliefs are more strongly held by men than by women.

However, a number of studies have shown that beliefs condoning violence and gender inequity are held by both men and women. Ditlopo, Mullick, Askew, Vernon, Maroga, Sibeko, Tshabalala, Raletsemo, Peacock and Levack (2007) found that $50 \%$ of men and $34 \%$ of women believe men should have the final word in decisions in the home, suggesting that stereotypes about male and female appropriate roles are still held by both genders. Similarly, Kim and Motsei (2002) found that both male and female primary health care nurses in a hospital in rural South Africa believed that physical punishment was appropriate for certain behaviours of wives, while Saffitz (2010) reported that women who had been victims of violence were more likely to believe that a man sometimes needs to beat his wife to teach her to behave. $29.3 \%$ of women who had been victims of violence believed this, as opposed to $9.6 \%$ of women who had not been victims of GBV in the past 12 months.

The fact that both men and women support these norms may provide some explanation for why patriarchal beliefs are so resilient in many cultures, as they are held by individuals of both genders. Thus, both men and women may think of certain forms of GBV as 'normal'. This means that interventions which aim to address GBV through focusing on conservative gender norms may encounter resistance from those engaged in the intervention, as well as those in the broader community in which the intervention takes place. As is discussed in later chapters, this resistance from the broader community is often an aspect which makes it difficult for intervention participants to sustain any positive impacts they may gain from the 
interventions. However, it also suggests that there is a need for a focus on problematizing conservative gender norms in order to address the levels of violence associated with them.

Despite the literature supporting the link between conservative gender norms and GBV, the focus on 'cultural practices' runs the risk of demonising or othering specific cultures while normalising practices in 'Western' cultures. This then implies that the 'cultural practice' in question is the reason for GBV, or that GBV only occurs in countries which implement these practices (Armstrong, 1994; Adelman, 2003; Greig, 2004). For example, certain kinds of female genital mutilation (FGM, also known as female circumcision, or female genital cutting) have been listed as forms of GBV (Pedwell, 2007; Valasek, 2008). In some instances, it is used as a way of controlling female sexuality, through the process of removing the clitoris or sewing parts of the labia together, which means that the woman will not be able to have or enjoy sex without medical intervention. The stitching in the labia is usually only removed once the woman is married. There are also cases of labial elongation or stretching, which is thought to increase the male partner's sexual pleasure, which is considered an example of FGM. However, it has been noted that in 'Western' cultures, a process with a similar intention takes place, in which the labia are trimmed or shortened (known as labiaplasty) because smaller labia are considered more attractive to men in these cultures. Yet, this is not considered to be 'mutilation', but rather 'beautification' or cosmetic surgery (Pedwell, 2007). While labial elongation and labiaplasty are both carried out in order to make a woman's body more attractive to men, only labial elongation is called FGM and considered a form of GBV. Thus, blaming levels of GBV on 'cultural practices' risks othering certain societies, while ignoring harmful practices in Western societies.

The focus on certain cultures rather than others suggests that GBV only occurs in countries which practise them. However, research has consistently shown that GBV is a worldwide phenomenon, no matter what the culture of the country being investigated (Walby, 1990; Lau, 2009). Garcia-Moreno, Pallitto, Devries, Stöckl, Watts and Abrahams (2013) found that roughly $35 \%$ of women worldwide have experienced violence, either physical and/or sexual intimate partner violence or non-partner sexual violence; and that high income countries (such as the USA, Northern and Western Europe, or Australia) had a prevalence of around $32.7 \%$. Roughly $41 \%$ of ever-partnered women in a study from Tanzania reported experiencing physical or sexual abuse by a partner at some point in their lifetime (Saffitz, 2010), while Heise et al. (2002) found that up to $38 \%$ of teenage mothers in the USA reported physical or sexual abuse during their pregnancy. Thus, the problem is not limited to certain countries or geographic regions, or to specific cultures, but exists across the world, leading Saffitz to state that, 'GBV exists in virtually every society' (2010:99). 
In the context of designing interventions which aim to reduce GBV, problematizing conservative societal norms is important, as addressing the context in which participants live can help to improve the impact of the intervention. However, focusing on specific cultural practices may not have much impact at all. The fact that men perpetrate violence in all societies and that it is predominantly men perpetrating violence in all societies, implies that the expectations of masculinities are more of a factor in enabling violence than any particular cultural practice, and the link between these masculinities and violence needs to be investigated. Thus, it is important to engage with literature which focuses on why specific groups of men are more likely to perpetrate violence than others. This requires that one engages with theories that discuss what leads to a crisis of masculinity, and this includes strain theories and the men's rights movement.

\subsubsection{Crisis of masculinity and strain theories}

A factor which is sometimes used to explain men's perpetration of GBV is the notion of a 'crisis of masculinity'. According to this, when men are unable to achieve the norms assumed to be relevant for them within their society, they compensate by over-emphasising other aspects of masculinity (Messerschmidt, 1993; Dolan, 2002; Harders, 2011). For example, if men are unable to act as the financial providers for their family, they will compensate by turning to other ways to 'prove' their masculinity (Walby, 1990), and these alternative markers tend to include the use of violence, or risky sexual practices such as multiple partners or not using condoms (Mankayi, 2008). The idea of a crisis of masculinity is often taken to be the case in places with high unemployment, where men are unable to fulfil their expected role as provider for their families. This is also thought to be true in areas with structural inequality, where men in some groups are unable to achieve certain levels of status (Moffett, 2006; Alden, 2010).

In support of this notion, a number of studies have reported links between lower economic status and violence. Peralta and Tuttle state that poverty is linked to higher rates of IPV, which is theorised to be the result of stress (2013), in that lower economic status can lead to higher stress, and this is coupled with limited access to the kinds of resources that can help to reduce stress. Episodes of IPV are therefore linked to 'compensatory masculinity in that violence stems from attempts to compensate for economic shortcomings and to assert dominance through deviant means' (Peralta \& Tuttle, 2013:258). Jewkes concurs by stating that, '[s]ince poverty is inherently stressful, it has been argued that intimate partner violence may result from stress, and that poorer men have fewer resources to reduce stress' (2002:1424). A similar situation is expected to arise in countries in conflict where men are often unable to own land because of internal displacement, or cannot earn money because a wartime economy has limited the job options available (Goldstein, 2004; United Nations 
Inter-Agency Working Group [UN-IAWG], 2012). As civilian men are usually unable to access the authority afforded to soldiers, who gain status by virtue of their weapons and use of violence, it is thought that they will be impacted by this 'crisis' more acutely (Dolan, 2002). These writers therefore use strain theories to explain the crisis of masculinity.

One such example is General Strain Theory, or GST, which posits that if an individual is unable to achieve their goals through lawful behaviour, it can lead to them using violence as a means to achieve these goals instead (Muntingh \& Gould, 2010). In other words, strain is the failure to achieve positively valued goals (Agnew, 1992:56), where the strain is created by the gap between expectations and actual achievements, and these gaps can lead to anger, disappointment and dissatisfaction, with attempts to reduce the gap potentially including deviance or crime (Agnew, 1992:52). In the case of masculinities, an example would be a man being unable to achieve the desired status of financial provider, with strain theories suggesting he would then use alternative means such as violence or having multiple sexual partners to achieve the requirements of masculinities.

'Classic' strain theories often focus on how lower-income groups struggle to achieve the strived-for middle- to upper-class status symbols, and how this causes 'strain' (Agnew, 1992). However, these theories have a number of shortcomings, as they fail to account for middle- and upper-class crime, ignore goals besides monetary success and do not focus on barriers besides social class (such as race, gender, religion, or ethnicity) (Agnew, 1992). Thus, adaptations to the theory have been suggested, such as Peralta \& Tuttle (2013) who have applied strain theories to masculinities and intimate partner violence. While the most salient markers of masculinity tend to be the ability to support one's self and one's family, in times of economic insecurity it can be easier to exert physical control over a partner, rather than establishing financial security (Peralta \& Tuttle, 2013). Thus, '[s]triving for an "appropriate masculinity" creates stress which may in turn contribute to IPV' (Peralta \& Tuttle, 2013:265). Strain theories can therefore provide some explanation for why being unable to achieve the norms associated with hegemonic masculinities can result in men becoming frustrated and turning to violence as an alternative.

While strain theories can be useful in the context of masculinities studies, a drawback to using them to explain men's use of GBV is that studies on why certain people turn to violence and others do not are hard to conduct. It is difficult to control all the external variables that can impact on a person, and therefore almost impossible to determine which particular variable caused the behaviour being studied. Given this, the literature on the exact risk of certain factors causing violence, or of which factors can act as protective factors, is inconclusive. This uncertainty therefore limits the effectiveness of strain theories, as it results 
in their having to remain quite vague on which strains cause stress, and which do not. Thus, while they can provide suggestions for why some people perpetrate violence in certain situations, they do little to explain why others in a similar situation do not turn to violence. Nonetheless, some studies (such as Muntingh \& Gould, 2010) have outlined seven general 'risk' factors that can impact on a person's likelihood to resort to violence when lawful means are not available. Thus, according to Muntingh and Gould, while 'criminal behaviour can be used as a resource when other resources are not available for accomplishing masculinity', certain factors make the use of criminal behaviour more or less likely (2010:13). These factors provide some nuance to traditional strain theories, which tend to imply that all people in a situation of poverty or inequality automatically turn to violence, and that all those who have wealth will never use violence. However, as has been noted above, cases of IPV are recorded in all contexts and by those from all socio-economic groups.

The first factor is having limited skills and resources for lawful coping, and this includes low intelligence, low constraint, low socio-economic status, and negative emotionality. The second is having abundant skills for violent coping, suggesting that if a person is physically strong, and has fighting skills or access to a gun, they are more likely to turn to violence. The third factor is having low levels of conventional social support, such as parents, teachers, or employers. The fourth factor is being in a situation of low social control, with little or no close supervision, and with little investment in conventional institutions, an example of which could be a child in a single-parent household where the parent is full-time-employed and is therefore not at home very often. The fifth factor is associating with others who are violent. Sixth is holding beliefs favourable to violence, which includes believing that violence is justifiable or desirable, or that it is excusable under certain conditions. The final factor is being in situations where the costs of violence are low and the benefits high. When these risk factors are present, the likelihood of an individual using violence to achieve their desired status is higher (Muntingh \& Gould, 2010). These seven factors are particularly relevant in looking at masculinities arising out of institutions such as the military, and this is discussed in more detail in a later chapter.

These factors make strain theories somewhat more refined, as they no longer simply apply to every person in any situation which could be considered stressful. However, I would argue that a flaw in this theory is that it still takes little notice of the fact that it is men, rather than all people, who are likely to respond to strain by using violence. Thus, it risks ignoring that some versions of masculinity specifically condone or expect violence against women (Gibson \& Rosenkrantz Lindegaard, 2007) as a way to achieve masculinity, rather than being an abnormal response to perceived strain. As noted in a Sonke report, '[m]en who use violence do so because they equate manhood with aggression, dominance over women and 
with sexual conquest' (2008:26-27). Controlling one's partner (e.g. through domestic violence) is often a central feature of constructions of masculinity in a range of societies, where men are expected to be the heads of their households (Jewkes, Sikweyiya, Morrell \& Dunkle, 2009). In addition, men are usually expected to have an 'insatiable' sexual appetite and to not be able to take no for an answer when wanting sex (Mankayi, 2008). Their use of violence against women who refuse to have sex with them is therefore seen as justified or understandable.

Along with this, the discussion of a 'crisis' implies that only those who are poor or marginalised are likely to perpetrate GBV. However, as noted above, studies consistently show that many aspects of GBV are prevalent across all cultures and socio-economic status groups (Walby, 1990; Lau, 2009; Garcia-Moreno et al., 2013). The implication of a 'crisis' is that there is a single, homogenous version of masculinity which is being threatened (Sideris, 2004), yet there are always multiple versions of masculinity in any one space or time, and these are constantly changing. Concerns about a 'crisis' of masculinity also risk ignoring the political and structural aspects of gender inequality and patriarchy, and the methods used to maintain power (Sideris, 2004:36).

A group which has arisen as a result of the discussions of a crisis of masculinity is the socalled 'men's rights movement', which displays a form of 'backlash' against masculinitiesfocused work. While this backlash may be relatively small in scale, it is worth noting that it is an approach which may arise as a counter to discussions around masculinities as a contributing factor to violence. Men's rights movements typically result in men displaying resistance to working towards gender equality, because they believe that improvement in women's rights equates to a decrease in men's rights (Dworkin, Colvin, Hatcher \& Peacock, 2012). Some men seem to feel that rights are a zero-sum game, and if women's rights increase, there are fewer rights available for men. This is an important aspect to consider in the context of masculinities-focused interventions, as it may be raised by men during these interventions as a reason for being unwilling to change their behaviour. Movements that focus on men's rights are therefore discussed, and are broadly split into two groups: men's liberation groups, and men's rights groups.

Men's liberation groups arose in the 1970s and focused predominantly on raising awareness of how gender norms and masculinities limited and potentially harmed men as well as women (Messner, 1998). These groups tended to be pro-feminist, often allying themselves with women's movements. In contrast, the men's rights movement focuses more on maintaining or improving specific rights for men and tends to have an anti-feminist approach (Messner, 1998). This movement emphasises the toll that societal norms place on men 
today, including the fact that it is usually only men who are conscripted into armies, that men have far higher mortality rates than women, that men struggle to gain custody of their children, and that boys do worse in school subjects and drop out at a higher rate than girls (Messner, 1998; McDowell, 2000). The men's rights groups typically blame feminism for 'stealing' men's rights, and for prioritising women at the expense of men.

While the movement is relatively marginal, it can be a substantial stumbling block when working with men who may fall into a discourse of 'us versus them', seeing gender equality as an excuse for taking away men's rights and giving them to women, rather than a means for both genders to enjoy equal access to opportunities. It can also make men reluctant to acknowledge the contribution of masculinity to violence, as they feel that this simply 'blames all men' for violence. For this reason, the movement has received some support, for example in the increased granting of joint custody to men in Canada (Boyd, 2004). Yet it has been criticised on a number of grounds, with the first being that the movement is made up of a relatively homogenous group (predominantly white middle-class heterosexual men), which tends to ignore or minimise the experiences of non-white and non-middle class men. A second criticism is that the movement often uses incorrect statistics as a means to gain support. For example, if men's rates of mortality are substantially higher than women's, the men's rights groups may present this as evidence that women are killing men, rather than that men are killing other men too (McDowell, 2000). In a similar fashion to the issues with focusing on a crisis of masculinities, blaming feminism for a loss in men's rights hides the fact that institutional sexism still benefits the majority of men and that certain men benefit much more from patriarchy than others (Messner, 1998). Thus, while the men's rights movement does not suggest a possible cause of GBV, it is important to bear this in mind as a potential rebuttal when one discusses masculinities-focused work.

With regard to understanding the possible causes of violence, the theories outlined above can go some way to explaining why violence is perpetrated and providing suggestions on ways to attempt to address it in interventions. While none can explain all instances of GBV, theories which look at societal factors along with individual ones seem to provide the most comprehensive explanation of violence, as in the case of strain theories. Problematically however, none of these theories take into account the fact that many versions of masculinity specifically require men to use violence, rather than viewing the violence as something abnormal to be used when all other avenues are blocked. The fact that violence is expected from men in certain masculinities can provide some suggestion as to why it is men in particular who are likely to turn to violence, rather than women. For this reason, the focus of this research now turns to theories which specifically link violence to the expectations of masculinities. 


\subsection{Militarised masculinities and hypermasculinities}

Two bodies of literature which can provide some insight into instances where masculinities specifically call for the use of violence are those relating to militarised masculinities and to hypermasculinities. Militarised masculinities constitute a particular masculinity which is usually associated with those who have gone through military training or military groups, and these stereotypically have a strong emphasis on violence, strength, aggression and weaponuse (Adelman, 2003; Cockburn, 2010). Hypermasculinity (described by Mosher \& Sirkin, 1984) has three main characteristics: i) a belief that danger is exciting; ii) viewing violence as an acceptable means of demonstrating dominance; and iii) calloused sexual attitudes, reflecting a disregard of women's rights (Hamburger, Hogben, McGowan \& Dawson, 1996). The two therefore share an emphasis on violence and strength, but hypermasculinities are more closely associated with violence against women because of the disregard of women's rights and calloused sexual attitudes typically associated with them. Given these characteristics, there is a growing body of literature looking at the link between hypermasculine traits and GBV.

As a starting point, literature has shown that gender-inequitable beliefs are a strong indicator of violence, meaning that the more gender-inequitable a man's views, the more likely he is to report having perpetrated some form of GBV (Barker et al., 2011). In addition, Smeaton and Byrne (1987) found that men who identify strongly with hypermasculine characteristics scored higher on measures of self-reported proclivity to rape. Likewise, Hamburger et al. found that, 'sexual aggression is most prevalent in patriarchal societies with rigid, traditional sex roles and social norms that included acceptance of interpersonal violence and the necessity of dominance and toughness in men' (1996:158). In a similar vein, Lau (2009) noted that patriarchal beliefs are among the variables most associated with IPV in South Africa. These patriarchal beliefs can include the idea that men should have control over women, and that men are entitled to sex from their partners at any time, suggesting that hypermasculinities can align closely with patriarchal beliefs, particularly in their acceptance of interpersonal violence.

Due to the similarities between militarised and hypermasculinities, these kinds of hypermasculine identities are often found in societies with a history of conflict or militarisation. A possible result of this is the very high levels of GBV which tend to occur during conflicts. GBV in conflict has long been considered a regrettable, but inevitable sideeffect of war, one which is usually expected to end once the fighting is over (Brownmiller, 1975; Engels, 2004). However, in many regions which have experienced political or violent conflict, the rates of sexual violence actually increase, often to levels above those of the preconflict society (Schoeman \& Naude, 2007; Borer, 2009; Peacock, 2013). In order to 
understand this increase of GBV during periods of conflict, numerous explanations have been offered. Some authors suggest that the breakdown of social cohesion during conflict leads to higher levels of GBV because the normal societal restraints (such as stigma, ostracism, or social disapproval) have been eroded (Kaufman, 2012). Others believe that the violence results from the fact that so many people in these societies have witnessed violence during the conflict, meaning that it becomes a norm in the post-conflict period (UNIAWG, 2012), which ties in with the literature outlined above which links perpetration of violence to experiencing or witnessing it. However, I would argue that the presence of militarised and hypermasculinities are likely to play a significant role in the levels of GBV that are often experienced in post-conflict societies. This means that the use of violence is required or expected in order to achieve these versions of masculinity, and men who identify strongly with them are more likely to be involved in violent incidents.

In a number of respects, the link between militarised or hypermasculinities and violence seem to reinforce the theory put forward by Muntingh and Gould (2010), who suggest a number of factors which make it more likely for a person to use violence in a situation of strain, and these factors are now discussed with specific reference to militarised and hypermasculinities. For example, men who have received military training learn to be aggressive and embrace hegemonic masculinities, suggesting that they will be more likely to use aggressive than non-aggressive responses in situations of strain. Along with this, they will be surrounded by others who consider violence an appropriate coping mechanism, leading to low levels of social control or disapproval of this violence. Moreover, men displaying hypermasculinities believe that violence is favourable or desirable, making them more likely to use violence as a resource in situations of strain. While Muntingh and Gould's strain theory did not specifically mention that men are more likely to use violence than women, their additions to classic strain theories provide a helpful lens through which to view militarised and hypermasculinities, and their likely link to violence. The list of factors outlined by Muntingh and Gould which make men more likely to use violence in situations of strain therefore seem to apply in many ways to those men who aspire to militarised and hypermasculinities, and this could provide one suggestion for why these men are more likely to perpetrate violence.

Although hypermasculinities would seem to be an issue predominantly in countries which are currently experiencing conflict, they have application in a broader sense. While hypermasculinities are often prevalent in armies and in countries experiencing conflict, this version of masculinity is not only limited to those who have gone through military training. As stated by the UN-IAWG, '[f]or men and boys in the vast majority of cultures, societal conceptions of masculinity have already promoted some degree of violence' (2012:11). 
Therefore, the terms militarised or hypermasculinity can also be used to 'refer to a set of ideologically informed practices that normalise violence and conflict' (Ratele, 2012:4), meaning that even in the absence of an ongoing war or conflict, a militarised or hypermasculinity may become relatively mainstream in a society. While these may not have arisen from military training, they will share some aspects with militarised masculinities, particularly in relation to an emphasis on violence, and to the possession and use of weapons.

There are a number of situations which can contribute to the development of militarised or hypermasculinities in regions not currently experiencing conflict. For example, many cultures have strong militaristic backgrounds and socialise boys into this from a young age, creating a form of militarised society which places a strong emphasis on military service as a means for achieving manhood, and often glorify war and war heroes (Cockburn, 1999; Adelman, 2003). This is often the result of a history of conflict, with the valorising of war and violence continuing after the conflict has ended. The ways in which the militarisation of masculinities occurred in South Africa will be discussed in more detail in the Chapter Four. Along with this, in countries which are currently experiencing conflict or have long histories of conflict, it can become difficult to distinguish between civilian and militarised or hypermasculinities (Lwambo, 2011). Militarisation impacts on and is impacted by civilian society, resulting in civilian identities which are heavily influenced by militarisation and military culture. The norms of militarisation become so prevalent in these societies that even those who are not or have never been in an armed group may begin to emphasise violence and weapon-use in their achievement of masculinities.

The presence of militarised and hypermasculinities in a society can therefore contribute to high levels of violence because of their emphasis on violence and aggression. Additionally, hypermasculinities are closely linked to GBV due to their inclusion of calloused attitudes towards women. However, in a similar manner to strain theories, an issue with using the concepts of militarised and hypermasculinities is that they imply that only those men who subscribe to these masculinities are going to use violence. Along with this, linking specific definitions of masculinities to violence also risks implying that other men do not use violence, or that violence has not been normalised in most masculinities. As has been mentioned above, many versions specifically encourage the use of violence, and this seems to be particularly prevalent in South Africa. Possible explanations for this will be discussed in more detail in Chapter Four.

Militarised and hypermasculinities may not adequately explain all incidences of GBV, but I would argue that acknowledging that certain forms of masculinities specifically expect 
violence from men makes them more useful than many of the other theories outlined in this chapter. Thus, they provide a more compelling explanation of violence than those which focus on individual factors (such as substance abuse), or on external issues (as in strain theories), as they focus explicitly on why it is men in particular who are more likely to use violence than women. They therefore provide some understanding of the reasons why men are more likely to use violence in situations of strain or in response to experienced abuse than women. This suggests that the literature surrounding militarised and hypermasculinities is important when designing interventions which aim to reduce GBV.

\subsection{Conclusion}

In order to provide a backdrop for later discussions of ways to respond to gender-based violence, this chapter focused on the process of socialisation of gender roles and the link between gender roles and violence. This research is primarily concerned with finding ways to reduce GBV, which entails both an understanding of what causes the violence and how to respond to this. Numerous studies have suggested potential causes, including factors such as substance abuse, witnessed or experienced abuse, and situations of strain, and these have all been linked to the perpetration of violence, suggesting that addressing these in work with individuals can be an effective way to reduce violence. Where these theories fall short is in explaining why it is predominantly men who perpetrate violence, rather than any person who has experienced abuse or is in a situation of strain. Additionally, there is little problematizing of the notion that violence is seen as a permissible way for men to respond to strain, while this is not the case for women.

Focusing on cultural or traditional norms can go some way to explaining why it is men perpetrating the violence, as the roles prescribed for men may enable or encourage the use of violence as part of their cultural identity. As numerous authors have explained, the notions of 'culture' or 'tradition' are often used to excuse or justify this violence, yet this risks othering or demonising specific cultures as problematic, while ignoring equally problematic norms in other cultures. It also tends to gloss over the fact that violence occurs in all regions and countries, no matter which culture is prevalent. Once again, the vast majority of this violence is perpetrated by men, which suggests that focusing on culture still obscures the fact that masculinities often specifically expect or condone violence by men, rather than seeing it as an aberration.

For this reason, literature which explicitly looks at the links between masculinities and violence plays an important role in understanding the causes of violence, and the ways in which to address it. While not all masculinities specifically expect violence, militarised and hypermasculinities do. In countries or regions where militarised and hypermasculinities are 
present or form part of the hegemonic masculinities, it seems likely that the levels of violence tend to be high. Both of these forms of masculinity have an emphasis on violence, with hypermasculinities in particular encouraging the belief that violence against women is acceptable. In the context of interventions which aim to reduce GBV, this literature suggests that focusing on masculinities and problematizing the assumption that violence is an important aspect of masculinity, should play a central role in our understanding of GBV. The following chapter will therefore look at efforts to address GBV through different interventions, including both women-focused and men-focused programmes, paying particular attention to the effectiveness of masculinities-focused interventions. 


\section{CHAPTER 3}

\section{MASCULINITIES-FOCUSED INTERVENTIONS}

\subsection{Introduction}

The widespread prevalence of GBV in almost all countries worldwide has resulted in numerous different kinds of interventions being implemented in an attempt to address this. These tend to fall into two broad categories: reactive, and preventative. As with the literature on GBV detailed in the previous chapter, many of the initial interventions, both reactive and preventative, were women-focused. Reactive programmes aimed to provide support to female victims of GBV, usually in response to incidences of rape or domestic violence. Preventative women-focused programmes have tended to aim for empowerment of women, often providing them with a skill-set which enables them to earn their own income and gain a measure of independence.

Such interventions have often had limited success in reducing GBV, and some have argued that this is because the focus has been on victims and potential victims, rather than on perpetrators. Providing support to victims or survivors of violence can help in their recovery, but does little to deter future incidents of GBV, because it does not engage those who are going to perpetrate this violence. Additionally, working only with survivors risks shifting the blame for the violence away from those perpetrating it onto those who have experienced it, by implying that they should have done more to prevent or avoid it. The result of the focus on reactive women-focused programmes is that the majority of funding for GBV remains geared in this direction, and few efforts have been made to include or work with men. However, some attention has begun to turn towards men-focused programmes. These often take as a given the concept of gender as a socialised aspect of a person's identity, and of masculinity's link to GBV. They therefore aim to problematize gender norms in a particular society by questioning the roles that men are expected to portray.

This chapter aims to provide an overview of the current scope of GBV-focused interventions. It begins by describing 'traditional' women-focused GBV interventions to outline the context in which the bulk of the work is being implemented. While recognising the importance of these women-focused interventions as a support process, this chapter argues that they do little to reduce such violence and that a new approach is necessary to address this. I argue that masculinities-focused interventions have the potential to be a part of this new strategy. Many of these interventions aim to problematize or question existing gender norms, requiring a form of re-socialisation of participants into new or alternative versions. For this reason, the successes and failures of programmes which have attempted re-socialisation with men are then outlined, including descriptions of their theoretical backgrounds and implementation. 
The chapter ends with a discussion of the current state of masculinities-focused GBVprevention interventions, in order to provide a framework for the later investigation of the OMC case study intervention described in Chapter Five.

\subsection{Traditional GBV interventions}

'The first generation of interventions mainly focused on provision of support services for survivors of violence' (Ellsberg, Arango, Morton, Gennari, Kiplesund, Contreras \& Watts, 2015:1555), meaning that the bulk of current responses to GBV are predominantly reactive, with a focus on women or children. There are a number of features that tend to be included, such as counselling, medical treatment, legal and court support, support groups, and places of shelter (Ellsberg et al., 2015). The intention of these is to provide support to survivors of violence in order to facilitate their recovery, and to partner them during the judicial process if they choose to press charges. The alternative form of women-focused intervention is preventative, which tends to aim at empowering women through the provision of skill-sets as a means of earning their own income and gaining self-respect and confidence. This can enable women to leave abusive marriages or homes as they begin to earn their own income and are no longer dependent on their abuser, and to begin to challenge the norms which encourage or allow men to use violence against women. The different facets of womenfocused interventions are discussed below, beginning with reactive victim support interventions (counselling, medical and legal support) and moving onto more preventionfocused programmes (awareness and women-empowerment campaigns).

\subsubsection{Victim support}

A primary service offered to survivors of incidences of GBV is individual counselling, which aims to provide a safe space for survivors to process and work through their emotions, experiences and possible trauma. The counselling may be offered to families, partners, spouses or friends of survivors as well. There have been reports of some positive impacts of counselling services. In a set of guidelines for responding to IPV and sexual violence against women, the WHO note that some forms of counselling or therapy can reduce PTSD and depression for women who have experienced IPV, compared to those who receive no counselling (2013:20). While the WHO guidelines do not suggest possible reasons for this, a 2004 study postulates that counselling may help to address some of the guilt that IPV survivors feel as a result of the violence, and this reduction in guilt can play a role in reducing their PTSD symptoms in the future (Kubany, Hill, Owens, lannce-Spencer, McCaig, Tremayne \& Williams, 2004). A review of existing literature by Jewkes, McLean Hilker, Khan, Fulu, Busiello and Fraser (2015) notes that some studies show counselling can lead to reductions in the violence experienced by women who use these services, but caution that there is insufficient evidence to make a recommendation regarding their use. In a similar 
vein, Dey, McDonald and Strydom (n.d.) found that reliving the experience during counselling may result in victims suffering secondary trauma, suggesting that the counselling needs to be planned and managed carefully in order to avoid causing further distress to survivors.

An alternative to individual counselling is support groups, which act as a form of group counselling. The intention is to allow survivors to share their stories with others, and to reduce the feeling that the victim is alone in having experienced GBV (Dey et al., n.d.). Another aspect which centres may provide as a form of therapeutic intervention is an opportunity for victims to speak out, either publicly or anonymously, as a way of destigmatising GBV in their community. This starts to challenge the stereotype of GBV as a private issue, or one which survivors are alone in having experienced. In addition, it can be a means to provide encouragement for other victims to come forward so that they feel less isolated (Rape Crisis, n.d.).

The provision of counselling as a means of emotional healing for survivors can play an important role in their recovery, but equally important is access to medical care and support. The WHO (2012) emphasises that these should be integrated into existing health services such as clinics and hospitals, rather than being offered as a stand-alone service. This is because these stand-alone services may be difficult to sustain, and the stigma attached to domestic or sexual violence may mean that these centres struggle to attract funding or staff. Medical care and support can cover a range of aspects. An initial step is treating any injuries the survivor sustained during the GBV incident, such as providing the morning-after pill, or emergency contraceptive, in instances of rape (Dey et al., n.d.). In South Africa, with its very high rates of HIV, anti-retroviral treatment is usually included as part of post-exposure prophylaxis to ensure that the survivor does not contract the virus. Another aspect of medical treatment is gathering evidence which can be used in a trial against the attacker. This is especially true in cases of rape, where medical evidence can play a role in the successful conviction of an attacker (Dey et al., n.d.).

The process of laying charges in instances of GBV can be lengthy and damaging to the survivor in both psychological and physical terms. The legal system is often noted as hostile to those who report instances of GBV (Dey et al., n.d.), which can lead to secondary trauma for survivors. Additionally, survivors may need some form of protection from the perpetrator once the charges have been laid. To assist survivors in managing the hostility of the legal system, a number of centres provide legal support, which aims to assist survivors in bringing their attackers to justice, to 'reduce perpetrators' impunity and increase the effectiveness of the justice system' (Ellsberg et al., 2015:1556). Such support can include a number of 
activities. Gathering physical evidence in the immediate aftermath of an incident is an important first step, which is best conducted during the initial medical treatment that a victim receives. In addition to this, some centres work closely with public prosecutors to help bring a perpetrator to trial. For example, South Africa has specialised Sexual Offences Courts which focus specifically on cases of sexual offences (these will be explained in more detail in Chapter 4), and a number of centres work closely with these courts.

Along with the collection of physical evidence and close collaboration with Sexual Offences Courts, another aspect of legal support is providing training or preparation for the trial itself. This is in an attempt to lessen the secondary trauma that many victims experience when going through the legal system. Victims will be provided with information about how the trial will unfold, including the kinds of questions that they are likely to be asked, and how to respond to them. In cases involving minors, or those with limited capacity, centres may organise for victims to testify in camera or via CCTV, so that they do not need to face their attacker in a courtroom (Dey et al., n.d.).

With regard to ensuring the safety of survivors, legal support can include assisting survivors to get some form of legal protection against their attacker, such as restraining or protection orders. There is contradictory literature on the effectiveness of these orders. While such orders may provide some level of safety, they have often been found to be relatively ineffectual, as they can only be as helpful as the justice system which imposes and enforces them. Jewkes et al. (2015) report that while protection orders reduce violence for some survivors some of the time, the levels of post-protection order violence remain high. Additionally, the justice sector may be reluctant to assist survivors in meaningful ways. Mathews and Abrahams (2001) report that in South Africa, even when men are arrested for violating a protection order, they are often released rapidly and many women therefore fear for their safety. Unless members of the police force or the courts are relatively quick to respond to infringements, the orders may end up being useless. However, Heise (2011) cites literature which states that women who received protection orders actually felt safer, even if those orders were violated. The reason given was that the protection orders constitute a break in the cycle of violence, and one which gives victims a measure of power for the first time.

An alternative method to provide safety to survivors is through the provision of a temporary place of shelter. This is a temporary safe space where survivors can stay in order to remove themselves from their attacker, until they are able to make more permanent arrangements. These places of shelter will generally include space for the children or dependents of the survivor, as well as food and clothing (Jewkes et al., 2015). Sullivan (2012) reports that 
women who used shelter services were more likely to leave abusive partners, and that use of shelters results in women having less violence perpetrated against them in the long-term. Shelters can therefore act as a means of restraining order enforcement, as the perpetrator will not be allowed access to the survivor while the survivor remains in the shelter.

Problematically, Jewkes et al. (2015) note that there is a risk of women returning to an abusive partner after a period of time spent in a shelter, potentially because they have few alternative options. This suggests that an important aspect missing from traditional GBV programmes is some means of empowering victims to be independent from their attackers, and to question the norms which enabled the violence in the first place. A number of organisations have therefore begun to implement awareness and empowerment campaigns as a means to address this shortcoming.

\subsubsection{Awareness and women-empowerment campaigns}

Concerns regarding the effectiveness of reactive interventions in reducing violence have resulted in the development of numerous campaigns which have a stronger focus on prevention. However, a number of attempted campaigns appear to have been poorly planned, in that they also seem to have little impact on levels of GBV. A first example is media or information campaigns which aim to improve women's safety, mostly by encouraging women to be more vigilant, drink less, dress more conservatively, or not move around by themselves at night. Alternatively, campaigns may appeal to men to protect women, by focusing on the link to their wives/daughters/mothers etc. These campaigns have been heavily criticised for numerous reasons. They tend to imply that the onus is on women to prevent their own victimisation through changing their behaviour, dress and movements, meaning that if a woman is attacked, it is her 'fault'. This moves the blame for the violence from the perpetrator and places it on the survivor instead. As noted by Gqola, '[t]hese warnings do not work... because they communicate quite unequivocally that South African public spaces do not belong to the women who live in this country' (2007:121).

The primary reason why women changing their behaviour and movements is unlikely to prevent violence is because it is usually not a stranger who is perpetrating the violence. Statistics consistently show that women are most likely to be attacked or raped by somebody that they know - either a partner, family member or another person known to them (WHO, 2013). As noted by Hossain, Zimmerman, Kiss, Abramsky, Kone, Bakayoko-Topolska, Annan, Lehman and Watts, '[g]lobally, 30\% of women aged 15 and over have reported physical and/or sexual violence from an intimate partner during their lifetime' (2014:340). This means that a woman's own home may be the least safe space, and telling these women to avoid certain areas or strangers does little to improve their safety. 
In addition, the campaigns risk implying that only 'other' men rape or perpetrate GBV. By appealing to men to 'protect' women, the discourse suggests that only deviant men commit acts of GBV, and one can be safe by keeping away from those men. However, as noted in the previous chapter, numerous versions of masculinity specifically expect violence (and particularly GBV) from men. Thus, it is not simply a case of a few 'bad apples' perpetrating violence, but is much more of a systemic issue. Violence is widespread in all parts of the world, meaning that it is usually not only 'deviant' men who are perpetrating it. For example, in a study in South Africa, $27.6 \%$ of men reported having raped a woman, with $46.3 \%$ of these having done so more than once (Jewkes, Sikweyiya, Morrell \& Dunkle, 2009). While not the majority, it is a substantial minority of men committing these acts, and it would be difficult for a woman simply to avoid that large a portion of the population. In addition, the evidence stating that women are most likely to experience violence at the hands of someone that they know means that expecting women to intuit which men are 'dangerous' and which are not once again places the onus on women to avoid violence, rather than on men to stop perpetrating it. This shifting of the blame from perpetrators to survivors suggests these campaigns are unlikely to be effective at reducing violence.

As an alternative, some organisations have begun to attempt to empower women as a means of preventing GBV against them in the future, predominantly through teaching them a skill-set which enables them to earn their own income, combined with some form of counselling or psychosocial support. As noted by the WHO, empowerment can help women to 'feel more in control of their lives and able to take decisions about their future' (2013:vii). For example, some programmes have begun focusing on microfinance groups for women, with the rationale being that, "newly acquired business skills may be accompanied by improvements in self-esteem and self-confidence, the ability to resolve conflicts, household decisionmaking power, and expanded social networks' (Kim, Watts, Hargreaves, Ndhlovu, Phetla, Morison, Busza, Porter \& Pronyk, 2007:1794-5). This will then give women a means to become independent, both financially and emotionally, which can enable them to leave violent relationships if these arise.

An example of such a programme is the Intervention with Microfinance for AIDS and Gender Equity, or IMAGE. There are a number of variations of this, but generally the programme involves a microfinance system, combined with some form of psychosocial support or education, and these have been positively evaluated in the literature. In one such evaluation, a group of women received both psychosocial support and became involved in a microfinance group; control groups received either only psychosocial support or only became involved in a microfinance group. The findings of the evaluation suggested that women who receive both interventions (psychosocial support and microfinance) were more 
likely to report lower levels of violence at follow-up than those who received only one version of the intervention (Heise, 2011).

An alternative version used HIV/gender training instead of psychosocial support. In this study, those who had received both aspects recorded improvements in economic well-being and empowerment, reduction in incidences of IPV, and reduced HIV risk behaviour (Kim, Ferrari, Abramsky, Watts, Hargreaves, Morison, Phetla, Porter \& Pronyk, 2009). Those who participated only in the microfinance group reported improvements in economic well-being, but not in empowerment, or reduction in IPV or HIV risk behaviour. The study did not provide reasons for the lack of empowerment in the microfinance-only group, but suggested that the positive results in the IMAGE group arose because it enabled women to challenge the acceptability of violence, expect and receive better treatment from partners, leave violent relationships, and impact on community norms around GBV by engaging in community groups and raising awareness about the need to address domestic violence (Kim et al., $2009: 829)$. Thus, the combination of strategies seems to improve the impact of the intervention as a whole. Confirming this, Kim et al. (2009) and Heise (2011) both note that single-strategy interventions seem to have less impact in improving the lives of women who have experienced GBV.

The literature outlined above suggests that women-focused interventions can play an important role in assisting survivors in the aftermath of an incident of GBV, but the fact that many of these interventions use a single strategy to achieve this limits their effectiveness. Along with this, few interventions seem to have much impact on the levels of GBV in the countries in which they are implemented. The limitations of these interventions are discussed now.

\subsubsection{Criticism of women-focused interventions}

RAPCAN, a South African NGO, has noted that, 'decades of work that was aimed at empowering women to be able to resist, avoid, address and, if necessary, abandon abusive situations have not improved the actual situation of abused women' (2008:4). As described above, while these reactive women-focused interventions are important, they do not seem to significantly reduce levels of violence. A study by Ellsberg et al. (2015) looked at over 100 reviews and evaluations of reactive GBV interventions in terms of their efficacy, and found that only two studies showed significant decreases in violence as a result of a womenfocused intervention. The studies in question described lower rates of revictimisation among women who had received a psychosocial intervention compared with women in control groups. In agreement with the literature on the IMAGE intervention, the effective interventions in the Ellsberg et al. (2015) study included both psychosocial support and the 
provision of additional assistance to help identify and access services. This seems to confirm that effective interventions involve multiple strategies.

Despite the "crucial value of provision of timely and appropriate services to survivors of violence, little evidence exists that such programmes alone can lead to significant reductions in violence against women and girls' (Ellsberg et al., 2015:1564). Along with the more recent research focusing on masculinities as a possible cause of a wide range of forms of GBV, the lack of impact on levels of violence of women-focused programmes has led to an increase in interventions that work with men. 'These interventions have been motivated by a desire to address the role of men in violence perpetration, and recognition that masculinity and gender-related social norms are implicated in violence' (Jewkes, Flood \& Lang, 2015:1580). The following section will therefore discuss programmes which specifically focus on masculinities.

\subsection{Re-socialisation programmes}

Masculinities which enable or encourage violence by men contribute to the high levels of GBV experienced in numerous countries. In order to address these masculinities, programmes which focus on men usually aim to introduce alternative gender norms, ones which problematize the existing notion that men 'should' be violent to prove their masculinity. As noted in the previous chapter, many consider gender to be a social construct which people are socialised into throughout their lives. If gender is created through a process of socialisation, it implies that a person could also be re-socialised, and their gender role reconstructed or adapted. There are numerous examples of re-socialisation processes, and these generally involve learning a new set of norms, values, attitudes and behaviours, with varying degrees of disruption in a person's life (Henslin, 2010:86). For example, it can be as simple as learning a new set of norms in a new workplace, within the same profession; or as major as fundamentally altering one's values and behaviours with regards to gender equality. It can range from a once-off intervention of a few hours, to living full-time in an institution for months or years. Re-socialisation can apply to many aspects of a person's identity, but for the purposes of this chapter, I will focus only on gender.

The aim of this section is to investigate the effects of re-socialisation programmes as a means to address GBV through masculinities-focused interventions. The section therefore begins with a definition of gender re-socialisation, followed by aspects which have been highlighted as improving the effectiveness of these programmes. Examples of different kinds of masculinities-focused re-socialisation programmes are then described and critiqued, in order to provide context for the discussion of the case study programme used for this research in Chapter Five. 


\subsubsection{Gender re-socialisation}

As explained in the previous chapter, gender socialisation is strongly influenced by important people in an individual's life (such as peers, family members and the community). This implies that the people surrounding the individual play a large role in any further socialisation or re-socialisation process, and specifically in its success or failure. Or, as stated by Davidson and Gordon, '[n]ew versions of gender roles can be internalized to replace old versions if similarly strong social supports for the new and constraints against the old are developed' (1979:33). This suggests that aspects such as supportive peer groups, and positive models of hoped-for norms can play a powerful role in successful re-socialisation, along with shifts in the community to begin seeing the old norms as problematic. However, the literature on the effectiveness of re-socialisation programmes is somewhat ambiguous, with some reports suggesting it can contribute to lasting change, and others arguing that the changes are minor if they exist at all. Mortimer and Simmons (1978) also stress a difference between simple behavioural conformity, and attitudinal change, stating that attitudinal change may require stronger socialising influences.

\subsubsection{Aspects of effective re-socialisation programmes}

A number of studies have suggested aspects of re-socialisation interventions which produce the most significant impact. Effective programmes seem to be between 10 and 16 weeks in duration, and lasting roughly 2.5 hours per session (Ricardo \& Verani, 2010), with programmes which are longer in duration seeming to have a larger and longer-lasting impact than shorter programmes. As the WHO notes (2007), it is somewhat unrealistic to expect short-term programmes to overcome the long-term effects of social construction, societal norms, policy and law, and thus the longer an individual spends being immersed in a new behaviour, the greater the impact can be. However, interventions which last too long per day (longer than three hours) risk participants losing focus or fatiguing. Having time between sessions can also give participants the space to reflect on the intervention and begin to apply aspects of it to their own life (WHO, 2007), meaning that weekly sessions can have a more profound impact than those that take place too close together.

Along with suggestions on the length and duration of interventions, a number of studies have shown that interventions tend to be more effective when voluntary, rather than compulsory (Goffman, 1961; Scott, 2010). This is because those who voluntarily enter an institution (such as soldiers voluntarily joining an army, or monks joining a monastery) often already agree with its goals and aims, and want to achieve them (Mortimer \& Simmons, 1978). Achieving these aims is seen as desirable, and becomes closely linked to the participant's identity and masculinity in the future, and consequently the effects of these interventions tend to be longer-lasting. However, those who are forced to participate in an intervention 
(such as a prison, or mental institution) may whole-heartedly reject the principles and aims behind the process, and actively try not to achieve them as a way to display this rejection (Scott, 2010). In these cases, rejecting the authority responsible for the intervention is seen as the desirable marker of masculinity.

A linked important factor is therefore the perceived desirability or potential rewards of the intended role. As stated by Mortimer and Simmons, '[t]he absence of rewards... may prevent successful disengagement from the previous, more gratifying roles' (1978:433). People are more likely to shift to roles that have positive connotations or status, rather than those which are disapproved of or frowned upon. In the contexts described above, an inmate who takes on the roles expected by a prison system is likely to be rejected by fellow inmates, while a recruit who takes on the expected roles in the military will often be praised or emulated by other recruits. Thus, a desired role is likely to be more durable than one which is frowned upon. These factors suggest that a potential issue masculinities-focused interventions targeting GBV might face is that the alternative masculinities may have a lower status in the community than ones which emphasise or encourage violence. Two aspects which could help to offset this are positive role models and supportive peer groups within the intervention, both of which are discussed in more detail below.

The presence of positive role models as examples of the desired gender norms has been highlighted as an aspect which can make interventions more successful. For example, Barker (2003) notes that having a positive role model who shows alternative gender norms can result in young men having more gender-equitable attitudes, although this impact is not a given. The literature on role models is generally split into two main categories: youth engaging with positive role models (often called mentors); and facilitators as positive role models in masculinities-focused interventions. Although the focus of this research is on adult re-socialisation, I will briefly cover youth mentorship, as it relates to the 'crisis of masculinity' which was discussed in the previous chapter.

Along with the 'crisis of masculinity' that has been mentioned, there is growing concern that boys often lack male role models in the home, due to the fact that fathers or other adult males are absent or uninvolved in their lives. This is reported to have a number of negative impacts. For example, Jewkes, Sikweyiya, Morrell and Dunkle (2009) state that men with absent fathers were more likely to report having raped a woman than those who did not have an absent father. Some (such as Thomson, 2002) state that boys growing up in femaleheaded households will be more likely to look to external sources for markers of masculinity, and these sources may be negative, in the form of street gangs, or harmful media images and social norms. Biddulph (1995) similarly claims that boys with absent fathers are more 
likely to be violent, get into trouble, and do poorly in school. It seems that positive male role models can therefore fill an important gap in the lives of young men. One suggestion is that male school teachers can go some way to filling the gap left by absent fathers by modelling positive masculinities (e.g. Hoff-Sommers, 2000). However, in reality, rather than countering the lack of positive role models, it seems that male teachers are more likely to endorse a version of masculinity focusing on athletic ability and strength, rather than academic achievement (Martino, 2008). Thus, male teachers may in fact play a relatively negative role in modelling alternative masculinities for young males, by enforcing existing norms that praise strength and physicality.

In addition, the gender of their teachers seems to be a matter of little concern to students, suggesting that teachers do not need to be male in order to impact on male learners (Carrington, Tymms \& Merrell, 2008). In their study, Carrington et al. found that matching students and teachers by gender has 'no discernible impact on either boys' or girls' attainment, or their respective attitudes to school' (2008:312), as students are more likely to highly value the ability of a teacher to maintain discipline in the classroom in a friendly and impartial manner (Lahelma, 2000). Additionally, Martin and Marsh found that the gender of a teacher had little impact on a student's motivation and engagement (2005). In fact, research suggests that a child's peers play a larger role than teachers in shaping a child's behaviour, especially regarding their creation of masculinities (Ashley, 2003). From a young age, boys tease each other for non-involvement in sport, fights and interest in girls - the 'fighting, fucking and football' reported by Mac an Ghaill (1994:56). Those who do not take part in the expected activities are mocked, and this contributes to the perpetuation of hegemonic masculinities which are linked to violence.

As noted in the previous chapter, while children (and adults) do have agency in choosing which aspects of their gender identity to perform, their context will play a strong role in shaping which aspects they feel able to perform. If not taking part in 'fighting, fucking and football' will result in public mockery, many boys will feel as if they need to do so to achieve hegemonic masculinities. Confirming the impact of peer groups, positive peer support has been mentioned in a number of the studies of masculinities-focused interventions as a way to encourage the adoption of alternative masculine norms (Silvergleid \& Mankowski, 2006; Roy \& Das, 2014). This will be discussed in more detail below.

A final issue raised with the notion that boys 'need' male teachers in order to perform is that this risks blaming their current (predominantly female) teachers for any problems which boys have (Martino \& Kehler, 2006). In some ways, this ties in with literature suggesting that women alone are responsible for ending GBV against women, as in the empowerment or 
awareness campaigns discussed above. By stating that boys 'need' male teachers, the implication is that female teachers are not sufficient. Thus, boys' failure is the 'fault' of female teachers (Frose-Germain, 2006). However, Carrington et al. found that, 'children taught by women - both boys and girls alike - were more inclined to show positive attitudes towards school than their peers taught by men' (2008:321). This suggests that, far from boys needing male teachers to encourage adoption of more positive masculinities, simply matching children and teachers by gender does not necessarily result in positive role model effects.

In contrast to the literature on the effect of male teachers as positive role models, the literature on mentoring relationships is more promising, with studies showing that youth who have mentors show a number of positive results. Rhodes and DuBois (2008) found that adults who had been mentored as teenagers showed better outcomes in education and work, better mental health, lower levels of problem behaviour, and better care for their health. The impacts were more positive if youth reported trusting their mentor, with regard to their reliability in keeping appointments and promises, and if they accepted the youth as they were (Gaddis, 2012). Nevertheless, the positive impacts are not significantly greater in mentoring programmes than in other intervention programmes (Rhodes \& DuBois, 2008).

It was also found that the process was more successful when youth and mentors were wellmatched, in terms of having similar interests, or the mentors having an educational or occupational background which matched with the goals of the mentoring programme (DuBois, Portillo, Rhodes, Silverthorn \& Valentine, 2011). Similar to the findings regarding matching students to teachers along gender lines, matching of youth and mentors based on shared interests was more important than racial or ethnic matching (DuBois et al., 2011). In addition, Gaddis (2012) found that racial similarity did not seem to play a significant role in creating positive links between youth and mentors. Nonetheless, if youth and mentors were poorly matched, or if the relationship ended prematurely, the process could actually result in negative impacts on youth instead (Rhodes \& DuBois, 2008).

These studies suggest that, while positive male role models can play an important role in gender re-socialisation for boys and men, this is not a given, and male role models can have a negative impact instead. Prominent men may encourage negative or aggressive masculinities rather than positive ones, and a youth's peer group will often play a more important role in their re-socialisation than teachers or other adults. The existence of a supportive peer group has therefore been noted as an important aspect in improving the impact of masculinities-focused interventions (Davidson \& Gordon, 1979:205; Silvergleid \& Mankowski, 2006). As discussed in the section on socialisation in the previous chapter, a person's peer groups will play a large role in the way they choose to present their gender in 
specific situations, and this can have both positive and negative impacts (Mortimer \& Simmons, 1978; Walby, 1990). For example, Barker (2003) reported that if young men were part of a male peer group that supported more gender-equitable attitudes, the young men were more likely to be more gender-equitable themselves. This is echoed in the literature outlined above on the impact of a child's peers, rather than their teachers, during their schooling.

While the impact of a supportive group of peers is an aspect which arose in my own research, and is discussed in greater detail in Chapter Seven, I was not able to find much literature on it, suggesting that there is scope for future studies to focus on this in more detail. Along with the factors outlined above, two final aspects have been noted as improving the effectiveness of re-socialisation interventions, and these are more closely related to the content and structure of the programme: the first is the use of a gender-transformative approach in the design of the programme, and the second is the use of multi-sectoral and multiple strategies.

The literature suggests that the process of re-socialisation can be aided by creating more self-awareness among participants, both of their own behaviour and of the expectations of others (Silvergleid \& Mankowski, 2006; Lorber \& Garcia, 2010). Thus, while compulsory programmes tend to be less effective than voluntary interventions, their results improve when they are linked with a gender-transformative focus (Ricardo \& Virani, 2010; Dworkin, Hatcher, Colvin \& Peacock, 2013). Gender-transformative programmes are those that specifically aim to problematize and question gender norms, and ask participants to reflect on their own gender identity. They will generally provide space for discussion around alternative gender norms, and time to practise these alternatives (WHO, 2007). As the name suggests, the goal is to transform problematic gender norms. In contrast to this, genderconscious programmes are those which mention gender, and potentially define it, but do not necessarily question gender norms or seek to transform them, while gender-neutral programmes are those which make little or no mention of gender (Ricardo \& Verani, 2010). For example, they may rather focus on a specific behaviour, such as a violent response to provocation, without necessarily linking it to the gender role which encourages it. Both gender-conscious and gender-neutral programmes are less effective than those which aim to be gender-transformative.

An important facet of gender-transformative interventions is the creation of a safe space in which to practise alternative versions of gender roles (Karp, 2010). Participants are encouraged to discuss alternative roles as a means of becoming more comfortable in them, and to role-play these alternatives as preparation for use in real life situations. Confirming 
the discussion above, two factors which can improve the efficacy and safety of these spaces are the use of positive role models who can provide examples of the desired behaviour and attitude (Silvergleid \& Mankowski, 2006), and a sense of community and support among intervention participants (Roy \& Das, 2014).

The final aspect which seems to make an intervention effective is the use of multiple strategies, rather than a single form of intervention. These strategies can include education, community engagement and information-sharing, and focused group work (WHO, 2007). As already noted in the section on women-focused interventions, programmes using only one strategy tend to be less effective, while those employing multiple strategies (such as psychosocial support alongside microfinancing) have a greater impact, and the same is true in masculinities-focused interventions. As stated by Ellsberg et al., '[m]ultisectoral programmes that engage with multiple stakeholders seem to be the most successful to transform deeply entrenched attitudes and behaviours' (2015:1564).

For example, the provision of education and information during interventions is usually an important starting point, yet it has been repeatedly shown that simply providing information is not enough to create sustained behavioural or attitudinal change (WHO, 2007; GarciaMoreno, Hegarty, d'Oliveira, Koziol-McLain, Colombini \& Feder, 2015; Petitfor, Lippman, Selin, Peacock, Gottert, Maman, Rebombo, Suchindran, Twine, Lancaster, Daniel, GómezOlivé, Kahn \& MacPhail, 2015). Similarly, while providing a safe space for the practising of alternative masculinities is important, it will often be difficult for men to sustain the impact when faced with disapproval or censure in the broader community (Peacock \& Levack, 2004). Thus, including community engagement as an aspect of a preventative intervention can play a big role in creating a more supportive community for men.

An example of community engagement is the use of media and social media to encourage more gender-equitable lifestyles among men (Barker, 2003). This can include advertising, music, theatre, television and billboard marketing. By disseminating messages more broadly through media, the community norms supporting violence and GBV can begin to be eroded. Usdin, Scheepers, Goldstein and Japhet note that, 'edutainment, where social issues are integrated into entertainment formats... has been shown to be a powerful mechanism to achieve social change objectives' (2005:2435). For example, Soul City is a weekly television drama aired in South Africa which deals with a number of social issues, with one season focusing specifically on partner violence. An evaluation of this season found that exposure to Soul City was consistently associated with both help-seeking and support-giving, and this programme will be discussed in further detail in Chapter Four (Heise, 2011). Thus, by 
diversifying and implementing multiple strategies, the reach of an intervention can be broadened, and this can result in more positive and longer-lasting effects.

The factors listed above can all play a role in improving the effectiveness of re-socialisation interventions, and suggest that these kinds of intervention can have an important and lasting impact on participants. Bearing these aspects in mind, this study now turns to examples of different kinds of re-socialisation programmes, with a specific focus on those which work primarily with men.

\subsubsection{Examples of re-socialisation}

There are numerous forms of re-socialisation, and these can range from relatively short-term or once-off interventions (such as a one-day workshop) to institutions which participants enter for months or years at a time (such as a prison). Many of these have focused on violence as their primary target, as in the case of prisons, batterer intervention programmes, and post-conflict interventions such as disarmament, demobilisation and reintegration programmes. However, in line with an increase in literature suggesting masculinities as a causal factor in violence, a number of interventions have begun to include a specific focus on masculinities as well. This section discusses four different examples of re-socialisation interventions, looking at their processes, aims and results. These are total institutions, batterer intervention programmes, disarmament and demobilisation programmes, and masculinities-focused interventions.

\subsubsection{Total Institutions}

The most extreme example is the total institution, where individuals are completely cut off from the outside world while undergoing an intensive re-socialisation process. These can include prisons, mental institutions, the military, or monasteries. Goffman first described the concept of the total institution in 1961 in his book 'Asylums: essays on the social situation of mental patients and other inmates'. He defined a total institution as, 'a place of residence and work where a large number of life-situated individuals, cut off from the wider society for an appreciable period of time, together lead an enclosed, formally administered round of life' (1961:xxi). The aim of a total institution is to remove an inmate from their past and everyday life, and immerse them in a new situation.

Often, the stated goal of a total institution is rehabilitation, '...that is, with resetting the inmate's self-regulatory mechanisms so that after he leaves he will maintain the standards of the establishment of his own accord' (Goffman, 1961:71). An example of this could be an inmate in prison, where the stated aim is for the inmate to leave as a law-abiding citizen. Despite this stated aim, Goffman notes that this goal tends to remain unrealised or, if there is a lasting change, that the change is not of the kind intended by the institution staff. Thus, in 
the example of the inmate in prison, it is more likely that they will re-offend after release. The lack of achievement of the stated aim of rehabilitation is often linked to whether the participant has voluntarily joined the institution or not. Goffman also notes that the more voluntary the enrolment, the more likely it is that the norms espoused by the institution will take hold for the inmate. If the participant's involvement is forced or compulsory, the institution may have the opposite effect. As Goffman (1961) notes, membership of a total institution automatically disrupts the inmate's membership of other groups or institutions, known as role dispossession. This then creates a break from the inmate's past, and provides space for adoption of the aims of the new institution.

In the case of an organisation such as the military, there tends to be a heavy emphasis on 'making a man' out of recruits, and instilling military ideals and ethos into them. To this end, daily routines will involve strenuous physical exertion and training, and may include verbal abuse and name-calling. Much of the name-calling relates to names which imply femininity or effeminacy (sissy, faggot, ladies, girls etc.), with the implication being that women and homosexual men are weak, while men in the military need to be physically and emotionally strong (Conway, 2008). In addition, there is a heavy focus on arms, and an association between the recruit's masculinity and their weapon (Theidon, 2009). As already noted in the previous chapter, the military aims to instil a militarised masculinity, meaning a lack of emotional display, enforced heterosexuality and an emphasis on violence as a means to solve problems (Lopes, 2011). Recruits are expected to obediently follow orders and authority, and their decision-making capacity is strictly limited. This means that they may become reliant on those in authority to make decisions for them.

Another example of a total institution is prison. Although prisons house both men and women, men make up the vast majority of inmates in almost all prisons across the world. In South Africa, men make up $98 \%$ of the sentenced prisoner population (Jules-Macquet, 2014). Here, men are kept in single-sex housing, often sharing rooms with one or more other inmates, and their freedom is heavily curtailed in terms of their movements and daily routine. Inmates tend to be referred to by surnames or a number, wear similar uniforms, and are generally not allowed to wear anything that could identify them as an individual. This is intended as a form of punishment for whichever crime the inmate has been convicted of, and the assumed end-goal is for the inmate to be rehabilitated, and therefore able to return to life outside the prison as a law-abiding citizen. Some prisons also provide work experience and rehabilitation programmes, but this is not always the case. Mental institutions are further examples of total institutions, although in this instance the intention may be for the inmate to remain there permanently. While treatment is provided, a number of mental disorders are not 
expected to be 'cured', meaning many patients are going to be resident for extended periods of time.

Some total institutions (such as the military or monasteries) seem to be very effective at resocialisation, resulting in lasting behavioural and attitudinal change in participants (Davidson \& Gordon, 1979; Henslin, 2010). Others, such as prisons or drug rehabilitation, seem to be more likely to result in change in the opposite direction to that intended (Goffman, 1961; Ezzell, 2012). As noted above, the fact of whether the participant has voluntarily joined the institution or been forced into it will impact on the likelihood of a long-lasting impact in the desired direction (Scott, 2010). Men sent to prison are expected to emerge as law-abiding citizens, but this is seldom the case. Goffman believed that those in prisons would feel that the punishment they were receiving was random and excessive, and that society had been too harsh. This would cause them to want to get 'revenge' on society by committing further acts of crime upon their release. Thus, the re-socialisation process undergone in the total institution would have the opposite impact to that intended.

Regardless of the direction of impact, the literature suggests that total institutions can and do have a lasting re-socialisation effect on participants. However, removing a participant entirely from their everyday life and community is quite impractical in terms of cost, resources and the amount of time required. Thus, while the impact of a total institution can be major, this form of re-socialisation is unlikely to be useful in the context of relatively limited GBV prevention interventions. Along with the impracticality, the fact that few total institutions are likely to provide supportive space for the questioning of problematic gender norms means that they will likely have little effect on the reduction of GBV. For the purposes of this study, total institutions therefore have limited applicability.

\subsubsection{Disarmament, demobilisation and reintegration (DDR)}

While it has been noted that total institutions often have a long-lasting impact on participants, there has been little attention paid to efforts to change the norms which become instilled during the total institution re-socialisation process. As noted, militarisation tends to have a strong and long-lasting impact on recruits, suggesting that efforts to de-militarise recruits would require a similarly intensive process. The literature pointing to the links between militarised masculinities and violence would further suggest that re-socialisation of recruits could be an important means to limit their violence once they return to civilian life. However, the process of demilitarisation is surprisingly silent on the aspect of masculinity. The most common example of demilitarisation is the disarmament, demobilisation and reintegration (DDR) programmes which are frequently conducted in post-conflict environments. These programmes aim to demobilise ex-combatants and reintegrate them into civilian society in 
the post-conflict context (World Bank Report, 1996). DDR is defined in the Integrated DDR Standards (IDDRS) as a process that, "contributes to security and stability in a post-conflict recovery context by removing weapons from the hands of combatants, taking the combatants out of military structures and helping them to integrate socially and economically into society by finding civilian livelihoods' (UN-IAWG, 2006:6). Importantly, there is no mention of masculinities in this definition.

The following definitions of the three stages of DDR are all taken from the IDDRS Glossary Section 1.20 (page numbers in brackets). Disarmament refers to the process of collecting, documenting, and likely disposal of small arms and ammunition (6). Demobilisation is the formal and controlled discharge of active combatants from armed forces or other armed groups (6). Reintegration is the process through which ex-combatants acquire civilian status and gain sustainable employment and income (19). These definitions suggest that the reintegration phase is where a focus on masculinities could play a role, as the process whereby ex-combatants acquire civilian status would likely entail reducing their reliance on violence and aggression as means to resolve conflicts or problems in their lives. There is significant faith in the DDR process, as seen by the fact that it has been implemented in multiple post-conflict contexts across the world (e.g. South Africa, Burundi, DRC, Chad, Haiti, Nepal, etc.) Nevertheless, as noted by Muggah, 'there is a surprising lack of evidence as to whether it works or not' (2006:32).

Combatants go through an intense masculinity re-socialisation process upon entering the total institution that is the military, "where [b]eing a soldier is purposefully linked to being a 'real man" (Clarke, 2008:52). As already noted, the impact of this re-socialisation is usually considerable and long-lasting, with former soldiers and combatants struggling to reintegrate into civilian society, and levels of violence in post-conflict contexts remaining high. This is seemingly confirmed by the UN-IAWG (2012:10) who note that:

High levels of violence often persist in post-conflict settings, on occasion exceeding levels during wartime. For many ex-combatants... who internalize violent identities during the war or find few opportunities and gains in the post-conflict period, displays of aggression continue during transitions to civilian life.

There has been a considerable amount of literature discussing the different ways in which ex-combatants may contribute to this violence in the post-conflict period (e.g. Collier, 1995; Douglas, Gleichmann, Odenwald, Steenken \& Wilkinson, 2004). The first is the risk of remobilisation, where former combatants re-join armed groups despite the demobilisation process (Myrttinen, 2009). The second risk is that combatants may turn to crime as a means of either earning an income or achieving alternative versions of masculinity, since their 
access to a militarised identity becomes limited (Collier, 1995). The third risk is of excombatants using violence more generally in their home communities as a means of problem-solving, securing an income, or through being unable to respond to stress in more appropriate ways (Farr, 2002:22; UN-IAWG, 2012).

The risk of ex-combatants continuing to use violence has led to numerous calls for DDR and SSR (security sector reform) to include a re-socialisation aspect which would help to prepare ex-combatants for return to a non-militarised context. As Theidon states, DDR requires 'a gendered analysis that includes an examination of the salient links between weapons, masculinities, and violence in specific historical contexts' (2009:3). While the primary focus of this section will be on the reintegration phase, as the step most closely matching resocialisation, the disarmament phase is also briefly discussed. This is because a growing amount of literature, outlined below, has described the link between masculinities and weapons.

In the disarmament phase, combatants and armed groups are expected to turn in their weapons and arms, and if possible are often encamped separate from the civilian population. This is to attempt to reduce the number of small arms and light weapons (SALW) in circulation in a region (Douglas et al., 2004). However, encampment may not always be an option, because of limited resources or infrastructure. The focus therefore tends to be more on the process of removing weapons and arms from combatants. The association between weapons/weapon-use and masculinities is generally very strong for those who have gone through the militarisation process, where weapons become closely linked with a militarised masculinity. As Farr states, 'the ownership and utilization of arms is profoundly attached to perception of masculinity in many cultures' (2002:20). Disarming combatants is therefore a complex procedure. The process risks 'robbing' men of one of the most potent aspects of their masculinity, without providing a viable (non-violent) alternative (UN-IAWG, 2012). The ongoing insecurity in many post-conflict contexts also means that disarming is a dangerous proposition for many, as this leaves men with no means of protecting their families. As Theidon points out, disarmament 'presents many of these young men with a conundrum: surrender their guns and trust [others] to protect them, and in turn diminish their capacity to protect their families in the event that armed actors come for them' (2009:20). This suggests that a masculinities focus during the disarmament phase could assist in easing the transition to civilian status for many combatants.

The primary aim of the reintegration process is to enable 'ex-combatants to become economically independent' (Farr, 2002:25). This can include job or skills training, job placement, healthcare, cash payments or compensation in kind. This phase of DDR is 
typically long-term, yet it is a complicated process for a number of reasons and in many cases may be a compulsory, rather than a voluntary, process. The first complication is the strong association between militarised masculinities and violence. A major aspect of combatants reintegrating is the fact that they will no longer be able to use violence as a legitimate means of problem-solving. This raises the concern that ex-combatants may in fact become increasingly aggressive because they lack the skills to respond in other ways (UNIAWG, 2012). Strain theories (discussed in the previous chapter) would suggest that the removal of one highly salient means of achieving masculinity may lead to an increase in violence as compensation. Thus, replacing the violence typically linked to militarised masculinities with an alternative method of achievement could potentially limit the use of aggression as a viable option.

A second complication in the reintegration process is that the job/skills training may be inadequate preparation for ex-combatants' re-entry into the job market (Heideman, 2007). Being the primary breadwinner is a salient marker of masculinity in many communities worldwide, and this would seem an ideal means of 'replacing' militarised masculinities with a less-violent alternative. However, the skills training in DDR is often minimal or incomplete, or provides training for jobs which are not in demand in the post-conflict context (UN-IAWG, 2012:12), meaning that it does not provide a viable option for finding employment. In addition, employers may be reluctant to hire former combatants because of a fear of their unreliability or supposed violence (Zuckerman \& Greenberg, 2004). This exacerbates the difficulties that former combatants would face in trying to find work.

In a similar vein to being unable to find employment, men will often be unable to acquire or own land in the post-conflict context. This is closely linked to the need to be a primary breadwinner in a family, as land ownership is seen to be tied to wealth. However, in postconflict settings, land may be even more difficult to come by than employment (Douglas et al., 2004). Many areas will have been burnt or destroyed by conflict, arable land may be tightly controlled by governing forces, or men may be in refugee camps with no option of owning the land on which they live. This means that another important avenue for achieving manhood is blocked to those returning from conflict (Lwambo, 2011). Thus, as Dolan (2002) states, the ability of men to achieve the standards of hegemonic masculinity are severely hampered during and after conflict. The literature on strain theories outlined previously suggests that this may result in these men turning to violence as an alternative method of displaying their masculinities.

Aside from the skills-training aspect of reintegration, an additional criticism is that little attention is paid to the fact that many ex-combatants will have suffered trauma during the 
conflict, and may well experience PTSD (Everatt \& Jennings, 2006). As mentioned in the previous chapter, experienced or witnessed violence is often a strong factor in a person's later perpetration of violence. Thus, those who have engaged in conflict are potentially more likely to carry that violence into the peacetime context, and Farr (2002) suggests that excombatants who are traumatised may end up being burdens on their community through violent and dangerous behaviour. The UN-IAWG also mentions the fact that PTSD among ex-combatants is closely linked to violent behaviour, including IPV and suicide (2012:12). Despite these concerns, there tends to be very little inclusion of psychological care or assistance during the DDR process (Gear, 2002). This once again seems likely to increase the risk of ex-combatants turning to violence, rather than decreasing it.

Thus far, there have been very few attempts to incorporate masculinities-focused aspects in post-conflict contexts, despite the fact that the militarisation process has such an intensive period of masculinities re-socialisation, as discussed above (UN-IAWG, 2012). Due to the intensive re-socialisation process, there have been a number of calls for a masculinities focus to become an aspect of the process (Clarke, 2008; Theidon, 2009; UN-IAWG, 2012). However, as noted by Hossain et al. (2014), much of the literature on gender-transformative interventions as prevention mechanisms for GBV has been drawn from non-conflict settings. This means that despite the opportunity for this work to be implemented in post-conflict environments, there is 'little rigorous evidence on interventions that work directly with men in conflict-affected settings' (Hossain et al., 2014:340).

In one example that has been carried out, the International Rescue Committee (IRC) implemented a male-targeted VAW prevention intervention in the Ivory Coast, as part of their Engaging Men through Accountable Practice (EMAP) initiative. Although the programme works with both men and women in single-sex groups and a same-sex facilitator, this section will focus on the male-only groups, as this is the primary emphasis of the current research. The intervention holds weekly discussion groups during which men, 'engage in dialogue and reflections about their experiences, attitudes and values regarding gender, and about VAWG and its consequences' (Lehmann, 2013:16). The primary goal of the intervention is to reduce harmful behaviour and attitudes, and to increase gender equity in the homes of participants. It does this through providing male participants with tools and knowledge to question traditional gender norms, and prevent GBV through individual behavioural change (Lehmann, 2013:27). Thus, the intervention has a gender-transformative focus in that it problematizes traditional gender norms, and suggests alternative ways to behave in order to prevent GBV. The EMAP intervention does not specifically work with ex-combatants, although some participants may have been involved in armed groups prior to their participation in the workshops. However, this is one of the few programmes implemented in 
a post-conflict context in which it is likely that many men, civilian and ex-combatants, will display or aspire to some version of a militarised masculinity. Thus, it can give some notion of how effective this kind of programme would be if it were to be implemented with excombatants.

The intervention was evaluated by Hossain et al. (2014) and the results listed here are all from this source. The evaluation was based on participants' self-reports of attitude and behaviour, and measured whether the discussion groups had an impact on four factors. These factors were men's intention to use physical IPV, men's attitudes towards sexual IPV, men's use of hostility and conflict-management skills, and men's participation in traditionally gendered household tasks. The evaluation found that after one year, there was a lower prevalence of men's reported intention to commit physical IPV, and an increase in men who believed that women have the right to refuse sex under all circumstances. In addition, there was a positive impact on men's reported use of hostility and conflict management skills, and on involvement in gendered household tasks (Hossain et al., 2014:345).

The results of this intervention are relatively positive, suggesting that it can have an impact on both behaviour and attitude among those who participate. This bodes well for the use of similar interventions in other post-conflict contexts, and with those leaving armed groups. However, one should be cautious of generalising these results too broadly as they are based on a single evaluation, and rely on self-reporting from participants, which can skew results in a positive direction. Until further research has been done, and more programmes are implemented in different post-conflict zones, the evidence for the effectiveness of gendertransformative programmes in these settings will remain speculative. Nevertheless, the fact that a re-socialisation intervention can have an impact in a highly militarised context suggests that it is possible to re-socialise those leaving armed groups, despite the usually long-lasting impacts of the militarisation process.

With regard to the focus of this research, these results support the notion that masculinitiesfocused re-socialisation programmes can and do have a positive impact on participants in terms of reducing GBV, even with participants leaving the total institution of the military and its intense re-socialisation process. An alternative method for doing this is battererintervention programmes (BIPs) which are offered as a form of non-custodial sentence for those who have been convicted of domestic violence. These are relevant to the current study in that they provide an example of a compulsory programme which specifically focuses on reducing GBV, and can therefore provide evidence for how effective this kind of intervention could be. 


\subsubsection{Batterer-intervention programmes (BIPs)}

Batterer-intervention programmes (BIPs) are interventions for those convicted of domestic violence, in which men are offered the choice of attending a BIP as a form of non-custodial sentence for a domestic violence conviction. BIPs tend to be run weekly, for anything from around 10-32 weeks, and are typically presented as group sessions. BIPs have become mandatory for domestic violence convictions in the USA, hence there is a substantial amount of literature on these programmes in that country.

There are two models which are used in the majority of cases: the Duluth model; and the cognitive-behavioural treatment (CBT) model. These will be described separately below, although they are often discussed and evaluated together, and it is difficult to find results for one programme individually. Many programmes are a combination of Duluth and CBT models. In fact, Arias, Arce and Vilariño (2013) found that the type of intervention (Duluth or CBT) had almost no impact on the effectiveness of the programme, while Babcock, Green and Robie (2004) found that there was no difference in effect sizes between the two. Thus, the effectiveness of these programmes will be discussed concurrently below.

In the United States, the most commonly used version of BIP is informed by the so-called Duluth model, a feminist-based approach which aims to make men more gender equitable in their beliefs, behaviours and attitudes (Shrock \& Padavic, 2007). The Duluth model is based on the knowledge that masculinities are closely tied to battering and that, "men who harm women often do so when their sense of traditional manhood - such as being a breadwinner or having women meet their often-unspoken needs - is threatened' (Shrock \& Padavic, 2007:628). The focus in the Duluth model is therefore on the context of societal norms within which the individual lives. The theory behind the model is that domestic violence arises from gender-inequitable beliefs on the part of the abuser, and that this can be addressed through a gender-transformative approach (Stuart, Temple \& Moore, 2007). As noted above, a gender-transformative approach aims to problematize and question existing gender norms as a way to introduce alternative possible expressions of gender. To this end, the sessions focus on encouraging men to take responsibility for their actions, acknowledge their own emotions, and to gain empathy for their victims (Shrock \& Padavic, 2007). In addition, men are taught alternative methods of conflict-resolution, such as time-outs, and tension-reducing and problem-solving skills (Feder \& Wilson, 2005).

An alternative version is the cognitive-behavioural treatment (CBT) model, which suggests that domestic violence arises from previously learned problematic thought and behavioural patterns (Arias et al., 2013). In other words, since violence 'is a learned behaviour, nonviolence can similarly be learned according to the cognitive-behavioural model' 
(Babcock, Green \& Robie, 2004:1026). The aim of CBT programmes is to teach participants alternative ways of responding to stimuli (Feder \& Wilson, 2005; Stuart et al., 2007), such as anger management, or conflict-reducing communication (Stuart et al., 2007). For example, a workshop could teach men listening techniques, or identify anger-provoking situations, which would help men to respond less violently when these situations arise. CBT models are therefore more focused on the idea of violence as arising out of the individual, rather than from societal norms or expectations. The remedial skills are less to do with awareness of the impact of masculinities, and more about the individual's own responses.

The literature on masculinities-focused interventions outlined above seems to suggest that the Duluth model would be more effective in producing lasting behavioural or attitudinal change in participants because its focus is gender-transformative, rather than gender-neutral (as in the CBT model). However, both models are compulsory for participants, which often impacts negatively on the effectiveness of interventions. Research on the effectiveness of BIPs is somewhat contradictory. Initial evaluations were positive, with Feder and Wilson showing reductions in frequency and/or the severity of subsequent violence. For example, 'a woman is $5 \%$ less likely to be re-assaulted by a man who was arrested, sanctioned, and went to a batterers' program than by a man who was simply arrested and sanctioned' (2005:242). Similarly, Taylor, Davis and Maxwell found that, 'the rate of new incidents reported to criminal justice authorities was reduced significantly among batterers assigned to treatment' (2001:196). The positive impacts tended to be relatively small, with Rosenfeld (1992) finding that there was only a slightly lower recidivism rate for treatment completers $(36 \%)$ versus $39 \%$ for those who received only legal system interventions such as jail time.

Many other evaluations have tended to be less positive. For example, a meta-analysis of evaluations of BIPs by Feder and Wilson (2005) found that many of the positive benefits that were reported tended to be the result of flawed methodology. Studies often lacked appropriate comparison groups, such as men who had been convicted of battery but had not gone through a BIP, or who had completed a different kind of intervention (Taylor, Davis \& Maxwell, 2001). Along with this, studies often had a sample bias in that they would only evaluate the impact of the intervention on those who had completed the programme, rather than on all those who had started the programme (Rosenfeld, 1992; Sartin, Hansen \& Huss, 2006). This then excludes those who drop out during the intervention, meaning that the results would be artificially skewed in favour of the intervention.

This has important implications for treatment efficacy, as it once again raises the issue of voluntary versus compulsory involvement. Those who complete the programme are more likely to agree to some extent with the aims and outcomes of the intervention, and want to 
achieve them, while those who drop out are more likely to reject the aims and ideologies of the intervention, and to purposefully not want to achieve them. As Rosenfeld states, 'internal motivation is necessary for change to occur' (1992:221). Thus, excluding the drop-outs from the official evaluations skews the results quite heavily - if they had completed the programme and gone on to re-offend, the drop-outs would have brought down the effectiveness ratings of the programmes.

A further issue with many of the studies is that they focused on official reports of reoffending, meaning they only measured whether a person had been reported to the police for further instances of violence. When the official re-offending results were compared to longitudinal victim reports of perpetration of abuse, the benefits of BIPs often dropped to almost zero. For example, Rosenfeld (1992) found that recidivism rates varied drastically when comparing criminal records ( $7 \%$ recidivism rate) to partner reports ( $36 \%$ recidivism rates), while Arias et al. (2013) found slightly different figures $(21 \%$ for official reports versus $35 \%$ for couple reports from both parties). Nevertheless, the fact that there is such a large discrepancy between official versus victim reports is a worrying aspect in the evaluations of BIPs, and suggests that the intervention does little to lower the recidivism rates of participants.

In fact, some evaluations found that a perpetrator's attendance of a BIP gave victims a false sense of safety, and that victims were more likely to remain with an abusive partner and not report further abuse if the abuser had attended a BIP than if the abuser had not (Babcock, Green \& Robie, 2004). Similarly, Shrock and Padavic (2007) found that those who completed the programme were as likely as dropouts to continue their violence, but less likely to be recharged than those who had dropped out (11\% for completers versus $42 \%$ for drop-outs). This suggests that these programmes could in fact represent an increase in the danger of continued domestic violence for victims, with victims more likely to forgive further abuse because the abuser was 'working on it'.

A final concern with BIPs is the lack of individual attention or counselling, as sessions are predominantly run in group format with little one-on-one time (Shrock \& Padavic, 2007). This risks ignoring issues such as substance abuse or a history of witnessed or experienced abuse that may be co-occurring with the participant's use of violence. For example, Sartin et al. (2006:431) report that, 'substance abuse difficulties lead to an increased probability of post-treatment domestic violence recidivism'. Being abused as a child was also found to be related to an increase in recidivism. While CBT programmes focus more on the individual, there is still little space made for individual counselling. As noted in the previous chapter, the two individual factors most closely tied to domestic abuse are witnessed or experienced 
abuse and substance abuse. While societal factors such as cultural norms and hegemonic masculinities will play a role, ignoring the impact of individual factors may limit the effectiveness of this kind of intervention.

The evidence outlined above suggests that BIPs are not very effective as a re-socialisation tool, with limited behavioural or attitudinal change being reported once the intervention is complete. Despite the gender-transformative nature of the Duluth model, it is as ineffective as the CBT model, suggesting that the compulsory nature of the programme may play a role in limiting its effectiveness. Men being sentenced to undertake a BIP may view it in a similar way to inmates sentenced to prison, and to be as reluctant to adapt to the alternative versions of masculinity suggested. Thus, BIPs have limited use as a tool for combating GBV in their current format. For this reason, the focus now turns to interventions which have a similar focus on GBV, but which are voluntary in nature.

\subsubsection{Masculinities-focused interventions}

With the more recent focus on men and masculinities in order to address GBV, there are an increasing number of programmes which work specifically with men as a means of preventing GBV, and which intentionally aim to problematize gender. A World Health Organisation (WHO, 2010) review of masculinities-focused interventions found that these kinds of programmes can result in a number of positive outcomes. These included selfreported decreases in physical, sexual and psychological violence in intimate relationships, increased contraceptive use, more equitable treatment of children, and increased use of sexual and reproductive health services by men who participated in these kinds of intervention. This supports the thesis underpinning this research which suggests that masculinities-focused interventions can have a positive impact on levels of GBV in the communities in which they are implemented. As stated by the WHO,

'...the evidence included here confirms that men and boys apparently can and do change attitudes and behaviour related to sexual and reproductive behaviour, maternal, newborn and child health, their interaction with their children, their use of violence against women, questioning violence with other men and their health-seeking behaviour as a result of relatively short-term programmes.' (2007:16).

Three examples of masculinities-focused programmes will be described below. These are Program H in Brazil; the Men's Action for Stopping Violence Against Women (MASVAW) programmes in India; and Stepping Stones (which has been implemented in a number of countries and regions, including South Africa). Many of these workshops focus on problematizing gender-inequitable views, and on providing information to contest these views (Paine, Khanyile, Herstad \& Nkurunziza, 2011/2012; Garcia-Moreno et al., 2013). They also provide a safe space for men to discuss and practise alternative versions of 
masculinities, namely ones which do not necessarily rely on violence or aggression (Hu \& Salie-Kagee, 2007).

Program H was developed in 1999 by a group of NGOs, coordinated by Instituto Promundo in Brazil, with the aim of problematizing gender stereotypes by 'helping young men question traditional norms related to manhood' (Pulerwitz, Barker \& Segundo, 2004:3). Additionally, Program $\mathrm{H}$ looks at the costs of traditional masculinities, and the advantages of more gender-equitable behaviour. For example, one session asks men to discuss violence they have experienced and perpetrated, and then talk about the emotions they felt because of this (Hu \& Salie-Kagee, 2007). This aims to lead to a better understanding of what constitutes 'violence' and is considered 'acceptable' violence, as well as allowing space for participants to discuss emotions in response to this violence. The primary tool in the intervention is a manual of activities to be covered in same-sex groups, with facilitators who act as gender-equitable role models, and workshop sessions take place for two hours each week for a period of roughly six months. The activities consist of role plays, brainstorming exercises, discussions, and individual reflections (Pulerwitz et al., 2004). The intervention therefore has a gender-transformative focus in that it aims to question traditional norms of masculinity and gender, and support participants in discussing and taking on alternatives.

Some positive results of the intervention have been documented. For example, Pulerwitz et al. (2004) reported that those involved in Program $\mathrm{H}$ activities showed less support for traditional gender norms both at six months and a year after completion of the programme, and this finding was confirmed by Hu and Salie-Kagee in 2007. Additionally, Pulerwitz et al. (2004) found a decrease in STI symptoms among programme participants, and an increase in condom use. These results were maintained at both six months and one year follow-ups. These positive impacts were also linked with support for more equitable gender norms, which suggests both an attitudinal and behavioural shift. Similarly, Barker (2003) reported that participation in the activities led to increased empathy, reduced conflict among participants, and positive reflection by participants about how they treated their female partners. Heise (2011) noted that after participating in Program $\mathrm{H}$, young men reported greater acceptance of domestic work as men's responsibility, improved relationships with friends and partners, higher rates of condom use, and lower rates of self-reported sexual harassment and violence against women. Program $\mathrm{H}$ has therefore shown positive impacts in a number of different studies, suggesting that the programme does play a positive resocialisation role for participants. The success of the intervention has led to its continued implementation to the present day, with the organisation reporting that it is being used in 22 different countries. 
Due to the success of Program $\mathrm{H}$, a similar approach was used in the initial design of the MASVAW programme in India, which was first implemented in the state of Uttar Pradesh in 2002. It arose out of a 'dialogue between men and women engaged in addressing women's health rights' (Erdström, Shahrokh \& Singh, 2015:13). The programme aims to create 'rolemodel activists' in communities, who call themselves 'MASVAW men', with the intention of combating the high levels of GBV in the state by specifically focusing on masculinities. The activists, 'become vehicles for creating awareness among men about the different ways to express their masculinity, and how this affects women's lives and social status' (Roy \& Das, 2014:30). Along with this, MASVAW encourages men to allow their wives to work and own property, in a culture where women are more commonly expected to stay home and look after children (Roy \& Das, 2014). In a similar fashion to Program $\mathrm{H}$, the MASVAW intervention takes the form of activities conducted in group workshops, with the intervention typically lasting for six months, with weekly workshop sessions.

As noted in the literature outlined above on the aspects which make masculinities-focused programmes more effective, the presence of positive role models and supportive peer groups can play an important role in improving the impact of an intervention, and the MASVAW intervention uses both of these tactics. The MASVAW men provide examples of alternative forms of masculinities within their communities, and once more men become involved in the project, they also act as leaders of these new peer groups. These groups then act as both a support for the men involved, and as a form of monitoring of their behaviour (Silvergleid \& Mankowski, 2006). As noted in one report, '[p]eer support between activists and "role models" was... essential in maintaining the work and expanding the network' (Erdström et al., 2015:28). The facilitators of the programmes were also found to be important as role models, as they could model gender-equitable behaviour and create safe spaces for men to discuss issues they felt were important to them (WHO, 2007).

A 2012 evaluation of MASVAW found that involvement in the programme was correlated with more progressive gender attitudes and behaviours in men (Das, Mogford, Singh, Barbhuiya, Chandra \& Wahl, 2012). A review by Bhandari (2008) also found a number of positive self-reported impacts, including the fact that men who were MASVAW activists reported using less coercive sex, and had an awareness about the need for changing their attitudes towards women and violence. Along with this, 'MASVAW men' reported having a broader range of emotional expression, using new tools for the management of conflict and anger, and being able to take on leadership roles in their community, which encouraged them to live up to the ideals of the intervention. The evaluations of the MASVAW intervention therefore seem to confirm the findings regarding Program $\mathrm{H}$, in that masculinities-focused interventions can play a positive role in reducing attitudes and behaviours linked to GBV. 
Despite these positive results, some men found that they encountered resistance from their families for being involved with the intervention (Bhandari, 2008). While trying to effect changes in their own lives, they struggled to maintain this within their extended families, who were still predominantly patriarchal (Erdström et al., 2015:24). The existence of supportive peer groups would therefore be very important as a means of helping participants sustain any positive behavioural changes in the face of negative feedback from their families. Along with this, Roy and Das (2014) noted that often men were not required to give up their position of authority in their household, despite 'allowing' wives to work and own property, as the result was rather that these men actually doubled their own income through sharing in their wife's. This implies that the behavioural change may have been more related to a desire for increased income on the part of the husband than to a sincere wish to improve gender equity in the relationship. Roy and Das' findings therefore seem to indicate that the intervention has more of a behavioural than an attitudinal impact on participants, suggesting that that programme needs some adaptions to make it more effective.

The third example is the Stepping Stones programme, which was first developed for Uganda and has since been adapted for use in more than 40 countries, including South Africa (Jewkes, Wood \& Duvvury, 2010). The programme has a specific focus on HIV, with a primary goal being the reduction of the incidence of HIV, and was developed in response to studies which noted that gender inequality and norms play a role in HIV infections. For example, Jewkes, Dunkle, Nduna and Shai (2010) report that IPV and power inequity in relationships increase the risk of HIV infection in young South African women. Women in unequal relationships have little agency, and are unable to refuse sex or demand condom use because of power dynamics and gender norms in their community (Jewkes \& Morrell, 2012). Along with this, hegemonic masculinities which encourage men to have unprotected sex and multiple partners play a major role in the spread of the virus. Thus, HIV-focused interventions have begun to target men and their behaviour as a means of reducing the rate of infections.

Programmes which only provide education or information tend to have an impact on knowledge and attitudes, but very little actual behavioural change (Jewkes et al., 2010). Recognising this, the Stepping Stones programme introduced the use of participatory learning, such as drama and role plays, to achieve both attitudinal and behavioural change, with an emphasis on skills building alongside education (Jewkes, Nduna, Levin, Jama, Dunkle, Wood, Koss, Puren \& Duvvury, 2007). Stepping Stones involves 13 three-hour long sessions over six to eight weeks, and incorporates meetings with single-sex peers (Jewkes, Wood \& Duvvury, 2010). Along with this, the intervention can be combined with voluntary counselling and testing (VCT) for HIV which allows participants to know their HIV status and 
make more informed decisions regarding their sexual behaviour going forward (Jewkes, Nduna, Levin, Jama, Dunkle, Khuzwayo, Koss, Puren, Wood \& Duvvury, 2006).

Evaluations of the Stepping Stones programme have reported a number of positive impacts. In a 2007 evaluation, Jewkes et al. found that the intervention resulted in some reduction in sexual risk-taking and violence perpetration by young, rural African men, while a later evaluation reported that men became more caring and less violent after participating in the intervention (Jewkes et al., 2010). A 2006 study by Jewkes et al. reported on the results of a group which had completed the Stepping Stones intervention versus a group which had completed an information-only intervention, and found that the HIV seroprevalence of the intervention group was lower than that of the control group for both men and women. Those in the intervention group also reported slightly lower rates of having sex with casual partners within the past 12 months, and were more likely to have had two or fewer sexual partners in the past year, suggesting that the intervention has a positive behavioural impact on participants.

However, evaluations also found that there was no evidence of a rejection of their patriarchal power among men. Rather, there was a move towards creating a more 'benign patriarchy' (Jewkes et al., 2010:1083), meaning that the gender norms were somewhat shifted, but the power imbalances remained, suggesting that there will be little change in levels of gender inequality in communities where Stepping Stones is implemented. In addition, the 2006 study by Jewkes et al. found that on some risk behaviours, those in the intervention group actually had more negative scores than those in the control group. For example, those in the control groups were more likely to have always used condoms in the past year than those in the intervention group. While the programme does have positive impacts, these more negative results highlight the difficulty of creating lasting positive behavioural change in participants after the completion of an intervention.

While the masculinities-focused interventions described above have had a number of positive impacts on participants, the evaluations tend to suggest that these are more behavioural than attitudinal changes. Behavioural changes are important, but these tend to be limited to only one or two specific behaviours at any one time, such as allowing a wife to work, or having fewer casual sexual partners over a 12 month period. However, without a change in the attitudes which underpin these problematic behaviours, there will only ever be limited shifts in the social norms that maintain inequality. Thus, it would seem that masculinities-focused interventions can play a role in changing specific behaviours, but have less of an impact on the norms which drive these behaviours. Their effect on reducing GBV may therefore be limited. 


\subsection{Conclusion}

Many organisations which work in the field of GBV have tended to implement reactive women-focused programmes as their primary form of intervention, offering aspects such as counselling, medical care, legal support and places of refuge. Although these interventions are undoubtedly important for helping survivors to process and move on after experiencing GBV, they have done little to lower levels of this kind of violence in the contexts where they have been implemented. Consequently, efforts have been made to design and implement programmes which have a greater emphasis on prevention of GBV, and these have often taken the form of awareness or women-empowerment campaigns. Unfortunately, the evidence suggests that awareness campaigns do little to prevent violence, as they simply shift the blame for GBV from the perpetrators onto survivors and other women, implying that it is women's duty to avoid violence, rather than expecting men to not perpetrate it. Alternatively, empowerment campaigns have shown some positive results in preventing violence, but this seems to hold true predominantly in instances where a multi-approach strategy is used, including both microfinance and counselling or education aspects.

The effectiveness of using multiple strategies is also noted in literature on the creation of successful re-socialisation interventions, along with voluntary involvement, the presence of role models and a supportive peer group, and having a gender-transformative focus. These five aspects have consistently been highlighted as helping to improve the impact and sustainability of an intervention's content, and this seems to be confirmed in the literature on masculinities-focused programmes, which tends to show that incorporating these five factors can have a positive effect on a programme's effectiveness. However, the masculinitiesfocused interventions outlined above also suggest that while these factors may be helpful, they do not guarantee change in the desired direction.

A total institution may have a powerful impact on an inmate or recruit, but the direction of change seems to be closely tied to whether they enter the institution voluntarily or by force. Voluntary involvement (as in the case of a soldier who chooses to join an army) has a profound impact, to the extent that it can be very difficult to shift these norms once the recruit leaves the institution. Programmes which attempt this, such as DDR, have had little success to date, and I argue that a primary reason for this lack of success is that there is almost no focus on masculinities in DDR, meaning the programmes aim to be gender-neutral rather than gender-transformative. In the few instances where a gender-transformative programme has been implemented in a post-conflict context, the results have been promising, although it is too early to generalise these results due to the limited number of evaluations produced thus far. BIPs have also tended to have minimal impact, potentially due to the fact that participants are compelled to take part, and are likely to resent this fact quite strongly. 
Programmes which have specifically chosen to focus on masculinities in order to reduce GBV, such as Program H, MASVAW and Stepping Stones, primarily include the five factors listed above in order to maximise the positive impact, and the results seem to show that this has worked in a number of instances. However, the literature also notes that the positive changes seem to be primarily behavioural, with minor adaptations in specific behaviour, rather than attitudinal shifts which would result in changes in a broader range of behaviours. While the lack of attitudinal change is worrying, it is promising that these interventions can impact on problematic behaviours, and that they seem to result in more positive behavioural change regarding GBV than women-focused reactive programmes. I would therefore argue that these positive impacts provide sufficient reason for these kinds of interventions to be continued, albeit with some alterations to improve their attitudinal impact.

It is against this background that this paper begins to narrow its focus specifically to South Africa and the challenges it faces as a result of GBV, and how a specific masculinitiesfocused intervention is being implemented in the country. The following chapter therefore provides geographic and historical context through a description of the current situation in South Africa, with a specific focus on GBV and the development of violence and masculinities. 


\section{CHAPTER 4}

\section{THE SOUTH AFRICAN CONTEXT}

\subsection{Introduction}

This study focuses on South Africa, a country which has experienced extremely high levels of violence and gender-based violence in recent years. While frequently hailed as an example of successful and peaceful transition from racial segregation to democratic government, the perpetration of GBV remains extremely common, with a number of writers stating that South Africa has the highest rates of violence of any country not at war (Moffett, 2006; Peacock, 2012). The high rates of violence have led to a considerable body of literature discussing the reasons for this violence, with some focusing on the impact of the history of Apartheid (Anderson, 1999/2000), and others looking at the current extremes of income inequality (Morrell, Jewkes \& Lindegger, 2009). Along with this, writers such as Hamber (2000) and Machisa (2010) argue that the high levels of violence under Apartheid led to a normalisation of violence in more recent years, which then perpetuates the cycle of violence.

Much of the violence is of a sexual nature and perpetrated against women, with the Tshwaranang Legal Advocacy Centre estimating that roughly 50000 women are raped in the country each year (2012), leading a number of writers to focus more specifically on the gender norms that may underpin this violence. Reinforcing the literature outlined in Chapter Two, some literature has focused on the history of militarisation in the country, and the resultant presence of militarised and hypermasculinities (e.g. Cock, 1991; Conway, 2004, 2008; Ratele, 2012). Along with this, it has been suggested that the extreme levels of gender inequality and patriarchal attitudes which exist in South Africa could play a role in causing violence against women (Viitanen \& Colvin, 2015), and this has also been linked to the existence of a rape culture in the country (Baugher, Elhai, Monroe \& Gray, 2010; Gqola, 2015). This chapter therefore begins with a description of the levels of violence in the country, followed by an outline of some of the causes that have been suggested for this in the literature, in order to provide the context of the current state of GBV, to begin to examine possible means to address it, and why there is a need to address masculinities as a means of prevention.

The high levels of GBV have led to a large number of attempts to respond to and prevent this violence, and the chapter therefore moves on to investigate the different ways in which both government and civil society have tried to do so. This includes brief descriptions of existing non-governmental organisation (NGO) interventions and their effectiveness, within the framework of literature on GBV. The description of the GBV-focused interventions 
creates the backdrop for the case study which was used for this research (discussed in Chapter Five), and helps to understand why a masculinities focus was chosen by Sonke Gender Justice as a means of addressing GBV.

\subsection{South Africa and gender-based violence}

Daily life in South Africa has been significantly shaped by the country's history of colonialism and Apartheid, and racialised policies implemented by the National Party (NP) impacted on South African's lives in a multitude of ways. From 1948, when the official policy of Apartheid was introduced, until the early 1990s when it was finally abolished, the country underwent many years of violent confrontations between the state and different sectors of the population. While the country was never officially declared a conflict zone, some have argued that there was continuous low-intensity conflict for many years, which Cock has defined as 'a strategy to defeat liberation movements without engaging in full-scale conventional war' (1989:2). During this time, numerous armed groups emerged in opposition to the state security forces (namely the South African Police force (SAP), and South African Defence Force (SADF), and these armed opposition groups included UmKhonto weSizwe (MK), the armed wing of the African National Congress (ANC), and the Azanian People's Liberation Army (APLA) of the Pan-African Congress (PAC). Along with these, a number of more informal self-defence and self-protection units (SDUs and SPUs) were later set up in some areas as neighbourhood defence groups, and these are discussed in more detail below.

Beginning in 1948, when Apartheid was officially implemented, increasingly racist laws were enacted by the government with the intention of separating the different racial groups as much as possible. All people were classified as either white, black, Indian or coloured, with those classified as white receiving preferential treatment, services, housing, education and living space ${ }^{1}$. Areas were classified according to who could live there and this entailed the forced removal of communities from areas which had been classified for a different racial group (Anderson, 1999/2000). Inter-racial contact was policed by a large number of pieces of legislation, which banned inter-racial marriage and relationships, while public services and amenities (such as transport, entrances to buildings, public benches, and beaches) were segregated by race.

Resistance to these policies and laws began soon after they were implemented, and while initially a policy of passive resistance was encouraged (also known as the Defiance

\footnotetext{
${ }^{1}$ While these racial terms are increasingly problematised and contested in South Africa, they are still widely used and understood in the country, and they are therefore used in this paper when differentiation between different groups of people of colour is required. For the remainder, the term 'people of colour' will be used.
} 
Campaign), the struggle against Apartheid became increasingly militant as actions by the state became more violent (Ross, 1999). The development of armed resistance groups and the violent militarised response from the state is important in the context of this research, as I argue that these two factors impacted heavily on the current levels of violence being experienced in the country. The process of militarisation which occurred in the SADF, MK, APLA, SDUs and SPUs contributed to the development of militarised and hypermasculinities among large segments of the population, and these are still evident today. Along with this, the violence carried out by both the state and resistance groups led to a situation where the use of violence became accepted and normalised in a wide range of situations. These aspects are both discussed in more detail in section 4.3 below.

A primary event which contributed to resistance to Apartheid becoming militarised was the Sharpeville shooting in 1960. Under Apartheid legislation, all people of colour in South Africa were required to carry passes if they were in white-designated areas (Davenport, 1991), and in 1960, the PAC organised a march to a police station in the township of Sharpeville to protest against this. The police responded by opening fire on the protestors, killing more than 60 people (Ross, 1999), and this led to both the ANC and PAC forming armed wings in 1961 (Landau, 2012). By the 1980s, a state of emergency was declared by the government, with the country essentially becoming a police state (van Kessel, 2000), where the SAP were given wide-ranging powers, and the rights of those arrested or in custody were increasingly eroded (Anderson, 1999/2000). Detention without trial was used for those classified as 'terrorists', and banning orders were placed on those who criticised the state, meaning their writing and speeches were censored (Hinds, 1998/1999). Travel restrictions were an additional constraint on the freedom of movement of those who opposed Apartheid, and many activists went into exile in neighbouring African countries, or further afield in countries which supported the struggle (Ross, 1999). The SADF was eventually deployed internally in different areas of the country and in the townships to counter the growing unrest and opposition to the Apartheid government (Simpson, 2009). The use of the military against civilians once again contributed to the acceptance of militarism and violence in the country. In addition to the violence taking place between the state and resistance groups, violence between rival political and social groups occurred, with one side often covertly supported by the South African government as a means to divide communities, thereby aiming to disrupt the potential for united resistance to the state (Anderson, 1999/2000; Hamber, 2000). Much of this fighting took place between the ANC and the rival Inkatha Freedom Party (IFP), and due to the violence in some neighbourhoods, self-defence and self-protection units (SDUs and SPUs) were established (Langa \& Eagle, 2008). These were informal armed groups which were nominally meant to provide community safety, yet were often used as an excuse 
for criminality and factional violence. The impact of this constant presence of violence and militarisation on masculinities is also discussed in more detail in section 4.3 below.

Along with militarisation, another aspect of the country's history which contributed to the normalisation of violence was the unequal level of policing provided to different racial groups. Apartheid legislation designated different living areas for the different racial groups, with the most desirable areas, predominantly urban and close to services and workplaces, mostly being reserved for white people. This meant that people of colour were forced into more peripheral areas surrounding towns and cities, which often led to the development of informal settlements in these areas, predominantly populated by black and coloured people. While these provided somewhat convenient housing for people working in the cities, they were neither sustainable nor safe communities, as policing was usually lax, and more often used as a tool to keep people afraid of the state than as a means of community safety (Anderson, 1999/2000). Many people in these townships therefore distrusted the predominantly-white SAP, and were unlikely to report crime, contributing to relatively high levels of crime and violence in these areas, with perpetrators usually going unpunished (Hamber, 2000). This played a role in the growing normalisation of violence which was taking place across the country.

Eventually, the combination of internal unrest and international condemnation and sanctions resulted in the Apartheid state losing power, and the first democratic elections were held in 1994 (Anderson, 1999/2000). Since then, the country has stabilised in a number of ways, yet many problems remain, and the normalisation of violence has continued, becoming widespread and commonplace, and affecting almost all groups of South African society. In fact, Hamber believes that, ' $[\mathrm{t}$ ] he experience of being violently victimised in South Africa has almost become a statistically normal feature of everyday life in many urban and rural settings' (2000:7). The suggested causes of this violence are discussed in the following section, but the remainder of this section provides a description of the extremely high levels of violence and GBV in the country. This description is necessary in order to highlight the importance of work which aims to respond to and reduce this violence, and to explain the context in which South African GBV-prevention interventions are working.

The rates of violence perpetrated and experienced in South Africa are some of the highest in the world outside of a conflict zone. Peacock believes that, 'one of the most terrible legacies of apartheid is that the levels of men's violence against women and against other men rival those in conflict settings' (2012:10). In addition, Moffett notes that the levels of rape in South Africa are reported to be the highest of any country not at war (2006). Although not all agree with the classification of South Africa as a post-conflict context, a number of writers such as 
Cock and Nathan (1989) and Lerche (2006) have termed it as such. However, whether or not it is defined as post-conflict, the levels of violence are incredibly high, suggesting that quite significant steps need to be taken to address them. For example, based on statistics from previous years, more than 50000 women are likely to be raped in the country this year (Tshwaranang Legal Advocacy Centre, 2012), and a woman will be killed by her intimate partner every six hours, the highest rate ever recorded in the world (Mathews, Abrahams, Martin, Vetten, van der Merwe, \& Jewkes, 2004).

In 2012, GenderLinks and the Medical Research Council (two South African NGOs) conducted a survey on the prevalence of gender-based violence in four provinces (Gauteng, Western Cape, KwaZulu-Natal and Limpopo). Between one third and three quarters of women in all four provinces reported experiencing some form of violence at least once in their lifetime, with Limpopo (77\%) reporting the highest rates, followed by $51 \%$ in Gauteng, $45 \%$ in Western Cape, and 36\% in KwaZulu-Natal. In addition to this, men were asked whether they had ever committed some form of violence against women. In some provinces (41\% in KwaZulu-Natal, and 35\% in Western Cape), the numbers of men reporting having committed violence was similar to the levels of violence experienced by women. However, in Limpopo (48\%) the levels reported by men were substantially lower; while in Gauteng (78\%), the rates were much higher than the rates reported by women. As noted by the authors (2012:6), 'the study in the four provinces confirms the disturbingly high prevalence of violence against women in South Africa'. An earlier study by Jewkes, Sikweyiya, Morrell and Dunkle found that $27.6 \%$ of South African men reported having raped a woman and of those, $46.3 \%$ had raped more than once (2009).

These high levels seem to add credence to Anderson's claim that South Africa is facing a 'rape crisis' (1999/2000), but also supports the notion of that this is due to the ongoing normalisation and acceptance of violence. While initially much of this normalised violence would have taken place between the state and armed resistance groups, the perceived acceptability of violence has seemingly spread to other types of violence as well. The fact that so many different forms of violence have become normalised is important to bear in mind when looking at efforts to respond to this violence, as it suggests that a societal-level approach will be required. If large parts of society have begun to think of GBV as 'normal', it will be more difficult to shift this belief through working only with individuals or small groups. This is an aspect that needs to be kept in mind when discussing GBV interventions.

While the levels of violence against women are worryingly high, numerous other forms of GBV are also present, and it is important to recognise that these need to be addressed in GBV interventions as well. For example, violence between and against men is even more 
common than violence against women, with Seedat, Van Niekerk, Jewkes, Suffla and Ratele stating that, '[d]eaths of men from homicide outnumber those of women by more than $7: 1$ ' (2009:102). $81.5 \%$ of homicide victims recorded in 2008 were men (UNODC, 2013), and according to Indexmundi (2013), South African men had the highest mortality rate in the world in 2011 (572.01/1000 male adults). Despite this, violence against men is often not highlighted as a specific concern. In addition to this, South Africa has high levels of 'corrective rape', where men rape lesbian women as a supposed attempt to 'correct' their sexuality, and the extent of the issue was documented in a Human Rights Watch report, titled 'We'll show you you're a woman' (Nath, 2011).

South Africa as a country therefore displays extremely high levels of numerous kinds of interpersonal and gender-based violence, ranging from assault and murder to sexual crimes such as rape and corrective rape. Thus, as Hamber notes, "[m]any commentators have come to refer to South Africa as a 'culture of violence' - a society which endorses and accepts violence as an acceptable and legitimate means to resolve problems and achieve goals' (2000:5). This section suggested that the history of militarised and political violence played a major role in the development of this culture of violence; however, other writers have provided alternative explanations, and these will be discussed in more detail now.

\subsection{Possible reasons for violence}

It is difficult to find one definitive cause of the high levels of violence in South Africa, and numerous answers have been suggested, with many analyses focusing on the system of Apartheid that officially existed in the country from the 1940s until the 1990s. However, I would argue that it is important to unpack the different aspects of Apartheid which have contributed to the current situation. While many of these factors also exist in other countries, their link to the history of Apartheid may well be what makes them so relevant in the current context of South Africa, and some of these different aspects are discussed separately below. The ways in which these aspects link to the suggested causes of violence outlined in Chapter Two will be highlighted, along with the correlation between each aspect and masculinities. Thus, the focus remains on the ways in which masculinities combine with numerous other societal pressures to legitimate the use of violence for men, but not for women.

The first aspect which will be discussed is the racial inequality, dehumanisation and extensive use of violence that occurred under the Apartheid system. Following on from this, the discussion will turn to the vast discrepancies in income and wealth that existed under Apartheid, which have in many ways continued or been exacerbated since the advent of democracy. The levels of unemployment have increased, the income gap has grown, and 
the resultant inability of many men to achieve the hegemonic norms of being an economic provider may contribute to their use of violence as a reaction. The next aspect is the fact that many people witnessed and/or experienced violence during Apartheid, and as was outlined in Chapter Two, this has been linked to the generational cycling of violence. Along with this, high levels of gender inequality existed under Apartheid, and while this has been addressed in legislation since the first elections in 1994, the actual situation for women in the country has not improved in many respects. Thus, a system of extreme gender inequality has arisen, and this has been linked to high levels of violence, as was discussed in Chapter Three. Finally, and linked to gender inequality, a 'rape culture' has developed in the country, and has been noted by a number of authors as an important contributing factor to the high levels of particularly sexual violence occurring in South Africa. Rape culture was not specifically discussed in previous chapters, as it relates to only one form of GBV and is somewhat limited as an explanation for the wide range of types of GBV. However, numerous writers have noted the existence of a rape culture in South Africa, and the fact that it contributes to the ongoing normalisation of violence and gender inequality in the country, and it is therefore included as a possible contributing factor to GBV.

\subsubsection{Apartheid as a system}

The first factor which tends to be highlighted as contributing to the violence currently being experienced in South Africa is the policy and implementation of Apartheid as a whole. The creation of a hierarchy of races entailed a purposeful process of dehumanisation of those not classified as white, with racist propaganda and legislation becoming the standard. Violence and brutality were normalised during this period, with the SAP and SADF increasingly using violence against those who opposed the government. In addition to this, the notion arose of 'acceptable' kinds of violence, either by the state against opponents, or by those involved in the struggle against the state (Anderson, 1999/2000). As has been noted a number of times in this study, this normalisation creates a situation in which the use of violence becomes seen as more acceptable, which reduces the societal disapproval and potentially increases the rates of perpetration of violence. Thus, the normalisation of violence can contribute to its ongoing perpetration.

However, the violence perpetrated under Apartheid did not impact on all citizens in the same way, and tended to be used in a calculated fashion, with Breckenridge (1998) arguing that the violence by white men against men of colour was intended to be emasculating, and to emphasise the lack of power that men of colour held or could exert. Morrell agreed, writing that the 'word [boy] captured a condescension, a refusal to acknowledge the possibility of growth and achievement of manhood amongst African men' (1998:616). As was discussed in previous chapters, when men are unable to achieve hegemonic masculinity through 
socially salient markers such as employment, wealth, or being the patriarch in a household, there is a very real risk of their turning to violence as a means of compensation. This suggests that the process of emasculation that men of colour experienced could well have contributed to the levels of violence that the country faced, both during Apartheid and since. In addition, the normalisation of violence, which Hamber termed 'the socially sanctioned use of violence to solve problems' (2000:9), places a different pressure on men than it does on women. As violence becomes an acceptable way to respond to situations, the use of violence can become an expected aspect of the achievement of masculinities, placing increased expectations on men to display these kinds of behaviours to achieve the standards of hegemonic masculinities. Breckenridge claims that, 'organised violence was a central feature of the upbringing of both white and black men... it was central to the definition of masculinity for both groups' (1998:674), and Ratele concurred that, 'violence, like steroids, becomes a resources for producing a masculine stereotype' (2012:15). Because violence was socially sanctioned and normalised, it became accepted as a means to achieve masculinities. This could become especially salient in situations where men are unable to achieve masculinities through other avenues such as employment, as explained in the discussion of strain theories in Chapter Two.

However, there is a danger that blaming violence on Apartheid in this way implies that violence is only perpetrated by men of colour, because they were the ones who would have struggled the most to achieve certain standards of masculinity during that time (Moffett, 2006). While statistics tend to show that black women experience more violence than white women (Gqola, 2015), there is little evidence to suggest that white men do not also perpetrate a wide range of forms of violence. As discussed in previous chapters, the problematic assumption behind many strain or deprivation theories is that only those who are marginalised in some way will resort to violence. However, as already argued, statistics continually show that this is not the case, with violence and particularly gender-based violence being perpetrated by men from all sectors of the population. This is true in South Africa and around the world. The process of dehumanisation and the normalisation of violence which occurred under Apartheid can therefore go some way to explaining the current levels of violence in the country, but does little to explain why those from nonmarginalised groups also perpetrate violence. Alternative explanations for the extreme levels of violence in South Africa have therefore been suggested, which often include a focus on the levels of income inequality in the country. 


\subsubsection{Income inequality}

The legislated system of racial inequality under Apartheid created very disparate opportunities for attaining wealth, or even a basic income, and this resulted in a large income gap between the predominantly white middle and upper classes, and the lower and working classes made up mostly of people of colour. Writers such as Hamber believe that, "the enormous deprivation caused by the apartheid system [is] at the root of most violence in South Africa' (2000:9), and the recent economic downturn and growing levels of income inequality have therefore been noted as possible reasons for the current levels of violence in the country. While South Africa is not the least developed country on the continent, the levels of income inequality (i.e. disparity between socio-economic groups) are high. Morrell, Jewkes and Lindegger note that South Africa 'is a middle-income country with enormous mineral and agricultural wealth, but has a very high unemployment rate... and extreme wealth inequalities' (2012:13), and it has been reported that roughly one third of the South African population is unemployed (Seedat et al., 2009).

A number of studies have noted the link between income inequality and violence in the context of South Africa. For example, Seedat et al. note that income inequality and low economic development, 'are strong positive predictors of rates of violence... South Africa had the worst income inequality and highest rate of homicide of the 63 countries studied...After income inequality, unemployment... was the most consistent correlate of homicides and major assaults' (2009:1015). The suggested reason for this is that high levels of income inequality limit men's opportunities for achieving financial ideals of hegemonic masculinities, which results in their turning to violence as an alternative, and this is in line with the strain theories outlined in Chapter 2.

The impact of this income inequality on men's achievement of masculinities tends to be seen as a factor which contributes to their perpetration of violence, with Cock explaining that, '[u]nemployment and low wages are among the factors that make it very difficult for fathers to live up to support functions' (1991:41). In other words, being able to earn a living and provide financially for their families are seen as important markers of masculinity for many men, and if they are unable to do so, they may feel like they need to compensate in other ways. Jewkes describes it as follows: 'men living in poverty were unable to live up to their ideas of "successful" manhood... in the resulting climate of stress, they would hit women... ideals of masculinity are reshaped to emphasise misogyny... and participation in crime' (2002:1424). In a later study, Jewkes et al. reiterate this, stating that 'an inability to meet with social expectations of "successful" manhood may trigger a crisis of male identity, and rape and IPV are [a] means of resolving this crisis because they act to reconfirm the nature of powerfulness otherwise denied' (2009:10). Thus, being unable to achieve masculinities 
through economic means can contribute to men using violence against others as an alternative method of attaining these masculinities.

These studies therefore suggest a link between poverty, income inequality and violence, yet the idea of the strain of poverty causing violence once again implies that violence only occurs in poor, marginal communities where financial aspects of masculinity are difficult to achieve. As noted in previous chapters, violence and particularly GBV is a global phenomenon, committed in all countries and social groupings, and it is not absent in developed countries. For example, Garcia-Moreno et al. (2013) found that worldwide roughly $35 \%$ of women have experienced physical and/or sexual intimate partner violence or nonpartner sexual violence. 'High income countries', such as the USA, Northern and Western Europe, and Australia had a prevalence of around 32.7\% (2013).

These statistics tell us that even those who objectively are not facing strain in terms of poverty or income inequality are still committing GBV, suggesting that the link between poverty and violence is less clear than has been outlined in the studies mentioned above. Along with this, using poverty to explain violence still does not help us to understand why it is that men are more likely than women to turn to violence when in situations of poverty. Thus, I argue that many versions of masculinity in South Africa and around the world expect or demand violence from men as a primary part of their display of masculinity, rather than as an alternative when they are unable to achieve economically. As Moffett writes, 'many men rape not because they want to or are 'tempted', but because society tells them they can (and in some cases, should) do so with impunity' (emphasis in original) (2006:13). A report by Sonke Gender Justice has a similar message: 'Men who use violence do so because they equate manhood with aggression, dominance over women and with sexual conquest' (2007:26-27). Their use of violence is therefore not a last resort in response to a crisis, but rather a fundamental aspect of their achievement of hegemonic masculinity. While poverty may help to explain some incidents of violence, alternative suggestions need to be looked at, and one such alternative is the experiencing or witnessing of violence, which was also discussed in Chapter Two.

\subsubsection{Experiencing or witnessing violence}

As has been outlined above, violence became increasingly commonplace under Apartheid, with a combination of state violence against citizens, armed resistance by citizens, and violence between rival groups within the country. Because the violence was considered acceptable in numerous circumstances, it became more common and this led to its normalisation, and Machisa (2010:14) states that, 'the more community violence is spoken about and overestimated, the more likely the perpetration of interpersonal violence increases 
in tandem'. Thus, as more people witnessed, experienced, and spoke about violence, the more common it seemed, and the more normalised it became. Hamber argues that this might in fact lead to an overinflated fear of crime, which is out of proportion to the actual threat that is posed, although he maintains that the rates of crime are 'genuinely high' (2000:12).

This seems to confirm the discussion in Chapter Two, which suggested that witnessing or experiencing violence is closely linked to later perpetration and experience of violence, with Seedat et al. stating that, 'exposure to trauma and violence during childhood can give rise to both revictimisation and intergenerational cycling of violence' (2009:1015). Hamber agreed, saying that, 'certain victims of past violence are at risk of becoming perpetrators of retributive violence or displaced social and domestic violence' (2000:13). In addition, in a fact sheet on IPV in South Africa, Lau (2009) noted that men's use of intimate partner violence in South Africa is often associated with having witnessed violence in their own family. Because of the high levels of numerous forms of violence in South Africa, many people have witnessed or experienced violence while growing up or during their current daily life. This, coupled with the normalisation of violence which was discussed in previous sections, may well go some way to explaining the high rates of violence that the country is currently experiencing.

However, as was also noted in Chapter Two, the difficulty with this body of work is that the line of causation is often difficult to determine, with witnessed or experienced violence being linked to both perpetration and revictimisation. Along with this, the literature outlined in Chapter Two suggests that this too has a gendered dimension, with men seeming more likely to become perpetrators, while women tend to be more likely to become victims. Thus, I would argue that the violence witnessed or experienced by men links to the expected violence that is tied to the hegemonic masculinities currently at play. Violence is therefore both normalised and expected for men, meaning that the constraints against violence are relatively low, making it easier and more acceptable for men to continue to perpetrate violence going forward, or to choose violence as a response in specific situations. This suggests that attention needs to be paid to the fact that violence is specifically expected from men in their achievement of certain masculinities, and the discussion therefore moves to focus on examples of violent masculinities in the South African context.

\subsubsection{Militarisation and hypermasculinities}

As described above, the Apartheid state's response to the growing levels of unrest and violent resistance was to increase their use of violence in return, with the SAP and SADF being used against South African citizens in numerous areas, and it is therefore little wonder that some have described South Africa as having a 'culture of violence' (Hamber, 2000). 
Others have called the current situation one of 'militarised peace' (Magadla, 2013), with no official conflict yet high levels of violence and weapon use. This section discusses how the history of militarisation has contributed to the creation of militarised masculinities, which in the post-Apartheid period has fed into a culture of hypermasculinity associated with violence and the denigration of women in the country. Thus, despite the concerns raised above about the use of the terms 'militarised masculinities' and 'hypermasculinities', they can be useful in helping to understand why it is that South Africa in particular has such high rates of violence.

According to Conway, Apartheid South Africa was a 'profoundly militarized society. The militarization was premised on a particular construction of masculinity and citizenship' (2004:26). During periods of instability or conflict, and particularly in countries with policies of conscription, masculinities can become heavily influenced by the military. In this regard Cock wrote that, "the key theme in this process is socialization into a rigidly masculine and militarized construction of self... "Notions of masculinity" are a powerful tool in this process of making men into soldiers' (1991:56-58). Because of this, Gqola states that, 'given the patriarchal structure of both Black and white societies in South Africa, this high militarization could only take on gendered forms and play itself out along sharply gendered lines' (2007:113). In other words, the process of militarisation heavily impacted on men in particular, and on the forms of masculinity that developed as a result of it.

All white men were conscripted into the SADF from the 1960s until the late 80 s, and had to spend at least a few months receiving training, with the length of time served eventually increasing to two years. White masculinity was closely linked to military service over the years, with heavy propaganda around white men's need to protect their wives, children and country from the threat of communists and terrorists (Cock, 1994; Swart, 1998). Men who refused to enlist were labelled 'moffies ${ }^{2}$ or 'gay', and were derided and potentially imprisoned for refusing to serve their country (Conway, 2004, 2008). This meant that the majority of white men through a number of generations spent at least some time receiving military and weapons training, which would have had a large impact on the kinds of masculinities that became salient in these communities. This means that the expected characteristics of militarisation, such as strength, weapon use and aggression have become markers of hegemonic masculinities for many white men in post-Apartheid South Africa.

Similarly, the armed groups that fought against the Apartheid state contributed to the development of militarised and hypermasculinities amongst people of colour too. Many political parties created armed wings (such as MK and APLA), while some neighbourhoods created SDUs and SPUs to protect themselves against the increasing violence and

\footnotetext{
${ }^{2}$ A derogatory term for gay men.
} 
instability in their communities. Masculinity became closely linked to militarism and the fight against the Apartheid government and rival community groups (Suttner, 2007; Langa \& Eagle, 2008). Those who joined in the struggle were referred to as 'comrade' (Andrews, 2007), while those who refused to get involved were branded 'askaris' or traitors, which again emphasised the positive impressions associated with militarised men. Thus, as noted by Barker and Ricardo (2005: 31):

In many parts of South Africa... both white and black young men were often socialised into a militaristic version of manhood through the formation of a brotherhood of combatants, whether for or against apartheid.

This celebration of militarised masculinities has continued in the post-Apartheid context, with political parties such as the ANC and the Economic Freedom Fighters (EFF) using weapons like spears in their party logos, and military terminology (e.g. Commander-in-chief) to refer to their leaders (Magadla, 2013), while the current South African president, Jacob Zuma, sings 'Bring me my machine gun' as his theme song (Suttner, 2009). As a further example of the continuing importance given to militarised language and culture, a number of gangs use terms related to a military command structure to refer to their members' rankings, which further normalises the idea of militarism being associated with masculinities in the country (Steinberg, 2004). While aggression and strength are often closely linked to militarism, the reliance on weapons as a symbol of masculinity is also an important factor, and this has retained salience in the present South African context as well. There are large numbers of firearms in circulation in the country, and these remain closely linked to versions of militarised masculinities, with Abrahams, Jewkes and Mathews noting that, '[g]un ownership is mainly a male phenomenon, a means to demonstrate manhood' (2010:586). It is difficult to find statistics which dis-aggregate gun ownership by gender in South Africa, although a report released by the Small Arms Survey showed that men held more than 95\% of licensed firearms in nine different European countries (Dönges \& Karp, 2014), and Dimock, Doherty and Christian found that men are three times as likely as women to own a gun in the USA (2013). Thus, while the exact numbers may differ, it is likely that gun ownership in South Africa follows the trend of male ownership far outnumbering female ownership.

The ongoing celebration of militarised masculinities, military terminology and symbolism, and the high levels of gun ownership have led to some writers, such as Ratele, describing South Africa as a militarised society, defining this as a context where 'a set of ideologically informed practices... normalise violence' (2012:4). While this will impact on both men and women, the societal pressure on men to achieve these militarised standards of masculinity is more likely to encourage them to use violence in a range of situations than it is to encourage women to use violence. Thus, I would argue that the fact of South Africa being a militarised 
society contributes significantly to the high levels of violence perpetrated by men in the country.

However, as was noted in Chapter Two, militarised masculinities are not the only form of masculinity which rewards violence, and militarism often feeds into a culture of hypermasculinity, which encourages men to value aggression and strength. Along with this, hypermasculinities combine aggression with the denigration of women, with Mosher and Sirkin explaining that these masculinities are 'joined with a conception of women as dominion and sexual objects' (1984:151). The presence of hypermasculinities can therefore provide an additional means to understand the high levels of particularly gender-based violence in the country. In addition, hypermasculinities relate closely to gender inequality and the presence of a 'rape culture' in the country, as explained below. However, the fact that this militarism has become so prevalent in South African society suggests that the norms surrounding militarised masculinities have become relatively 'mainstream'. Violence has therefore become a normalised or allowed expectation for many men. Thus, despite the usefulness of the terms militarised masculinities and hypermasculinities in relation to the country's history, their limitations in explaining wide-spread violence by men need to be kept in mind.

\subsubsection{Gender inequality}

Gender inequality has been highlighted as an issue which contributes to violence in a variety of ways and places, and typically occurs in societies with more traditional or conservative norms about the position of women (Jewkes, Levin \& Penn-Kekana, 2002). Because these norms tend to place women in subordinate roles to men, they often provide 'justifications' for violence against women, as explained in Chapter Two (Heise, Ellsberg \& Gottmoeller, 2002). This connection has been described by a number of authors, such as Buscher (2005), who notes that gender inequality perpetuates cultures of violence, and particularly gender-based violence. He explained that in gender unequal societies, women are seen as less important than men, or as men's possessions, meaning that men feel less hesitation in abusing women, and believe that their satisfaction is more important than women's.

In a similar vein, Dworkin et al. (2012) and Ditlopo et al. (2007) note that gender inequality in South Africa tends to be closely linked to both violence against women and a high prevalence of HIV/AIDS. This finding is echoed by Viitanen and Colvin (2015), who note that norms supporting gender inequality, such as believing that men have an entitlement to exert dominance over women, are closely linked to GBV. A possible explanation for the link between gender inequality and HIV/AIDS risk is that gender unequal societies tend to allow women little agency in controlling their sexual interactions. This is because men's pleasure 
and sexual desires are prioritised, meaning that women feel unable to refuse sex when it is expected, or to use condoms if their male partner does not want to (Ditlopo et al., 2007). Along with this, risky sexual behaviour is equated with manliness, while health-seeking behaviour (such as getting tested for HIV) is seen as unmanly (Ditlopo et al., 2007). Thus, it seems that gender inequality can be closely linked to GBV, and particularly to sexual violence against women and girls.

As in many other countries in the world at the time, Apartheid South Africa had high levels of gender inequality alongside the more legislated racial inequality, and while there was some hope that the struggle against Apartheid would include a fight for gender equality as well, it seems that gender equality was side-lined by the liberation movements as 'less important' than the push for racial equality. As noted by Morrell, Jewkes and Lindegger, it was often believed that 'gender was relatively unimportant in the context of race oppression' (2012:19), suggesting that the fight against the racial inequality of Apartheid was more pressing than efforts to achieve gender equality. Armstrong (1994) and Andrews (2007) explain that some were worried that fighting against GBV could be considered a divisive issue by those involved in the struggle, and divert attention from the fight against Apartheid. The fact that achieving gender equality was not taken seriously by those on either side of the political spectrum during Apartheid provides some explanation as to why the situation has changed little since the achievement of democracy in 1994.

In what would seem to be an attempt to achieve some level of gender equality in South Africa, much legislation has been passed affirming the rights and equality of women since 1994. The Bill of Rights in the Constitution (Republic of South Africa, 1996) explicitly bans discrimination on the basis of gender, and affirms that all should have equal access to rights. In addition to this, South Africa has ratified a number of international treaties which focus on the rights of women and condemn GBV, including CEDAW (Convention on the Elimination of All Forms of Discrimination Against Women), and the African Union Protocol on the Rights of Women in Africa. As a result of this, South Africa was ranked highest in Africa in the Organisation for Economic Co-operation and Development (OECD) Social and Gender Index in 2012; and was fourth out of the 87 countries ranked by the organisation in the Index.

However, current statistics suggest a very different picture in reality, with a 2013 publication on gender by StatsSA showing ongoing high levels of gender inequality. Women are more likely to be employed in unskilled occupations than men, and women are over-represented in the lower earning categories, while men were more likely to be in higher earning categories. Women with tertiary education who are employed only earn around $82 \%$ of their male 
counterpart's salaries, and women's hourly earnings are lower than men's in all population groups. While women work fewer paid hours, they work substantially more unpaid hours at tasks such as housework, care of others, and collecting fuel and water. In all population groups, women work more than double the number of unpaid hours as men. Women are more likely to be living in households in the bottom two quintiles in terms of income, while men are more likely to be living in the top two quintiles. In other words, women are more likely to be living in homes with low income, while men are more likely to live in homes with higher incomes. Thus, StatsSA notes that in a range of areas, 'there are still worrying disparities in the situation and circumstances of women and men' (2013:50). This shows that gender inequality is still a very widespread reality for women in all population groups in South Africa, despite legislation being passed to address this.

It has been suggested that gender inequality is more common in certain cultures in South Africa than others, yet the statistics listed above seem to disprove that suggestion.

Numerous writers have noted the fact that gender inequality seems to be the case across cultural and racial lines in South Africa, with Cock stating that, 'in all South African cultural traditions gender roles are highly structured and unequal' (1991:29). Andrews agrees, stating that patriarchy is the only 'truly non-racial institution in SA' (2007:48). Because gender inequality has been linked to violence in a number of studies, this ongoing culture of gender inequality, across all population groups, could therefore be a significant factor contributing to the levels of GBV being experienced in the country. Hypermasculinities which endorse the denigration of women combined with extreme levels of gender inequality can therefore provide some answers as to why men's use of violence against women is so widespread in the country. The following section focuses on one specific form of violence against women - rape - which is often closely linked to gender inequality, and which I argue is an additional factor contributing to men's overall use of violence.

\subsubsection{Rape culture}

Although this paper uses a broader definition of GBV than just sexual violence and rape, this section specifically focuses on rape culture as a phenomenon that enables sexual violence in South Africa and a number of other countries around the world. 'Rape culture' describes a setting where rape is common, and the norms, attitudes and practises of that culture normalise, condone, excuse, encourage or ignore rape (Flintoff, 2001). In other words, this describes contexts where the 'predominant cultural attitudes... facilitate continued tolerance of aggression toward women, and thus the occurrence of sexual violence' (Aosved \& Long, 2006:481). 
A number of behaviours are associated with rape culture. These include victim blaming, sexual objectification, the trivialisation of rape, denial of widespread rape, and refusing to acknowledge the harm caused by sexual violence. Also, rape myths tend to be widespread in places which exhibit rape culture. Rape myths are 'false beliefs used mainly to shift the blame of rape from perpetrators to victims' (Suarez \& Gadalla, 2010:2010), and can relate to the behaviour of both victim and perpetrator. These include sayings such as 'men cannot control their sexual urges', 'women who wear short skirts/drink too much invite rape', 'rapists are mentally ill/monsters' etc. (Baugher, Elhai, Monroe \& Gray, 2010; Gqola, 2015). Rape myth acceptance is correlated with other forms of conservatism, such as racism, sexism, homophobia, and religious intolerance (Aosved \& Long, 2006), and with an acceptance of interpersonal violence (Burt, 1980). Thus, societies with high levels of rape myth acceptance may exhibit high levels of other forms of interpersonal violence as well.

While much of the initial literature on rape cultures focused on the United States, there has been a growth in attention to the rape culture prevalent in South Africa. For example, Gqola recently published a book entitled, 'Rape: A South African nightmare' (2015), which outlines the varied ways in which a rape culture exists in South Africa, as well as numerous rape myths which are prevalent, and how these contribute to the extremely high levels of sexual violence in the country. Gqola attributes a large proportion of this violence to the hegemonic masculinities present in the country, specifically discussing hypermasculinity, as well as current examples of men who continue the legacy of violence, such as Jacob Zuma during his rape trial, and Oscar Pistorius during his murder trial. A further example of the rape culture in South Africa is the practice of 'jackrolling', in which groups of boys and men forcibly abducted women and girls and gang-raped them (Anderson, 1999/2000; Armstrong, 1994; Gqola, 2015). This was reported to have been widespread in certain communities in the 80 s and early 1990s, and while this is no longer commonly reported, the acceptance of the practice and lack of consequences for those perpetrating the rapes has contributed to the present rape culture.

It is difficult to determine the exact rates of sexual violence in South Africa, as it is estimated that anything from one in four to one in nine rapes are reported, and some have argued that 'attempting to quantify the problem is not helpful' (Rasool, Vermaak, Pharoah, Louw \& Stavrou, 2002:4). Whatever the exact figures, the rates are unacceptably high. In addition, over $90 \%$ of rapists go unpunished (Sonke, 2008). While this only relates to one form of GBV, it contributes to the normalisation of violence in South Africa, and the belief that violence is an acceptable way to demonstrate masculinity. 
There are therefore numerous factors which contribute to the high levels of violence in the country today, including the normalisation of violence under Apartheid, income inequality and poverty, and witnessed or experienced violence. However, I argue that these tend to ignore the fact that the vast majority of this violence is perpetrated by men, suggesting that attention needs to be paid to the requirements of masculinities in order to understand why it is specifically men who use violence as a resource. Factors which focus on masculinities include the presence of militarised and hypermasculinities in the country, along with extreme levels of gender inequality, and the existence of a rape culture. While none of these factors alone is able to explain all incidences of GBV, the focus on masculinities and their impact on violence provides us with an important framework in which to begin developing means to address this violence.

\subsection{GBV interventions in SA}

The extremely high levels of gender-based violence in South Africa have led to a wide range of interventions aiming to address the issue in a number of different ways, and these range from national-level activism, legislation and government policies, to local-level and NGO interventions. The predominant focus of these interventions, as also occurs in other countries, tends to be women or children in the aftermath of incidents of GBV, although there have been some attempts at preventative programmes, in the form of media or information campaigns. In order to provide the context in which the case study intervention is being conducted, a number of government and civil society interventions and programmes are briefly discussed. These are not investigated in any great detail in this study, as the intention is to rather provide a sample of what has typically been implemented in the country. This is done merely as a means to highlight the type of interventions and how these differ from those which focus on masculinities, which is the space this study aims to fill.

\subsubsection{Government initiatives}

'Recognising that domestic violence is a serious social evil [and] that there is a high incidence of domestic violence within South African society', the South African government has rolled out a number of different initiatives to attempt to combat gender-based violence, particularly violence against women and children (Constitution of the Republic of South Africa, 1998:Preamble). Primary among these are acts of parliament which aim to address specific aspects of violence against women, such as the Domestic Violence Act, which was enacted in 1998 and aims to provide protection orders to victims of domestic violence; while the Sexual Offences Amendment Act of 2007 is a wide-ranging piece of legislation which was passed to achieve two main objectives. The first was to expand the definitions of rape and sexual assault, while the second was to improve the services available to survivors of sexual offences to minimise secondary traumatisation. Consequently, the definition of rape 
in South Africa is one of the most expansive in the world, covering a range of acts against both men and women, including spousal rape. In addition, a National Council Against Gender Based Violence (NCAGBV) was established in 2012 to 'provide strategic leadership, coordination and management of gender-based violence initiatives in South Africa' (South African Government, http://www.gov.za/issues/violence-against-women-and-children). However, a new Minister of Women was appointed in 2014, and the NCAGBV was not reconstituted after her appointment.

Along with this legislation, a specialised Sexual Offences Court was established in Wynberg, Cape Town in 1993 as a pilot project, aiming to respond to and prevent the 'soaring figures of rape cases that were reported in the area at the time' (Ministerial Advisory Task Team on the Adjudication of Sexual Offence Matters [MATTSO], 2013:17). The court was intended to limit secondary traumatisation of sexual offences survivors by creating a more victimsensitive legal process, and the court also provided a coordinated system among the various actors who deal with sexual offences in order to improve the investigation, prosecution, and conviction of sexual offences cases. For example, the courts provided trial preparation for victims and ensured that they did not come into contact with the accused during the proceedings. The pilot project was a dramatic success, maintaining an $80 \%$ conviction rate in the first year (MATTSO, 2013), and it was therefore decided to roll them out across the country.

However, the courts began facing problems as they were under-funded and over-worked, and many staff members did not receive the recommended training (MATTSO, 2013). Concerns were also raised about the availability of these courts to those not living in regional centres. In 2005, the Minister of Justice and Constitutional Development decided to review the courts and this was 'interpreted to mean that a moratorium was imposed on the further roll-out' of the courts, effectively leading to the suspension of the services of many of the courts (MATTSO, 2013:23). In 2013, MATTSO was established to review the courts, and provide recommendations on their future, with the report recommending that 'the Sexual Offences Courts be re-established in South Africa' (MATTSO, 2013:50). Consequently, there are 55 Sexual Offences Courts in the country, although only about 18 are functional, which seems to be primarily due to a lack of resources, in both staff and facilities for the centres (Mofokeng, 2016). In an interview on a local radio station, Dr Mofokeng (the vice-chair of the Sexual and Reproductive Justice Coalition) attributed this to limited political will to address the issue.

Another strategy implemented by government are the Thuthuzela Care Centres (TTCs), which are one-stop integrated centres operating in public hospitals in communities where the 
incidence of rape is particularly high (United Nations International Children's Emergency Fund [UNICEF], http://www.unicef.org/southafrica/hiv aids 998.html). There are currently about 50 centres in the country, providing medical examination, investigating officers to take a victim's statement, medication, and transport home. Along with this, crisis counselling is provided, and the centres are linked to the Sexual Offences Courts. In line with literature which suggests that providing all services in one place improves the support to victims of GBV (WHO, 2012), the TTCs can help to reduce survivor fall-out during the legal process and improve the likelihood of conviction in cases of rape, sexual or domestic violence.

Alongside these initiatives, an annual 16 Days of Activism Against Violence Against Women and Children takes place, which usually includes events and media campaigns organised by both government and NGOs. However, the events and activities organised by government have been criticised by numerous sources as an attempt to pay superficial 'lip service' to the concept of women's rights and equality. In a 2012 study by GenderLinks and the Medical Research Council (MRC), it was found that many women had never even heard of these campaigns and had little awareness of any legislative protection that they might be entitled to. Similarly, while many of the above-mentioned strategies are seemingly positive moves, actual actions by government officials (or in some cases, the lack of actions) imply less commitment. As noted by Seedat et al. (2009:1019), '[t]here has been a conspicuous absence of government-promoted stewardship and leadership', despite the fact that, 'the value of prevention [of GBV] is nominally recognised' (2009:1017). This suggests that there is limited political will to follow through on strategies to address GBV, with interventions being initiated but then often failing due to lack of support and resources. Government initiatives therefore seem to have done little to stem the rising levels of GBV, and a large number of civil society and non-governments organisations have attempted to step into the gap left by government.

\subsubsection{Non-governmental organisations}

There are numerous organisations which work in the field of GBV in South Africa, utilising a broad range of approaches. Examples of four different kinds of interventions will be discussed below and these are a women-focused reactive intervention, a reactive 'one-stop' centre for children who have been abused, a research NGO, and an 'edutainment' initiative which uses popular culture to discuss themes related to HIV and domestic violence.

Descriptions are provided of each example, followed by a brief discussion of their effectiveness in the context of the literature on GBV interventions. This section therefore explains the context in which the case study intervention works, highlighting the gap which the intervention aims to fulfil. 
The first example is Rape Crisis, a relatively 'traditional' reactive women-focused intervention based in the Western Cape, which primarily aims to provide support to victims after an incident of rape, sexual or domestic violence. It offers services such as individual and group counselling for survivors and their families, as well as 'speak outs', which are opportunities for survivors to tell their stories publicly, either anonymously or by name, which is intended as a means of de-stigmatising rape survivors, and letting other survivors know that they are not alone (Rape Crisis, http://rapecrisis.org.za/). Along with this, Rape Crisis provides assistance during the legal process, such as criminal justice system training and court support. In addition, the organisation carries out advocacy work around sexual offences legislation, the creation of survivor support centres at police stations, and of specialised sexual offences courts.

Rape Crisis also has GBV prevention as an aspect of their strategy and to this end the organisation conducts peer education programmes in schools, and community mobilisation interventions in the areas that they work. The peer education programme involves three main aspects. The first is providing information to youth in schools to dispel common rape myths. The second aspect is training the selected youth to be the support person in schools for those who have been raped. This includes training on how to report the incident to the authorities and where to go for counselling and support. Finally, the peer educators are encouraged to organise activities that will challenge others in the school. The community mobilisation programmes are similar initiatives which take place in the broader community. Locals from that community are trained to become rape counsellors, and the organisation encourages those communities to create safe spaces for women.

As discussed in the previous chapter, reactive programmes have a number of benefits for those who use the services, such as reducing PTSD and depression for survivors. Along with this, support groups and speak-outs can help to challenge the notion of GBV as a private or shameful issue that survivors are alone in having experienced. The challenging of rape myths which Rape Crisis conducts both in schools and the broader community can help to reduce rape myth acceptance in these areas. As noted above, the acceptance of rape myths is linked both to acceptance of interpersonal violence and other forms of 'violent' beliefs, such as racism, sexism, homophobia and religious intolerance (Aosved \& Long, 2006).

The next example is the Teddy Bear Clinic (TTBC), which is also a reactive intervention, but with a more specific focus on child survivors of abuse, aiming to provide a 'one-stop' centre of services, in order to minimise the secondary harm to children and their families when they enter the child protection system. TTBC therefore has a number of different areas of service. 
The first broadly fall under 'Victim Support Services', and these include medical and legal examinations, forensic assessments, psychological assessments, therapeutic counselling and support, and court preparation and support. The intention is to assist children through the entire legal and healing process in the aftermath of abuse or experiences of violence in order to help make the process less traumatising for children, and to minimise the risk of cases being 'lost' in the system (TTBC, http://ttbc.org.za/). TTBC does this by providing access to all services in one place, ensuring that support is easily accessible to those who need it.

As was noted in Chapter Three, interventions which use a multi-sectoral approach and which can provide a wide range of services are generally thought to be more helpful than those which use a single strategy or which only provide one means of support. A guidance note developed by the Department for International Development (DFID) supports this, stating that multi-sectoral approaches, which operate across sectors (such as counselling, legal support, medical support and advocacy work) are the most likely to have an impact (Alexander-Scott, Bell \& Holden, 2015). Thus, TTBC provides an important range of services to children who have been victims of violence or abuse.

The next example is GenderLinks which is primarily a research organisation conducting and producing research on gender equality and GBV. There are a number of goals to this research. The first is to provide a more accurate picture of the current levels of violence in the country, as official statistics are often misleading. Secondly, the research is intended to suggest more effective responses to this violence, both through evaluation of current interventions, and through the development of action plans that can guide policydevelopment. Thirdly, by providing more accurate descriptions of the rates of violence, the research can help to counter harmful stereotypes and rape myths. The research is therefore primarily intended to play a preventative role. Along with this, and in a similar vein to the speak-outs and community mobilisation organised by Rape Crisis, the research produced by GenderLinks makes it more difficult for rape myths to be perpetuated, as the organisation produces research which outlines the reality of the extent of the problem in the country. In this way, GenderLinks can therefore contribute to the shifting of social norms and beliefs around GBV, rape and domestic violence.

The final example is Soul City, a form of 'edutainment', in which issues around HIV and GBV are highlighted through the use of mainstream media, including a television and radio series, and mass distribution of booklets. The primary aim behind the campaign is to reach as broad an audience as possible with positive messages around HIV and GBV. Through this, Soul City can potentially have an impact on norms in the broader community, which can help to 
start shifting these norms to more positive or productive attitudes. To this end, Soul City specifically targets IPV and violence against women in the hopes of shifting 'rigid ideas of masculinity' (Alexander-Scott, Bell \& Holden, 2016:33). The campaign also encourages widespread conversation around issues such as GBV, and provides information on ways to both seek and provide support by modelling specific behaviours which viewers can use. These include phoning a helpline and bringing attention to instances of spousal abuse by neighbours banging pots and pans in protest when they hear of these cases. Soul City is therefore intended primarily as a preventative intervention.

While awareness campaigns have been criticised, the Soul City campaign has been evaluated in a number of sources, and has been found to have a relatively positive impact. $A$ study by Usdin, Scheepers, Goldstein and Japhet (2005) established that exposure to the television series had positive benefits in knowledge, attitudes and behaviour. In terms of knowledge, having watched the television series increased knowledge of where to find support for domestic violence, and of women's rights. With regard to attitudes, exposure to the series was correlated with a shift to being less likely to believe that domestic violence is a private affair, and to enabling women to make decisions around their health and wellbeing. For behaviour, having seen or heard about the series was associated with supportseeking behaviour around domestic violence. In addition to this, Alexander-Scott et al. (2005) found that the modelling of specific behaviours helped communities respond to GBV more often, as it gave them something concrete to do, rather than simply suggesting that they 'do something'. The study found a consistent association between exposure to Soul City and both support-seeking and support-giving. In other words, people were more likely to call the helpline, or to do something concrete to stop domestic violence. The Soul City edutainment initiative therefore seems to have had a relatively positive impact in communities where it is broadcast.

The list of interventions described above is by no means exhaustive, and is intended more as a review of the types of interventions which are generally being implemented in the country. This section therefore provides the context in which the case study intervention is being implemented.

\subsection{Conclusion}

South Africa as a country experiences extremely high levels of GBV, levels which are often described as being some of the highest in the world outside of conflict zones. In order to try and understand this, a wide variety of reasons for the extremely high rates of GBV in South Africa were outlined above, a number of which focused on the system of Apartheid and its lingering effects. These included the normalisation of violence which occurred under 
Apartheid, income inequality, witnessed or experienced violence, gender inequality, and the presence of a rape culture. In particular, South Africa's history has contributed to the development of versions of hegemonic masculinity in the country which expect or require violence from men in order to be achieved, and I suggest that this is an important driving force behind the levels of violence which the country is experiencing. While government has done much in terms of legislation to empower women, this seems to translate to minimal improvements in the day to day life of many women. Thus, despite significant rhetoric, it does not seem as if the South African government takes the issue very seriously.

Due to this perceived failure on the part of government, many non-government organisations are also working in this field, predominantly focusing on providing support to female survivors who have experienced violence. Despite the importance of these interventions as a means of support for survivors, their efforts do not seem to have contributed much to reducing these rates of violence thus far. This could be partly explained by the fact that they are focusing on the wrong 'end' of the issue - the survivors, rather than the perpetrators.

Thus, 'spurred by the recognition that men's attitudes and behaviors can either impede or promote sexual and reproductive health... organizations across the world have launched initiatives to encourage positive male involvement' (Ditlopo et al., 2007:4). 'In other words, if the problem lies with male behaviour then men and boys need to be engaged' (Ricardo \& Verani, 2010:12). The literature on re-socialisation interventions described in Chapter 3 suggests that working with men to problematize gender norms and encourage the development of less-violent alternatives is one important way in which working with men can happen. One such example, Sonke Gender Justice, has been used as a case study for this research, and will be outlined in more detail in the following chapter. 


\section{CHAPTER 5}

\section{SONKE GENDER JUSTICE AND ‘ONE MAN CAN’: A CASE STUDY OF A MASCULINITIES-FOCUSED INERVENTION}

\subsection{Introduction}

As indicated in the previous chapter, South Africa is a country with extremely high levels of GBV, which has resulted in a wide range of interventions being implemented to address this. Many of these have focused on women and on survivors of violence, and while the interventions have provided important supportive resources for these survivors, the rates of GBV in the country have remained incredibly high. As a result, some organisations have begun to focus more on men as a means of reducing the rates of GBV, in recognition of the fact that certain versions of masculinities tend to encourage and fuel GBV. Hence, problematizing masculinities in an effort to prevent GBV is considered an important way to address the root of the problem.

For this reason, a specific masculinities-focused intervention being implemented in South Africa has been chosen as a case study. This is the One Man Can (OMC) programme, implemented by Sonke Gender Justice (Sonke, previously known as Sonke Gender Justice Network), a South African NGO. Accordingly, this chapter describes Phase One of the case study, which involved a desk top review of both OMC and Sonke, including the reasons for their having been chosen as a case study. The description includes the theoretical background and aims of the organisation, as well as an evaluation of the effectiveness of both Sonke and the OMC programme. This chapter is based on an evaluation of both primary and secondary sources and acts as the backdrop to the discussion and findings outlined in later chapters. Phase Two of the case study involved my own fieldwork on the organisation, and this is described in more detail in Chapters Six and Seven.

As a preliminary note, while there have been some masculinities-focused interventions implemented in South Africa in the past, it has been frustratingly difficult to try find up-to-date information on these interventions. This includes information on whether they are still running, who is currently implementing them, or why they are no longer being implemented if this is the case. Online searches of organisation's webpages often yielded little information on whether programmes were still running, while programmes that are no longer being implemented are still listed on webpages as current interventions. In cases where interventions are not being implemented, it is often difficult to find information on why this is the case. In a number of instances, the only way I was able to find this information was through interviews with NGO practitioners. This section therefore provides as complete a 
picture as I was able to gather of the masculinities-focused interventions which acted as precursors to OMC, and the development of the OMC intervention implemented by Sonke.

\subsection{Sonke Gender Justice}

I chose to use Sonke and the OMC intervention as a case study for two primary reasons. The first is that Sonke is one of the only NGOs in South Africa that is currently running workshops that focus specifically on men and masculinities as a means of GBV prevention. Secondly, the intervention has already been evaluated by a number of authors, meaning there is literature available on its implementation in different settings. Both of these aspects are discussed in more detail below.

As noted above, it is very difficult to find information on whether or not other organisations are currently implementing masculinities-focused interventions. Thus, as far as I could establish, $\mathrm{OMC}$ is one of very few which are active at this point in time. Despite this, it was not the first such intervention in the country, as a number of other NGOs initially developed and implemented masculinities-focused interventions, but it seems that few of these are still running. The exact reasons for interventions no longer running are difficult to come by, as organisation websites tend to list programmes that have been implemented in the past, without indicating whether or not they are currently operational. As an example, the Stepping Stones programme, discussed in detail in Chapter Three, was implemented and yielded numerous positive evaluations, yet even this programme no longer seems to be running. After an extensive online search and conversations with practitioners at different NGOs, I was unable to find information on any organisations that are currently running it in South Africa. In a telephone discussion, one of the evaluators was also unsure if any organisations are currently implementing the programme. Thus, the primary reason for using Sonke as a case study was practical, as finding information on existing masculinities-focused interventions was very difficult, and Sonke and the OMC programmes are one of the only examples I was able to find up-to-date information about.

Another reason for using $\mathrm{OMC}$ as a case study is that there are already numerous evaluations that have been conducted on the programme, covering its implementation in a number of different settings. This means that there is a fair amount of literature available on the intervention, providing quite a broad framework in which to situate future work.

Evaluations of the workshops have been conducted in South Africa (by Dworkin et al., 2012; Dworkin, Hatcher, Colvin \& Peacock, 2013; and Viitanen \& Colvin, 2015) and the Ivory Coast (Hossain et al., 2014), and these evaluations are discussed in more detail after the OMC intervention is described in the following section. However, to date the evaluations have 
been predominantly quantitative, and looked at self-reported attitude and behaviour changes. Thus, as noted in one evaluation:

'the evidence base for precisely how health interventions encourage men to shift masculinities and how men embrace and contest this work in health programs is limited... Evidence from existing health programs with men is limited to a handful of recent interventions... In addition, the available studies tend to be quantitative and with limited exceptions... .little is known qualitatively about what a process of change within health programs looks like.' (Dworkin, Hatcher, Colvin \& Peacock, 2013:184).

In other words, despite a fair amount of literature already available on this intervention, what is lacking is an understanding of which aspects make an impact, and why this is the case. I attempt to fill this void in the following chapters, but first it is necessary to reflect on the existing literature on Sonke and the OMC programme.

\subsubsection{Sonke Gender Justice as an organisation}

Sonke Gender Justice began in 2006 with the intention of 'reducing violence against women, reducing HIV/AIDS risks for both women and men and promoting more gender-equitable relationships' (Dworkin et al., 2012:101). While Sonke primarily focuses on working with men in order to achieve this, the organisation identifies itself as 'a feminist organisation working to advance women's rights and to challenge destructive models of masculinity' (Peacock, 2013:129). By specifically identifying as feminist, and mentioning 'models of masculinity', Sonke's programmes explicitly frame masculinity as socially constructed, and as context and time-specific (Dworkin et al., 2013:187). In other words, there is recognition of the fact that masculinities are not inherent, but rather created through socialisation, meaning that the programmes and organisation as a whole aim to be gender-transformative (Dworkin et al., 2012).

In order to achieve its stated aims, Sonke runs a wide range of programmes which include three major aspects: a) community education and mobilisation (CEM); b) policy development and advocacy (PDA); and c) research, monitoring and evaluation (RME) (Sonke Gender Justice Vision and Mission, 2015). As little has been published on this, the information provided below is drawn mainly from their website, unless otherwise indicated. While all aspects contribute to the multi-sectoral nature of Sonke's interventions, the community education and mobilisation is described in most detail as this is the programme under which the OMC intervention falls.

\subsubsection{Community education and mobilisation (CEM)}

The community education and mobilisation (CEM) strategies cover a wide range of activities and programmes. These include facilitated workshops (such as $\mathrm{OMC}$ ), community action 
teams (CATs), seminars, and awareness-raising campaigns (Sonke Gender Justice, 2006). The topics for these include gender equality, GBV, HIV/AIDS and safe sex. Ultimately, CEM initiatives aim to provide the information, training and resources necessary to enable community members to plan and implement activities themselves. In this way, the intention is for community members to as far as possible take ownership of the process of reducing GBV and HIV/AIDS infections in their communities. The reason for this is that community ownership has been noted as one of the most effective ways of creating sustainable and lasting change, because it enables community members to feel a sense of ownership of an intervention, which means that they are more likely to try and ensure it continues to run in the future (Ellsberg et al., 2015). A primary means of creating this sense of ownership is to encourage community members to take over the organisation and implementation of interventions, and for them to run it as far as possible. Another reason for encouraging community ownership was outlined by Petitfor et al. (2015), who found that combining group education with community mobilisation may be more effective in changing norms and risk behaviours than group education alone. Thus, community ownership and mobilisation can improve the impact of education initiatives.

There are numerous workshops which fall into Sonke's CEM programme, and these include the OMC intervention, the Tsima Treatment Prevention Organisation, and the Prisons Transformation Project. The OMC intervention will be discussed in more detail below, but the other two are only briefly described here. A number of the other workshops incorporate aspects and activities which are used in the OMC intervention, and these are described more fully when OMC is discussed in the following section. Thus, this section is intended more as an overview of the range of programmes under the CEM heading, rather than an indepth discussion of these programmes.

The Tsima Treatment Prevention Organisation is an intervention in the Bushbuckridge area of Mpumalanga, intended as a three-year intervention which aims to teach communities about HIVIAIDS, and specifically to 'activate treatment as prevention' (Sonke Gender Justice, 2015:4). The programme focuses on the knowledge that being on HIV treatment, such as ARVs, can drastically reduce the risk of an HIV positive person infecting an HIV negative partner. Thus, the programme encourages community members to get tested and know their status, and to start taking ARVs if they are HIV positive, in order to avoid infecting their partner. The programme began in 2015 through a partnership between Sonke and a number of other agencies, including University of Witswatersrand, Right to Care, and Population Council. The intention of the project is to increase the number of people who are aware of their HIV status and who are on ARVs. This can help to reduce the rate of infection in this area; thus, the intervention is intended as an HIV prevention mechanism. 
The programme consists of two aspects. The first is training community members to become 'community mobilisers' or educators, with these 'mobilisers' then training and educating others in the community about HIV and AIDS. The second aspect is the training of Community Action Teams (CATs) through two-day workshops, facilitated by community mobilisers, which focus on aspects around gender, power and HIV. Once these workshops are completed, CAT members assist in community mobilisation and education. A number of the workshop activities and the use of CATs to keep workshop participants engaged in community mobilisation are aspects used in the OMC workshops as well, and will therefore be discussed in more detail below. Because the project is still in its early stages, no evaluations are available on the results as yet.

The Prisons and Transformation Project aims to educate correctional officials and inmates around sexual violence and HIV, in order to reduce the rates of rape and HIV infection within prisons. There are two aspects to this project: community education and mobilisation, and policy development and advocacy. The community education aspect involves the implementation of the OMC campaign in correctional service centres in the Western Cape, and with former inmates once they have been released. Inside prisons, the programme aims to train prison officials and inmate peer educators about HIV, STIs and TB. This includes information on how to reduce the risk of these diseases spreading, how to encourage HIV testing, and how to improve access to HIV prevention services. In addition, the programme aims to train Department of Correctional Services (DCS) officials to address sexual abuse. Sexual abuse in prisons contributes to high rates of HIV both within the facility and in communities when inmates are released (Ghanotakis, Bruins, Peacock, Redpath \& Swart, 2007), and Sonke therefore produces training manuals and information pamphlets to assist DCS officials in addressing sexual abuse.

Along with this, Sonke implements a Beyond the Bars CAT, which helps former inmates return to life outside of prison, consisting of a group of former inmates who meet once every second week for a support group, facilitated by a Sonke staff member. The format of these groups seems to be relatively fluid, with members discussing issues ranging from difficulties gaining employment to the stigma they face in communities as ex-inmates. These groups therefore provide a source of peer support for former inmates.

While these are not all the activities under the CEM branch at Sonke, these projects focus on similar issues to the OMC intervention, including masculinities, gender, HIV/AIDS, safe sex, and power dynamics. As much as possible, community members begin to take ownership of these interventions at an early stage, and implement them in their own communities which contributes to the effectiveness and sustainability of the interventions. 


\subsubsection{Policy development and advocacy (PDA)}

While the focus of this research is primarily on the CEM aspect of Sonke's work, the following sections will briefly discuss a number of the other programmes that the organisation carries out. As noted in previous chapters, multi-sectoral and multi-level interventions have a bigger and longer-lasting impact, suggesting that the additional programmes that Sonke runs can also play a role in sustaining the impacts of the interventions, and in creating broader community-wide change.

The policy development and advocacy (PDA) programme aims to 'shape South African and international legal and policy decisions on gender equality, gender-based violence, sexual and reproductive health and rights' (Sonke Gender Justice, n.d.), as part of Sonke's larger strategy to begin shifting harmful societal norms. There are numerous areas of focus for this, including gender equality and sexual and reproductive health, but the overarching theme relates to sexual violence. There are a number of aspects to this, and each of these will be elaborated on in more detail below. These aspects are the decriminalisation of sex work, prisons transformation, monitoring the implementation of the Sexual Offences Act, the Shukumisa campaign, a campaign to demand that the South African government develops a National Strategic Plan to combat GBV, and the gender transformation of the judiciary. As a whole, these programmes aim to enable institutions to prevent and respond to sexual violence more effectively than they are currently doing.

Many sex workers experience extremely high levels of violence in the workplace, and legal frameworks which criminalise sex work 'have been shown to greatly increase sex workers' vulnerability to violence and illness, while reducing the likelihood that abuse will be reported' (Sonke Gender Justice, n.d.). In South Africa, all aspects of sex work are criminalised, and Sonke and other organisations have campaigned to have these decriminalised. In addition to this, the programme aims to reduce the stigma around sex work, sex workers and sex worker clients, through the dissemination of more positive media regarding these groups. This aspect of the programme therefore aims to help prevent and reduce GBV against sex workers, as part of the broader strategy to lower levels of GBV in the country. Although sex workers represent only one of the many groups of women who experience GBV, they are often on the receiving end of much higher rates of violence than other women, suggesting that an improvement in their rights and protection could result in a much broader shift in norms relating to GBV and how acceptable it is seen to be. In other words, if people are willing to extend protection to sex workers and view violence against sex workers as criminal, they are more likely to extend these same views and protection to all women. 
The work on prisons transformation is an aspect of both the CEM and the PDA units' work, and the CEM branch of this has been described above. To expand the impact of the CEM unit's work, the PDA unit advocates for law and policy reform around sexual abuse, HIV and TB prevention, broader definitions of prisoner rights violations, and strengthening independent oversight and accountability mechanisms for prisons. The first aim is therefore to achieve a decrease in the number of inmates who experience sexual abuse, and contract HIV and TB. Secondly, the programme hopes to improve the oversight and accountability mechanisms of the DCS and government, to ensure that they are held accountable for preventing these issues in prisons. Thus, this programme also has a preventative focus with an emphasis on reducing the incidence of GBV, HIV and TB through the development of more effective policies and accountability mechanisms for those in charge of prisons.

The final four aspects of the PDA unit are closely related, and predominantly focus on the enactment and implementation of legislation relating to sexual violence and GBV. The intention is to lobby for the passing of new legislation, and to monitor the implementation of existing legislation, to ensure that sufficient protection is being provided to survivors of sexual violence and GBV. One of the key focus areas is the Sexual Offences Amendment Act 32 of 2007, which created very broad definitions of sex crimes, and ensures access to post-exposure prophylaxis for rape survivors. To this end, Sonke and a number of other organisations created the Shukumisa campaign which monitors implementation of the Act. This entails monitoring police stations, courts and hospitals to ensure that the terms laid out in the Act are followed, and after each round of monitoring, Shukumisa compiles the results into a report, which is submitted to the SAPS, the DJCD, and the DoH. The next aspect to this is a campaign to demand that government draft and enact a National Strategic Plan to combat GBV. Finally, Sonke advocates for gender transformation of the judiciary.

These aspects all aim to create norms and standards in the country which try to reduce the levels of sexual and GBV (SGBV). By changing the way that the police, courts and hospitals respond to survivors of violence, the campaign strives to reduce the secondary trauma that survivors often experience in the judicial system, which can contribute to an increase in reporting of instances of sexual violence. These aspects are therefore primarily reactive as they aim to improve the way that GBV is responded to by different institutions in the country. However, it could also be considered a preventative campaign in that shifting the norms and standards around GBV in the country could help to reduce the notion that GBV is acceptable, and therefore hopefully begin to lower the rates of this violence in South Africa. The final advocacy aspect relates to gender transformation of the judiciary. This entails both the appointment of more women judges to the bench, and a commitment by all judges to the 
principle of gender equality. To this end, Sonke engages with the South African Judicial Education Institute to understand what training judges receive in relation to gender issues and sexual offences, and works to understand what structural barriers impede women's progress in the legal profession (Sonke Gender Justice, n.d.). By improving the way that the judicial system responds to GBV, the aim is to improve the conviction and sentencing rates of perpetrators of GBV, which may begin to change the levels of acceptance of GBV in communities. The more strictly it is policed, and the less easy it is to get away with, the less of a reward it becomes, and this will hopefully reduce the incidence of GBV in the country. In addition, it is hoped that appointing more female judges to the bench will result in rulings which are more sympathetic to female survivors of GBV, which can in turn help to encourage more survivors to come forward and lay charges.

The PDA unit's activities therefore target the broader cultural and societal norms in the country that encourage or condone GBV, predominantly as a means of preventing future incidents of GBV. By improving both the content and enforcement of the legislation relating to GBV, it is hoped that these initiatives will reduce the incidence of this kind of violence, and improve the service and support for survivors.

\subsubsection{Research, monitoring and evaluation (RME)}

The RME unit aims to measure the effectiveness and impact of Sonke's programmes in order to expand and strengthen the evidence base on gender-transformative practice and policy, so that more effective interventions can be designed to improve the impact and scale of work. Thus, there is continuous evaluation of Sonke's own programmes, as well as collaboration on research on the work of others. This research then contributes to the global evidence base on the effectiveness of these interventions, as elaborated on below. In addition to research on South African programmes, Sonke contributes to a number of global research initiatives, two of which are described below. Once again, the intention behind this is to broaden the knowledge base on interventions and programmes which try to reduce GBV, often through interventions which focus specifically on men. The two projects are the What Works to Prevent Violence Against Women and Girls (VAWG) Global Programme (What Works); and the International Men and Gender Equality Survey (IMAGES). These two research initiatives are described here as a means of highlighting the range of Sonke's work, but also because they contributed to the body of knowledge around preventing GBV which informed Sonke's development of the OMC intervention. Thus, some information is provided on the content of these research initiatives.

What Works conducts research to evaluate what the most effective strategies are for preventing VAWG (What Works, 2014). The consortium has five-year funding from DFID, 
and has thus far produced a number of initial surveys of the current state of VAWG prevention. Four reviews have been published: one outlines the state of research in the field of preventing VAWG (Fulu \& Heise, 2015); a second looks at the effectiveness of current interventions which aim to reduce VAWG (Fulu \& Kerr-Wilson, 2015); the third assesses the value for money and opportunities for scaling up of current interventions to prevent VAWG (Remme, Michaels-Igbokwe \& Watts, 2015); and the final review assesses the effectiveness of current response mechanisms to prevent VAWG (Jewkes, McLean Hilker, Khan, Fulu, Busiello \& Fraser, 2015).

The review outlining the current research on violence against women echoes much of the literature discussed in previous chapters. The review confirms that IPV and non-partner sexual violence are significant problems worldwide (Fulu \& Heise, 2015), and supports the research on the factors at an individual level which contribute to these forms of violence. These factors are violence experienced in childhood, gender unequal attitudes and norms, alcohol use, and harmful notions of masculinity. However, there is less research available on which community and societal level factors impact on violence and on men's perpetration of violence, as the focus tends to be on women's victimisation. In addition, the review suggests more research on what helps to promote resilience in individuals, an aspect which is mentioned in evaluations of the Sonke programmes discussed below.

The next What Works review outlines which aspects tend to contribute to the creation of interventions which effectively target VAWG, and suggests that there is fair evidence that the following programme types show positive impacts (Fulu \& Kerr-Wilson, 2015). The first is relationship-level interventions (such as Stepping Stones), the second is interventions which combine microfinance with gender-transformative approaches (such as IMAGE), and the third is community mobilisation interventions which aim to change social norms (such as OMC). Stepping Stones and IMAGE were both described in Chapter Three, while the OMC intervention will be discussed in the following section. Thus, this section aims to highlight the findings relating to these interventions, rather than repeating detailed descriptions of them.

Relationship-level interventions are those which focus on relationship and communication skills in order to reduce IPV and HIV infection. Similar to Stepping Stones, this is done through workshops which have an emphasis on participatory learning through the use of drama and role plays. Fulu and Kerr-Wilson (2015) report that this resulted in a $38 \%$ decrease in men's reports of IPV perpetration after 24 months. In an intervention such as IMAGE, participants become part of microfinance interventions, which are 'group-based approaches to savings and lending to women normally excluded from formal banking/loan systems' (Fulu \& Kerr-Wilson, 2015:12). Along with this, participants receive psychosocial 
support, and are involved in women-only gender discussion groups. In this regard, the Fulu and Kerr-Wilson report showed that the IMAGE intervention resulted in a 55\% reduction in women's experience of physical and/or sexual IPV. Finally, community mobilisation interventions which aim to change social norms, such as OMC, can also play a role in reducing IPV. However, programmes which only consist of a single component (such as a strictly educational campaign) are less effective, leading the report to recommend multicomponent programmes (Fulu \& Kerr-Wilson, 2015).

The review evaluating the cost-effectiveness of existing interventions to prevent VAWG found that there are very few reports available which provide information on this (Remme, Michaels-Igbokwe \& Watts, 2015). While some outline the cost of a specific project, very few looked at the costs of the problem the programmes targeted. For example, a report would provide information on the cost of a VAWG intervention without looking at the societal and economic cost of VAWG to both society and individuals. Alternatively, the cost of a programme would be noted without comparing it to other forms of intervention, meaning there was no evaluation of whether the existing intervention was the most cost-effective way of responding to the issue of VAWG. Thus, the cost-effectiveness of interventions is difficult to determine, and this is an area which needs additional research to provide a more complete picture of what can make VAWG programmes more cost-effective.

The final What Works review focuses on the effectiveness of current response mechanisms to VAWG, which includes responses from the police and criminal justice system, health system or social sector. The review focused on whether these interventions were effective in preventing VAWG (Jewkes et al., 2015), and found that the only responses which have sufficient evidence to recommend them are protection orders and shelters. All other policies reviewed, such as community policing, women's police stations, specialised courts, violence hotlines, sexual offender policies, and single complement communications campaigns show either insufficient evidence to recommend them, or the evidence available is conflicting. Thus, as the review states, 'there is potential for some... response mechanisms to prevent violence occurrence, but prevention interventions have not yet been fully optimized and further work is required to improve our approaches' (Jewkes et al., 2015:4).

The information contained in the above-mentioned reviews therefore confirms much of what was discussed in Chapter Three around the causes of GBV and IPV, and of ways to attempt to prevent it. Thus, witnessed or experienced abuse, substance abuse, unequal gender norms and attitudes, and harmful masculinities contribute to IPV to a large extent, while multi-sectoral preventative interventions are more effective at reducing GBV than singlecomponent interventions or those which are predominantly reactive. Sonke's programmes 
are therefore relatively in line with this research, in that they use multiple strategies and a multi-sectoral approach in a preventative capacity, through community mobilisation, advocacy, and education. This suggests that their interventions should have a positive impact on GBV levels in the country.

An additional international research collaboration which Sonke is involved in is the IMAGES programme, a 'comprehensive household questionnaire on men's attitudes and practices along with women's opinions and reports of men's practices - on a wide variety of topics related to gender equality' (Barker et al., 2011:7). The survey has been carried out in a number of countries worldwide, including Brazil, Chile, Croatia, India and Mexico, while Sonke has assisted in conducting the survey in the DRC, Rwanda, Mali, Malawi and Mozambique. As noted by Barker et al., the overall aim of IMAGES is to 'build understanding of men's practices and attitudes related to gender equality in order to inform, drive and monitor policy development to promote gender equality' (2011:11). In other words, IMAGES strives to create a more realistic portrait of masculinities in different regions, in order to develop better policy and responses with regards to improving gender equality. The issues covered in the survey include gender equality, work-related stress, division of household labour, parenting, mental and emotional wellbeing, use of violence, risky sexual practices, and knowledge of and attitudes about gender equality legislation.

In a number of instances, the IMAGES results have confirmed accepted aspects of hegemonic masculinities, with the results from Brazil, Chile, Croatia and Mexico showing that there is a widespread belief that being a man means being a provider, that men's reported alcohol use is higher than women's, that men have lower HIV testing rates than women, and that men are more likely to experience violence outside the home than women (Barker et al., 2011). In addition, attitudes towards gender influenced men's behaviour in numerous ways, in that gender inequitable attitudes were linked to perpetration of violence, regular alcohol abuse, reported sexual violence against a partner, suicidal behaviour and depression, and involvement in crime (Barker et al., 2011). However, the survey also found that certain factors tended to moderate gender inequitable beliefs. Married men seemed to have more equitable attitudes, and those with higher education levels believed more strongly in gender equality, although this was relatively one-sided: when asked about their contribution to household tasks, men's self-reporting of their involvement was higher than that reported by the women (Barker et al., 2011). Despite this, women did not report high levels of dissatisfaction with the situation, suggesting that they believed that the division of labour was 'correct'. 
In the survey conducted by Sonke in the DRC, the post-conflict environment combines with gender inequitable attitudes to contribute to violence in a number of ways. For example, the percentage of men who never have the means to sustain their family has almost doubled in the post-conflict period compared to pre-conflict (38.5\% pre-conflict, versus $71.1 \%$ postconflict). This led to intense feelings of shame for men - up to $75 \%$ were ashamed to face their families because they could not provide basic financial needs, which led to feelings of emasculation (Slegh, Barker, Ruratotoye \& Shand, 2012). Levels of violence and sexual violence were high, with almost $22 \%$ of women and $9 \%$ of men reporting having been raped, while $48 \%$ of men report having used physical violence against a partner, although this number was lower for men who had not been forced to leave their homes during the conflict (37.3\%). However, in both instances the percentage of men who report using physical violence against a partner is lower than that of women who report having experienced violence by a partner (52\%).

The survey also showed that gender inequitable attitudes were common in the country, but that this had already been the case prior to the conflict. For example, men who had seen their fathers use violence were more likely to use it themselves, and while more than half of women reported being exposed to some form of sexual violence, the majority of this occurred outside of the conflict. Attitudes were generally conservative: almost $75 \%$ of men believe that women who don't dress 'decently' are asking to be raped, and $62 \%$ believe that sometimes women deserve to be beaten. In addition, sexual violence had long-lasting effects beyond just the physical - women who had been raped frequently reported being rejected by their families and partners, while men reported feelings of helplessness for not being able to protect their families and property. 'Men and women frequently spoke of men's self-esteem loss and sense of lost "manhood"' (Slegh et al., 2012:6), suggesting that the violence taking place in the country left men feeling emasculated in many instances, potentially increasing their likelihood of turning to violence themselves.

The IMAGES results therefore provide an overview of the hegemonic masculinities present in these regions, and create some insight into attitudes promoting or maintaining gender inequality. These results can help to plan and implement interventions which effectively target these masculinities as a means of GBV reduction. Sonke's involvement in global research initiatives such as IMAGE and the What Works reviews contributes to the creation of a body of knowledge on interventions which are attempting to reduce GBV, as well as suggesting direction for future interventions and policy. These include masculinities-focused interventions, as well as those which focus more specifically on survivors of violence. The intention behind this research is therefore to create an evidence base from which to 
generate more effective interventions, and this evidence base helps to inform the decisions taken by Sonke in terms of the development of their own strategies.

This section has provided an overview of the different aspects of Sonke's work, all of which contribute to their efforts at implementing a multi-sectoral strategy to address and help reduce GBV in the country. This includes a wide range of activities and programmes, from community mobilisation to advocacy and research. In this way, Sonke hopes to assist in shifting the societal norms relating to GBV and gender equality, making GBV less acceptable and gender equality more of a reality, in order to begin lowering rates of GBV in South Africa. This section has therefore outlined the framework of preventative strategies in which the OMC intervention is situated.

\subsection{OMC as a case study}

This section focuses in more detail on the OMC programme, beginning with an explanation of the structure and content of the intervention, along with its theoretical background and how it was developed, before moving on to look at OMC in the context of the literature surrounding masculinities-focused interventions, including existing evaluations of the programme. This provides the framework for my own research by detailing what is already available in terms of knowledge regarding the programme, as well as highlighting some gaps in the literature which this research hopes to help fill.

The OMC campaign is part of the community education and mobilisation (CEM) branch of Sonke's work, whose primary activity is a series of OMC workshops. The campaign 'encourages men to become actively involved in advocating for gender equality, preventing gender-based violence (GBV), and responding to HIV and AIDS' (Sonke Gender Justice, 2006, http://www.genderjustice.org.za/news-item/one-man-can/). In order to achieve this, it uses a 'human rights framework and masculinities-based approach to promote gender equality' (Viitanen \& Colvin, 2015:3). A primary aim is to enable participants to carry out the bulk of the mobilisation and education work in their own communities and to this end, workshop participants are often trained to become peer educators, and are supported in conducting awareness-raising activities.

\subsubsection{Outline of workshops}

The first aspect of the campaign is a series of workshops in which groups of participants take part in a range of activities focusing on different topics, with the activities then facilitating discussions on the selected topics. These topics are gender, power and health; gender and violence; gender, sex and HIV/AIDS; healthy relationships; and ways for participants to remain involved in the organisation and carry out community mobilisation. The workshops aim to provide, "safe' spaces for discussion and critical reflection on the topics of 
gender, human rights, women's rights, and masculinities' (Viitanen \& Colvin, 2015:3), and are designed to be gender-transformative by problematising gender and gender norms, and discussing issues around gender equality and power differentials in communities. In addition, the content focuses on the harm that hegemonic masculinities can cause, to both the men enacting them, and to other people in their lives (Dworkin et al., 2013; Peacock, 2013). In order to standardise the workshops, Sonke has developed an OMC manual which lists 19 activities, the materials required for each, how long each activity will take, and which topic the activity focuses on (Sonke Gender Justice Network, 2008). Facilitators can carry out all the activities listed if there is sufficient time, or choose a few that focus on a specific topic if time is limited.

The workshops are 'intended to encourage men to reflect on their own attitudes and values about gender, women, domestic and sexual violence, HIV/AIDS, democracy and human rights' (Sonke Gender Justice Network, 2008), and while the manual explains that the intervention is geared towards work with men, the workshops do not necessarily need to be men-only, with many of the activities being effective in mixed-gender groups as well. The workshops are voluntary, meaning that participants are not required to attend, (as they would be in a BIP or drug rehab), and are usually conducted at Sonke facilities in predominantly urban areas, although they can be provided to other organisations on request. The workshops are flexible in format and can run for anything from one to five days, depending on which and how many topics the workshop is intended to cover, and how much time is available. Thus, a workshop could cover all the aspects listed above over a number of days, or focus only on the activities relating to safe sex and HIV in a one-day workshop.

The manual does not prescribe a number of participants for the workshop, and I observed workshops ranging from four participants up to 28 , with the number of facilitators depending on how many participants attend. Smaller groups can use one facilitator, while larger groups may need two or three. Facilitators tend to be men who come from the community in which the workshops are taking place, although this is not always the case. The rationale behind using local facilitators is that they have a better understanding of issues that are relevant to those communities, and are more invested in helping to improve those communities. Thus, as noted in the OMC manual, 'men and boys do worry about the safety of women and girls ... and want to play a role in creating a safe and more just world ... materials provided here will help men to take action in their own lives and in their communities' (Sonke Gender Justice Network, 2008:4-5). In some cases, the result of men attending the workshops and wanting to take action to help their communities is that workshop participants have remained involved in the organisation and gone on to become workshop facilitators after receiving training. 
Participants are asked to identify issues that they feel are relevant in their communities and at the end of the workshops, participants are divided into teams and asked to draw up specific action plans to address these. The intention is for participants to remain involved in Sonke, and in community mobilisation and education through Community Action Teams (CATs) (Viitanen \& Colvin, 2015). These CATs are made up of groups of participants who live in the area, and who remain aligned with Sonke, carrying out community education in their communities. In some cases, participants later become workshop facilitators themselves after working in the CATs for some time.

\section{$\underline{\text { 5.3.2 Examples of activities }}$}

While the manual includes 19 activities, I describe two particular activities in more detail as they were mentioned most often in my interviews as having the biggest impact on participants, a view that was shared by both facilitators and participants. More detail on why these activities were so powerful for individuals will be given in the Findings chapter. The descriptions are taken both from the workshop manual, and from my participant observation of the workshops.

One activity is called the 'Gender Fishbowl', which can be especially effective when used in mixed-gender groups. In it, firstly all the men sit in a circle, with all the women sitting in a larger circle around them. The facilitator then asks the men questions, often along the lines of 'What is the most difficult part about being a man?' or 'What do you wish women understood better about men?' While the men are answering, the women are not allowed to speak or respond. Once the questions have been completed, the groups switch places, with the women now sitting in the centre, and the men sitting around the outside. The process is then repeated, with the women now answering questions, and the men not allowed to speak. Because each group has to remain silent during the other's conversation, this activity forces groups to listen to the other in a way which may not happen in normal daily interactions.

Another powerful activity is called Gender Values Clarification, in which corners of the room are labelled with 'Agree', 'Strongly Agree', 'Disagree', and 'Strongly Disagree'. Participants gather in the middle of the room, and statements are read out one at a time, with participants then moving to the corner of the room which corresponds with how strongly they agree or disagree with the statements. The floor is then opened for discussion on the topic, and participants can attempt to convince others to move to their corner, resulting in lively (or heated) debate. Statements discussed include 'Gender is always related to sexuality'; 'Men should always pay for a meal'; and 'Jealousy in a relationship can be a good thing'. This activity can be powerful for two primary reasons. The first is that it encourages participants to explicitly explain their viewpoint on a certain aspect, and it may be the first time they will be 
challenged on it. Secondly, participants can hear the rebuttal to their view explained in similarly clear language, which may convince them to reassess their own opinion.

\subsubsection{Background to the workshop}

The OMC workshop activities were drawn from three main sources: the first is a manual developed by Planned Parenthood Association of South Africa (PPASA) and EngenderHealth for the Men as Partners programme (MAP). The second is the 'From Violence to Peaceful Co-existence' manual developed by Instituto Promundo's Project H, for work with men in Brazil. The third source is the "Manual for men working with men on gender, sexuality, violence and health", developed by MASVAW in India (Sonke Gender Justice, n.d.:5). Each of these will be discussed in more detail below.

The MAP programme was in some ways a precursor to OMC. It was implemented in South Africa by EngenderHealth and PPASA in 1996 and ran until the early 2000s, but is no longer being run, although I was unable to find reasons for the suspension of the programme. The format of MAP was similar to OMC, in the use of workshops, the workshop activities, and community mobilisation through CATs, and the intervention in South Africa produced some positive results. For example, Peacock and Levack (2004) found that workshop participants' knowledge around HIV tended to increase through the workshops, and that this was accompanied by a number of positive attitudinal changes. In addition, participants were more likely to disagree with the statements that men should make all decisions in a relationship, that women cannot say 'no' to sex, and that women who dressed in a sexy manner want to be raped.

A 2007 report supported the finding that participants had better knowledge about HIV transmission, and were more willing to accept joint decision-making with women (Ditlopo et al., 2007). In addition, some attitudinal changes were reported, with participants showing increased agreement with needing to stop violence against women and children, using condoms to prevent STIs and pregnancy, sharing household chores, and needing to teach boys to respect girls. However, the 2007 evaluation also reported a number of less positive findings, such as a drop in reported condom usage with both long-term and non-regular partners, suggesting that improved knowledge did not necessarily lead to behavioural changes. Along with this, few men participated in CATs and other activities beyond the workshops, suggesting that the impact of the intervention may have been limited to the duration of the workshop. Despite these drawbacks, a number of activities were taken from the MAP workshops to be used in OMC, and these include the Gender Values Clarification and Gender Fishbowl described above. 
A further source for the OMC activities was the 'From Violence to Peaceful Co-existence' chapter in a manual produced by Instituto Promundo in 2002, titled 'Working with Young Men Series'. The manual describes a series of activities that are intended to be carried out in workshops, preferably with 15-20 participants and at least one facilitator, and the manual 'starts from the assumption that young men should be seen as allies... and not as obstacles' (Barker \& Nascimento, 2002:13). As the manual explains, '[i]f we expect boys to be violent, if we expect them not to be involved with the children they may father... then we create selffulfilling prophecies' (2002:13). The activities therefore aim to encourage young men to take responsibility to be part of the solution to GBV, rather than treating them predominantly as part of the problem. The manual notes the fact that male facilitators can act as positive role models for young men, and that often it will be the first time for these young men to interact in all-male groups on topics around gender, emotions and violence. However, the manual does state that mixed-gender groups can be effectively used, and that the qualities of the facilitator are more important than the gender. Thus, facilitators should be able to engage a group, and to listen to and inspire them, no matter their gender (Barker \& Nascimento, 2002).

The module 'From Violence to Peaceful Co-existence' begins with the question, 'Why is it that young men are disproportionately the perpetrators of violence?' (2002:144), going on to discuss the fact that although violence is predominantly perpetrated by boys and men, it is not an inherent nor an essential part of boys' and men's biological make-up' (2002:148). The intervention therefore focuses on the role of gender socialisation in the creation of male violence, and aims to encourage young men to prevent violence and promote peace. The activities from the 'From Violence to Peaceful Co-existence' manual that were included in the OMC workshops are those which focus on violence as an expected aspect of masculinities, including discussions of violence experienced and perpetrated by workshop participants, and the contradiction of valorising those who have died in violent ways (an activity named 'Live Fool/Dead Hero'). Activities relating to community involvement beyond the duration of the workshop were also included.

The final source for the OMC activities was the Working with Men on Gender, Sexuality, Violence and Health manual which was put together in 2005 by practitioners in India working in the field of GBV. As explained in the manual's introduction, the intervention arose out of a recognition of the 'need to work with the perpetrators of violence, as well as the victims of violence' (Fernandes, Sharma, Kukade, Jeena, Khanna, Singh \& Vaze, 2005:1). The manual was created as a resource for facilitators or trainers working in the areas of gender, sexuality and health, and as with the Instituto Promundo manual, it describes activities to be used in workshops with groups, though it does not make recommendations on whether these should 
be men-only, or mixed gender. In addition to this, the facilitator manual includes handouts and readings on topics covered in the workshops. These include the texts of different Human Rights instruments, such as the UN Declaration on Human Rights.

The activities from this source which have been used in OMC predominantly relate to power differentials, and to creating awareness of the different ways in which people experience privilege or oppression in society. For example, an activity called 'Power, Status and Health' was included, in which all participants begin by standing in a line, and are given a specific identity, such as a male taxi driver, a female refugee, a grandmother, or an unemployed male. Statements are then read out, such as 'I can read and write', or 'I can negotiate safe sex with a partner'. If the statement applies to the participant's given identity, they take a step forward. By the end of the activity, some participants will be at the other end of the room, while others will barely have moved forward. This quite starkly highlights power differentials at play in society, and how these impact on different groups.

The three interventions outlined above provided the majority of the content of the OMC workshops, and impacted heavily on the theoretical grounding for the programme. Each of the three were informed by similar theory and beliefs regarding gender socialisation, hegemonic masculinities, and the need for gender-transformative programming. In other words, all three recognise that masculinities are socialised and that hegemonic masculinities require men to behave in ways which can be harmful to themselves and to those around them, and the interventions therefore problematize existing gender norms as a means to allow men to practise alternative versions of masculinity. This same thinking underpins the $\mathrm{OMC}$ intervention. The following section discusses $\mathrm{OMC}$ in the context of the literature on GBV interventions more broadly, and then moves on to specific evaluations of OMC which have been conducted.

\subsubsection{OMC in context of masculinities-focused re-socialisation interventions}

The OMC workshops are relatively well-aligned with the general literature on making effective and impactful masculinities-focused interventions, with a primary factor being that participation is voluntary, which has been noted as an important aspect in ensuring the strength and sustainability of the impact of interventions (Mortimer \& Simmons, 1978; Scott, 2010). Along with this, the aim of the intervention is to be gender-transformative, rather than gender-neutral or gender-aware, meaning that the programme seeks to 'transform gender relations through critical reflection and the questioning of individual attitudes, institutional practices and broader social norms that create and reinforce gender inequalities and vulnerabilities' (Ricardo \& Verani, 2010:14). As noted previously, gender-transformative programmes have been identified as having a greater impact than gender-neutral or gender- 
aware interventions, and $\mathrm{OMC}$ is therefore in line with the literature on this aspect as well. In addition, the programme includes multiple different features, such as workshops, community mobilisation and engagement, social media, and policy development, and the use of multisectoral or multi-pronged approaches, which have been found to be more effective than those which use a single strategy (WHO, 2007; Ellsberg et al., 2015). In a similar vein, the use of community mobilisation has been specifically noted as an aspect which improves the effectiveness and reach of interventions (Ellsberg et al., 2015).

Along with the factors outlined above, the OMC intervention is well-aligned with the literature on GBV interventions in its use of facilitators as positive role models, and the creation of supportive peer groups of participants. The presence of facilitators as positive role models has been noted as important, in that it improves the effectiveness of masculinities-focused interventions (Roy \& Das, 2014), while the ongoing support networks which are created through the CATs and the support groups for ex-inmates play a large role in helping participants to sustain the positive impacts of the interventions (Roy \& Das, 2014). Along with this, it has been shown to be important for men to have the space to practise alternative versions of masculinity in order to sustain the impact of any changes, and this is also included in the OMC process (Viitanen \& Colvin, 2015). Finally, the OMC workshop cycle is shorter in duration (two days to one week) than the suggested 10 to 16 weeks, but each session is longer in duration (usually a full day of six to eight hours) than the recommended 2.5 hours per session (WHO, 2007; Ricardo \& Verani, 2010). Thus, despite its shorter duration in terms of number of days, the intensity per day can improve the sustainability of the impact.

In theory, the OMC workshop is well-aligned with the recommendations arising out of the literature on masculinities-focused GBV-prevention interventions, suggesting that its impact on participants should be relatively positive and sustainable. The discussion now turns to evaluations which have been conducted on the intervention, as a means of gauging whether its positive theoretical alignment has translated into actual positive results.

\section{$\underline{\text { 5.3.5 Evaluations }}$}

A number of evaluations have been carried out on the OMC programmes, both in South Africa and in Cóte d'Ivoire, and these will be outlined in order to highlight both the positive and negative aspects of the intervention that have been uncovered thus far. This section will therefore help to point out the gaps in existing knowledge on the intervention which the current research hopes to address.

A 2013 evaluation of the OMC programmes in South Africa found that the workshops have a positive impact on men's perceptions of women's rights, as well as on the power dynamics in 
the men's relationships with women (Dworkin et al., 2013). Along with this, participants reported reductions in violence against women, children and other men, although the evaluation found that men struggled to maintain lower levels of violence, especially in emotionally charged or frustrating situations. Additionally, some men felt that working solely with men implies that men are only able to be perpetrators, rather than partners in efforts to reduce levels of GBV. This suggests that while the intervention can have a positive impact in the short-term, many participants find it difficult to sustain these positive impacts, and still feel pressure to use violence as a resource in frustrating situations. This points to more of a behavioural change than an attitudinal one, as the participants now view a specific behaviour (violence) as problematic, but do not question that aggression is an appropriate response for men in situations of stress. Along with this, the evaluation does not provide any insight into which aspects of the intervention contributed to the positive behavioural change, or why they had this effect. Thus, there is still a gap in understanding how the intervention affects participants.

The intervention in Cóte d'Ivoire ran for 16 weeks, and a 2014 evaluation found that after one year, there was a decrease in women's experience of physical and sexual IPV in the intervention community, lower prevalence of men's reported intention to commit physical IPV, and increased levels of men who believed women have the right to refuse sex under all circumstances (Hossain et al., 2014). There was also a positive impact on men's reported use of hostility- and conflict-management skills, and on men's reported involvement in gendered household tasks. This study is interesting for a number of different reasons. The first is that it takes place in a post-conflict context in which militarised and hypermasculinities are likely to be prevalent, and it is encouraging that the intervention can have an impact in communities which have a strong adherence to violent masculinities. The second is that the evaluation includes information from women in the community as well, rather than only relying on self-reports from workshop participants, which suggests that the results are more reliable as they have been confirmed by others from the broader community. However, this evaluation also does not speculate on why or how the intervention impacts on participants, or on which factors enable participants to maintain these positive impacts in societies which emphasise violent masculinities.

A 2015 evaluation of the programme in South Africa by Viitanen and Colvin (2015) found that despite the short-term nature of the OMC intervention, participants' longer-term community engagement in CATs, as well as Sonke's advocacy and policy development activities, could result in longer-term attitudinal changes for participants. A primary aspect of this was men's recognition that masculinities are 'costly' to men, meaning that hegemonic masculinities require men to act in ways that are damaging to their health, and the health of 
others around them. As the study noted, 'our findings suggest that messaging around the costs of masculinity was generally well-received' (2015:5). However, there seemed to be some contradictory results. While participants could discuss multiple masculinities in theory, there was constant reference to what 'men are like', implying that there is only one available version of masculinity, leading the authors to suggest that, '[t]he influence of the hegemonic norm made it difficult to talk about anything except positive but relatively small modifications away from this ideal' (Viitanen \& Colvin, 2015:9). This therefore raises the question of how much of an actual attitudinal impact the intervention can have on participants' behaviour.

Participants were receptive to the idea that masculinities can have serious costs for men attempting to enact them, and for those close to them, and these costs include risky sexual behaviour, depression and other mental health issues, drug and alcohol abuse, poor healthseeking behaviour, sexual and physical violence against women, and physical conflict with other men. However, participants seemed less willing to acknowledge the socially constructed nature of hegemonic masculinities, seeing them more as inherent and unchangeable (Viitanen \& Colvin, 2015). Thus, gender roles may be shifted somewhat, but the fact of gender as a social construction is less easily taken on board. This 'made it difficult for people to recognise the diversity of masculinities in their own lives and communities or to accept that they fit anywhere outside of the hegemonic box' (2015:9). In addition to this, while many men who go through the workshops may begin to see violence against women as an issue, they tend to be less likely to afford this same respect to marginalised groups such as LGBTIs. This once again points to a relatively small behavioural change, with little impact on participants' overall attitudes. While the study suggested one way in which the intervention made an impact (through participants' longer-term engagement with OMC activities), it provides little understanding of why this might be the case, or of what enabled participants to sustain these changes. Thus, in a similar fashion to the earlier evaluations, Viitanen and Colvin's study raises questions about the longer-term sustainability of the impact of the intervention.

An issue raised in two separate studies by Dworkin et al. (2012; and 2013) is that some men's attitudes and behaviours are changing without the impact of interventions, and that more attention should therefore be paid to the factors that are influencing these shifts. In other words, men are voluntarily joining these kinds of interventions, implying that their attitudes towards gender equality and masculinities may already have begun to shift, yet there has been little research thus far on why men choose to join such initiatives, or on what initiated their attitudinal shift. Understanding men's reasons for participating in gendertransformative interventions can provide useful information in terms of attracting more men to choose to become involved, and thereby broadening the reach of the programme. Along 
with this, highlighting the factors that are contributing to these behavioural and attitudinal shifts allows those working in the field of masculinities to better adapt interventions to encourage and enable these shifts.

Thus, existing evaluations have predominantly noted that the intervention has positive impacts on participants, although many of these impacts seem to be more behavioural than attitudinal, suggesting that they might not be sustained in the long-term. However, there is little information on how the intervention creates this impact in terms of the specific activities and processes that participants remembered or felt strongly about. Along with this, evaluations to date have spent little time asking why participants chose to become involved in the intervention in the first place, thereby leaving a gap in our understanding of ways that attitudes may be shifting in society without the influence of specific gender-transformative interventions. As a final point, current evaluations have generally not focused on what factors hinder or support participants in sustaining the impact of the intervention. Due to these gaps, I aimed to try and understand why participants chose to join the intervention, how the intervention impacted on them, and the broader societal conditions that supported or hindered them in sustaining any positive impacts that they may have felt.

\subsection{Conclusion}

As discussed in the previous chapter, the levels of GBV in South Africa have remained extremely high, despite numerous women-focused and reactive interventions attempting to address the issue, and this has led to alternative responses being explored. One such example is the OMC intervention, implemented by Sonke Gender Justice, an organisation which aims at reducing violence against women and promoting gender equality, and this chapter provided an outline of the organisation and OMC in order to explain what information is currently available, and where there are existing gaps in understanding. Sonke employs a multi-sectoral strategy, combining community mobilisation and education, policy development and advocacy, and research and evaluation as tools in attempting to reduce GBV. The organisation therefore attempts to impact on a broader audience than just participants of its OMC workshops, by working to influence societal norms around gender and GBV.

As part of its community education and mobilisation programme, the OMC workshops focus specifically on masculinities as part of a gender-transformative intervention, aiming to problematize the norms around masculinities and violence as a means of reducing GBV in the communities. The intervention does this through a range of activities which facilitate discussions around issues relating to gender, power, violence, HIV, health, gender equality and healthy relationships, and provides space for participants to discuss these topics and 
work out how to remain involved as community mobilisers and educators themselves. OMC has been positively evaluated in a number of studies, with the results suggesting the intervention can help in reducing men's use of violence, and improving men's perceptions of women's rights and gender equality. However, the majority of these studies have noted that the impacts seems to be more behavioural than attitudinal, impacting on specific 'problematic' behaviours rather than changing men's attitudes regarding gender inequality in general. Similarly, Viitanen and Colvin (2015) found that although workshop participants could identify specific behaviours as problematic, they were less willing to view hegemonic masculinities as socialised and therefore adaptable. Thus, participants still focused on the notion of 'how men are' and would only make relatively minor refinements to this.

However, the existing evaluations have left a number of gaps in understanding regarding the impact of the intervention, predominantly relating to the reasons participants have for choosing to join, and how the programme achieves its impact. Along with this, little information is available on factors in the broader community which assist or hinder participants in maintaining the positive impacts that they felt they gained from the workshops. The focus in my own research has therefore predominantly been on these three aspects as a means of understanding the impact of the programme as an example of a masculinities-focused intervention, and the impact it is able to have on GBV in those communities. The following chapter therefore explains the research methodology used in the study, before the final chapter discusses my own findings. 


\section{CHAPTER 6}

\section{METHODOLOGY}

\subsection{Introduction}

The previous chapters have outlined the extremely high levels of GBV currently being experienced in South Africa, and have provided a number of possible reasons for this. While the range of answers is relatively broad, I argue that a focus on masculinities is necessary to help understand why such a vast majority of the violence is perpetrated by men, both in South Africa and internationally. An overview of the different ways in which GBV is being addressed, which is predominantly done through reactive women-focused interventions, also showed that this type of intervention seems to be doing little to lower the rates of GBV in the contexts in which they are being implemented. This has resulted in a shift towards focusing on men and their role in violence, and Chapter Three provided an overview of different forms of masculinities-focused interventions as a means of examining the effectiveness of these programmes, including both their strengths and weaknesses.

Chapter Five focused on the specific masculinities-focused intervention which is being used as a case study for this research, the OMC programme implemented by Sonke Gender Justice, examining the results which previous evaluations have reported. While the intervention has generally been evaluated positively, a number of shortcomings were identified, along with some gaps in the existing literature. This research therefore aims to fill this void by understanding the impacts of the OMC intervention, as an example of how and why masculinities-focused interventions can assist in reducing GBV. Thus, the fieldwork focused on which aspects of the intervention had an impact and why, and this included participants' reasons for joining OMC along with why they remained involved in the organisation beyond the workshops. Additionally, when talking to facilitators and practitioners, the intention was to uncover their opinions on the best ways to respond to GBV in South Africa, with a focus on both masculinities-focused interventions, as well as alternative methods of addressing the issue.

This chapter outlines the research methodology used for the research, beginning with why specific methods were chosen, and then providing descriptions of the different stages of the research process. The research for this study was qualitative, and involved a number of different processes, including participant observation, focus groups and one-on-interviews. However, as with all research, there were a number of limitations and these are highlighted, before I move on to reflect on my own role and identity in the research process. 


\subsection{Research approach}

There were two main reasons for selecting a qualitative approach for the study. Firstly, the sample size was relatively small, focusing on only one case-study including a small number of participants. This meant that medium- to large-scale survey-type research would be inappropriate. Secondly, the aim in this research was to look more at the understandings of participants, rather than on quantifying any aspect of the experience. As noted by Strebel, qualitative research 'values the subjective experience of participants [and] is concerned with meanings rather than frequencies of events' (1995:59). Thus, qualitative methods were more appropriate in gathering this type of data.

\section{$\underline{6.2 .1}$ Case studies}

A case study is defined as 'the detailed and intensive analysis of a single case' (Bryman, 2008: 691), where the aim is to study individual cases as individuals, rather than as representative members of a population (Lindegger, 2002). The primary reason for choosing this approach was practical. As noted in previous chapters, there are very few masculinitiesfocused interventions currently run in South Africa and of those being implemented, OMC is the only intervention that I was able to find current information about, either online or regarding evaluations. This meant that finding comparative examples for this study would have been difficult, and thus a single case study was the only viable option. In addition, as was discussed in previous chapters, the OMC intervention conforms to many of the suggestions in the existing literature about what constitutes an effective masculinitiesfocused programme, thus acting as a kind of 'exemplary' model of this form of GBV reduction programme. An investigation of how such an intervention impacts on participants in both the short- and medium-term can therefore provide an understanding of ways to improve the design and impact of similar masculinities based intervention programmes that address GBV.

\section{$\underline{6.2 .2 ~ F o c u s ~ g r o u p s}$}

The primary method of gathering data from workshop participants was in the form of focus groups, which were conducted after they had taken part in the intervention. Focus groups are defined as, 'a group interview - centred on a specific topic....and facilitated and coordinated by a moderator or facilitator - which seeks to generate primarily qualitative data, by capitalising on the interaction that occurs within the group setting' (Sims, 1998:346). In other words, the focus is both on the topic or theme that is being discussed, and on how that topic is discussed by a group of participants, meaning that the interactions and context both form part of the data that is analysed. Focus groups tend to be less formal than one-on-one interviews, and this can create interactions that are closer in nature to everyday discussions (Flick, 2014). 
Sims (1998) lists some additional advantages of focus groups which informed the decision to use these in the current research. Focus groups provide an economical way of tapping the views of a number of people, as it can be time-consuming and costly to organise individual interviews with multiple respondents. An additional reason is that focus groups can provide information on the dynamics of attitudes and opinions in the context of the interaction that occurs between participants. Understanding group dynamics was important in this research because much of the OMC intervention takes place in groups, meaning that the ways in which participants discussed and understood gender and masculinities in a group setting provided information on how the intervention achieves its impact. Along with this, focus groups can provide a safe forum for the expression of views, and this again aligned with the group-based nature of much of the OMC intervention. Participants would have spent a fair amount of time creating a safe space for discussion during the workshops, and this could then be continued into the focus groups. This links to another advantage mentioned by Sims, which is that participants may feel supported and empowered by a sense of group membership and cohesiveness which serves as a form of bonding capital. As a final point, focus groups have the additional advantage of de-centring the authority of the researcher, as the focus is more on the interactions between participants, rather than the interaction between participant and researcher (Kamberelis \& Dimitriadis, 2005). As I was more interested in how participants related to each other than on how they related to me, focus groups provided an important means of understanding this.

However, focus groups can have a number of disadvantages, and I experienced many of these whilst conducting this research. Although they can be more economical, they are often more complicated to organise because of needing to coordinate an appropriate time and location for a group of people (Flick, 2014). This can also result in focus groups which are constrained for time, with different participants being available for only a limited period, and this was an issue which arose during my fieldwork, which I will expand on in my reflections on the research process. Along with this, there are some difficulties relating to the moderation or facilitation of focus groups. For example, it can be difficult for the moderator or facilitator to try and keep the group focused on the topic without becoming too directive and steering the conversation in an artificial manner (Strebel, 1995; Flick, 2014), and trying to strike a balance between formality and informality can be tricky. This is due to the need to create a context where participants can discuss the issues relatively freely, but without simply chatting about irrelevant topics (Överlien, Aronsson \& Hydén, 2005). Finally, focus groups can result in certain participants dominating the conversation, while less-confident or outspoken members are not heard very often (Sims, 1998). Thus, the role of the moderator 
is important in the success of a focus group, and these were aspects I had to constantly keep in mind during the focus groups I conducted.

There were other more practical reasons for choosing to use focus groups for this research. Primarily, this was related to the fact that the OMC workshops are a group-based process, meaning that it was appropriate to use group discussions to uncover people's opinions about and impressions of the workshops. In addition to this, I was interested in the interaction between participants on different subjects, and focus groups helped to create the space for this. Along with this, the focus group participants had spent quite some time together in a supportive group environment during the workshop and had developed strong social bonds, which reduced the need for introductory sessions, and meant that participants were already comfortable having discussions with each other. The focus groups also encouraged a continued dialogue and discussion between participants about the workshop process, and allowed me to take more of a background role in the conversation. Finally, on a logistical level it was possible to gather a group of people in one place at one time, often after a workshop session, meaning that focus groups were a feasible method of gathering data.

\subsubsection{Participant observation}

While focus groups provided an opportunity to hear participants' opinions and views on many aspects of the workshop process, I was also interested in watching how a gendertransformative masculinities-focused intervention such as OMC is implemented. I therefore observed workshop sessions on a number of occasions as a means of gaining a better understanding of the intervention and its impacts. Participant observation is the process by which the researcher observes participants in a particular setting. The level of participation by the researcher can vary, but the fact of the researcher being present will almost always impact on the participants being observed. In other words, the researcher will 'observe from a member's perspective, but also influence what [they] observe due to [their] participation' (Flick, 2014:312). This method is generally divided into observation as a participant (observing from inside as a group member), and observation as an observer (from outside of the group). Due to the fact that I was not actively participating in the workshops in the majority of cases, I predominantly observed as an observer, as someone from outside the group.

As noted by Flick (2014), participant observation is often useful when looking at a small number of cases in detail, and is usually only one part of a broader research programme which involves other methods as well, such as interviews, focus groups, etc. Thus, it was appropriate in this context because of the research's focus on one specific case study, and was used in combination with interviews and focus groups. Nevertheless, unless the setting 
is a public space or the group being observed is very large, it is often not possible to be completely outside of a group, as the participants will be aware of the researcher's presence, and this may impact on group dynamics. Thus, the challenge is "how to become a member of the field as far as possible and at the same time keep the distance big enough to remain a researcher and observer' (Flick, 2014:296). However, I am aware that it is impossible to be a 'neutral' or objective researcher, and this aspect will be discussed in more detail in the section on one-on-one interviews below.

Flick (2014:308) lists a number of issues that need to be decided when using observational data collection methods, and my own decisions regarding these five issues are discussed below. The first issue is that of overt versus covert observation, meaning how far is the observation revealed to those being observed? The second issue is non-participant versus participant observation, which relates to how far the observer has to go to become an active part of the observed field. Third is the issue of systematic versus unsystematic observation, asking how standardised the observation needs to be or whether it can remain flexible and responsive to the group processes? The fourth decision is whether the observation will take place in a natural or artificial situation, choosing between settings such as a lab or the field of interest? The final decision is that of self-observation versus observing others, which relates to how much attention is paid to self-reflexivity by the researcher.

While the aim of the observation in this research was to see how the workshops are implemented and facilitated, and how participants responded to the content and discussion that takes place, I did not intend to be a covert observer. Although I hoped to observe without significantly impacting on the content, I was aware that I would stand out in the workshop settings, as an outsider in the communities in which they were taking place, and therefore would not be able to remain a purely anonymous observer. In settings with a fairly large group taking part in the workshop (roughly 28 people), I was able for the most part to remain an observer, rather than a participant, while in others with smaller groups of only five or six people, I was expected to become more involved in the workshop as a participant. It was difficult to standardise my observation to any great extent, as the workshops involved participants who came from very disparate backgrounds and communities, and the content and facilitators varied as well. However, the intention in this research was not to compare identical workshops, but rather to gain an understanding of the full range of ways in which such masculinities-focused interventions impact on participants. Thus, while I was able to observe in a relatively 'natural' setting, in which the workshops would have taken place regardless of my presence, achieving standardisation was complicated. Finally, although my focus was on observing others in the workshops, I hoped to retain some self-reflection of my own role and impact on the research process. 


\subsubsection{One-on-one interviews}

The final method of data gathering was one-on-one interviews with workshop participants, workshop facilitators, and practitioners working in the field of GBV. One-on-one interviews aim to delve deeper into the selected themes with single subjects at a time, allowing for a more intensive discussion of relevant topics (Terre Blanche \& Kelly, 2002). I therefore used these as a means of gaining a deeper understanding of aspects of the intervention which had the biggest impact on participants, including the reasons they decided to join the workshops, and the factors which impacted on their ability to sustain any positive impacts. Along with this, I was interested in the views of facilitators and practitioners on the causes of GBV in South Africa and ways to reduce this, and one-on-one interviews provided a good platform to access these.

There are three main types of interviews, and these are structured, semi-structured, or unstructured (Fontana \& Frey, 2005). Structured interviews are more commonly used for survey purposes, and the questions tend to be close-ended, often with multiple choice answers. In semi-structured interviews, an interview schedule is available, but the questions are open-ended and participants are encouraged to provide more detail on specific topics. Unstructured interviews tend to be used more for narrative purposes, where the participant her/himself is the main focus of the research, rather than their opinions on a specific topic. In my own research, I predominantly used semi-structured interviews with an interview schedule, which meant I asked similar questions of all participants, but remained was relatively flexible, allowing participants to discuss certain points in more detail.

Initially, interviewing was thought to be a neutral, objective information-gathering process, with the interviewer as a silent recorder of data who had little impact on the information collected (Fontana \& Frey, 2005). However, more recently there has been acknowledgement of the fact that interviewers and interviewees each bring their specific identities into the interview process, and that this impacts on the method of data gathering, and what data will be collected. In other words, "[w]e are beginning to realize that we cannot lift the results of interviews out of the contexts in which they were gathered and claim them as objective data with no strings attached' (Fontana \& Frey, 2005:716-717). This need for awareness of the context in which the research takes place also applies to focus groups, where the participants and the facilitator are situated in particular contexts, and the researcher needs to take this into account during both the information-gathering and the data analysis processes. Traditionally, there is thought to be an asymmetrical relationship in an interview, with the interviewee being in the subordinate position and the interviewer in a relatively dominant one. However, this can become more complicated when both party's identities are taken into 
account in the broader social context in which the research is taking place. For example, if the interviewer is a female interviewing males, as was often the case in this research, this will need to be noted in the context of the predominantly patriarchal nature of South African society. In addition, it can raise issues in a country such as South Africa with complex racial and gendered histories. In this regard, Kelly noted that, '... one also often encounters largerscale political issues in research contexts. In South Africa, where there is hardly an area of social life which has not been a site of struggle, this is the rule rather than the exception' (2002:384). Thus, awareness of the social contexts in which the interviews take place is essential, and these are discussed in more detail in the section on self-reflection below.

I decided to conduct semi-structured interviews with participants, rather than survey-type interviews, primarily due to a gap in the literature mentioned in previous chapters. Although quantitative research has already been done on the short-term impacts of the OMC programme (e.g. Dworkin et al., 2013), there has been little qualitative focus on why or how these impacts occur. In other words, the participants' opinions about the intervention have not been researched to any great degree. In addition to this, there is little information relating to the broader societal factors which may encourage participants to attend workshops, or impact on their ability to maintain the effects once the workshop has finished. Thus, although I could speculate about their motivations and the aspects which impacted on them, semistructured interviews enabled participants to suggest their own reasons and motivations, rather than providing a list of possible options that they could choose from. Semi-structured interviews were therefore a more appropriate means of understanding participants' views in this instance.

\subsubsection{Data analysis, coding, textual analysis}

All interviews and focus groups were audio-recorded with participants' consent, and later transcribed verbatim by me. Transcripts were coded based on important themes that arose from the focus groups and interviews, and these themes were then analysed using AtlasTI. The analysis was inductive, in that the themes were data-driven (Braun \& Clarke, 2006), and arose from the transcripts, rather than being decided upon prior to the fieldwork. Flick (2014) has termed this form of inductive thematic analysis Grounded Theory coding, with codes emerging from the data, rather than being imposed upon it. As mentioned previously, the lack of existing qualitative research on these interventions means that there was little literature available to suggest definitive topics for interviews or codes for the data, and I therefore decided to generate codes from the data, rather than assuming these in advance. According to Flick (2014), the coding process starts with open coding, where broad themes are developed from the data, and moves on to categorising the codes by grouping them around relevant phenomena arising from the data. This is followed by axial coding, where 
the codes and categories most relevant to the research question are selected, and passages from the transcripts are matched to these categories. The final step is selective coding, where groups of codes and categories are compared to others, with the aim of focusing on potential core concepts and themes.

The transcripts were analysed primarily on the content of what participants discussed. Much of what is discussed in a focus group arises because of the context of that discussion (Sims, 1998), and the analysis therefore needs to take this context into account, along with the identities and subjectivities that the participants and interviewer bring to the process (Willig, 2000). In addition, this involves awareness that, 'available discursive resources can constrain as well as enable what can be thought, said and done by individuals' (Willig, 2000:561). Thus, the context can place constraints on what participants say, and why. Interviews with practitioners were divided into those with Sonke employees, and those with practitioners from other organisations, with both sets of interviews broadly focusing on the practitioners' opinions surrounding GBV in the country. This included what they felt the causes of this violence to be, as well as the best ways to respond to it, and these questions hoped to understand the reasons for organisations choosing the approach that they had - in some cases, this included a masculinities-focused approach, and in others a specifically women-focused one. Interviews with Sonke facilitators then focused on the OMC workshops in a number of ways, beginning with why the workshops specifically focused on men and masculinities, and what the workshops hoped to achieve. The interviews then turned to the impact that the facilitators saw the workshops having, including a focus on which activities and aspects have the biggest impact, and why participants joined the workshops in the first place. Finally, facilitators were asked their views on how to expand the reach of the intervention to also impact on those who did not initially wish to attend workshops.

The interviews with workshop participants took place roughly three months after the workshop and focus group. These mostly focused on the workshops in the context of the community in which they took place, and initial questions therefore looked at which activities participants could remember, and which had the biggest impact on them. The interviews then returned to the topic of what helped participants sustain the impact of the workshop in broader society, which included discussing how others in the community felt about participants' involvement in the workshop, and about the content of it. Finally, the interviews asked for participants' opinions on the causes of GBV in their community, and whether they felt the workshops could play a role in addressing these. These interviews hoped to understand how and why a masculinities-focused intervention such as this can impact on participants and on the broader community, as a potential means of reducing GBV. 
A number of initial categories were identified in the coding process, in response to three main research areas. The first research area was the causes of GBV in South Africa, the second looked at ways to respond to this violence, and the third looked at the impact of a masculinities-focused intervention as a means of reducing GBV. While the broad areas of focus were defined in advance, the categories arose from the data, rather than being preexisting. This allowed the coding to be responsive to what arose in the interviews and focus groups, without trying to force data into specific categories. The findings in the following chapter are predominantly separated into responses from workshop participants and responses from facilitators and practitioners. However, in the initial analysis, the coding used the same themes for both.

Four main categories were identified and were then broken down into sub-themes, which will be explained in more detail below. As the primary research area looked at how and why the intervention had an impact, the initial category focused on which aspects of the workshops had the biggest impact on participants, and why. Following this, the next category looked at the extent and causes of GBV in South Africa, leading to the following category which focused on the societal norms and influences which impacted on participants. The final category related to how to respond to the levels of violence present in the country. Passages from the transcripts were assigned to the different categories, and these were then broken down into more specific sub-themes.

The category which focused on the impact of the intervention was broken down into a number of sub-themes, including aspects arising specifically during the workshops and those impacting on participants both before and after their involvement in OMC. The initial subtheme was coded as 'father figures/role models', and this included the importance of both being and having positive role models. The next sub-theme was coded 'sense of community', which was separated into the importance of a supportive peer group, and wanting to put something back into one's own community. The following sub-theme looked at specific activities from the workshops that participants could remember, with the final subtheme focusing on why people joined the intervention, including their expectations of the workshops and what they hoped to achieve through attending.

The following category looked at participants' views on the extent and causes of GBV in South Africa, and this was broken down into two main sub-themes. As this research focuses on the causes of violence in order to understand ways in which to address it, the initial subtheme focused on reasons for the levels of violence in South Africa, and three primary aspects were noted: masculinities, substance/alcohol abuse, and the normalisation of violence through witnessing or experiencing it oneself. The next sub-theme focused on 
interview participants' own experiences of violence. This was not initially intended to be part of the research focus, but the sheer number of participants who reported experiencing some form of violence meant that it arose repeatedly as an important aspect in people's lives, and strongly underlined just how widespread violence is in the country. It was therefore included in the findings and discussion.

The next category was broadly coded as 'societal norms/influences', and this was divided into sub-themes which looked at the societal factors impacting on people's gender roles. The initial sub-theme was gender norms and masculinities, which included patriarchy, the fact that masculinities are socialised, and the aspects which are linked to the achievement of masculinities in participants' communities. In a similar vein, the next sub-theme looked at the difficulties that people could face if they did not conform to gender norms, including the fact that the achievement of gender roles can be difficult in and of itself. The final sub-theme related to gender-role strain, and the fact that it is used as an excuse for violence in numerous situations. The reason for the focus on societal norms and influences was to understand the factors which impact on participants outside of the 'official' intervention, as these will play a major role in a participant's success or failure in adhering to the alternative norms they practise during the intervention.

The final category looked at different responses to GBV, and this was broken into two subthemes. The first sub-theme related to what was perceived by participants and practitioners to be a lack of response by the police and government to the issue of GBV in the country, and the reasons given for this ranged from a lack of political will through to a lack of available resources. The second sub-theme looked at opinions on how to respond to GBV, which included how to encourage men to become involved in these kinds of interventions. Focusing on possible responses to GBV also provided space for suggestions of alternative options which could be included in efforts to prevent this kind of violence in the country.

The data and findings from these categories and codes will be discussed in the following chapter.

\subsection{Methods}

While the previous section outlined the different research methods chosen for this study and the reasons for these choices, this section explains the way in which the research was carried out. It therefore begins with the method of sampling that was used to access participants, before moving on to describe the contexts and processes of the different focus groups, as well as the one-on-one interviews with workshop participants. The section finishes by outlining the interviews conducted with Sonke facilitators and practitioners working in the field of GBV. 


\subsubsection{Sampling method}

Due to the fact that almost all interview and focus group participants were either working for or engaged in workshops with Sonke, the sampling method was primarily purposive. The majority of participants had either taken part in OMC workshops, or were facilitators of the workshops. Thus, initial contact and gatekeeping was almost all through Sonke. Observation of the workshops was coordinated through the organisation, and specifically through the facilitators of the different workshops, and this had both positive and negative impacts on my reception in the groups. On the one hand, it provided me with a form of legitimacy in the eyes of participants, who often viewed me as part of the organisation, rather than as a 'researcher' (a relatively vague term) or a student. On the other hand, it implied a bias on my part towards the organisation, which may have meant that participants were less open to voicing concerns or issues about the workshops that they felt were problematic, as they might have thought that it would get back to the facilitators or the organisation and potentially result in negative repercussions. This was more noticeable in instances where Sonke facilitators sat in on the focus groups. In one instance (Gugulethu), the facilitators had previously been participants in OMC workshops, and they therefore joined the focus group in their dual role of workshop participant and facilitator. In another case (Ceres), a facilitator observed the focus group but did not take part. The difficulties that arose around this issue will be discussed in more detail in the self-reflection section of this chapter.

A further six interviews were carried out with practitioners who work in the field of GBV in South Africa, not related to Sonke. These included authors who have written on masculinities and GBV, those working at reactive women-focused organisations, and one working at an LGBTIQ support organisation. The sampling for this was predominantly by word of mouth, as most practitioners were recommended by other contacts, so a snowball approach was followed, but one which was still purposive.

\subsubsection{Focus groups and interviews - Ceres}

The fieldwork began with observation of an OMC workshop being conducted in Ceres in the Western Cape, a small farming community roughly 1.5 hour's drive from Cape Town. Sonke does not normally provide workshops in rural or agricultural areas, mostly focusing on urban areas and areas close to cities where they have regional offices. However, in this instance two local NGOs, Witzenberg Rural Development Centre (WRDC) and Ceres Safe Space, had contacted Sonke to ask for an OMC workshop to be conducted there in the aftermath of the gang rape and murder of a local gay man. Because of this, the workshop had a heavier focus on issues of sexuality and LGBTIQ rights than the usual OMC interventions. 
WRDC is an organisation which focuses on numerous social issues in the Witzenberg region, including housing, women's rights, and farm labourers' rights. The group also provides paralegal advice, financial advice, and early childhood development training for those running crèches, with a focus on community education and support. Ceres Safe Space is a relatively new group which aims to provide support and information to the LGBTIQ community in and around Ceres. The trial of the accused in the abovementioned murder case attracted the attention of Sonke, who liaised with local NGOs to organise protests and pickets outside the court, protesting against the poor police work in the case, and the threat posed to the LGBTIQ community in Ceres. As a result of this collaboration, Sonke was asked to conduct an OMC workshop with interested community members, and a four-day workshop was carried out, which I observed.

My initial plan had been to conduct a focus group with participants prior to the workshops as a means of gaining some insight into their reasons for wanting to attend the intervention before they began discussing the 'correct' discourse surrounding gender and GBV. However, this was not logistically possible for a number of reasons. To begin with, the facilitators at Sonke were wary of allowing a focus group prior to the beginning of the workshop, as they felt that they first had to establish a relationship with the participants before I could conduct focus groups with them. As this was in an area in which Sonke had not previously worked, they had not yet developed strong working relationships with NGOs in the area, which also meant that it would have been difficult to get participants to the venue early, or a day before. However, the timing of a focus group at the end of the workshops posed its own difficulties. At the end of each day, participants usually had to leave quickly in order to catch their transport as very few had their own vehicles. This meant that I was limited to using their lunch hour to conduct the focus group. In addition to this, because the sessions during a day were quite intensive, the Sonke facilitators asked me to not use the participants' entire break, and the focus group therefore lasted about 40 minutes.

The workshop had an average of 28 participants each day, with some participants leaving after the first day and others joining for only one or two days. All the participants in the workshop were coloured, and lived in either Ceres, Prince Alfred Hamlet, or Bella Vista, which are two smaller towns close to Ceres. Participants ranged in age from their late teens to late 60 s, and consisted of a roughly 50/50 split of males and females. Almost all of those attending the workshops were affiliated in some way to either Ceres Safe Space or WRDC, and because of the involvement of Ceres Safe Space, about five out of the 28 participants in the workshops on any given day were openly gay men. 
On the final day of the workshops, I conducted two focus groups. One involved three staff members from WRDC who had been attending the workshop, and the second involved ten participants of the workshop who volunteered to be part of a focus group. During the workshop in the morning, the facilitators had asked those who were willing to be part of a discussion group to remain inside during their lunch break, and these ten participants formed the focus group. The group had five males and five females, all coloured, and ranging in age from 16 to their early 60 s. Four of the five males were gay men from Ceres Safe Space.

The focus groups discussed three main topics which aimed to uncover how the intervention impacted on participants, and why. Thus, the focus groups discussed why participants joined the workshops and how they had heard about it, then looked at which aspects of the workshop impacted on them the most, before turning to how they hoped to use what had been covered in their future work. Due to the fact that I had been present at all four days of the workshop, a relationship had already been established between myself and a number of the participants. I had heard their discussions and debates about numerous topics over the course of the workshop, and this meant we had shared experiences which we could refer to during the focus group. In addition, this helped to create a more relaxed atmosphere in the focus groups, and we were able to start discussions almost immediately, without needing much in the way of introductions or explanation of terms and concepts. However, one difficulty was that the participants often moved into simply chatting, or recounting stories of their work and community involvement, and it became necessary to occasionally interrupt them and bring them back to the topic at hand. This will be discussed in more detail in the section on self-reflection below.

Around three months later, I returned to Ceres to conduct follow-up interviews with participants from the OMC workshop, and these participants were contacted by a staff member from WRDC, who acted as my contact in Ceres. All interviews took place in the WRDC offices over the course of two days, with five one-on-one interviews being carried out the first day, and a further two on the second. Initially there were 10 interviews scheduled, but three participants did not arrive, and therefore only seven follow-ups were conducted. Four of the interview participants were gay men who were connected to Ceres Safe Spaces, either working there or using their services, and the fifth man worked with WRDC. Two women were interviewed, one of whom was employed by WRDC, and the other who volunteered for them. All seven interview participants were coloured, and ranged in age from mid-20s to early 60 s, but as I did not specifically ask their ages, this is an estimation on my part. 
The interviews were semi-structured with open-ended questions, lasting from 30-45 minutes, and were conducted in English or Afrikaans, depending on the preference of the participant. The interviews began by asking in more detail about why participants had joined the workshops, and then returned to what aspects they remembered the most or felt had the most impact on them. This was following by asking whether they had remained involved in community education or mobilisation since the workshops, and finally turned to asking whether they were able to use what they had learned in their daily work and life in the community. Thus, the general focus was on the factors which impacted on participants in terms of encouraging them to join the intervention and to remain involved in community education and mobilisation after its completion, as well as which specific aspects from the workshops they felt had the biggest impact.

\subsubsection{Focus group - Gugulethu}

The third focus group took place in Gugulethu, a township roughly 20 minutes' drive from Cape Town, at one of Sonke's satellite offices. There were eight participants, all of whom were black. Five of these were Community Action Team (CAT) members who had previously attended OMC workshops and were gathered for training, two participants were Sonke facilitators, one of whom had initially been an OMC workshop participant and CAT member and who was later hired by Sonke as a facilitator, and the final participant was a new Sonke staff member who wanted to participate in the workshops to see what they entailed. The age range was quite broad, from early 20 s to mid-50s, and there was a 50/50 gender split (four men, four women).

The initial intention was for me to observe a two-day workshop, and then conduct the focus group at the end of the second day. However, the first day started very late, and it was ultimately decided that I would conduct a focus group on the first day, and that a shortened version of the workshop would take place on the second day. Due to the fact that seven of the eight participants had previously attended OMC workshops, it was more of a follow-up than a standard workshop, and only certain topics were covered. This focus group went on much longer than the one in Ceres, lasting for an hour and 45 minutes. After consultation with the workshop facilitators, it was decided to conduct the focus group in English, as it was a common language that all participants could speak at either second or third language level.

Participants in this group had spent a considerable amount of time together, both during previous workshops and in ongoing involvement in CATs at Sonke, and therefore had established strong bonds and friendships which enabled an easy conversation between members of the group once the conversation began. However, because it was my first time 
meeting the participants, there was a greater distance between myself and the participants than there had been in Ceres. To try reduce this as much as possible, I spent some time both before and after the focus group answering questions about myself and my research, as a means to try and establish some rapport with the focus group participants. Along with this, there was a significant language gap, as even though all participants could speak English, it was not a first language for any of them, and this created frustration at times, when they were unable to properly explain what they wanted to say in English, and I could not understand if they spoke in their first language (either Xhosa or Zulu). Thus, occasionally participants would just speak in their first language, and other participants would translate for me. The focus group once again had four main topics, beginning with asking how participants had initially become involved in the OMC workshops, before discussing which aspects of it had impacted on them the most. After this, the focus turned to how they used the content of the workshops to assist in their day to day work in the communities, finishing with some discussion about what factors in the community either helped or hindered their ability to maintain the impacts of the workshops.

The workshop on the following day had five participants, four of whom had attended OMC workshops before, and one who was a new staff member at Sonke and was participating in the workshops for the first time. In this instance, the workshop had quite a stilted feel, and this may be due to a number of reasons. The group in this workshop was very small, which diminished the opportunities for discussion, and almost all the participants had already attended similar workshops, which meant that the topics under discussion were not new to them. An alternative possible reason is that the workshop was conducted almost completely in English for my benefit, which was a second or third language for all the participants, with the group pausing to translate what was said if participants spoke in Xhosa or Zulu. These reasons meant I was unable to remain a relatively silent observer in this workshop, and I was asked to act much more in a participant capacity, being involved in activities and discussions. I was a bit reluctant to get too involved, as I felt that this was then heavily impacting on both the content and process of the workshop, with both facilitators and participants 'staging' the workshop for me, which limited the usefulness of my observing the process. My difficulty in remaining an external observer is discussed in more detail in the self-reflection section.

\subsubsection{Beyond the Bars focus group - Gugulethu}

A fourth focus group was carried out with members of the Beyond the Bars support group. As described in a previous chapter, Beyond the Bars is a support group for ex-inmates who took part in OMC workshops while in prison, with the group meeting every two weeks at the Sonke satellite office in Gugulethu. In this instance, I was invited to sit in during the support 
group, and then carried out the focus group afterwards. There were five participants and one facilitator present, all of whom were black men. While this was not technically an OMC workshop, members of the Beyond the Bars group would have attended OMC sessions while they were in prison, and then chosen to remain involved in Sonke's community mobilisation initiatives after their release. I was therefore interested in understanding how and why these men would have chosen to get and stay involved in this kind of intervention. Along with this, while not all the men would have necessarily been in prison for using violence against others, it was interesting to discuss a gender-transformative intervention with men who had spent time in a hypermasculine and very violent total institution such as a prison. If the workshops were able to have an impact on men even in such a hostile environment, it suggests that the intervention is applicable in a very wide range of situations. The majority of the conversation during the support group was in either Xhosa and Zulu, so I could understand very little of it and in this instance, I preferred not to have translation done for my benefit. This allowed the participants to carry out their support group without the constant interruption of having to translate for me, and although it was useful to observe one of the support systems in place for those completing OMC interventions, the actual content of the support group discussion was less relevant to my research. I therefore did not record the support group. Once the support group was complete, I carried out a focus group with the five participants which lasted for around 45 minutes. The discussion covered how participants had become involved in Sonke programmes, the impact that they felt the intervention had on them, and how others in the community viewed their participation. Thus, once again the focus was on the impact of the intervention, and the impact of societal factors in encouraging participants to get and stay involved in the intervention.

As a number of the participants have been attending this support group for quite some time (up to four years in the case of one participant), they had a well-established connection and rapport with each other, which meant that the conversation between them was able to flow relatively easily. However, I had spent very little time with the group, and this meant that it took some time for the discussion to start properly, yet participants were surprisingly willing to openly discuss quite personal issues once they had become more comfortable. Once again, the language issue was significant, and often led to frustration on both my part and that of the participants, and this will be discussed in more detail in the limitations section below.

\section{$\underline{6.3 .5 \text { Interviews with facilitators and practitioners }}$}

Along with the focus groups, one-on-one interviews were conducted with a number of Sonke employees, and with those who work in the area of GBV-prevention at other organisations. 
Two Sonke facilitators and two Sonke workshop planners were interviewed, all four of whom were male, and two were black, one coloured, and one white. In addition, practitioners were interviewed at three other organisations which do not have a specific masculinities focus. The first practitioner is a white male who works in a support office for discrimination and harassment at a university, while the second is a coloured female working for a reactive women-focused organisation which focuses on GBV, and the third is a black female working in an LGBTIQ support organisation, which also focuses on GBV. Along with these, two authors who have written on the topic of masculinities and GBV were interviewed, both of whom were female, one white and one black. Thus, nine practitioner interviews were carried out. All practitioner interviews were semi-structured with open-ended questions, taking between 30 and 60 minutes, and the majority of these interviews took place in the participants' offices or workplace. In two instances, the interview was conducted telephonically, while in a third instance the interview took place in a coffee shop. As with the other interviews and focus groups, these were audio-recorded with permission, and transcribed before being coded.

The interviews with Sonke workshop facilitators focused primarily on their experiences of facilitating masculinities-focused interventions, discussing which aspects they perceived as having an impact on participants, what changes (if any) the facilitators could see in participants' behaviour or attitudes as a result of the workshops, and the facilitators' opinion on how to increase the scope of masculinities-focused work to reach a broader audience. Interviews with practitioners from other organisations and with authors who have written on the topic of GBV had a broader focus, which began by asking about their opinions on the causes of GBV in the country, and ways to respond to and reduce this, and then moving to their opinions on the usefulness of masculinities-focused interventions as a means to address this GBV. As the majority of these other practitioners do not work at organisations which have a specific masculinities focus, it was interesting to gain a perspective on alternative ways to respond to GBV, and to hear their reasons for why they employ their current strategy.

Thus, the interviews and focus groups as a whole were primarily interested in participants' experiences of the intervention (i.e. Which aspects made an impact, and why), as well as the societal norms and factors which influenced both their participation in the intervention and their ability and willingness to maintain any positive impacts that they experienced. This is intended to try and fill some of the gaps in the literature surrounding masculinities-focused interventions which were outlined previously. However, as was briefly mentioned above, there were a number of limitations to the study, both regarding logistics and my own identity in the process of the research that need to be mentioned. 


\subsection{Limitations}

There were a number of limitations which arose during this study, both theoretical and methodological, and these are discussed in more detail below. The primary limitation was the sample bias of workshop participants, along with the presence of Sonke staff members during focus groups. Added to this, there was a lack of research on family members or partners of the participants. All of these aspects have potential impacts on the research findings, and these potential impacts are also discussed below.

A methodological limitation was the potential sample bias of workshop participants. Due to the fact that $\mathrm{OMC}$ is a voluntary programme, those involved are likely to already agree with the aims of the programme, and therefore are more likely to want to sustain the effects of the intervention in their lives going forward. Hence, their experiences may be different to those of other men and women in the broader community. However, the aim of case studies is usually not to generalise the results to other contexts, but rather to generate a rich amount of data on the respondents used (Bryman, 2008). Thus, this study can help to provide more detailed information on the people who do self-select for masculinities-focused interventions, rather than on the general population in a community.

In practical terms, although it may have produced an interesting comparison, it would have been very difficult to obtain feedback from those who are not currently part of any Sonke activities or programmes, which could have included those who had attended the workshops, but opted not to remain involved after their completion, or those who had chosen not to become involved in workshops in the first place, as finding and contacting these groups would likely have proven complicated. Setting up the existing follow-up interviews took an enormous amount of time and effort, even though it involved people who were willing to be contacted and interviewed, which suggests that finding details and setting up interviews and focus groups with those who were unwilling to remain involved in Sonke's programmes would have been even more difficult. However, understanding the reasons why participants choose to not remain involved is also an important aspect which has predominantly been ignored until now, and this is an area which requires more attention in future. An additional practical limitation is that a suitable basis for comparison would have to have been drawn up, and considering the wide range of people who attended the OMC workshops, this would have been complicated. Participants were very diverse: both male and female, ranging in age from late teens to mid-60s, homosexual and heterosexual, working and unemployed, married, single and divorced, from a wide range of communities. Thus, creating a relevant comparison group would have been complex. 
An additional way in which this sample bias could have been addressed would have been to interview family members or partners of participants, and this is a further limitation of the current research. Interviewing family members or partners would have provided some information on the impacts that they saw the intervention having on participants, as well as on how the intervention is viewed from the outside. While this was something I was hoping to do during this research, it proved difficult to try and organise for much the same reason as finding those who had opted out of the intervention and chosen to not be involved in the first place. Contacting family members or partners would have required going through the participants to gain permission and access, before setting up and conducting interviews with people with whom I had no formal connection. However, despite the difficulties that this would have entailed, this would have been an important additional source of information, and this is another area which requires further research in future. Despite this limitation, the issue of sample bias was addressed to a small extent by interviewing practitioners at other organisations, which provided some external input to weigh against that from participants and facilitators of the Sonke workshops. While practitioners at other organisations are mostly positive about the kind of work that Sonke does, they were likely to have felt less 'obliged' to avoid negative feedback. This therefore acted as at least some counter to the sample bias of those attached to Sonke.

An additional limitation was my perceived identity in relation to Sonke, as I was often introduced to workshop participants as someone attached to or working for the organisation. This may well have impacted on the kinds of responses participants were willing to give to me, as they may have been concerned that negative answers would be recorded and shown to Sonke staff, and this was exacerbated in cases where Sonke facilitators sat in on focus groups. However, because my access to the workshops and focus groups was wholly negotiated by Sonke staff, I did not really feel able to ask the facilitators to leave the focus groups, and this was therefore an issue in three out of the four focus groups I conducted.

In the first Gugulethu focus group, both of the workshop facilitators present had been participants of OMC workshops in the past, and their experiences of the workshops had strongly influenced their decision to later become involved at Sonke full-time. Thus, they participated in the focus groups as both workshop participants and facilitators. However, it did feel as if their presence impacted on the responses from other workshop participants, who stuck to mostly positive answers about the workshops. However, participants who have stayed involved in Sonke initiatives are already more likely to feel positively about the programme than those who have not, and their positive feedback may have had little to do with the presence of Sonke staff. This once again links to the point raised above about the importance of case studies to provide an in-depth picture of an intervention, rather than to 
provide generalizable results. In Ceres, one Sonke facilitator observed the focus group but did not take part in the discussion, and this seemed to have slightly less impact on participants' responses than in the Gugulethu focus group. The lack of impact of the facilitator's presence may have been due to the larger group size (10 focus group participants), and to the fact that the group came from a small community and were relatively familiar with one another already. Thus, their conversation was quite open to begin with, with less attention paid to the facilitator.

As an additional means to try and address this, in the case of the Ceres focus group I carried out follow-up interviews with seven of the initial ten focus group participants. These interviews were organised by someone from the WRDC and were carried out at their offices, meaning my contact with the group was no longer primarily facilitated through Sonke, and as a result of this, I was better able to explain my positioning with regards to Sonke. This meant that participants were less likely to feel that negative feedback from them would be relayed to the organisation, or result in repercussions for them. Unlike in the case of the participants in the Gugulethu focus groups, the Ceres participants had relatively little ongoing contact with Sonke because the community is outside of Sonke's normal area of operation. Thus, they were less likely to answer out of a sense of 'loyalty' to the organisation, or because they were concerned about the impact of any negative feedback, and this hopefully resulted in their feeling more able to give answers which reflected both positive and negative aspects of the intervention.

Although these measures will not have entirely balanced the sampling bias mentioned above, in some respects the fact of this bias is a part of why this intervention is useful as a case study. As noted in previous chapters, voluntary involvement in an intervention is more likely to result in positive and longer-lasting impacts than forced involvement, and the reasons why participants choose to engage and remain engaged in an intervention is therefore an important aspect to investigate, as noted by Dworkin et al. (2012). Thus, the bias expressed by a number of the participants became an interesting additional factor in this research. However, understanding barriers to people's involvement in such interventions is an aspect which requires further research in the future, and including opinions from 'comparison' groups (such as those who opted out of the OMC intervention) or family members of participants would have provided an important source of information here.

As was noted above, my difficulty in explaining my position relative to the organisation may well have had an impact on the data that I collected, but this was not the only way in which my identity played a role in the research process, and the following section therefore focuses on how my own identity and ability to facilitate may have been significant. 


\subsection{Self-reflection}

South Africa's history of political, racial and gender inequality impacted heavily on all interactions that took place for this research. Despite more than 20 years having passed since the first democratic elections, identity politics still play a major role in the country, and my own identity as a white, privileged, tertiary-educated female doing research in the field of masculinities therefore impacted on my fieldwork in a number of ways.

\subsubsection{Outsider identity}

As an initial example, in each of the workshops and focus groups, I was the only white person present, while all the participants and facilitators were people of colour, but it is difficult to know what the real outcome of this was, given South Africa's complex history. In some respects, it may have assisted me in terms of my being so visibly an outsider. I could be seen as a comparatively neutral external observer who would be unlikely to pass on any information I was told to those in the broader community as I did not know anyone in those areas. In Ceres, which is quite a small community where most participants knew each other prior to the workshop beginning, the fact of my being an outsider may have allowed interview participants to be more open in their conversations with me because of the relative anonymity of speaking to someone far removed from that community. However, my racial identity set me apart quite obviously in the sense of being an outsider in those communities.

The fact of being white in South Africa is generally assumed to be associated with privilege in numerous different spheres, such as wealth, education, and employment opportunities, and this can understandably often be a source of resentment. Additionally, being a white researcher doing fieldwork in communities where most residents are people of colour raises serious issues. For example, it can contribute to a sense of white people being seen as someone who can 'fix' or 'save' people of colour, or it can contribute to the assumption that GBV only occurs in marginal communities, an assumption which is present in much of the literature. In this instance, there were few other options available, as all the communities that Sonke works in the Western Cape are predominantly marginalised, with residents who are people of colour, and it was therefore difficult to access interventions in predominantly white communities. This therefore remains a major issue in the literature, and one which I am very conscious of potentially contributing to.

An additional obvious impact of my racial identity was on my ability to observe the workshops relatively unobtrusively, as I was always the only white person present. In the first workshop, which consisted of a large group, I was better able to observe without engaging in the workshop to any great degree. Although the participants were aware of me observing, which was highlighted by my obvious outsider identity, the large group size meant I could 
mostly remain outside the content of the workshop and not take part in the activities. Occasionally efforts were made to specifically include me, but for the majority of the sessions, I was able to observe without impacting too heavily on the content and discussion that took place. However, the second workshop was much smaller with only four participants, which meant that my being in the room was much more noticeable.

In addition to my obvious racial outsider identity, I also could not always understand all the banter and local slang, especially when it was in a different language. The language barrier was often significant, and meant that there were situations where large parts of the conversation had to be translated for my benefit, which occasionally created a stilted feel in the discussion, as participants had to wait for the translation before they could continue speaking. In addition, it was difficult for me to know how accurate the translations were, as I was reliant on those in the group to translate for me. Involving a translator was a possibility, but this would have created additional issues, as a translator would first need to be relatively neutral and acceptable to those in the group. If the translator was from the community, this could have raised worries about whether or not they would maintain the confidentiality of those in the group, and this would then have impacted on how open participants were willing to be in the discussion. If the person was from outside the community, it would have been an extra outsider to introduce to the group and attempt to get comfortable with in a short space of time. Due to the fact that all the participants spoke at least some English, I opted to rather conduct the focus groups myself and allow the participants to translate for me.

Along with my racial identity, an additional aspect was the fact that I was very obviously from a different economic background to the majority of workshop participants. While I could drive to the focus groups in my own car, most participants were either walking or had come by bus or minibus taxi. This then raised difficult questions of how extractive or exploitative my research was, in terms of how I could compensate participants for being involved. In most cases, I would cover transport costs for those involved in the focus group, and contribute towards food and drinks, although in one instance, my offer for this was turned down. In other instances, the remuneration of travel costs was taken as an incentive to join the focus group, with one participant in Gugulethu saying, 'Yes sissie, we all will be involved, we want the taxi money.'

In a third case, a participant asked for my phone number, so that he could phone me and ask for assistance in the future, and I was unsure how to respond to this. I knew that I did not want him to have my private number, and did not want to be phoned in the future to be asked for favours, but I was also very aware that the favours he asked would likely be relatively minor in terms of what I could afford, and that I was indebted to him and his fellow 
participants for agreeing to be a part of my focus group. In this situation, I was 'lucky' in that the participants had to leave quite quickly at the end of the focus group to catch their transport, and there was no time for him to follow up on his request. Thus, the issue of how to adequately compensate someone for participation in my research is one which I have not yet resolved.

A further issue is the fact that it is likely that my research will have minimal, if any, impact on the lives of the participants. The organisation may slightly adjust their programmes or workshops because of it, but it is unlikely to result in any real-life impact for the majority of them, and this once again points to the extractive nature of this research, in that I am taking something out, but not putting much back. I have yet to work out a satisfactory way of sharing my research findings with the participants, who in a number of cases have been interviewed more than once because of their involvement in a high-profile and wellrespected intervention. While I can share my final dissertation with Sonke and with the other local NGOs who assisted me, a 200 page document is unlikely to provide easily accessible information to workshop participants. A condensed report may be more appropriate, but it is still difficult to work out how to disseminate this to all respondents.

Despite my outsider identity raising some difficult questions regarding how comfortable participants would be in responding to me, in the majority of cases participants were surprisingly open in their responses. Many were willing to be interviewed for long periods of time, or sit in quite lengthy focus groups. I tried to be as up-front as possible about the likely impact of the research, and I tried to answer as many other questions that participants may have had about my research as I could. While this did not necessarily negate all the difficulties outlined above, it at least contributed in some way to making the participants more comfortable and aware about taking part in the research.

\subsubsection{Workshop facilitation and resource constraints}

Along with issues relating to my own identity in the South African context, some interesting factors arose around the facilitation of the workshops more generally. As an example, I faced a dilemma of how far to engage with the content while observing workshops. In one instance, the facilitator stated that 'gender is the same as sexuality', implying that your sexuality will always arise out of your gender, with the general assumption that heterosexuality is 'normal'. This was in contrast both to my own understanding of the terms, and to the information that is contained in the resource manual for the workshop, which explicitly separates gender from sexuality, and I was therefore unsure how to respond to this. I did not want to argue with the facilitator about it during the workshop because I was hoping to impact on the workshop content as little as possible, but I felt that it was a quite 
crucial aspect in a gender-transformative curriculum. This could also go some way to explaining the finding in the 2015 study by Viitanen and Colvin described in the previous chapter, which suggested that participants were more willing to afford human rights to women than to those in the LGBTIQ community. In this instance, I decided not to raise the point during the workshop, as the way in which masculinities-focused interventions are carried out was part of the focus of my research, and this included both positive and negative aspects of the process.

This aspect also highlights the fact that the NGO does not carry out facilitator evaluations, meaning that once facilitators have received the resource manuals and observed a number of workshops, they begin to facilitate and are not evaluated again. To a large extent, this is due to resource constraints, as Sonke conducts a large number of workshops across the country at any given time, and it would be difficult to carry out continuous evaluations of facilitators in all the workshop sites. However, this may be something that needs to be changed in the future, as the content of the workshop may become quite distorted over time if the facilitators are not at least occasionally monitored or evaluated, and this risks damaging the reputation and message of both the intervention and the organisation as a whole.

\subsubsection{Facilitation of focus groups and interviews}

Regarding the practical aspects of conducting the fieldwork, I found that the facilitation of focus groups was sometimes quite difficult. Some focus group participants were much more willing to talk than others, which often resulted in certain members interrupting others, or taking over the conversation repeatedly, and this was primarily an issue in the Ceres focus group which had the most participants. I tried to interrupt as little as possible, as I was hoping for a relatively unrestricted conversation on the topics being discussed, but on certain occasions I intervened to try and stop single group members from monopolising the conversation. Along with this, participants sometimes began simply relating stories about their own experiences which had little bearing on the topic being discussed, and on these occasions I had to step in to bring the conversation back on track.

Focus group facilitation was less of a problem in the Gugulethu focus groups, and this may be partly due to the smaller group size, as there were fewer participants and opinions to manage. Alternatively, the fact that participants were speaking in their second or third language in the Gugulethu focus groups may also have inhibited their conversation somewhat. In Ceres, most participants spoke in their first language (Afrikaans) during the focus group, which I was able to understand and respond to, but speaking in their first language was not possible for the Gugulethu focus group participants, who either had to 
speak in their second or third language, or wait for someone to translate what they had said into English. Having said this, it was not difficult to encourage these participants to talk, and there was seldom a time when I had to specifically ask individuals for their opinion on an issue. For the most part, they were quite eager to talk, even with a language barrier.

When facilitating the one-on-one interviews, one of the most difficult aspects was if participants began to describe violence that they themselves had either experienced or perpetrated. This was not something that I asked about at any point, but it was mentioned in almost every single interview, and it was difficult to know how to respond to this. On the one hand, I was trying to keep participants on the topic of the intervention, rather than becoming engaged in life narratives. On the other hand, I was unwilling to cut someone off while they were discussing their experiences of violence. For the most part, I would allow the participant to finish their point, before trying to steer the interview back towards the general interview schedule. However, an unexpected result of the constant references to violence is that it added an important dimension to research, which related to the prevalence and normalisation of violence in the country. This prevalence also described the kinds of conditions that most participants lived in on a daily basis, therefore providing an interesting description of the levels of violence that are experienced by many people in the country, and suggesting possible reasons why participants may have chosen to become involved in the intervention in the first place.

\subsubsection{Female doing masculinities-focused research}

A final aspect which arose is that of being a female doing research on masculinities, and this once again relates to trying to do research on a group while being an 'outsider'. Along with my racial, economic and language differences from the participants, in a number of situations I was the only female, and being female and asking male participants about masculinities and violence can be complicated. In past research, I found that male participants would either try to shield me by not talking about violence, or shock me by being very graphic in their descriptions of it, and I wondered if the same would occur in this research. In the current research, there was little specific discussion of personal use of violence, and all participants had already attended a masculinities-focused workshop, so were much more aware of gender dynamics and violence. Despite this, there was still an obvious gender difference which may have impacted on the kinds of topics that men would have been willing to discuss with a female interviewer. It is likely that most male participants would have 'censored' their conversation to a greater or lesser degree because of my being a female, meaning that a male interviewer may have got very different responses. In one case, a male in his mid-60s became very uncomfortable about mentioning sex during his interview, and while it is unclear whether this was a generational issue or because he did not 
want to discuss sex with a female, it is unlikely that a male interviewer would have got the same response.

However, an interesting factor that I had not originally anticipated is the fact that some of the one-on-one interviews were conducted with gay men, and this once again could have impacted on how comfortable they would have felt in responding to questions from a female interviewer. So much of masculinity is tied to heterosexuality, which can lead to gay men feeling very uncomfortable in discussions with heterosexual men, and this discomfort was mentioned a number of times by the interview participants, who mentioned feeling like they were not 'real' men, or of being harassed because of being gay. In these instances, the fact of my being female may actually have helped them to feel more comfortable in discussing issues with me.

In many ways, my own identity in the South African context impacted on my fieldwork quite heavily, particularly in the sense of being an 'outsider' doing research on communities that I am not a part of, and potentially contributing to the worrying stereotypes that the only ones who perpetrate violence are people of colour in marginalised communities. As far as possible, I tried to counter this in my explanations of the literature and my own findings, and hopefully this offset the impact of my outsider identity to at least some extent. However, the issues relating to the potentially extractive nature of my research, and the difficulties in how to appropriately prevent or respond to this, is something I am still struggling with.

\subsection{Ethical considerations}

Ethical approval in accordance with the regulations of Stellenbosch University was adhered to. All participants for focus groups and interviews read and signed an informed consent form prior to the focus group or interview starting, and consent forms were available in both English and Afrikaans, with the content being explained if participants did not understand the form. All interviews and focus groups were audio-recorded, with consent from participants, but no identifying features (e.g. name, age) were recorded, and I explained that no other person would have access to the recordings, which would be stored on my passwordprotected computer. I also explained that they could withdraw at any stage during the focus group or interview, and their recording would subsequently not be used for the study.

Although none of the questions discussed experiences or perpetration of GBV, there was a possibility of this being raised by participants, and a counsellor's details were therefore made available for free sessions, if any participants felt this was necessary. If participants had to specifically travel for an interview or focus group, they were reimbursed for their travel costs, at a rate agreed upon in consultation with either the Sonke facilitators or the local contact person. 


\subsection{Conclusion}

The methodology used for this research was useful in some instances, while being somewhat limited in others. While participant observation was effective in the larger workshop group, it often played more of an inhibiting role when I tried to observe smaller groups, in that it resulted in workshop participants being very aware of my presence and adapting their behaviour accordingly. Participant observation was therefore less helpful in these instances in terms of seeing how the workshop was implemented. However, the focus groups tended to be richer when they had fewer participants, and to generate more significant discussion specifically on the impact of the intervention. The one-on-one interviews with both participants and facilitators were also helpful in discussing topics in more depth, and this was often where participants discussed violence in the South African context. In relation to this, the decision to allow themes to be generated from the research rather than pre-deciding them meant that a number of interesting topics arose which I did not anticipate in advance, and this contributed some unexpected additional areas of focus.

In some ways, the fieldwork for this research was limited by the realities of masculinitiesfocused work in South Africa, in which there are few organisations implementing these kinds of interventions, and those that are being implemented are predominantly conducted with people of colour. These limitations therefore impact on the generalisability of the results of this research. While the intention in this instance was to focus on a specific example and provide in-depth information on it, rather than to produce results which could be generalised to other contexts, the limitations in this study nevertheless point to a number of gaps that could be addressed through future research.

A primary example is the overwhelming focus on marginalised communities in literature on masculinities-focused interventions. However, there are few opportunities for producing research on interventions in more affluent or white communities, considering how few such interventions are currently being implemented. An option to address this could therefore be to conduct interviews or focus groups in more affluent communities on similar topics, such as their opinions on the causes of violence and GBV, and the best ways to respond to it. These could act as an interesting comparison with those of participants of the workshops from more marginal communities. It may also be worthwhile to see how members of more affluent communities responded to researchers, considering that they are a much-less 'researched' group, meaning that far fewer researchers conduct research in affluent areas, and this could lead to quite different responses from participants. This is therefore an important area for future study. 
The issue of creating some distance between myself and Sonke in the eyes of participants was one that I struggled to address. To some extent, this was modified in the one-on-one interviews, and through interviews with participants from other organisations, yet the bias towards the organisation was quite apparent in a number of the interviews and focus groups. The lack of options for masculinities-focused interventions makes a broader view quite difficult to achieve, and it is therefore hoped that based on the positive evaluations which have been produced thus far, more of these interventions will be rolled out in the future. An alternative manner in which to get a different view on the organisation's activities would be to interview participants who chose not to remain involved in Sonke's initiatives after completion of the workshop, or the family members of participants, and these are both additional areas that require future study.

The complexities of my own identity in the South African context and in relation to the fieldwork participants are difficult to unpack, and it is hard to know exactly what the impact was, especially as this is likely to have been different in each situation. These identities will remain a factor in research in the South African context for quite some time, but hopefully awareness of these issues can go some way to making their impact useful in the research, rather than a drawback. Thus, I attempted to keep these limitations and concerns in mind while writing my own findings, and these are discussed in the following chapter. 


\section{CHAPTER 7}

\section{FINDINGS}

\subsection{Introduction}

There has been an increase in interventions which specifically target men and masculinities, both in South Africa and internationally, coinciding with a growing body of literature that discusses and evaluates these interventions. These evaluations often include details on the design of the programmes and self-reports from participants on measurable outcomes of the interventions. However, there has been less attention paid to the reasons for participants becoming involved in the workshops, which aspects of the workshops have the greatest impact on participants, and the reasons why participants remain involved in organisations after completion of the interventions. While the content of the workshops is important to consider in terms of what messages to spread among participants, the reception of that content and the aspects that improve that reception are equally important to look at. Thus, because of the lack of existing studies on how a masculinities-focused intervention affects participants, the current research primarily looked at three aspects: the reasons for participants choosing to become involved in the intervention, which aspects of the intervention had the biggest influence, and what factors contributed to participants being able to sustain any positive impacts that they experienced.

Participant interviews are discussed first, and focused mainly on which specific aspects of the intervention made the biggest impact on them. Along with this, the discussion looked at what encouraged participants to become involved in the programme, and to remain involved after the workshops were completed. The chapter then moves on to interviews with facilitators or practitioners in the field, which mainly looked at which aspects the practitioners felt were most influential. Following this, the chapter looks at three aspects which had similar responses from both facilitators and participants: the lack of government response to GBV, experiences and levels of violence in South Africa including opinions on the causes of this violence, and the impact of masculinities on violence in the country. The final chapter then places these findings in the context of the literature which has been discussed throughout this dissertation.

\subsection{Responses from participants}

This section begins with an overview of the reasons participants had for joining the intervention, followed by the specific workshop activities which participants could remember, and the broader aspects of the intervention which participants felt had the biggest impact on them. 


\subsubsection{Participants' reasons for involvement in the workshops}

Understanding the reasons why participants were initially interested in attending the workshops can provide some guidance on the areas to focus on in order to expand the reach in the future, along with gaining some understanding of the societal factors that influence participants to want to become involved. The reasons provided varied considerably. A primary reason stated by a number of participants was a desire to be able to help in their communities, or to expand their skill set in order to improve the impact that they could have. As was described in the methodology chapter, some had already been involved in community development through various NGOs or local organisations, and therefore joined with the intention of skills development. However, others became more inspired to do so after attending the workshops, and this was true in both the rural and urban focus groups.

Some participants became engaged in the workshops as a means to enable themselves to expand or improve their existing community-focused work, and this was particularly noticeable in the Ceres workshops. One participant put it simply: 'Ons is hier om ' $n$ verskil te maak' (We are here to make a difference), with another stating, 'Ons is rêrig hier om vir die gemeenskap iets te beteken' (We are really here to mean something for the community). This learning process was seen as a form of empowerment, with participants joining 'in order to help myself um to empower myself... because it was mostly self-development'. This suggests that many participants had an existing desire to have a positive impact in their communities, which may not necessarily have been related to a desire to be involved specifically in a masculinities-focused GBV-prevention intervention.

Additionally, this suggests that there may well be more people who have an interest in improving their communities, but potentially do not know how to go about it. Participants agreed that the workshop was helpful in giving them new skills to be able to do their work more effectively, which may suggest that they had initially felt unsure about how to have an impact in their communities. One participant stated, 'it gives us a better perspective of how to deal with things. And for enabling us to go out and help, and assist where assistance is needed'. In a follow-up interview, another participant agreed that, 'we can use that information that we gained there, and to help to put it back into the community'. A third participant from the Ceres focus group also believed that 'we are now able to go back and educate our children, our husbands and our wives at home ... You are now enabling others and yourself'. The newly-gained knowledge about community mobilisation was more likely to be mentioned by those who had an existing involvement with local organisations, who assumedly would already have some idea of how to engage in community improvement. This could therefore provide support to the suggestion that those who are not currently involved in a local community organisation may not know how to do so. However, even 
those who previously had not been involved in community-focused work felt encouraged to do so, with one Ceres participant who was not a member of any local organisations saying, 'Is lekker om iets te doen vir iemand wat nie bevoorrêg is nie. Een van die basiese dinge wat ek geleer het' (It's nice to do something for someone who is not privileged. One of the most basic things that I learned.) The sense of community responsibility was therefore an important mobilising factor to join the intervention for many participants.

Importantly, many participants were determined that this motivation needed to be sustained without the involvement of external organisations. One participant summed this motivation up quite neatly by saying, 'die verskil moet nou nie buite gemaak word nie, die verskil moet by jouself gemaak word om te kan... die verskil buite in ons gemeenskap to kan maak' (The change must not come from outside, the change needs to come from you to be able to... to be able to make the change outside in our community). This was especially the case in Ceres, a relatively rural area, where interventions were only conducted on an irregular basis. A female participant who worked in a local NGO asked, 'Ons het baie geleer maar... wat gaan ons nou maak?' (We learnt a lot... but what are we going to do now?) Another female participant from the same NGO agreed, saying, 'Dit gaan nie hier einde nie. Nie vir my nie, want die wat ek hier geleer het is powerful ... ons moet dit verder vat' (It will not end here. Not for me, because what I learnt here is powerful. We must take it further). Participants in the more rural focus groups felt that the content of the workshops was useful in helping to empower themselves and others in the community and to be more effective in their own work, and this was echoed by both male and female participants. One female participant, a former social worker in the area, said, 'dit wat ons hier geleer het, ons moet gaan toepas buite' (The things that we learned here, we have to apply it outside). The knowledge referred to by participants tended to be that which arose during the brainstorming sessions on the last day of the workshop, when participants discussed specific problems in their communities and ways to address them. This was seen as helpful in devising concrete strategies to respond to these issues.

These sentiments were often restated in the follow-up interviews with focus group participants. A number believed that the workshops provided important information and skills that were useful in improving their work in their communities. One participant who was involved with Ceres Safe Space believed that the workshops had been useful because 'we could take these information [sic] that we got from these workshops, and implement it in our own groups'. A female participant who worked for WRDC stated, 'ons [kan] dit in ons groepe gebruik, uh en kan begin mekaar onself te bemagtig' (we can use it in our groups, and can start to empower each other ourselves). 
Similarly, those in the urban groups felt encouraged to become more involved in community outreach as a result of the intervention. One participant in Gugulethu who had initially heard about the organisation's intervention while in prison and joined after his release stated, 'I like everyone out there, to engage with them, to try to change their mindset on gender-based violence, about gangsterism, you see'. Another who had joined the group while in prison stated that part of his motivation for getting involved was a 'personal choice that I'm gonna be involved in community upliftment initiatives ... that's one of the benefits for me'. A third believed that, 'merely by being part of these initiatives ... I can be involved in something positive in the community, which is rare'. In one case, a focus group participant had begun as a workshop participant and remained involved in CATs until he later became a workshop facilitator. He stated, 'I do this ... for the benefit of community ... I want to benefit from it, and also to be a role model in my community'. Thus, the opportunity to give back to their community was a strong motivating factor for many participants in both joining and remaining in the workshops and, as was highlighted above, the workshop was seen as an opportunity to better understand how to become involved in this kind of work.

Along with this, the name of the intervention - One Man Can - was specifically taken to imply both a sense of personal responsibility, and of personal empowerment, suggesting that each person can and should make a difference. One female participant in Ceres stated, 'soos die training sê, "One Man Can", ons kan 'n verskil maak. Ons moet besluit om dit te doen. Ons elkeen kan ' $n$ verskil maak' (Like the training says, "One Man Can", we can make a difference. We must decide to do it. We can each make a difference). A male participant in a Gugulethu focus group had a similar feeling: 'I like the word [sic] One Man Can ... in other words ... I can do what I believed, irrespective of the opposition belief ... nothing can discourage me'.

The desire to have a positive impact on their community was therefore a primary motivating factor for many participants in joining the intervention, suggesting that there is already a strong wish in these communities to become involved in similar positive interventions. However, other responses to the question of why they joined were more mundane or practical, with one participant in Ceres stating, 'OK, I have nothing to do with my time, so why not attend these workshops?' Another in Gugulethu had a similar motivation: 'I stay at home, I clean the home, then if I finish cleaning the home, I get bored ... So [for] at least two or three hours, let me go there, man.' In the more rural areas, where farming is the predominant industry, 'most of the people are unemployed as well, or they are season workers so they are six months at home', meaning that they had available time to attend the workshops. One female participant became involved because '[d]it het my uit-gestress het, ek het 'n drank problem gehad, en dit hou my besig' (It de-stressed me, I had a drinking 
problem, and it keeps me busy). In other words, the intervention was seen as an available way to fill time for those who were unemployed or only part-time employed. Participants becoming involved through boredom does not necessarily imply a desire on their part to help reduce GBV in communities, but their willingness to engage in an intervention in order to pass the time does suggest that this is a resource which the organisation can use to their advantage in spreading the message of the intervention more broadly. A potential option for broadening the reach of the intervention could therefore be to focus more on training past participants to be facilitators of workshops in the future.

Thus, many participants became involved in the workshops through a desire to improve their knowledge about how to have a positive impact in their communities, and this was true both of those who were already involved in community organisations and those who were not. The workshops were therefore seen as a means of learning concrete skills to help improve their communities, suggesting that many people have an existing desire to help but that they may not know how to do so. The second common reason was boredom, which suggests that there is scope for many more participants to become involved as facilitators in efforts to broaden the reach of the intervention.

The discussion in interviews and focus groups then turned to specific activities which participants could remember, as a way to try and uncover how the content of the workshops contributes to the impact that the intervention has.

\subsubsection{Workshop activities that had a lasting impact}

As discussed in previous chapters, the content of the OMC workshops is quite closely aligned with those of other interventions, and with the literature on how to design an effective intervention, and it is therefore useful to uncover which of these activities have a particular impact. I therefore found it interesting that participants could often remember very few of the specific activities, rather focusing on the over-riding impression that they felt during the workshops. This suggests that even when the content is well-designed and effective, it may not be the aspect that participants remember going forward. However, there were two activities which were specifically mentioned by participants as having an impact.

The activity which was mentioned particularly by those in the Ceres groups was one called Body Mapping, in which participants are separated into groups, and a large outline of a person's body is drawn on paper. Participants then highlight areas of the body that they find erotic or sensitive, and they then present this to the other group. As one participant stated, 'one that they definitely won't forget is Body Mapping! [laughs]'.

The first reason why this activity had an impact was that men and women in the groups were often surprised at finding out which areas of the body were considered erotic for the other, 
and this was also true for gay and straight men in the groups - many straight men were surprised to discover that gay men found the same areas to be erotic. One gay participant highlighted this by saying, 'If we look at what desires the heterosexual male has to the desire that a homosexual male has ... it's the same. Our bodies are the same'. This therefore enabled participants in the group to view gay men and lesbian women as similar to themselves, hopefully encouraging them to believe that gay men and lesbian women were deserving of the same treatment and rights as straight men and women. Considering that previous evaluations had found that workshop participants did not necessarily extend their belief in equality to those in LGBTIQ groups (Viitanen \& Colvin, 2015), this could suggest that it is important to have groups consisting of heterosexual and homosexual people in future, as a way to improve this recognition of LGBTIQ rights.

Along with the recognition of the similarities between heterosexual and homosexual people, a number of participants also mentioned that they had used what they learnt during the Body Mapping activity in their own relationships at home. One female participant stated, ' $E k$ is in ' $n$ huwelik, en ek het geleer wow, ek het nooit geweet daar's goed wat mans rêrig van hou nie' (I am in a relationship, and I learnt wow, I never knew there are things that men really enjoy). Another participant described a similar situation:

...dit was vir my verbasend hoe die ou mense deel gevat, en hoe hulle dit geniet het... hoe hulle teruggekom het die dag daarna en kom sê het, maar hulle het dit ervaar aan by die huis, en het daaroor gepraat met die man [laughs] (For me, it was surprising how the old people took part, and how they enjoyed it ... how they came back the next day and said they had experienced it at home, and spoke about it with their husband).

The fact that participants were able to use what they had discussed in their home environments seems to confirm the fact that participants appreciated learning concrete strategies, whether this related to community engagement or their own relationships. Thus, the provision of practical suggestions was an important factor for participants.

The only other specific activity that participants mentioned was Gender Values Clarification, described in Chapter Five, which they tended to view as an opportunity to empower themselves and argue for something that they believed in. One participant stated that previously he had often merely followed his friends' decisions, but through this activity, 'I will say it felt like my first time whereby I will take a decision based on my own personal feeling, or based on my own decision'. Another participant believed that the activity allowed participants to become involved in debates, where previously they had not expressed strong opinions. 'Suddenly around the courtyard, there were debates going on around the issue. And other people who were viewed as stupid ... they will be excelling in those kinds of 
debates'. Thus, the activity allowed participants to clarify their own position on issues and to feel that they could take a stand on them too. This is an important aspect to bear in mind considering the fact that these workshop participants are likely to be the ones who will be spreading the messages from the intervention into the broader community. The fact that they felt able to argue their position or explain their view to others suggests that they will be more confident using these skills when discussing the workshop with others, thereby enabling them to play a positive role in broadening the reach of the intervention in future. I would therefore suggest that the creation of a safe space for participants to 'practise' these arguments is a vital aspect of the intervention to maintain.

A final interesting point regarding the content of the workshops that participants remembered is that those in the Ceres intervention often mentioned the information around the LGBTIQ community as being the aspect that they remembered most. As explained in the methodology section, this information is not always part of the OMC intervention, but was included and highlighted in this instance because the invitation to provide the workshop was in response to a hate crime killing of a gay man in the community. One male participant mentioned that, 'ek het beter verstaan, ek het geleer van die homoseksueel en gay' (I understood better, I learnt about the homosexual and gay). A female participant in the same focus group added, ' $m m$, want ' $n$ mens het ' $n$ ander persepsie van dit gehad, en nooit met dit gedeel het nie ... So dit het ons baie van ons oë oopgemaak' (Mm, because a person has another perception about it, and never shared it. So many of us had our eyes opened). A gay male participant also believed that this was an important aspect, as it meant that those who had attended the workshop 'handle us with more respect nowadays'. A second gay male participant felt that the workshops provided an opportunity for their LGBTIQ community to provide information to the broader group, to enable them to understand their situation better. Thus, 'we were able to communicate effectively ... and cuz people were more open to ask questions they didn't understand. So we were able to answer as clearly as we could'. Thus, it is interesting that an aspect which is normally not included in the workshops was considered the most powerful for many in the Ceres focus groups and follow-up interviews. This once again seems to suggest that there is scope for the inclusion of both gay and straight participants in future workshops, as many people may not have much knowledge or understanding of the gay community, and the workshops could provide a forum for this information to be shared.

Despite the fact that many of the activities contained in the OMC workshops have been successfully implemented in other interventions and positively evaluated in the literature, it is interesting that many participants remembered little of the specific content of activities regarding the information provided. Rather, participants seemed to better remember specific 
skill sets that they learned, such as defending their position in an argument, which potentially links to the fact that many participants joined the intervention as a means of improving their skills in terms of community improvement. In other words, participants seemed to appreciate concrete suggestions of how to respond to certain situations, again suggesting that many people may be unsure how to be more involved in community interventions. However, beyond the specific activities that participants could remember, the two aspects which were mentioned by far the most frequently were the supportive peer group which developed during the workshops, and the presence of positive role models, and these two aspects are discussed below.

\subsubsection{Sense of community - a supportive peer group}

The impact which was mentioned most often by focus group participants was the sense of community that the workshops helped them to develop, and this is an aspect which is discussed in the literature as contributing to the effectiveness of masculinities-focused interventions. Those who attended the workshops in smaller and more rural communities such as Ceres spoke about getting to know other workshop participants better than they had before, and even though many had previously known each other in passing, the experience of sitting through the four-day workshop together seemed to have an important impact, resulting in participants feeling that they had developed strong bonds. As one participant asked, 'hoe kan ek dit nou sê? ... ek vat julle as my eie mense' (How can I say it? I take you as my own people); while another simply said, 'jy voel tuis, jy's by familie' (You feel at home, you're with family). Another Ceres participant noted, 'Ek het hulle gesien maar nooit rêrig gekommunikeer nie. En daai workshop het gemaak dat ons nader aanmekaar ... so't ons nader aanmekaar geraak na elke workshop' (I saw them, but didn't really communicate. And that workshop brought us closer together ... We grew closer together after each workshop.) Participants in more urban areas also discussed feeling like they had developed strong networks during the workshop, although few of them knew each other prior to beginning the intervention. As one participant in a Gugulethu focus group stated, 'I find people who did share the same experience as I did [sic], and we are free to talk to them ... I did think, "Hey, I've got a group, man, there I can discuss everything"'.

The reason why participants felt that this was important was that these networks provided important sources of peer support. Thus, being surrounded by similar-minded peers may have provided participants with a 'safe space' to discuss issues and ideas which they may have felt less confident about discussing in the broader community. For example, according to one participant in a Gugulethu focus group, 
...you connecting with others, you being able to share freely without the fear of being judging [sic], because you know, we are sat here, always with a platform. And it's also good to get advices here [sic] ... So ja, it's one of the spaces that are very rare to find in our community.

Another participant stated, 'Anybody that is a CAT [Community Action Team member], I trust them, and able to share my problem and they can help me'. This support could take a number of forms, including advice on how to deal with personal or professional issues, with one participant discussing business support that he had received from the group in the form of referrals for jobs, while others mentioned learning opportunities that they had accessed through their peers in the workshop. Thus, the groups became resources for support in other areas of their lives, beyond the content of the workshops.

Along with this, a number of participants added that the support they received from the workshop groups was in contrast to other people in their lives and broader communities, who tended to be relatively unsupportive of their involvement in the intervention. As one participant in a Gugulethu focus group noted, 'we don't get support in our families. We get support here ... we take them as our families'. Another stated, 'Honestly, in our families, we don't get any support, I mean most of us, we don't have any support'. Family members were reported to be concerned that participants were not bringing home monetary compensation for being associated with the organisation, with one CAT member complaining, 'our families only think about money, that's all that they are asking us'. Another participant had a similar complaint, saying that those who knew him were only interested in the free t-shirts and condoms that he received at NGO events: 'Whenever there's an outreach...now they all want those t-shirts from me... whenever they see me, they ask for the condoms'. This suggests that participants struggled to find support in the broader community, with family members and friends often being relatively critical unless participants were able to provide them with gifts such as t-shirts or condoms.

Supporting this notion, some participants explained that the workshops provided a safe space to discuss their emotions, which was not an option in the broader community, with one participant stating,

you don't get that kind of people in the community [sic] ...they not expect you to be hurt as a man [sic] ... you understand, you are a sissie, you are a moffie. So when you here ...people around here, they will relate to you, they will understand you, because you get a platform.

Thus, the workshops became an important site for participants, and especially men, to be able to display emotions. This is a behaviour which is often frowned upon, as hegemonic masculinities demand that men do not display emotions, fear or pain. Creating a space in which participants feel able to display these emotions can therefore be a powerful tool in 
problematizing gender norms, and contributing to the gender-transformative nature of these kinds of interventions.

A final aspect related to the notion of a supportive peer group was that some participants noted that creating a large supportive group in communities could create a new and potentially more positive form of societal pressure, meaning that the norms of the workshop group would become more widespread in the broader community. One participant in a follow-up interview in Ceres said, 'the more people see a bigger group of people who are willing to change, people will immediately go and think, "But what are they doing different than what l'm doing? Maybe they are doing something right"'. This was echoed in another follow-up interview with a member of an LGBTIQ support group, who stated, 'they handle us with more respect nowadays and they also want to know ... people is [sic] starting to ask questions about [the organisation], the LGBTI and everything'.

This suggests that the presence of a supportive peer group impacted on participants in a number of ways, primarily through helping to create a safe space in which participants could discuss and problematize the gender norms that are prevalent in their communities. Having a space in which to try alternative behaviours (such as men being able to display emotions) is an important aspect in gender-transformative interventions. Along with this, the support that participants experienced in the intervention was felt to be in stark contrast to the disapproval that they experienced from others in their lives, such as family members and the broader community. Finally, being involved in a group which encouraged more positive gender roles was seen as contributing to the shift of traditional or more conservative norms in the broader community.

\subsubsection{Role models - the importance of having and of being role models}

While the presence of a supportive group was overwhelmingly the most common aspect mentioned by focus group participants, the second most common factor mentioned was that of role models, but this took two forms. The first was that participants felt the workshop provided them with positive role models, while the second was that the intervention encouraged participants to feel as if they could be positive role models themselves, and it is to these two aspects that the chapter now turns. The lack of positive male role models is an issue which has often been noted in literature around masculinities. Along with this, the fact that masculinities-focused interventions can provide examples of positive male role models is an aspect highlighted for contributing to the effectiveness of these kinds of interventions, and this seems to have been supported by the findings of my own research. The presence of workshop facilitators as positive role models was mentioned as important by a number of participants. Thus, as one participant stated, 'These two person [sic] [the workshop 
facilitators] plays big role ... these two trainers, they changed myself. Finish and klaar'. For many participants, this was in stark contrast to many other men they came into contact with, who instead fulfilled a number of negative stereotypes associated with masculinities in communities. For example, one mentioned the lack of responsible men in his life, noting that often male family members were either absent or substance abusers. 'I came this side to stay with my um uncle. So my uncle was drinking a lot, and also he was rude.' Another mentioned that this was not only the case in his own home, but for others too. '[...] so some of the matters that uh made the young boys ... to start to smoke, to be gangsters. It's that they don't get enough support in their families ... Maybe the father is not there'. A third spoke about having to move home after his father 'was sentenced to jail because of a drunk driving case... so everything, it looks like everything just fell apart'. The lack of positive close male role models was therefore something which a number of participants felt strongly about.

Along with these negative family role models, others in the broader community were often seen as negative examples. Participants spoke about how rich gangsters were treated as role models, despite them having committed crimes, with one participant stating,

when you come from this place, the guys that you see, they not role models ... those are the guys doing the criminal activities with their fancy cars, their big clothes, things like that, they credit as role models in the township [sic], because they are the most, I would say, influential...

It could therefore be argued that these stereotyped characters contribute to a narrowly defined version of masculinity remaining prevalent in their communities. Along with this, the presence of gangsters in the community and the fact that they are seen as role models could potentially contribute to the maintenance of relatively violent versions of masculinities, as gangs typically encourage violence as a means of achieving the standards of masculinity. These gangs would therefore contribute to violence continuing to be seen as acceptable and expected for men in these communities.

Thus, facilitators acted as examples of alternative ways to present as male, in contrast to the predominantly absent or violent examples which seem to be the norm for many, which then gave participants a chance to model themselves on a positive image rather than a negative one, and this had an important impact. One such impact was that participants began to feel that they could be positive role models themselves. For some, this meant being able to provide a positive example within their own family, which was a gap that many participants described experiencing, and which they were now able to fill. One participant mentioned the importance of remembering to be a positive role model in his family, 'because sometimes we 
change the community and leave behind our family', while a participant in a Gugulethu focus group noted,

...we've also got younger siblings, some of us have got kids ... I've got a younger sister who is five years old. So as much as she doesn't say, she looks up to me, the man, and she also looks at how I do things ... we also need to be models ourselves.

Another participant, who had joined the programme while in prison, spoke about the impact the intervention had on an older fellow inmate:

an old man about 80 years ... will say "Hey, this programme is changing my life. Because now I can have a conversation with my young daughter ... I used to hear that she's naughty at home... [but] the way I approached it, it made it worse ... But these programmes, they made, have made me to have a conversation whereby I listen to her, whereby I speak to her, whereby I go to her at her age and understand, using my experience. And by that time, I understand".

For others, the opportunity to be a positive role model related more to being a positive influence in their peer group or community, with one participant stating, 'I can't change my community while I'm busy doing a wrong things [sic]... You have to change yourself before you change other people'. Another put it more simply: 'We want to be role models. We want to do... not to say, be excellent.' Thus, the desire to be a positive role model provided an incentive for the participants to modify their own behaviour, and this was a powerful impact arising from the intervention. Once again, this seems to relate to the fact that many participants joined the intervention in order to be better able to engage in community mobilisation and improvement, reinforcing the notion that the desire to improve their communities was a primary motivation for many to become involved in these kinds of workshops.

Along with the responses from workshop participants, I was also interested in hearing the opinions of workshop facilitators on what the impact of the intervention could be, and how it achieved this impact. The following section therefore focuses on the responses from workshop facilitators.

\subsection{Responses from facilitators and practitioners}

In this section, the majority of findings are from interviews with facilitators of the OMC workshops. However, one other practitioner's responses are included here because, although he was not specifically working at a masculinities-focused organisation, he had conducted masculinities-focused interventions in the past, and his experiences in doing this were often similar to those of the Sonke facilitators. Data from workshop facilitators was collected via one-on-one interviews, either face to face, or over the phone. Interviews with Sonke staff members began with a specific focus on the impact of the OMC intervention on 
participants, asking what they believed participants' reasons were for joining, and the aspects which facilitators saw as having the biggest impact. In addition, I was interested in what impact (if any) the workshops had on facilitators themselves. This section therefore begins by focusing on facilitators' understanding of why participants joined the workshops, before moving on to the specific activities that facilitators believed had an impact, and ending with the impact that the facilitators felt the intervention had on them personally.

\subsubsection{Participants' reasons for involvement in the workshops}

As noted in the chapter on masculinities-focused interventions, men who voluntarily joined interventions were likely to experience longer-lasting impacts and to be more committed to the ideology involved in the intervention. It is therefore important to understand why men decide to attend the interventions, and how to ensure that it appeals to a broad spectrum of men. Facilitators discussed ways to engage men in the programmes, as well as some of the difficulties they encountered in doing so. For example, one facilitator at Sonke explained that the organisation targeted, 'the positive men. We target the men who do not abuse their partners and their families. We target the men who are not found guilty, or who do not perpetrate gender and violent crimes, things like that.' These positive men could subsequently take these messages, 'into bars, into churches, into mosques, so that they can speak about the "new man". Because we not able to always go into those spaces, we not there when they having these intimate conversations [sic]'. This seems to confirm what was found in the participant interviews, where the majority joined the intervention through being 'positive men', meaning they were already relatively committed to wanting to improve their communities, and be positive role models for others while doing so.

However, as already mentioned, not all participants joined because of a strong ideological conviction, with some participants joining for reasons such as boredom. A practitioner reporting a conversation with an intervention participant, said, 'And he says "But they've got nothing else. So anything that can make a difference would be welcome"'. He continued by saying that often a catalyst may be needed to get others in a community involved:

$[T]$ he voluntariness is not always about, "Oh, I want to join a programme that's going to make me... into a new-age sort of man" ... you need someone that's just in the right place at the right time and making the right noises, saying "Why don't we start this?" And someone else will join a particular programme, because it kind of looks and feels like the right thing, but when inside the programme, the actual switch, or the moving closer to the idea that you've articulated, will happen.

This suggests that even in cases where participants may not necessarily join the intervention because they agree with its aims and goals, the intervention can still have a positive impact 
on them and encourage them to remain involved in community mobilisation after completion of interventions, as a means to expand the reach and get others involved. I would argue that the presence of a supportive peer group and positive role models would make participants more likely to remain involved, as these two factors would act as a form of 'peer pressure', albeit with a positive intention. Thus, a supportive peer group and positive role models could help to convince participants who joined out of boredom to remain involved in community mobilisation after the workshops are complete.

\subsubsection{Workshop activities that facilitators see having an impact}

The focus then turned to the specific activities that facilitators believed had the biggest impact on participants, and in some cases, these overlapped with the answers given by participants. For example, two facilitators mentioned the Gender Values Clarification activity, which was one of the two activities mentioned by some of the workshop participants. The reasons given by facilitators also seemed to be relatively similar to those provided by participants, with one facilitator believing that this impacted strongly on participants because 'it relates to when people's personal beliefs are being challenged'. A second facilitator felt that the impact arose because this challenge encouraged participants to translate those beliefs into action. In other words, '[it] is more challenging us in making a change... more trying to clarify those kind of things within the process of moving manhood'. Thus, facilitators also believed that the activity provided participants with a platform to practise explaining or defending their values, which would be useful in their discussions with those in the broader community.

A second activity that was mentioned by a workshop facilitator was called, 'Who's your role model?', in which participants identified someone that they admired (either a public figure or someone from their community) and explained why they considered that person a role model. The workshop facilitators would then discuss the image that this role model presented, which often had a number of negative aspects to it. As a facilitator explained, 'maybe this person, this celebrity, is doing this, and [you] think that's wrong, what can you do ... to change your own life according to what you see. Because normally violence is what we live in, and it's what we see'. This activity would therefore seem to reinforce the responses from participants regarding the lack of positive male role models available in their communities, both in their families and publicly. Similarly, the activity problematizes existing notions of what men 'should' be, and helps participants to identity alternative ways for men to behave. However, it is worth noting that this was not an activity mentioned by any workshop participants during focus groups, suggesting that perhaps it was not as impactful as the facilitator thought it to be. 
Interestingly, an aspect which might be assumed to be a given but which was only mentioned occasionally by facilitators was that participants were strongly impacted by the information and knowledge that they received during the workshops, and this therefore seemed to be something which participants valued more highly than facilitators expected. One such example was given by a facilitator who spoke about how men began to change their behaviour as a result of the information they received through the workshops: 'we see that more men are ... willing to assist their partner to know about the issue around HIV prevention, or the importance of using condom. Ja, so then that's firstly, the first impact'. Another reported a case of a husband altering his behaviour after the birth of his child, as a result of the intervention:

[he] used to drink a lot. But since he came to our programme, then he said, "I used to take like four or five beer. Maybe I think now I have to take only one, and then save the money for my uh unborn child, because this is going to assist".

This reinforces the fact that participants seemed to value learning specific behaviours or skills which they could use in their lives beyond the workshops, rather than simply discussing concepts. The inclusion of specific skills, in this instance referring to HIV prevention, therefore seems to be an important aspect to retain or emphasise more in future workshops.

The final aspect which facilitators and practitioners mentioned was that the intervention provided participants with positive role models, often for the first time. However, given that a number of facilitators had previously been workshop participants themselves, I was also interested in the ways in which they felt the intervention impacted on them as facilitators, and whether the presence or experience of being a positive role model was something that they felt was important. Thus, this section finishes by focusing on this.

\subsubsection{Role models - acting as a positive role model}

The issue of a lack of positive male role models in participants' lives was noted by some practitioners and facilitators as well, with one practitioner who had run a small-scale breadbaking programme for men in Mannenberg ${ }^{3}$ explaining that, 'amongst the group that I work with, I know that for a fact, that there were just absent fathers mostly.' As noted above, workshop participants often confirmed this, saying that there were a lack of positive male role models in their lives, and describing the facilitators as filling this gap, and the facilitators seemed to be aware of being able to play this role. For example, a number of facilitators and practitioners mentioned needing to be able to provide an example of the alternative versions of masculinity that were discussed in the workshops. Thus, as one workshop facilitator put it, 'the work that we are doing also works on us'. Another facilitator elaborated, saying 'it

\footnotetext{
${ }^{3}$ A predominantly coloured township of Cape Town.
} 
impacts my life, because I can't go out into the community and advocate for something and I haven't implemented it ... and it often challenges us to engage with it [gender-related issues] differently. So I mean, I'm still on a journey'.

The intervention therefore seemed to impact on facilitators in a similar way to how it impacted on participants, by giving them an opportunity to be positive role models for others. As an example of this, facilitators mentioned that the interventions could show men that violence does not necessarily need to be involved in their day-to-day presentation of masculinity. As one facilitator put it, '[we] show them that growing up in this violent community or in a violent house doesn't mean that we have to continue promoting this'. This is therefore a way in which the intervention begins to counter the predominantly negative stereotypes attached to masculinities in many of the communities in which the workshops are being run.

While the responses from participants and facilitators regarding the impact of the intervention did not always correspond, in many ways the answers were similar, and both agreed that the workshops could have a profound impact on participants. Thus, people who became involved in the workshops often did so in order to learn new skills regarding ways to improve their communities, with a predominant aspect of this being the opportunity to act as positive role models for others. The responses from participants regarding the biggest impact of the intervention therefore often focused on specific skills they had learnt, rather than on any particular content. However, by far the most important impact on participants was the presence of a supportive peer group, followed by having positive role models in the form of facilitators, an aspect which facilitators highlighted as well. This suggests that the intervention could potentially increase its focus on providing concrete skills for participants to practise, with facilitators acting as role models for the ways in which these can be used in broader society.

Despite the strong impact of the workshops, much of this positive work can be undone if the broader society, and particularly government, show little ability or will to support these positive impacts, and the lack of support from government was noted by both participants and facilitators as an issue. The following section therefore focuses on this lack of response by government to the issue of GBV.

\subsection{The lack of state response to GBV}

Despite the South African government's stated intention of reducing GBV, many of those I spoke to were disappointed or angry at what they perceived to be the lack of political will and resources to actually address GBV by the state. Due to this failing by the state, both participants and practitioners mentioned feeling like the workshops could help community 
members to fill an implementation gap from government, suggesting that the workshops could empower participants to respond to cases of GBV when government or the police did not. While both groups highlighted the lack of state response to GBV, the focus of practitioners was often somewhat different to that of workshop participants, with practitioners often focused more on lack of response and implementation at a national and policy level. Some practitioners noted the lack of a national strategic plan (NSP) for responding to GBV, despite government's rhetoric around the importance of establishing one, with one workshop facilitator saying, 'if we have 16 days of activism, let's have an NSP for GBV, whereby we say, "If we wanna control violence in our communities, let's have a plan". But still our government is playing hide and seek'. A female workshop participant in Ceres agreed, saying 'dit help nie dat ons praat hier oor gender equality plan, en dan staan die munisipaliteit aan die ander kant, en hulle het nie 'n plan nie' (It doesn't help that we talk here about a gender equality plan, and then the municipality is on the other side and they don't have a plan).

Another practitioner mentioned the lack of implementation by the courts of the existing legislature, noting that, 'I think that there's reason for concern that the system ... has not moved with the legislative changes'. He continued, 'regardless of all the um legislative wakeup calls to try and un-mask the realities [and] suffering of women um in the context of gender-based violence ... it actually has not made much of a difference'. A participant in a Ceres follow-up interview focused more on the slow pace of implementation in the judicial system as an issue, describing a protest outside the court during a much-delayed trial of a man arrested for the rape and murder of a gay man in the community: 'ons het ' $n$ demonstrasie gehad het, en mense het soos skilpaaie gelyk, om te wys na slow service ... 'n beeld uit te wys, "OK government, you are slow"' (We had a demonstration, and people looked like tortoises, to refer to slow service ... to point out, "OK government, you are slow"). Workshop and focus group participants were more likely to mention the lack of response by police when called in cases of violence in their communities, and this was often explained as a lack of vehicles or officers available to respond. For example, one participant in Ceres mentioned that, 'when it comes to more serious cases, it takes them a little while, but like they informed us ... they only have a certain amount of vans ... so we have to wait, so that's understandable'. However, others saw it simply as lack of interest or care, and one female participant explained how the police would be slow in responding to a domestic violence case: 'hulle dink dat die man kan maar slaan en bel die polisie, hy kom na twee dae na jou toe' (They think that the man can just hit her and phone the police, they come two days later). Another female participant expressed her frustration at the slow responses from police when called: 'kom uit! Daar is 'n moord. In die tyd dat dit vat, is daai person dood!' (Come 
out! There's a murder. In the time that that takes, that person has died!'). Although this was an opinion mostly expressed by workshop participants, some practitioners also commented on it, with one, who had previously worked as a judge in a Sexual Offences Court, stating, 'from the South African Police Services point of view, I'm deeply concerned with the level of ignorance, apathy, non-responsiveness to what we consider to be urgent cases'.

Thus, there was a general perception from many that I spoke to that government and the police lacked the will to take GBV very seriously, and this has an impact on the ability of a masculinities-focused intervention such as OMC to effect much in the way of societal change. While working with individuals is an important means of shifting norms in a community, that change will only ever have limited effect if national level policies and attitudes from the state do not shift as well. Leadership from government is an important means of demonstrating the seriousness of GBV, while a lack of response suggests that government does not view the issue very seriously at all. This then can have the effect of encouraging others in the country to also view GBV as something which is not a serious problem, hindering efforts to address and reduce this kind of violence. The widespread perception of a lack of will on the part of government is therefore problematic.

Along with the lack of political will from the state, another systemic issue that some participants and practitioners highlighted was a lack of support within the education system for learners to report incidents of violence, and it was noted more than once that teachers were not supportive or responsive if learners reported violence. One practitioner from an organisation focusing on supporting women after incidents of sexual violence spoke about talking to a learner who had been harassed by boys at her school, "because the educators are just ... They don't care. You just come here and do your school work, and I'm just here to mark and ... let's get this over and done with, kind of attitude'. In a similar vein, a participant in a Ceres focus group described the mindset of teachers in the local primary school: '"OK fine, you a lost case, let's wait till you get to Grade 8, go over to high school, that's the high school's problem, let go"'.

This suggests a relatively widespread belief that there is a lack of political will to seriously address and reduce GBV in South Africa, and it seems as if this lack of will has impacted on those in the education system as well, with schools and teachers also being unwilling to address violence. As explained above, the lack of will on the part of the state can limit how much societal norms are likely to shift in terms of gender inequality, and thereby negatively affect the impact that an intervention such as OMC is able to have. Even if the state is in fact seriously attempting to address GBV, community members do not view these attempts as useful, and this contributes to an environment which will be seen as hostile to those trying to 
practise alternative gender norms. A result of this could be intervention participants feeling as if their efforts will not make a difference to broader societal norms, as they may feel like they are fighting a losing battle in the face of ongoing apathy from the state. It is therefore important to include efforts to lobby government to adapt and implement policies which seriously aim to address GBV.

\section{5 'Gender-based violence in our communities... it's normal'}

Along with the lack of response to GBV by the state, an additional aspect which both workshop participants and practitioners agreed upon was the very high levels of violence which are currently being experienced in the country, highlighting the fact that GBV remains a serious issue in South Africa. Although I did not specifically ask any questions about experiences of violence, participants and practitioners reported experiencing a wide range of violence, from witnessing or experiencing physical abuse in their homes, to muggings, verbal harassment, and rape. In fact, violence was mentioned so often that it was almost seen as 'normal' - experiencing or witnessing violence is not considered unusual for many people in the country, and I realised that this normalisation extends to myself as well. I did not even initially notice the pervasiveness of the discussion of violence until I began coding the interview and focus group transcripts, and this seems to support the literature discussed earlier, which highlights the pervasiveness and normalisation of violence in the country. I included this as a separate section as a way of highlighting the extent of the violence that many people experience in their communities, along with the fact that this violence is considered so normal. The fact that violence is considered so normal is important in the context of efforts to reduce violence, as the normalisation of violence can begin to make violence seem to be a given - in other words, it is not something worth addressing because it 'cannot' be changed. While this is obviously not true in reality, the impression that violence is normal can have a negative impact on efforts to reduce it.

The extent of violence was noted by a number of participants, with one practitioner noting that South Africa is a 'very violent um society, where gender-based violence is rife. And, statistics-wise, we're right in the forefront of something that, is you know, that we should really not feel proud of'. Similarly, a focus group participant described how common GBV was in his community: '[it] is everywhere ... it's like you're buying chips of 50 cents. Ja, you take out a 50c, you buy chips. Gender-based violence in our communities, seriously ... it's normal'. This section therefore starts with some descriptions of experiences of violence, and this is followed by participants' and practitioners' opinions on the causes of this violence. The reason for focusing on people's understandings of the causes of violence is that these opinions will impact on how people choose to try and address or reduce GBV in their communities. If many people believe that masculinities are a primary contributing factor to 
violence, this would suggest that masculinities-focused interventions would be a sensible means to address violence. Alternatively, if there is a strong belief that factors such as substance abuse or experienced abuse are the primary cause, this would suggest that interventions which focus specifically on individuals also need to be taken into consideration in any interventions.

\subsubsection{Experiences of violence}

Many participants reported experiences of violence in their communities, and this ranged from relatively 'minor' violence such as verbal harassment to more serious violence such as rape. Verbal harassment seemed to be particularly prevalent for those in the LGBTIQ community in Ceres. One gay participant stated that this happened, 'everyday still ... Even last night I was harassed by a group of young men'. A similar experience was described by a second gay participant: 'it's more verbal abuse ... Walking down the street, "Weh, jou moffie", stuff like that'. A third noted that this happened in schools as well, 'because you get abuse from the teachers in schools, verbal abuse towards the gay kids'. A final example was given by a participant from an LGBTIQ support group in the community: 'the occasional bully that walks past you and then shout bad words at you, or the kids will throw you with stones, or the mum will stand in the door and call ... "See, here's a moffie walking past"'. This seems to suggest that, along with widespread normalisation of violence, many in the community also maintained the notion that 'masculinity' implies 'heterosexuality', with those who do not achieve the heterosexual standard being mocked or harassed. This confirms the literature outlined in previous chapters which highlights the ways in which gender norms are maintained through positive and negative reinforcement. In this case, gay men are mocked for not conforming to the required norms of heterosexuality, and this will impact on the ways and places that gay men feel comfortable performing their gender.

A second form of violence mentioned by a number of participants, thereby seemingly confirming the normalisation of this form of violence, was domestic violence or abuse. One female participant in Ceres described her experience: '[V]ir hulle is dit basies jy wil geslaan word. Nou soos ek kom 'n verhouding uit ... die eerste kêrel wat ek gehad het, een ogie is nog nie gesond nie, dan blou hy die ander ene' (For them, it's basically that you want to get hit. Like me, I came out of a relationship ... the first boyfriend that I had, one eye is still not healthy, then he made the other one blue). A workshop facilitator also spoke about violence in his home growing up, saying 'it was something that was done by my father while I was young ... The violence I was seeing never happened to me, but it did happen to my mother'. A Ceres focus group participant explained his feelings about domestic violence as follows: 'ek hou nie van ... ek was twee maande oud toe my pa afgeskei word ... toe't my ma gaan trou met ' $n$ ander man ... hy't ook selfs hand gelig' (I don't like it ... I was two months old 
when my parents separated ... then my mother married another man ... he also lifted his hand).

Domestic violence or abuse tends to be the form of violence which is most commonly associated with GBV, and both the literature and responses from participants and practitioners in my own research suggest that it is quite widespread in South Africa. However, few respondents mentioned survivors of abuse accessing women-focused services such as counselling, medical or legal support, or places of shelter. While this does not necessarily indicate that women-focused interventions are not playing an important role in supporting survivors of violence, it does raise the question of how effective these interventions are at preventing future violence. Nevertheless, this was not something that I specifically asked participants, and this could therefore explain why it was not mentioned. Along with this, the continuing assumption that domestic violence is normal once again hinders efforts to begin preventing it. Although participants did not necessarily join the intervention because of their experiences of violence, a number of them mentioned that they had either witnessed or experienced violence in the past. The fact that these participants are now taking part in a masculinities-focused intervention aiming at preventing violence suggests that the cycle of violence, described in previous chapters, is not automatic and can be problematised. This therefore bodes well for future interventions which specifically intend to prevent future violence.

Along with verbal harassment and domestic abuse, a number of other forms of violence were mentioned by participants, including robbery and murder. However, what was most telling in all of these instances was how this violence was mentioned almost in passing. For example, a participant in a follow up interview in Ceres described an incident of robbery outside his accommodation in a relatively blasé manner: ' $[T]$ hey robbed me ... Brand new phone ... they just saw the phone in my pocket ... they took it out and left. They even threw me with a bottle [laughs]'. Even at the more extreme end, where people were killed, the incidents were often noted in a manner which seemed to contrast with the severity of the violence. One practitioner mentioned a participant who had participated in a bread-baking group, who was 'unfortunately shot dead a couple of months ago, um, you know, in gangrelated war'. A practitioner at a different organisation spoke about a teenager in a training workshop she had conducted: 'he's doing very well for himself, in terms of what he's been through in the past. His father, his uncle and his grandfather were shot and killed in front of him'. Quite unusually, one participant volunteered information about violence that he himself had committed, despite the fact that I did not ask about it: ' $E k$ was vir lang jare in die gevangenis en uh ek het ' $n$ man geskiet' (I was in prison for many years and um I shot a man). 
The casual way in which much of this violence was mentioned in interviews, the most extreme example of which was a man telling me in passing that he had murdered someone, again underscores two main facts. Firstly, violence is incredibly widespread and prevalent in South Africa, and seems to impact on almost every person at some stage in their lives, with many people experiencing multiple forms of violence in their lives. Secondly, this violence happens so often that it is now considered to be 'normal', which again suggests that it will be difficult to shift the norms relating to violence in community. I would therefore argue that a primary goal of GBV-prevention interventions, whether they are masculinities-focused or women-focused, should be problematizing the notion that violence is 'normal'.

Promisingly, it seems that this is already included in the OMC programme, with one facilitator noting that, "[we] show them that growing up in this violent community or in a violent house doesn't mean that we have to continue promoting this'. This process of problematizing the normalisation of violence is important, and one aspect of it is discussing how the violence is caused, rather than assuming that it is a 'given' or 'acceptable' behaviour on the part of men.

\subsubsection{Opinions on causes of violence}

The normalisation of violence outlined above was often noted as a contributing factor to the ongoing high levels of violence in South Africa, and this violence tended to be described as something that children would have seen growing up, and would therefore assume was the norm. For example, one participant from a Ceres workshop stated that some children would think that violence is allowable because, 'hulle het so groot geword met die verstand dat die pa abuse die ma in die huis ... daai kind groei op met die mentaliteit dat "my pa doen dit ... dit moet so wees. Ek moet my vrou so behandel"' (They grew up with the understanding that the father abuses the mother in the house. That child grows up with the mentality that "my father does this ... it must be like this. I must treat my wife like this"). A workshop facilitator had a similar view, saying, 'If I grown [sic] up seeing my father beating my mum, and my father beating us as a kid, so then I think it was the right way to do'. He continued, 'normally violence is what we live in, and it's what we see, it's what we do'. Similarly, a second workshop facilitator believed that men 'grow up seeing [violence] at home, at school, TV, community ... ja, you can't blame them'. A female practitioner from an organisation in Gugulethu believed that domestic violence is so common in many households that men, 'don't even know that [what] they are doing is abusive. They just do it because sometimes, he grew up looking at that, as the parents were fighting in front of him, so he take [sic] that thing as a good thing'. 
A Ceres participant believed that the violence was so normalised, some women thought it had to happen: 'Jy kry van daai tipe meisies wat sê as die ou nie vir haar slat nie, dan voel dit nie reg nie ... Hy moet vir haar slaan' (You get those types of girls who say that if the guy does not smack her, it does not feel right ... He must smack her). A second participant in Ceres agreed, saying, 'the children at home sees it [sic], and then they go outside and think it's OK, we can do it out to another person [sic] ... The roots are at home'. In fact, one practitioner believed that the violence is so normalised, 'it is always amazing ... that it is possible to find a guy who is not violent. Because you know ... violence is everywhere'. This belief in the normality of domestic violence was seen to extend to the police force as well, as shown in the following quote from a female participant in a follow-up interview in Ceres: 'die man vir al die jare haar slaan en dis niks nie, jy kan haar maar slaan en die polisie het nie geworry nie' (The man hit her for years, and it's nothing, you can just hit her and the police didn't worry).

It therefore appears that many people believe that experiencing or witnessing violence is a strong contributing factor to the perpetration of violence, in many cases seeming to suggest that if a man witnesses or experiences violence as a child, then it is a given that he will use violence himself later in life. This belief appears to be held by both men and women, extending to the police, and in some cases also extending to workshop facilitators. While this is in line with the literature outlined in previous chapters, it is encouraging that those in the workshops have begun to problematize the notion of an automatic link between witnessed/experienced violence and the later perpetration of violence. Thus, although many people noted that the link is often assumed to be the case by others in the broader community, they themselves were able to question that link, and highlight the fact that such violence was problematic, and this is a positive impact for the workshops to have.

However, somewhat problematically, many participants and practitioners seemed to maintain the notion that women's behaviour or dress was a cause of violence, and this seems to support the notion that South Africa has a rape culture, condoning or normalising sexual violence against women. For example, one female practitioner began by describing, 'the myth ... because the girl was wearing a mini-skirt, that's why she got raped', but continued by saying, 'we need to educate [girls] around "where am I actually wearing this mini-skirt to? Where am I walking?" Only to protect yourself ... if you see a group of guys standing there ... you as a girl must feel this kind of responsibility'. Thus, even though the practitioner believed it is a 'myth' that women wearing mini-skirts will cause rape, she still maintained that it is a women's responsibility to avoid certain areas while wearing a miniskirt, in order to avoid being raped. This then keeps the onus for preventing violence on women, rather than on men. 
The belief that women wearing short skirts contributes to violence seemed to be quite widespread. A male workshop facilitator also commented, almost in passing, 'you wanna rape that young girl. If she's wearing a short skirt, you wanna bounce her'. Although he was using it as an example (in this case, talking about how men respond once they have been taking drugs), the implication was that the blame or responsibility lay with the woman to dress differently to avoid being raped. Similarly, a participant in a Gugulethu focus group explained that, "we grow up ... with many social norms ... if a girl is passing in a short skirt, we say, "Woah, this girl must be raped" ... we believe that, as a young girl, you must not um wear a short skirt'. In a Gugulethu focus group, participants discussed how police would respond if a woman were to try and lay a rape charge:

R1: Sometimes they will ask you what clothes you were wearing when, were you wearing a short one, and then if you were wearing a short one, they will say, "You were asking for that, to be raped".

R2: And where were you at that time?

R1: And what were you doing? Who were you walking with? Going with?

Thus, numerous participants and practitioners linked men's perpetration of violence to women's behaviour and clothing in a variety of ways. Worryingly, many people seemed to believe that the way women dressed caused violence, implying that the responsibility for preventing this violence was on women rather than on men. Particularly worrying is the fact that these beliefs were held by both workshop participants and facilitators, suggesting that the understanding of sexual violence as an act arising from hegemonic masculinities has not really taken hold. This seems to point to the fact that although the intervention contributes to awareness that certain masculine behaviours are problematic, there is less shifting of the underlying attitudes of rape myth acceptance and gender inequality in these communities. This is therefore a serious concern relating to the workshops.

However, some practitioners at other organisations had a more nuanced understanding of this in relation to men's perpetration of violence, and while still noting that women's clothing impacted on it, their explanation related much more to men's attempts to maintain a status quo of gender inequality. A practitioner working for an LGBTIQ support organisation mentioned this factor while discussing 'corrective rape', which was described in a previous chapter. She noted that in the case of 'butch' lesbians, who do not conform to the accepted norms of femininity, the way that they dressed was also used as an excuse for their rape, explaining that that, '[P]eople think, "Now you think you're a man because you dress like a man ... we want to show you that you're missing out". That's what they say ... "We want to show that you're a woman"'. Similarly, a second practitioner explained this violence as a 
response to those acting outside of the acceptable norms of behaviour. 'I argue that [this] isn't a narrative about short skirts and drinking at parties. It's a narrative about cheekiness. In other words, unacceptable displays of individual autonomy'. She continued by expressly connecting this 'cheekiness' to the sense of affront that men would feel in response to it. She described the rationale that men might use as their explanation for choosing who to rape: "it's the cheeky ones, the ones that walk around like they own the place. The ones who think they're bigger than you, the ones who look you in the eye, the ones who wear jeans"'. Thus, while women's clothing or behaviour was mentioned in the explanation, the factor which caused the violence was men's attempts to maintain a gender unequal system.

Promisingly, a number of participants and practitioners agreed with this to some extent, saying that rape arose more from expectations of masculinities than from women's behaviour. This was seen to be true particularly for domestic violence or abuse. Similarly, hegemonic masculinities were sometimes offered as reasons for different forms of violence. Thus, as discussed above, men felt that violence against others, and particularly against their partners, was required of them in order to achieve socially-expected masculinities. This was summed up neatly by one participant in Gugulethu who simply said, 'then I lost temper, because I am a man'. A female practitioner gave a similar explanation, stating that, 'for so many men in family situations or in relationships, violence is a very ordinary everyday go-to strategy for managing their feelings and managing their relationship'. A female participant in Ceres explained it as follows:

Die mans sê hy werk vir die huis, hy bring brood op die tafel, en hy's die dak en jy's die vloer ... So as jy nou as vrouens sê "Maar dis nie reg, wat jy gedoen het nie", dan sal jy seker maar geklap word ... Vir hulle is dit reg. (The man says he works for the house, he brings bread for the table, and he's the roof and you're the floor. So if you as a woman say, "But what you're doing isn't right", then she'll certainly get hit ... For them, it's right).

Interestingly, this was also explained to be the case in lesbian relationships where one partner took on the 'masculine' aspects and behaved accordingly: 'for me it is actually the same. It is this whole male dominance ... if you present yourself as male, masculine ... so you have all the power and the control'. Thus, the expectations of masculinities applied to butch lesbian women as well as men.

The expectation of violence and sexual violence from men in order to achieve the standards of masculinities will be discussed in more detail in the next section, but it is at least promising that some participants and practitioners had begun to highlight the fact that it is masculinities, rather than a women's clothing, that contributes to sexual violence. However, it remains worrying that so many participants and practitioners still blame women and their 
clothing for violence against them, rather than focusing on those perpetrating the violence. This is particularly worrying in the case of facilitators and participants of the OMC intervention, as I would argue that this is a primary issue that should be covered in the workshops. This seems to confirm findings in previous evaluations that the impact of this kind of intervention tends to be more behavioural than attitudinal.

A final aspect which was noted in a number of instances as contributing to violence was substance abuse, and this was mentioned by a number of participants and practitioners, as can be seen in the following quotes. 'I think the main factor is drugs ... Drugs and alcohol abuse' (male participant, follow-up interview). 'I will have to say substance abuse' (male participant, follow-up interview). '[violence is caused by] the drug issue and the alcohol abuse issue ... because whenever you hear someone was murdered or someone was attacked, it was people that's under the influence of drugs' (male participant, follow-up interview). 'Ek sal sê dit kom alles deur van alcohol misbruik af. Sien jy, en drugs en dwelms ... daai tipe goed' (I would say it all comes from alcohol abuse. You see, and drugs ... That kind of thing) (female participant, follow-up interview). 'Die misbruik van drank is die grootste bekommernis in die gemeenskap' (The abuse of alcohol is the biggest worry in the community) (male participant, follow-up interview). A male workshop facilitator also believed the drug abuse played a big role in violence, saying 'it start [sic] with smoking a dagga and then, while you smoke a dagga, you see a girlfriend that is coming there and you wanna rape that girlfriend'.

This seems to agree with literature outlined in previous chapters which highlights substance abuse as a factor which strongly impacts on violence. This suggests that some attention needs to be paid to substance abuse in efforts to reduce or prevent GBV in future. However, in a similar manner to much of the literature on this, there is little understanding of why it is that substance abuse seems to be more closely linked to the perpetration of violence by men than by women. The following section therefore specifically focuses on participants' and practitioners' discussion of masculinities. This includes the roles that men are expected to play in South African communities, and the difficulties that can arise if they do not conform to these roles.

\subsection{The impact of masculinities}

Perhaps unsurprisingly for those who had attended a masculinities-focused workshop, there was a significant amount of discussion on the expectations that society places on men to achieve certain standards of masculinities. There were a number of aspects included in this, the majority of which tended to reinforce the aspects related to hegemonic masculinities in much of the literature: physical strength, not showing emotion or pain, using violence, visible 
displays of wealth, lack of involvement in childcare and raising, and multiple sexual partners. As one participant stated,

We grown [sic] in this society where we having ...old people to say to us, to be a man, you need to be strong. To be a man, you need to be tough, to have a last word ...not to cry, to beat up your wife. Those kinds of things that put us men into a box of being violent.

These different aspects of masculinity were closely intertwined. For example, physical strength often seemed to be related to violence against a partner, with one participant in a Gugulethu focus group talking about the expectations placed upon him by his father:

Because I remember ... my dad used to tell me I must act like a man. And then to act like a man ... I have to get um to have um multiple partners ... And I had to beat my partner so that I can show that I'm a man. Ja, I have that pride.

Another participant in a follow-up interview in Ceres explained that 'there's an expectancy that they have to be assertive ...they have to be the discipline in the house'.

Thus, there seems to be a heavy weight of expectation on men to achieve the norms of being the authority in the household, or of having multiple partners. Along with this, masculinities were explicitly linked to the use of violence, with men being told to 'beat up your wife', or having to 'beat my partner so that I can show that I'm a man'. However, little mention was made of weapon use or of militarised history or terminology suggesting that, while the militarised history of the country may have impacted on the versions of masculinity prevalent today, these currently tend more towards hypermasculinities than militarised masculinities. However, it is once again important to note that violence has become normalised for many men, as seen by the fact that it is a condoned and even expected part of the achievement of manhood. Thus, despite the usefulness of the notions of militarised and hypermasculinities in understanding the South African historical context, they seem to be less helpful in unpacking the levels of violence currently being experienced in the country. Linked to the expectation of aggression and violence against women, numerous participants and practitioners noted that men were expected to be physically strong, making it difficult for men to be able to show emotions or pain. Thus, men were expected to handle pain without displaying any sign of it. One female participant working at an NGO in Gugulethu explained: 'there's the fact that they were told, told to be strong. So that thing breaks inside them. Because now the man is feeling pain, he can't cry because he must be strong.' This was extended to seeking healthcare, or getting treatment for illnesses. The following exchange took place in a Gugulethu focus group, and highlights this expectation: 
R1: Because men been [sic] told that a man is expected to be strong, not to be vulnerable... Men tend to not go to the clinic... men will look at them to say, "Hey, look at that man he's so weak. He's going to the clinic."

R2: So not going to the clinic is a sign of ... a good sign of manhood, nê?

R1: Absolutely.

R2: Not going means you are strong.

This belief was reinforced by a number of facilitators, with one pointing out that, 'you can go to our public clinics here ... You'll find eight women, two men. Each and every clinic.

Because men been [sic] told that a man is expected to be strong, not to be vulnerable'. Another agreed, stating that, 'men tend to not go to the clinic, because once they go to clinic, men will look at them to say, "Hey, look at that men [sic], he's so weak. He's going to the clinic"'. This once again seems to reinforce the presence of hypermasculinities in these communities, with an expectation of physical strength on the part of men, which also again supports the notion of violence as an acceptable means of responding to situations. I would therefore argue that this supports the notion that hypermasculinities play an important causal role in much of the GBV which takes place in South Africa.

Alongside the expectation that men are required to be the authority in their homes, many participants and practitioners noted the pressure placed on men to be financially successful and to provide financial support for others. For instance, one facilitator mentioned that 'many people still see the role, especially in the religious sectors, the role of the man as the provider and the protector' in a family. Another discussed feeling like the only way he could show affection to his son was by providing money: 'I was like an ATM father before. What I did was ... give my boy the money, OK here's the money, and go'. The expectation of being a financial provider is one which is common to hegemonic masculinities in a wide variety of regions and areas, and seems to be relevant in the South African context as well. Related to the expectation of being a financial provider is being able to display physical symbols of wealth, and this was also noted as a pressure placed on men, with one participant talking about how younger children would look up to gangsters in the community, because '[t]hey have their big cars ... and they like their fancy clothes'. Thus, being able to display wealth, in the form of material possessions, was an alternative means of being seen as financially successful and therefore achieving the standards of masculinity.

However, it was also noted that the expectation of financial wealth was problematic in a country where many men will be unable to find work, as described by one practitioner as follows: 
Basically the message now is, you buy the right product, and this is what will come your way: babes babes babes, more babes than you can handle, and wealth wealth wealth ... This is what you get for showing up in the world as a man. What happens to men who are promised all of that, and there's no delivery?

In other words, many men will be unable to either be a financial provider for others or to display their wealth through buying material possessions, and it is argued that this contributes to their use of violence as an alternative means of achieving masculinities. This notion supports the literature on strain theories discussed in previous chapters which suggests that if men are unable to achieve the norms of hegemonic masculinities, in this case relating to being able to afford certain status symbols, they are likely to use violence as an alternative means of achieving masculinities.

However, as was outlined in the section discussing strain theories, the assumption that being unable to achieve financial standards of masculinity will lead to violence suggests that men in more marginalised or precarious groups - such as minorities, the unemployed, or those with lower levels of education - are more likely to use violence. As mentioned in the previous chapters, this has two negative effects. The first is that it implies that only a small number of men decide to use violence, when in fact these are often expected aspects of hegemonic masculinities across different societies. The second is that it implies that only those in marginalised groups are committing violence, as they are the ones experiencing gender role strain. This implication is often reinforced by the fact that many organisations conduct work primarily in poorer or more marginalised areas. As one facilitator explained:

The challenge that we still having, and not just Sonke, but many other similar organisations, is that we focus primarily in impoverished areas. Your Khayelitshas, your Mannenbergs, Phillippis, Nyangas ${ }^{4}$, areas like that. And that's a challenge. And it somehow creates, it somehow creates a ... picture that problems are only in poor areas. Only men in poor areas um struggle with gender identities. Only men in poor areas commit gender-based violence and domestic violence. And that's the sad thing ... or the unfortunate part about it.

The fact that most organisations work in predominantly impoverished areas contributes to the impression that only those from these areas perpetrate violence, yet the discussions with both facilitators and participants of the workshops demonstrate that violence is generally expected from men in all income groups, and will be expected whether or not they can achieve other masculinity norms.

\footnotetext{
${ }^{4}$ Four townships in Cape Town.
} 
Despite the fact that men are expected to provide financially for their families, there is an expectation that men will not, or should not, be involved in childcare, as shown in the following exchange from a Gugulethu focus group:

R1: ...for me, as a teenage mother, I can't take my child, to give my child to her father and tell him that he must take care of his child ... I don't have the heart to give him my baby and tell him that, "Go and take care of that. And then when I come back from school, I'll take back".

Interviewer: You think that because the father doesn't know how, or because it's your responsibility as a mom?

R1: Because it's my responsibility.

R2: I think the other thing is that, you know, as a man in our community, you are not trusted, seems that we are the most corrupt people ... I think it's the right thing that R1 is not able to take her child to be with the father because um most of the time... people that are raping babies are mad. People who are killing babies are mad. They are not trusted anymore.

This was an interesting discussion because the focus group participants in this instance were all CAT members, meaning they had all completed OMC interventions and had chosen to remain involved in Sonke's community mobilisation work. Despite this, they still felt that women should be the primary caregivers of children, and that men should not be trusted around children, almost suggesting that men would not be able to restrain themselves from harming children under their care. This once again points to the fact that the intervention seems to have much more of an impact on specific behaviours than on participants' attitudes, with little impact on participants' beliefs around women's 'responsibility' to take care of children and men's supposed inability to be involved in childcare. This conversation therefore emphasises the lack of attitudinal change in participants while also reinforcing stereotyped gender norms.

However, there was some awareness of the fact that these expectations could often place men in vulnerable positions, making them feel unable to access healthcare, or get support if they experienced violence. While this was not explored in much detail in the focus groups, a number of participants raised concerns about the difficulties men have in reporting violence. One participant in a follow-up interview in Ceres described a man who had been raped by a woman but felt he could not report it to the police because, "Wat gaan die mense van my dink? Ek is 'n man" ... Hulle is skaam. Hulle wil nie hê die ander mans weet' ("What will people think of me? I'm a man" ... They're ashamed. They don't want other men to know). The following exchange took place after one participant described a situation of a man being slapped by his girlfriend in public, with the man in the description then feeling compelled by 
societal norms to pretend that he had slapped his girlfriend, rather than the other way around. In addition, it was felt that the man would be unable to report the issue to the police:

R1: So there are those kinds of dilemmas in our culture setting. The police will laugh at you [for reporting abuse by a woman], to make you feel so small, feel so humiliated.

R2: As a man.

R1: As a man.

R2: Suppose it also is that issue that you spoke about. It's a sign that he's a weak man.

R1: Absolutely.

R2: Because he can get beaten up. So that kind of thing. That's why they laugh, 'Hau, how come you as a man, beaten by a woman, being a man?'

Along with this, there was a perception among participants that there was still widespread support among the police for certain aspects of hegemonic masculinities, with participants sometimes mentioning a worry that police would not take it seriously if men were abused or beaten by their female partners. One participant in a Ceres follow-up interview described a situation where a man's (female) partner threw boiling water over him but when he went to report it to the police, 'sê die kaptein vir hom, "Maar brand haar terug". Toe moet hy die saak los, hulle wil nie die saak vat nie' (The captain told him, "Burn her back". So he had to drop the case, they did not want to take the case).

Conversely, there was concern that police would respond excessively to what were considered to be 'reasonable' situations of men using violence against female partners. A female participant in Gugulethu described a situation where a woman tore her partner's shirt and bag, and he lost his temper in response:

Just klapped once, because I want her to stop doing that. But she is going to go to police station ... I have this shirt without the buttons and my bag is broken. But the police will not look at that. They will look at her because l'm man [sic], you see.

Thus, there were a number of ways in which achieving the norms of masculinities were recognised as being damaging to men as well as those around them. This helps to highlight the numerous ways in which GBV impacts on men as well as women. Thus, as one facilitator noted, 'sometimes men suffer even more due to these gender constructions ... or gender norms that has been created'.

The final aspect of hegemonic masculinities that was mentioned specifically in the Ceres focus group and follow-up interviews related to the expectation of heterosexuality among men, which is likely because a sizable minority of the group involved in the Ceres 
intervention were gay men. Thus, there was much more discussion throughout the workshop, focus groups and follow-up interviews about LGBTIQ rights, lifestyle and challenges. A number of the gay men mentioned feeling ostracised or threatened in their community because of their sexual orientation, and this ranged from verbal abuse to physical violence. One participant said that many in their community believed gay men are 'a disgrace to manhood and all that', which tended to be attributed by participants to conservativeness or ignorance on the part of the broader community. In addition, numerous participants spoke about the difficulty of coming out to their families, and how this impacted on their own lives. One participant, who was involved in an LGBTIQ-support organisation, explained that suicide was becoming more common as a 'solution' for gay people in their community, 'cuz then they take away the hurt, the pain, the abuse, the social injustice, they take away everything. So they resort to suicide, because things gets [sic] too much'. This was confirmed by another participant in Ceres, who described his own experience: 'Yes, it was hard for them [his family] to accept. Unfortunately for me, I had to go through a process where I tried to commit suicide and everything'.

This reluctance by families to accept men's homosexuality tended to be explained by stating that the families were concerned about the reaction from the broader community, and this reluctance often extended to educators or teachers, who might either verbally abuse a gay child, or pretend that homosexuality did not exist. One participant described the reaction from some educators who he had contacted regarding doing a talk at a school about homosexuality: 'dit was vir my skokwekkend dat een onderwyser nie van die idee gehou het. Dit wys net dat hulle die goed weet, dan skuif hulle als onder die mat in' (It was shocking for me that one of the teachers did not like the idea. It just shows that they know about it, and then sweep it all under the mat). Another participant discussed discrimination against gay people in terms of employment, as 'employment-wise in here, some people are still so conservative not to employ gay people'.

The above quotes highlight the fact that hegemonic masculinities in South Africa are often closely tied to heterosexuality, with homosexuality not being considered masculine. However, I also found it interesting that it was predominantly homosexual participants who remarked on this, with very few other participants or practitioners noting the difficulties that homosexual men might face by not conforming to the norms of heterosexuality required in hegemonic masculinities. Although homosexuality was not explicitly discussed in the focus groups in Gugulethu, the conversation always revolved around men as heterosexual, with girlfriends or wives, or multiple partners. Thus, the implication remained that heterosexuality was the norm. As has been mentioned above, I would therefore argue that this suggests 
there is a need to focus much more on homosexuality and equality for the LGBTIQ community in these types of interventions.

However, despite the shortcomings of the intervention in terms of creating attitudinal change on the part of participants, becoming involved in the workshops was credited with allowing men to start questioning these dominant versions of masculinity, and to begin seeing alternatives. One participant in Gugulethu stated, 'when I started to work with Sonke as a CAT member, I started to know that no, to act like a man is not um to be violent.' Another agreed, saying, 'ja, these workshops help with breaking that down, you know, and teaching the men that it's OK to be sensitive ... that it's OK not to be assertive all the time, not to be the head all the time, when you not able to.'

One important aim of many masculinities-focused interventions is to create a space where men are encouraged to consider alternative versions of masculinity, with one facilitator stating that, 'it's about creating this fashion ... because men not being involved, it's not fashion anymore. Men abusing their partners and their children is not fashion anymore'. While this is a somewhat simplistic (and optimistic) assessment of the situation, it does describe part of the intention of the intervention: to create alternative gender norms, and to provide support for men who are attempting to try these alternatives. As mentioned above, some workshop participants had similar responses, stating that the presence of a group who were all practising similar (but alternative) gender norms meant that others in the community would be more willing to do the same. In other words, the group who had participated in the workshops began creating new gender norms in their communities.

The findings presented in this chapter seem to confirm much of the literature on masculinities-focused interventions which tends to suggest that this type of intervention can have a behavioural impact on participants, though it seemingly has less of an attitudinal impact. Similarly, this study confirms two aspects which the literature has highlighted as contributing to the effectiveness of masculinities-focused interventions, and these aspects are the presence of a supportive peer group, and the presence of positive role models. Where this study expands on existing research is by questioning why participants choose to become involved in this kind of intervention, and on the reasons why they choose to stay involved in the work after the intervention is complete. The answer to both of these questions seems to be that participants feel a strong motivation to be involved in community improvement and mobilisation, and hope to learn new skills for doing so through the intervention. 


\subsection{Conclusion}

The interviews and focus groups described above provided a deeper understanding of the ways in which a masculinities-focused intervention impacts on participants. In a number of ways, this study confirms findings from previous research which state that the presence of a supportive peer group and of positive role models are two factors that improve the impact of a masculinities-focused intervention. Participants repeatedly mentioned these two aspects as being the most important impact of the intervention, and many valued the opportunity to be part of a group of like-minded people who were all hoping to contribute to community improvement and development. The presence of workshop facilitators as positive role models of alternative norms of masculinities was highlighted by both participants and facilitators as being important, with participants also valuing the opportunity to begin acting as positive role models themselves, in their families and the broader communities.

The desire to be a positive role model links to the primary reason why many participants decided to join the intervention: a wish to be better involved in improving their communities. Participants therefore viewed the intervention as an opportunity to learn new skills and information, and they often specifically highlighted concrete skills which they had as learned as being a powerful impact of the intervention. This suggests that many participants felt better able to become involved in community mobilisation after the intervention, because they now felt they had specific skills to share. Interestingly, facilitators seldom mentioned the development of specific skills as an impact of the intervention, suggesting that participants may be receiving the intervention in a slightly different way to how it is intended.

Despite the positive impact of a masculinities-focused intervention such as this, many participants, facilitators and practitioners noted a lack of will by the state to seriously address GBV, and this was thought to be true of government and the legal system in the form of courts and the police. This could negatively affect interventions such as $\mathrm{OMC}$, because apathy from the state contributes to the maintenance of gender inequality in the country, hindering efforts to shift gender unequal norms. This suggests that without a considerable increase in government's perceived desire to address GBV, efforts by NGOs and individuals to do so will only have limited impact.

This maintenance of the status quo was reflected in participants' and facilitators' discussion of the extremely high levels of violence that they saw and experienced, with few seeing much effort from the state to address this. In discussions on the causes of this violence, many attributed it to the normalisation of violence which occurs as a result of witnessed or experienced abuse, stating that most people would assume that this form of violence 'should' be perpetrated. While this is in line with some literature on the causes of violence, it 
was promising that many participants had begun to problematize the notion that there is an automatic link between witnessed/experienced violence and later perpetration of violence. Thus, the intervention seems to have succeeded in problematizing the notion that the cycle of violence is inevitable.

However, many respondents in this study subscribed to quite problematic beliefs around the causes of sexual violence, with both participants and practitioners stating, for example, that the onus is on women to change their clothing or behaviour in order to avoid sexual violence. This suggests that there has been little shifting of the predominant rape myths in the country, despite the presence of interventions such as OMC. Nevertheless, some participants and practitioners did seem to have begun problematizing the notion that sexual violence is the 'fault' of the woman, focusing instead of the effect of hegemonic norms of masculinities. Thus, it does seem as if there has been at least a small shift in the belief in rape myths.

Discussions around the norms of hegemonic masculinities in the country strongly supported the existence of hypermasculinities, with numerous respondents describing masculinities that required aggression and dominance over women, including violence against women and calloused sexual attitudes towards women. Along with this, a number of other aspects which are 'traditionally' linked to hegemonic masculinities were outlined, including the need to be a financial provider or display wealth, the need to not show emotions or pain, and heterosexuality. Thus, men felt pressured to be visibly wealthy, by providing for their families or through having material possessions, but many would be unable to access this financial 'success' due to high levels of unemployment in the country, and would therefore turn to violence as an alternative means to achieve their masculinity, supporting much of the literature on strain theories in previous chapters. However, as discussed above, this implies that only men in poorer communities will perpetrate violence, and this has been shown to be incorrect throughout the study. Similarly, the fact that many organisations specifically work only in poorer communities tends to reinforce the notion that these are the only places where violence occurs, and this is an aspect which needs to be addressed in future research.

The pressure to not show emotions or pain was noted as something which impacted negatively on men, meaning that they felt unable to access healthcare, or to receive assistance if they were victims of violence or sexual violence. This highlights the fact that GBV does not only mean violence against women, but includes violence against men as well. In another example of violence against men as an aspect of GBV, a number of gay men in the study reported numerous instances of violence that they had experienced, much of it linked to their sexuality, with seemingly constant verbal abuse occasionally being 
coupled with more serious violence. Thus, the expectation that men should be heterosexual results in negative impacts for men who are seen to deviate from this expectation.

Thus, these findings support some aspects of the literature on masculinities-focused interventions, showing that the current intervention can have a positive behavioural impact, but that it tends to be less effective at creating attitudinal change. The ways in which the intervention achieves this were partially in line with existing research, but also differed in some ways, by providing additional nuance to understandings of how and why such interventions impact on participants. These findings will therefore be discussed in greater detail in the following chapter, in the context of existing literature on masculinities-focused interventions. 


\section{CHAPTER 8}

\section{DISCUSSION AND CONCLUSION}

\subsection{Introduction}

South Africa as a country experiences extremely high rates of violence and gender-based violence, and a wide range of interventions have been implemented as a means to respond to these, including legislative changes from government, and women-focused reactive interventions which act as support for survivors of incidents of violence. However, these have had not a significant impact on reducing levels of GBV in the country, and this suggests that alternative methods need to be investigated.

A review of the literature focusing on causes of GBV points to a number of different opinions, ranging from individual aspects (such as substance abuse, or witnessed or experienced abuse) to more societal-level aspects (such as culture, and strain theories). However, few of these focus on the fact that it is men who perpetrate the vast majority of violence in all regions and cultures, and I therefore argue that an important issue to understand when looking at GBV is the impact of hegemonic masculinities on men. Certain versions of masculinity, such as hypermasculinities and those associated with the military, have a specific emphasis on violence as a means of achievement, and societies where these forms of masculinity are prevalent and praised are therefore likely to display high levels of GBV.

Consequently, I argue that addressing GBV requires a specific focus on men and masculinities, and this dissertation has examined a number of types of interventions which work with men, looking in detail at voluntary interventions which have a gendertransformative masculinities focus. While much of the literature suggests that these forms of interventions have a range of positive impacts on participants, there is less understanding of how and why these impacts take place, or of why participants choose to enter these workshops in the first place. This research therefore used a specific masculinities-focused intervention as a case study in order to gain some understanding of the factors motivating participants to become and remain involved in such programmes.

This chapter discusses the findings of this research in the context of the literature on the causes of violence, and on the impacts of a masculinities-focused intervention. The causes of violence are discussed in some detail, as the findings of this research suggested a different understanding of these causes than those highlighted in the literature. It is therefore important to uncover how those working in the field of GBV understand violence, as they are the ones implementing responses to the violence. The effects of the case study intervention 
are then discussed in the context of literature on similar programmes in order to understand how and why such interventions have an impact.

\subsection{Violence and masculinities}

There are a wide range of understandings of the causes of violence. This research specifically focuses on masculinities, as I argue that masculinities play an important role in causing violence, and this section therefore begins with an outline of the literature and my findings on masculinities, hegemonic masculinities and hypermasculinities in South Africa. Following this, a number of alternative explanations for violence which have been noted in both the literature and my own findings are discussed. I also argue that many of these alternative explanations either lack a focus on masculinities, or contribute to our understanding of how the expectations of masculinities cause violence, and these alternatives are therefore linked to the masculinities literature and my own findings.

An important starting point in understanding masculinities is the notion of hegemonic masculinities, which is the most desirable version of masculinity in a specific context (Connell, 1987). This generally includes that men are expected to be financial providers, to be physically tough, to need regular sex with multiple partners, and to be heterosexual (Connell, 2005; Muntingh \& Gould, 2010). Along with this, hypermasculinities often include an emphasis on the use of violence, and calloused sexual attitudes towards women (Hamburger et al., 1996).

The findings in this study suggest that the aspects outlined above are very prevalent in the South African context, with participants and practitioners repeatedly noting them as things that men are required to do to achieve masculinities. Participants described being expected to have multiple partners, and display physical strength, partly through using violence against their partners. Along with this, participants often highlighted the fact that the expectation of toughness meant men could not show emotions or pain, which often extended to seeking healthcare or getting treatment for illnesses. The expectation of heterosexuality was also highlighted by participants, and particularly by homosexual participants. The final aspect of masculinity which respondents discussed was the expectation of wealth on the part of men, who are expected to be the financial providers in their families, or to display wealth through visible material possessions.

The findings described here therefore suggest that many participants and practitioners strongly subscribe to the traditional norms of hegemonic masculinities, which expect men to have wealth, to be tough and not display emotions, to be heterosexual, and to have multiple partners. Along with this, there seems to be an expectation that men should have calloused sexual attitudes towards women, and to believe that violence is an acceptable means of 
demonstrating dominance, which suggests that hegemonic masculinities in South Africa are strongly influenced by hypermasculinities. Given these characteristics, a number of authors have highlighted the link between hypermasculinities and GBV (Hamburger et al., 1995; Barker et al., 2011). This suggests that the presence of hypermasculinities in South Africa will contribute to high levels of GBV, and this is a factor which is discussed in more detail when looking at the existence of a rape culture below. While hypermasculinities are often influenced by militarised masculinities, there was lack of evidence in this research to suggest that specifically militarised masculinities are present among the participants. There was no mention of weapon use, or of militarised terminology, suggesting that hypermasculinities are more prevalent in these communities than militarised masculinities.

Interestingly, few respondents in my own research suggested that masculinities contribute to violence, despite repeated assertions that masculinities expect or require violence on the part of men. In fact, only one participant explicitly linked the expectations of masculinities to men's perpetration of violence, saying that these expectations 'put us men into a box of being violent'. Perhaps it is assumed to be a given that telling men they need to be violent will therefore cause violence, but it was interesting that this was only mentioned once as a cause of violence, despite the fact that all respondents had either attended or facilitated a masculinities-focused workshop, or worked in an organisation that focuses on GBV. This suggests that there is something of a disconnect between the literature on masculinities as a causal factor in violence, and the masculinities-focused interventions which are being conducted in South Africa.

However, respondents in my own research had a number of alternate suggestions on the causes of violence which do coincide with the literature, and it is to these suggestions that the discussion now turns. Chief among these is witnessed or experienced abuse contributing to a person's use of violence themselves (Malinosky-Rummell \& Hansen, 1993; Paolucci et al., 2001). This opinion was held by a number of participants and practitioners in my own research, who seemed to believe that witnessing or experiencing abuse created an almost automatic link with a person's later perpetration of violence. The belief that violence is a given can often lead to its normalisation as well, suggesting that violence has become so normal that it is no longer seen as a problem.

In the South African context, this normalisation of violence was reinforced by the high levels of violence carried out in the Apartheid context. Numerous forms of violence became seen as 'acceptable', such as the state justifying its use of violence against its opponents, and those involved in the struggle becoming increasingly violent against the state (Anderson, 1999/2000). However, the impact of Apartheid on violence was seldom mentioned in my 
focus groups and interviews, suggesting that participants and practitioners do not necessarily link the current levels of violence and normalisation of violence in the country to its Apartheid past.

In addition, other literature has problematized this assumed automatic link between witnessed or experienced violence and later perpetration of violence (Stith et al., 2000). Interestingly, it was found that growing up in a violent home makes men more likely to become perpetrators of violence, while women are more likely to become victims, suggesting that the impact of cultural socialisation leads to different effects for boys and girls (Stith et al., 2000). Thus, the expectations of gender norms result in different outcomes for men and women, with men being more likely to use violence than women, and I argue that this is because the normalisation of violence places a different pressure on men than it does on women. As violence becomes an acceptable way to respond to situations, the use of violence can become an expected aspect of the achievement of masculinities, placing increased expectations on men to display these kinds of behaviours to achieve the standards of hegemonic masculinities (Breckenridge, 1998). This supports the notion that, while individual interventions focusing on witnessed or experienced violence could be useful in preventing future violence, the impact of masculinities needs to be taken into account to adequately address violence. However, this finding seems to have gained less traction among those attending and implementing masculinities-focused interventions, which suggests that there is some discrepancy between the literature and the reality of GBV interventions in South Africa.

Another individual aspect which is typically linked to violence is substance abuse (FalsStewart \& Kennedy, 2005), and workshop participants strongly supported this notion. The impact of substance abuse on violence therefore seems to imply that individual interventions focusing on substance abuse could be a viable way of addressing violence. However, literature has suggested that this relationship is more complicated than a simple causal one, with writers noting that it is difficult to determine if substance abuse causes violence or if violence causes individuals to abuse substances (Liebschutz et al., 2002). Nevertheless, many participants felt strongly that substance abuse is a primary cause of violence. This again suggests that those participating in masculinities-focused interventions may hold different opinions on the causes of violence to that contained in the literature on this topic. The implications of this regarding ways to address GBV will be discussed in the following section.

While factors such as experienced violence or substance abuse can provide some understanding of why individuals perpetrate violence, they are less helpful in understanding 
why it is that men are more likely to perpetrate violence than women. To try and explain this, a large amount of literature has arisen around the notion of a crisis of masculinity, which occurs when men are unable to achieve certain norms of hegemonic masculinities, and they compensate by over-emphasising other aspects of masculinity (Messerschmidt, 1993; Dolan, 2002; Harders, 2011). An alternative name for this crisis is found in strain theories which posit that if an individual is unable to achieve their goals through lawful behaviour, it can lead to them using violence to achieve these goals instead (Muntingh \& Gould, 2010). Classic strain theories were adapted for use in masculinities studies (Peralta \& Tuttle, 2013:265), and suggest that men being unable to achieve financial status may result in their using violence as an alternative means of proving their manhood (Hamber, 2000; Jewkes, 2002; Seedat et al., 2009; Peralta \& Tuttle, 2013).

However, the notion of strain or a crisis of masculinity contributing to violence was very seldom mentioned in my own research, with only one practitioner highlighting it as a potential causal factor in violence. In this interview, the practitioner explained the expectation of 'babes babes babes, more babes than you can handle, and wealth wealth wealth', yet wondered 'what happens to men who are promised all of that, and there's no delivery?' Thus, she suggested that men's inability to achieve specific norms of masculinity (in this instance, wealth and multiple partners) could result in their use of violence as a compensatory mechanism.

In this instance, it seems that the participants in my own research (tacitly) agreed with some of the literature on this topic, which problematizes the notion of a crisis or strain as a reason why men perpetrate violence, as these theories have been criticised on a number of fronts. A few of these were outlined above, such as failing to account for middle- or upper-class crime, and ignoring barriers besides social class, but two additional criticisms will be described here: the first is that the theories suggest that only those who are poor or marginalised are likely to perpetrate GBV, and the second is that they do not help us to explain why it is specifically men who perpetrate violence, rather than all people in situations of strain. Thus, strain theories risk ignoring that some versions of masculinity specifically condone or expect violence against women as a means of achievement, rather than viewing violence as an abnormal response to perceived strain.

A primary concern with the notion of economic strain resulting in violence is that it suggests that only those who are poor or marginalised are likely to perpetrate GBV. However, numerous studies have shown that GBV occurs in all cultures and across all socio-economic status groups (Walby, 1990; Lau, 2009; Garcia-Moreno et al., 2013). The implication that only poor or marginalised men are likely to perpetrate violence is also one which is often 
reinforced by the fact that many interventions addressing GBV are only implemented in impoverished areas. This problematic assumption has unfortunately been strengthened by much of the research on GBV, which also tends to focus primarily on poor or marginalised men, and I am very aware that my own research contributes to this. While in this instance, my options for alternatives were limited, a focus on violence in more affluent and less marginal contexts is an important avenue for future research.

Along with this, strain theories tend to view the use of violence as an unusual or extreme reaction by men in response to not being able to achieve economic markers of success, but risk ignoring the fact that a number of masculinities, and particularly hypermasculinities, specifically condone or expect violence from men as a means of achievement. Thus, violence is not an abnormal response to situations of stress, but rather a socially-accepted marker of masculinity, especially in societies which have experienced different forms of militarisation. However, as has been noted above, the impact of masculinities on men's perpetration of violence was seldom mentioned by either workshop participants or practitioners in my own research. While this does not necessarily suggest that the workshop facilitators view masculinities as unproblematic, it does seem as if this message is not always being conveyed as clearly to participants.

While strain theories did not seem to be useful in understanding violence in my own research, an aspect which arose more often was that of culture or tradition, typically suggesting that levels of violence are likely to be higher in societies with patriarchal or conservative cultural norms which maintain gender inequality (Buscher, 2005). More traditional or conservative gender norms tend to place women in subordinate roles to men, meaning that they may provide 'justifications' for violence against women, especially in situations where women are seen to not be fulfilling their expected role (Heise et al., 2002). Thus, norms supporting gender inequality, such as believing that men have an entitlement to exert dominance over women, are closely linked to GBV (Viitanen \& Colvin, 2015:2), and this opinion is often held by both men and women in these societies (Kim \& Motsei, 2002).

The link between gender inequality and violence in South Africa has been highlighted in numerous studies (Ditlopo et al., 2007; Dworkin et al., 2012). Along with this, a number of writers (such as Armstrong, 1995, and Gqola, 2015) have noted the existence of a rape culture in South Africa. My own findings seem to support the literature highlighting the existence of a rape culture, with many participants and practitioners maintaining that the way women dressed or behaved contributed to violence perpetrated against them. Thus, even those working to prevent and reduce GBV believe that the onus is on women to avoid the violence, rather than on men to stop perpetrating violence. 
The literature described above suggests a range of potential causes for violence, but due to the fact that the vast majority of violence is perpetrated by men, I argue that a primary factor which needs to be kept in mind is the impact of masculinities. However, it was interesting that few respondents in my own research highlighted masculinities as a causal factor in violence, although it is unclear whether this lack of focus on masculinities is because it is assumed to be a given, or because respondents do not actually view masculinities as a factor which causes violence. It is also somewhat surprising, given that so many of my respondents are involved in an intervention which has a specific masculinities focus as a means of addressing GBV. This could suggest that there is some disconnect between the stated aims of the intervention and the way it is implemented. It could also suggest that many of those involved in these interventions would instead prefer focusing on alternative ways to respond to GBV. Thus, the discussion now turns to ways to respond to GBV, primarily focusing on masculinities-focused interventions.

\subsection{Current intervention as a way to address violence}

The high levels of GBV, both in South Africa and a wide range of others contexts, have led to the development of numerous different methods which aim to address this violence, in both reactive and preventative manners. The majority of these interventions focus on providing support to survivors of violence, yet there is little evidence to show that these help to lower levels of GBV (Ellsberg et al., 2015). Along with the more recent research focusing on masculinities as a possible cause of a wide range of forms of GBV, the lack of impact on levels of violence of women-focused programmes has led to an increase in interventions that work with men on masculinities (Jewkes, Flood \& Lang, 2015).

Because gender is seen as something which is socialised, any attempt to re-socialise individuals will be dependent on the people surrounding the individual (Davidson \& Gordon, 1979). Thus, aspects such as positive role models (Barker, 2003) and a supportive peer group are important in any re-socialisation process (Silvergleid \& Mankowski, 2006). Along with this, numerous studies have shown that interventions tend to be more effective when voluntary rather than compulsory (Goffman, 1961; Scott, 2010), when they have a gendertransformative approach (WHO, 2007; Ricardo \& Virani, 2010), if they provide space for men to practise alternative versions of masculinity (Viitanen \& Colvin, 2015) and if they use multiple and multi-sectoral strategies (WHO, 2007; Ellsberg et al., 2015).

This research is primarily interested in masculinities-focused interventions, and therefore only discusses this form of intervention, and specifically looks at the OMC intervention implemented by Sonke Gender Justice as an example of this form of intervention. The OMC intervention is well-aligned with much of the literature on effective and impactful 
masculinities-focused interventions in that it is voluntary, gender-transformative, part of a multi-sectoral approach, uses facilitators as positive role models, creates supportive peer groups through its workshops, and provides safe spaces for men to practise alternative versions of masculinities. This would suggest that $\mathrm{OMC}$ should be relatively effective at impacting on participants, resulting in relatively significant or sustainable changes.

Numerous evaluations have been conducted on the OMC intervention, and these have reported some positive results, as discussed in an earlier chapter (Dworkin et al., 2013; Hossain et al., 2014; Viitanen \& Colvin, 2015). Thus, evaluations have shown a number of positive impacts which arise as a result of involvement in OMC interventions. However, two of the evaluations noted some concerns about the intervention, and these primarily related to the fact that the impacts of OMC seem to be more behavioural than attitudinal (Dworkin et al., 2013; Viitanen \& Colvin, 2015).

Although my own research did not specifically focus on what impacts the intervention had on participants, but rather on how the impact was achieved, responses from workshop participants did generally seem to indicate behavioural rather than attitudinal shifts. One striking example was the ongoing belief that women who wore short skirts 'deserved' to be raped, in that they should have dressed differently in order to avoid the rape, and this opinion was voiced by a number of participants and practitioners, as was described above. Thus, rather than viewing it as problematic that masculine norms expect men to not be able to control their sexual urges, participants and facilitators instead view women's clothing as the causal factor in sexual violence. This suggests that although participants may shift their own behaviour, in that they would not themselves perpetrate sexual violence, there is less shifting of the underlying attitude of rape myth acceptance and gender inequality, which points to a behavioural rather than an attitudinal shift.

A final aspect regarding the impact of the workshops that arose in my own research, and which supports previous evaluations of the intervention by others, is the seemingly ongoing belief that homosexuality is problematic or deviant. Viitanen and Colvin (2015) found that although participants now believed that women should have equal rights to men, this view did not extend to those in the LGBTIQ community, with participants believing that gay men and lesbian women did not deserve the same rights as heterosexual men and women. I found similar opinions during my own research. In one workshop that I observed, a facilitator stated that a person's sexuality is the 'same as' their gender, implying that a person's sexuality arises from their gender, and confirming the notion that heterosexuality is the norm. Although homosexuality was discussed in quite some detail in the Ceres workshop, this was due primarily to the fact that the workshop group included a sizable minority of gay participants, and most of the focus group and interview participants were gay men. In other 
focus groups, homosexuality was not mentioned at all, but the conversation always revolved around men as heterosexual, with girlfriends or wives, maintaining the notion that heterosexuality is the norm. This therefore again seems to confirm that while specific behaviours seem to be impacted by the intervention, there is less of an attitudinal shift regarding the norms of hegemonic masculinities which require men to be heterosexual.

However, as mentioned above, the specific impact of the intervention was not my primary focus, because this has been investigated in a number of prior evaluations. Instead, my research focused more on how and why the intervention had an effect, and this included three main questions: why participants joined the intervention, which aspects of the intervention influenced them, and what factors helped or hindered them in their desire to stay involved in Sonke's work after the evaluation was completed. The second two aspects will be discussed together, as there is a significant overlap between them.

The reasons why participants choose to join a voluntary masculinities-focused intervention have not previously been investigated to any great extent, and I was therefore unable to find literature specifically discussing this aspect, meaning that this section will primarily be a discussion of my own findings. A primary motivation for joining the intervention stated by a number of participants was a desire to be able to help in their communities or to expand their skill set in order to improve the impact that they could have. A number of participants had already been involved in some form of community development work through NGOs or local organisations, and their primary reason for joining the intervention was skills development, aiming to learn concrete skills to improve their capacity to help their communities. For those who had not previously been involved in community development, it seems a similar motivation was present, with participants joining to learn skills to help them become involved in this kind of work in the future. In the majority of cases, these skills seemed to refer to the action plans developed during the brainstorming session on the final day of the workshop which focused on how to address specific issues in the participants' communities.

Numerous participants cited a desire to help their communities as their primary reason for joining the intervention, and many saw the workshops as an opportunity to learn how to be better able to assist in their communities, which was seen as both a means of assisting others and a process of personal empowerment. While the aim of learning new skills to improve their community-focused work was more likely to be mentioned by those who had an existing connection to an NGO or local organisation, the desire to become involved in community development was also noted by those who were not currently doing so.

This suggests that while there is a strong sense of community responsibility among those who join these kinds of interventions, there may be some uncertainty about how best to 
engage in community development, with participants valuing the opportunity to develop new skills to do so. Responses from participants seem to support this suggestion, with a number of them specifically pointing to concrete skills that they learned as the most important impact of the intervention. This ranged from learning about sensitive areas on their partner's bodies through the Body Mapping exercise, to learning how to discuss and defend an opinion in the Gender Values Clarification activity. The ability to clearly argue or explain an opinion is particularly key in these types of interventions, as it can enable participants to feel confident in explaining the primary messages of the workshops in their broader community. The fact that participants feel able to spread the intervention messages in the community is one that was also highlighted as important by facilitators. I therefore argue that creating space for participants to 'practise' these arguments could be an important aspect to emphasise in the future.

However, not all participants necessarily joined because they felt a sense of community responsibility or a particular need to become involved in community development, with some participants stating that they had simply been bored, or wanted some distraction. While this may not be the hoped for motivation for participants joining the intervention, it seems as if attending the workshops often encouraged participants to remain involved in community mobilisation even though this had not been their initial reason for attending. This suggests that even if the initial voluntary joining of the programme has little to do with the intervention's stated aims of reducing GBV through a masculinities focus, engaging in the programme could still expose participants to alternative ways of understanding gender and gender norms, as well as the impacts of these gender roles on GBV.

The highlighting of concrete skills development as an important factor which impacts on participants leads to the second main focus of this research, which was on how the intervention achieved an impact on those who took part. Again, this is not an aspect which has received much attention in the literature (Dworkin et al., 2013). Thus, understanding how an intervention impacts on participants is an important gap in the literature. In this research, I found that participants did not mention specific activities which they felt influenced them, suggesting that while the content may be well-developed, it is often not the factor that participants feel had the biggest effect on them.

Instead of specific activities, three main factors were mentioned by participants as having influenced their lives. As described above, the findings in this study suggest that one way in which the intervention has an impact is through enabling participants to learn concrete new skills, and I suggest that providing a safe space for participants to practise these skills may be an important aspect which needs to be emphasised in the workshops. This seems to 
reinforce the literature pointing out that the creation of a safe space to practise alternative versions of gender roles has a positive impact on the effectiveness of gender-transformative interventions (Karp, 2010). The creation of safe spaces has been linked to two additional factors: the presence of positive role models, and the creation of a supportive peer group, and both of these factors were noted as important in my own findings.

Although the presence of role models has been highlighted in some of the literature as an aspect which can improve the effectiveness of a masculinities-focused intervention (e.g. Barker, 2003), other writers have problematized the notion that the presence of men in role model positions necessarily has a positive impact. This problematizing has predominantly arisen in literature which focuses on the impact of male school teachers on male pupils, or the impact of mentors (Carrington et al., 2008; Martino, 2008). Similarly, the literature on mentoring suggests that mentors can have a negative impact on youth if they are perceived to be unreliable in terms of keeping appointments and promises (Gaddis, 2012), and that a mentor could actually have a negative impact on youth if the mentors and youth were poorly matched in terms of interests (DuBois \& Rhodes, 2008). Thus, merely the fact of having male facilitators does not mean that they will necessarily act as positive role models for participants.

However, in this research, the facilitators were mentioned on a number of occasions as acting as positive role models. The ability of male facilitators to act as positive male role models seemed to be in stark contrast to other men in the lives of participants, with many respondents highlighting the lack of positive male role models in their families and communities. The lack of existing positive male role models for many participants suggests that the facilitators modelling alternative versions of masculinities can play an important role in participants feeling able to attempt these alternatives themselves. Along with this, the creation of a safe space for participants to practise and become comfortable with these alternatives has also been highlighted in the literature as important (Karp, 2010), but this aspect was not specifically noted by respondents in my own research. However, an interesting additional aspect to the notion of having role models was the fact that a number of participants mentioned that they now felt able to act as positive role models in their own families and communities. This suggests that the ability to feel like a positive role model was an important factor in how the intervention influenced participants. The notion of being positive role models also links to the motivation that many participants expressed for joining the intervention, which was becoming involved in community development and mobilisation. The presence of positive role models and the opportunity to act as positive role models provides an important insight into the ways that participants are able to sustain the impacts 
of the intervention after its completion, and this aspect will be returned to after discussion of the final way in which the workshops affected participants, which is through the presence of a supportive peer group. The literature on re-socialisation suggests that the people surrounding an individual can play an important role in encouraging or discouraging the shift to alternative gender norms (Davidson \& Gordon, 1979). In other words, re-socialisation is more likely to be successful if an individual is surrounded by others who have similar goals (Barker, 2003).

This aspect seems to be strongly supported in my own research, with participants consistently mentioning the existence of a supportive peer group as a the most important impact of the intervention. The primary factor here seemed to be that participants felt that the workshops created a space to be able to share or discuss any issues or problems that they may have, and this was mentioned on numerous occasions. In other words, being surrounded by supportive peers provided an important 'safe space' to discuss ideas and issues, and many participants felt that this was the only such space that they had. Participants' families and the broader community were reported to be relatively unsupportive of their involvement in the intervention. Thus, the workshops and the peers within the workshops provided one of the few sources of support that participants were able to access while trying to shift gender norms. This was especially true in situations where male participants were hoping to practise alternative versions of masculinity, including being able to show emotions. The supportive peers involved in the intervention therefore provided one of the few spaces in which participants felt able to express emotions and thereby problematize hegemonic masculinities.

A final feature which participants related to the existence of a supportive peer group is that creating a large supportive group in their communities could contribute to the shifting of gender norms in these areas, because the norms of the workshop group would become more widespread in the communities in which they are implemented. In other words, the alternative norms of the workshops would start to become prevalent in their communities because the group practising these norms would be continuously growing.

This suggests that the presence of a supportive peer group impacted on participants in a number of ways, primarily through helping to create a safe space in which participants could discuss and problematize the gender norms that are prevalent in their communities. Having a space in which to try alternative behaviours (such as men being able to display emotions) is an important aspect in gender-transformative interventions. Along with this, the support that participants experienced in the intervention was felt to be in stark contrast to the disapproval that they experienced from others in their lives, such as family members and the 
broader community. Finally, being involved in a group which encouraged more positive gender roles was seen as contributing to the shift of traditional or more conservative norms in the broader community. This leads on to the final main focus of this research, which was on how (or whether) participants felt able to sustain any impacts of the intervention, and this is an additional dimension which has generally not been investigated to any great extent in the existing literature.

It has been noted by some authors (such as Peacock \& Levack, 2004) that societal disapproval from the community may make it difficult for participants to sustain alternative masculinities, suggesting that including community mobilisation initiatives may be an important way in which to improve the sustainability of an intervention. Thus, it is important to remember that these interventions do not take place in a vacuum, and the context in which they are implemented will always play a role in how easy participants find it to sustain any of the impacts that they experience. Thus, the factors which helped or hindered participants are touched on now.

To a large extent, the two factors which participants felt influenced them most strongly were the presence of positive role models and supportive peer groups, and these were also the factors which seemed most important in enabling participants to sustain the positive effects of the intervention. As was briefly touched on above, the desire to act as positive influences in their communities was a primary motivation for a number of participants to join the workshop, as well as one of the factors which most impacted on them during the intervention. It is therefore perhaps not surprising that this motivation was also a factor which enabled them to sustain the positive impacts that they felt they had gained. Along with this, the presence of the facilitators acting as positive role models also improved the desirability of the 'new norms' suggesting that participants would see these alternatives as more desirable, and therefore want to achieve them as well.

The second main factor which enables participants to sustain positive impacts of the intervention is the ongoing presence of a supportive peer group. While many participants felt that others in their families and community were unsupportive or disapproving of their engagement in the intervention, the fact of having a supportive group of peers was highlighted as being a factor which made it easier to practise and sustain alternative gender norms. Similarly, a number of participants noted that a growing group of individuals who all practised alternative norms could then begin to positively impact on the surrounding communities as well, thereby helping to spread the message of the intervention beyond simply those who had attended workshops. These two factors therefore suggest that the 
peers surrounding an individual will have a large impact on the effectiveness and sustainability of this kind of re-socialisation intervention.

\subsection{Conclusion}

A significant amount of literature has been generated in recent years around the link between masculinities and gender-based violence, with many authors and studies highlighting the fact that adherence to violent masculinities is a primary contributing factor to men's use of violence. This is particularly the case for militarised or hypermasculinities, which specifically expect the use of violence in order to be achieved. However, the findings in this study suggest that many masculinities in South Africa have a strong emphasis on violence, with participants highlighting that violence, and particularly violence against female partners, is an expected aspect of 'being a man'. Thus, it is not only a few specific versions of masculinities which encourage violence, but rather hegemonic masculinities in the country. This then provides some explanation of why the levels of violence are so high in South Africa, an issue which arose repeatedly in interviews and focus groups, with numerous participants describing their experiences of violence.

Despite highlighting both the violence required by masculinities and the high levels of violence in the country, few respondents seem to link the two, with many participants and practitioners in this research seeming to hold different opinions on the causes of violence, primarily focusing on witnessed or experienced abuse, substance abuse and, in the case of sexual violence, the way that women dress or behave. It was interesting that this was the case even for those who are currently either participating in or facilitating masculinitiesfocused interventions. Thus, there seems to be some disconnect between the literature on causes of violence and the beliefs of those attending and implementing programmes which aim to respond to and reduce GBV. Worryingly, it also suggests that even those who work in the field of GBV prevention subscribe to a number of rape myths, supporting literature which has described South Africa as having a rape culture.

Traditional GBV interventions have tended to focus on women survivors of violence, providing counselling, legal support, medical support, group therapy, and places of shelter. While these provide an important system of support for survivors, there is little evidence to suggest that they reduce the levels of GBV to any great extent in the contexts in which they are implemented. Thus, alternative methods of reducing violence need to be investigated. Due to the literature suggesting that adherence to violent masculinities contributes to violence, a number of masculinities-focused interventions have begun to be implemented with the specific aim of reducing and preventing GBV. These interventions have a primary focus on re-socialising participants into alternative, and less violent, gender norms. A range 
of other re-socialisation methods were outlined, including total institutions, BIPs and DDR, yet each of these have numerous shortcomings, particularly with regards to practicality, and I therefore focused specifically on voluntary masculinities-focused interventions. Much of the literature around this is optimistic, suggesting that these kinds of interventions can have positive impacts on those who participate in them, often resulting in reductions in violent behaviour and more gender-equitable beliefs. However, it seems that these impacts tend to be more behavioural than attitudinal, impacting on specific behaviours, but not on the attitudes and norms behind them. These results suggest that although masculinities-focused interventions could play a positive role in GBV prevention, more research needs to be done to understand how to improve the attitudinal impact, rather than just the impact on specific behaviours.

As a result of the relatively large body of literature already existing on the impacts of masculinities-focused programmes, this study rather tried to focus on the aspects which have not yet been investigated in much detail. Thus, I focused on the reasons why participants chose to join this form of intervention, how the intervention achieved its impact, and what enabled participants to sustain any positive impacts that they may have experienced. It is hoped that this can contribute to understanding how to better design and implement such interventions in order to improve their impact.

To do this, I looked at the OMC programme implemented by Sonke as a case study of a masculinities-focused intervention, one which is largely in line with what the literature highlights as aspects of effective interventions. Thus, it is voluntary, gender-transformative, uses facilitators as role models, provides supportive peer groups, and uses a multi-sector strategy. A number of evaluations have been conducted of the programme, suggesting that it has similar positive effects to other masculinities-focused interventions. These include a reduction in violence against women and children, improvements in men's perceptions of women's rights, reductions in men's reported intention to commit IPV, and a recognition that masculinities are 'costly' to men. However, in a similar fashion to other masculinities-focused interventions, these impacts seem to be predominantly behavioural, rather than attitudinal, with little impact on participants' beliefs that hegemonic masculinities are 'the norm', and little desire to do more than small shifts away from this norm.

While my own focus was not on the impact of the intervention, as this has been covered in a number of previous evaluations, it was interesting to note that responses from participants in this study seem to support the findings of these previous evaluations which suggested that OMC has an effect on specific behaviours rather than participants' attitudes. Along with this, a factor which could have a major limiting effect on the intervention's impact is the fact that 
there is a general perception of a lack of political will to meaningfully address GBV. Although Sonke's programmes include a focus on lobbying government and developing more effective policies to respond to GBV, many respondents highlighted the lack of response from government and the police in terms of seriously intending to reduce the levels of GBV in the country. Government's position on this significantly impacts on how the issue is viewed in broader society, and the fact that there is a general perception that government does not take it seriously can hamper efforts to address the issue in the country. This therefore suggests that more efforts need to be made to engage government in altering their policies and implementation.

My interest was rather in how the intervention achieved these effects, and this initially focused on why participants joined the intervention. In the majority of cases, it seems that participants had a desire to become involved in community development or mobilisation, and viewed these workshops as a way to improve their skills to do so. This could also suggest that more people in these communities have a desire to be similarly involved in community development, but are unsure how to do so. Due to this, many participants noted that learning concrete new skills was an important way in which the intervention impacted on them.

Along with this, the presence of positive role models and of a supportive peer group were the two other factors most consistently highlighted by participants as having the biggest impact on them. Similarly, these two factors are also the aspects which contributed to participants' ability to sustain the positive impacts that they felt they had achieved through the intervention, supporting the literature which suggests that a person's peers will play the biggest role in their re-socialisation process. Respected role models who provide examples of the alternative behaviours and peers who support the use of these behaviours are both aspects which will assist participants in sustaining the impacts of the intervention. This therefore suggests that interventions should work on ways to incorporate this more explicitly into the workshops as a possible means of improving their impact.

This study has therefore provided some insight into the ways in which masculinities-focused interventions have an influence on participants, and has suggested possible means for this influence to be emphasised in the future. However, more research on the most effective means of doing so is required in the future, including on how to achieve a more attitudinal rather than simply behavioural impact. A possible means of doing this is to broaden the sample of those interviewed, involving a focus on participants who fell out of the intervention, and the family members or partners of participants. Including these groups could provide information on how the programme is seen from an external viewpoint, and of aspects which 
may have caused participants to drop out. This could therefore help to gain a better understanding of how to improve the intervention's effect.

An additional aspect which requires more research in the future is how such an intervention would be conducted and received in more affluent communities. The fact of privileged men's use of violence is very under-researched in GBV literature, which tends to contribute to the notion that GBV is only an issue in poorer or more marginal communities. Along with this, many organisations only implement programmes in poor communities, which reinforces this notion. Thus, there is very little research or practical work being done on middle- and upperclass violence, and on the best means to address this. Understanding this aspect more fully could once again contribute to improving the impacts of masculinities-focused interventions in the future.

In many ways, this study has supported literature on how to improve the effect of resocialisation interventions, highlighting that those surrounding an individual will play a major role in their willingness and ability to shift norms relating to gender. This can be positive, in the form of supportive peer groups who encourage individuals to practise alternative gender norms. However, it can also be negative, in that communities and government structures which are slow to recognise and respond to changing gender norms can hinder people's and group's efforts to address gender inequality. This suggests that advocacy and policy development need to become larger facets of GBV prevention efforts, with more active involvement and support from government being required. Until then, efforts such as OMC will remain small-scale in their influence on gender norms in the country. 


\section{REFERENCE LIST}

Abrahams, N., Jewkes, R. \& Mathews, S. 2010. Guns and gender-based violence in South Africa. South African Medical Journal, 100(9):586-588.

Adelman, M. 2003. The military, militarism and the militarisation of domestic violence. Violence Against Women, 9(9):1118-1152.

Agnew, R. 1992. Foundation for a general strain theory of crime and delinquency. Criminology, 30(1):47-87.

Alden, A. 2010. A continuum of violence: a gendered analysis of post-conflict reconstruction. POLIS, 3(Winter):1-37.

Alexander-Scott, M., Bell, E. \& Holden, J. 2015. DFID Guidance note: Shifting norms to tackle violence against women and girls (VAWG). London: VAWG Helpdesk.

Anderson, M.J. 1999/2000. Rape in South Africa. Georgetown Journal of Gender and Law, $1(3): 789-821$.

Anderson, E. 2008. "I used to think women were weak": Orthodox masculinity, gender segregation and sport. Sociological Forum, 23(2):257-280/

Andrews, E. 2007. Learning to love after learning to harm: post-conflict reconstruction, gender equality and cultural values. Michigan State Journal of International Law, 15(41):4162.

Aosved, A.C. \& Long, P.J. 2006. Co-occurrence of rape myth acceptance, sexism, racism, homophobia, ageism, classism, and religious intolerance. Sex Roles, 55:481-492.

Arias, E., Arce, R. \& Vilariño, M. 2013. Batterer intervention programmes: A meta-analytic review of effectiveness. Psychosocial Intervention, 22:153-160.

Armstrong, S. 1994. Rape in South Africa: an invisible part of Apartheid's legacy. Focus on Gender, 2(2):35-59.

Ashley, M. 2003. Primary school boys' identity formation and the male role model: an exploration of sexual identity and gender identity in the UK through attachment theory. Sex Education, 3(3):257-270.

Babcock, J.C., Green, C.E. \& Robie, C. 2004. Does batterers' treatment work? A metaanalytic review of domestic violence treatment. Clinical Psychology Review, 23:1023-1053.

Barker, G. 2003. How do we know if men have changed? Promoting and measuring attitude change with young men. Lessons from Program $\mathrm{H}$ in Latin America, in Expert group meeting 
on "The role of men and boys in achieving gender equality". Brazil: UN, DAW, ILO, UNAIDS, UNDP.

Barker, G., Contreras, J.M., Heilman, B., Singh, A., Verma, R. \& Nascimento, M. 2011. Initial results from the International Men and Gender Equality Survey (IMAGES). Washington/Rio: International Center for Research on Women, Promundo.

Barker, G. \& Nascimento, M. 2002. Working with young men series. Rio de Janeiro, Brazil: Instituto Promundo.

Barker, G. \& Ricardo, C. 2005. Young men and the construction of masculinity in subSaharan Africa: Implications for HIV/AIDS, conflict and violence. Social Development Papers - Conflict prevention and reconstruction. Washington: World Bank.

Baugher, S.N., Elhai, J.D., Monroe, J.R. \& Gray, M.J. 2010. Rape myth acceptance, sexual trauma history, and posttraumatic stress disorder. Journal of Interpersonal Violence, 25(11):2036-2053

Bhandari, N. 2008. Documentation of a campaign to end violence against women and girls and to promote gender equality in India - MASVAW. Uttar Pradesh, India: Save the Children, MASVAW.

Biddulph, S. 1995. Manhood. Sydney: Finch Publishing.

Borer, T.A. 2009. Gendered war and gendered peace: truth commissions and postconflict gender violence: Lessons from South Africa. Violence Against Women, 15(10):1169-1193.

Boyd, S.B. 2004. Backlash against feminism: Canadian custody and access reform debates of the late twentieth century. Canadian Journal of Women and Law, 16:255.

Braun, V. \& Clarke, V. 2006. Using thematic analysis in psychology. Qualitative Research in Psychology, 3(2):77-101.

Breckenridge, K. 1998. The allure of violence: men, race and masculinity on the South African goldmines, 1900-1950. Journal of Southern African Studies, 24(4):669-693.

Brownmiller, S. 1975. Against our will: men, women and rape. New York: Fawcett Books. Bryman, A. 2008. Social research methods $3^{\text {rd }}$ edition. Oxford: Oxford University Press. Buscher, D. 2005. Masculinities: male roles and male involvement in the promotion of gender equality: A resource packet. New York: Women's Commission for refugee women and children. 
Burt, M.R. 1980. Cultural myths and supports for rape. Journal of Personality and Social Psychology, 38(2):217-230.

Butler, J. 1988. Performative acts and gender constitution: an essay in Phenomenology and Feminist Theory. Theatre Journal, 40(4):519-531.

Carrington, B., Tymms, P. \& Merrell, C. 2008. Role models, school improvement and the 'gender gap' - do men bring out the best in boys and women the best in girls? British Educational Research Journal, 34(3):315-327.

Chafetz, J.S. 1997. Feminist theory and Sociology: Underutilized contributions for mainstream theory. Annual Review of Sociology, 23:97-120.

Clarke, Y. 2008. Security sector reform in Africa: A lost opportunity to deconstruct militarised masculinities? Feminist Africa, 10:49-66.

Cock, J. 1991. Colonels \& cadres: war and gender in South Africa. Cape Town: Oxford University Press.

Cock, J. 1994. Women and the military: Implications for demilitarisation in the 1990s in South Africa. Gender and Society, 8(2):152-169.

Cock, J. \& Nathan, L. 1989. War and Society: the militarisation of South Africa. Cape Town/Johannesburg: David Philip.

Cockburn, C. 2010. Gender relations as causal in militarization and war. International Feminist Journal of Politics, 12(2):139-157.

Collier, P. 1995. Demobilisation and insecurity in Ethiopia and Uganda: A study in the economics of the transition from war to peace, in J Cilliers (ed) Dismissed: Demobilisation and reintegration of former combatants in Africa. South Africa: Institute for Defence Policy.

Connell, R.W. 1987. Gender and power: Society, the person and sexual politics. Stanford: Stanford University Press.

Connell, R.W. 1993. The big picture: Masculinities in recent world history. Theory and Society, 22(5): 597-623.

Connell, R.W. 1995. Masculinities. Cambridge: Polity Press.

Connell, R.W. 2005. Growing up masculine: rethinking the significance of adolescence in the making of masculinities. Irish Journal of Sociology, 14(2):11-28.

Connell, R.W. \& Messerschmidt, J.W. 2005. Hegemonic masculinity: rethinking the concept. Gender and Society, 19(6):829-859. 
Conway, D. 2004. "Every coward's choice?" Political objection to military service in Apartheid South Africa as sexual citizenship. Citizenship Studies, 8(1):25-45.

Conway. 2008. The masculine state in crisis: State response to war resistance in Apartheid South Africa. Men and Masculinities, 10(4):422-439.

Cranshaw, K. 1991. Mapping the margins: Intersectionality, identity politics, and violence against women of color. Stanford Law Review, 43(6):1241-1299.

Das, A., Mogford, E., Singh, S.K., Barbhuiya, R.A., Chandra, S. \& Wahl, R. 2012. Reviewing responsibilities and renewing relationships: an intervention with men on violence against women in India. Culture, Health \& Sexuality, 14(6):659-675.

Davenport, T.R.H. 1991. South Africa: a modern history $4^{\text {th }}$ ed. Basingstoke: Macmillan. Davidson, L. \& Gordon, L.K. 1979. The Sociology of Gender. Chicago: Rand McNally College Publishing Company.

DeKeseredy, W.S. 2011. Feminist contributions to understanding woman abuse: Myths, controversies, and realities. Aggression and Violent Behavior, 16:297-302.

Dey, K., McDonald, S. \& Strydom, S. N.d. The road to recovery: You and Rape. Cape Town: DG Murray Trust.

Dimock, M., Doherty, C. \& Christian, L. 2013. Why own a gun? Protection is now top reasons: Perspectives of gun owners, non-owners. Pew Research Center for the People and the Press [online] http://www.people-press.org/files/legacy-pdf/03-1213\%20Gun\%20Ownership\%20Release.pdf [25.08.2016].

Ditlopo, P., Mullick, S., Askew, I., Vernon, R., Maroga, E., Sibeko, S., Tshabalala, M., Raletsemo, R., Peacock, D. \& Levack, A. 2007. Testing the effectiveness of the Men as Partners Program (MAP) in Soweto, South Africa. South Africa: USAID, PEPFAR.

Dolan, C. 2002. Collapsing masculinities and weak states - a case study of Northern Uganda, in F. Cleaver (ed) Masculinities Matter! Men, gender and development. Cape Town: David Philip.

Donaldson, M. 1993. What is hegemonic masculinity? Theory and Society, 22(5): 643-657. Dönges, H. \& Karp, A. 2014. Women and Gun Ownership. Research Notes: Armed Actors, 45. Geneva: Small Arms Survey. 
Douglas, I., Gleichmann, C., Odenwald, M., Steenken, K. \& Wilkinson, A. 2004. Disarmament, demobilisation and reintegration: A practical field and classroom guide. Germany: GTZ, NODEFIC, PPC, SNDC.

DuBois, D.L., Portillo, N., Rhodes, J.E., Silverthorn, N. \& Valentine, J.C. 2011. How effective are mentoring programs for youth? A systematic assessment of the evidence. Psychological Science in the Public Interest, 12(2):57-91.

Dworkin, S.L., Colvin, C., Hatcher, A.M. \& Peacock, D. 2012. Men's perceptions of women's rights and changing gender relations in South Africa: Lessons for working with men and boys in HIV and anti-violence programs. Gender and Society, 26(1):97-120.

Dworkin, S.L., Hatcher, A.M., Colvin, C. \& Peacock, D. 2013. Impact of a gendertransformative HIV and Antiviolence Program on gender ideologies and masculinities in two rural, South African communities. Men and Masculinities, 16(2):181-202.

El-Bassel, N., Witte, S., Wada, T., Gilbert, L. \& Wallace, J. 2001. Correlates of partner violence among female street-based sex workers: Substance abuse, history of childhood abuse, and HIV risks. AIDS Patient Care and STDs, 15(1):41-51.

Ellsberg, M., Arango, D.J., Morton, M., Gennari, F., Kiplesund, S., Contreras, M. \& Watts, C. 2015. Prevention of violence against women and girls: what does the evidence say? The Lancet, 385(April 18):1555-1566.

Engels, B. 2004. Rape and constructions of masculinity and femininity. Politikon - The IAPSS Journal, 8:59-70.

Erdström, J., Shahrokh, T. \& Singh, S.K. 2015. The new 'MASVAW men': Strategies, dynamics and deepening engagements. A case study of a networked approach to challenging patriarchy across institutions in Uttar Pradesh. Empowerment of women and girls Evidence Report 143. England: IDS.

European Institute for Gender Equality (EIGE). N.d. What is gender-based violence? [online] http://eige.europa.eu/content/what-is-gender-based-violence [09.12.2013].

Everatt, D. \& Jennings, R. 2006. A survey of ex-combatants in South Africa, in D. Everatt (ed.) Only useful until democracy? Reintegrating ex-combatants in post-apartheid South Africa. Johannesburg: Atlantic Philanthropies, 3-11.

Ezzell, M.B. 2012. "I'm in control": Compensatory masculinity in a therapeutic community. Gender and Society, 26(2):190-215. 
Fals-Stewart, W. \& Kennedy, C. 2005. Addressing intimate partner violence in substanceabuse treatment. Journal of Substance Abuse Treatment, 29:5-17

Farr, V. 2002. Gendering demilitarization as a peacebuilding tool. Bonn: Bonn International Center for Conversion.

Feder, L. \& Wilson, D. 2005. A meta-analytic review of court-mandated batterer intervention programs: Can courts affect abusers' behaviour? Journal of Experimental Criminology, 1:239-262.

Fernandes, A., Sharma, D., Kukade, P., Jeena. R., Khanna, R., Singh, S. \& Vaze, V. 2005. Working with men on gender, sexuality, violence and health: Trainers' Manual. India: SAHAJ, SAHAYOG, TATHAPI.

Flick, U. 2014. An introduction to qualitative research. Los Angeles: Sage Publications.

Flintoff, R. 2001. Sexual Assault, in J. Nicoletti, S. Spencer-Thomas, C.M. Bollinger (eds) Violence goes to college: The authoritative guide to prevention and intervention $2^{\text {nd }}$ ed. Illinois: Charles C. Thomas.

Fontana, A. \& Frey, J.H. 2005. The interview: from neutral stance to political involvement, in N.K. Denzin \& Y.S. Lincoln (eds) The Sage Handbook of Qualitative Research $3^{\text {rd }}$ edition. London, New Delhi: Sage Publication.

Frose-Germain, B. 2006. Educating boys: tempering rhetoric with research. McGill Journal of Education, 41(2):145-154.

Fulu, E. \& Heise, L. 2015. State of the field of research on violence against women and girls. What works to prevent violence against women and girls evidence reviews Paper 1. WhatWorks, DFID.

Fulu, E. \& Kerr-Wilson, A. 2015. Interventions to prevent violence against women and girls. What works to prevent violence against women and girls evidence reviews Paper 2. WhatWorks, DFID.

Gaddis, S.M. 2012. What's in a relationship? An examination of social capital, race and class in mentoring relationship. Social Forces, 90(4):1237-1289.

Garcia-Moreno, C., Hegarty, K., d'Oliveira, A.F.L., Koziol-McLain, J., Colombini, M. \& Feder, G. 2015. The health-systems response to violence against women. The Lancet, 385(April 18):1567-1579. 
Garcia-Moreno, C., Pallitto, C., Devries, K., Stöckl, H., Watts, C. \& Abrahams, N. 2013. Global and regional estimates of violence against women: prevalence and health effects of intimate partner violence and non-partner sexual violence. Geneva: WHO, MRC, LSHTM.

Gear, S. 2002. Now that the war is over - Ex-combatants and the question of violence: A literature review, CSVR Violence and Transition Series. Cape Town: CSVR.

GenderLinks and Medical Research Council. 2012. The war@ home: Findings of the Gender Based Violence Prevalence Study in Gauteng, Western Cape, KwaZulu Natal and Limpopo Provinces of South Africa. Gauteng: GenderLinks, MRC.

Ghanotakis, E., Bruins, M., Peacock, D., Redpath, J. \& Swart, R. 2007. Stop prison rape in South Africa. Agenda, 74:68-80.

Gibson, D. \& Rosenkrantz Lindegaard, M. 2007. South African boys with plans for the future: why a focus on dominant discourses tells us only a part of the story, in T. Shefer, K. Ratele, A. Strebel, N. Shabalala \& R. Buikema (eds) From boys to men: Social constructions of masculinity in contemporary society. South Africa: UCT Press.

Goffman, E. 1961. Asylums: essays on the social situation of mental patients and others inmates. New York: Anchor Books.

Goldstein, J.S. 2004. War and gender: How gender shapes the war system and vice versa. Cambridge: Cambridge University Press.

Gqola, P.D. 2007. How the 'cult of femininity' and violent masculinities support endemic gender based violence in contemporary South Africa. African Identities, 5(1):111-124.

Gqola, P.D. 2015. Rape: A South African Nightmare. Johannesburg: MFBooks Joburg. Greig, A. 2004. Prevention of HIVIAIDS in the South African armed forces: addressing high risk sexual behaviours caused by gender roles. Johannesburg: EngenderHealth, Sonke Gender Justice Network.

Hamber, B. 2000. "Have no doubt it is fear in the land" An exploration of the continuing cycles of violence in South Africa. Southern African Journal of Child and Adolescent Mental Health, 12(1):5-18.

Hamburger, M.E., Hogben, M., McGowan, S. \& Dawson, L.J. 1996. Assessing hypergender ideologies: development and initial validation of a gender-neutral measure of adherence to extreme gender-role beliefs. Journal of Research in Personality, 30(2):157-178. 
Harders, C. 2011. Gender relations, violence and conflict transformation, in B. Austin, M. Fischer \& H.J. Giessmann (eds) Advancing conflict transformation: The Berghof Handbook II. Opladen/Farmington Hills: Barbara Budrich Publishers.

Heideman, L. 2007. The struggle for democracy and ex-combatants in South Africa, in D. Everatt (ed) Only useful until democracy? Reintegrating ex-combatants in post-apartheid South Africa. Johannesburg: Atlantic Philanthropies.

Heise, L. 2011. What works to prevent partner violence? An evidence overview. London: STRIVE.

Heise, L., Ellsberg, M. \& Gottmoeller, M. 2002. A global overview of gender-based violence. International Journal of Gynecology and Obstetrics, 78(1):S5-S14.

Henslin, J.M. 2010. Sociology - A down-to-earth approach. Boston: Allyn \& Bacon.

Hinds, L.S. 1998/1999. The gross violations of human rights of the Apartheid regime under international law. Rutgers Race and Law Review, 1:213-317.

Hoff-Sommers, C. 2000. The war against boys. The Atlantic Monthly, 285(5):59-74.

Honorine, S. 2013. South Africa's 'strike season' underway. VOA News [online]. Available at http://www.voanews.com/content/south-africa-strike-season-underway/1743350.html [12.07.2016].

Hossain, M., Zimmerman, C., Kiss, L., Abramsky, T., Kone, D., Bakayoko-Topolska, M., Annan, J., Lehman, H. \& Watts, C. 2014. Working with men to prevent intimate partner violence in a conflict-affected setting a pilot cluster randomized controlled trial in rural Côte d'Ivoire. BMC Public Health, 14:339-351.

Hu, L. \& Salie-Kagee, M. 2007. Working with boys on crime prevention: Evidence-based research. Cape Town: RAPCAN.

Indexmundi. 2013. Mortality rate, adult, male (per 1000 male adults) - Country ranking, http://www.indexmundi.com/facts/indicators/SP.DYN.AMRT.MA/rankings [14.01.2014].

Jewkes, R. 2002. Intimate partner violence: causes and prevention. The Lancet, 359(April):1423-1429.

Jewkes, R., Dunkle, K., Nduna, M. \& Shai, N. 2010. Intimate partner violence, relationship power inequity, and incidence of HIV infection in young women in South Africa: a cohort study. The Lancet, 376:41-48. 
Jewkes, R., Flood, M. \& Lang, J. 2015. From work with men and boys to changes of social norms and reduction of inequities in gender relations: a conceptual shift in prevention of violence against women and girls. The Lancet, 385(April 18):1580-1589.

Jewkes, R., Levin, J. \& Penn-Kekana, L. 2002. Risk factors for domestic violence: Findings from a South African cross-sectional study. Social Science and Medicine, 55:1603-1617.

Jewkes, R., McLean Hilker, L., Khan, S., Fulu, E., Busiello, F. \& Fraser, E. 2015. Response mechanisms to prevent violence against women and girls. What works to prevent violence against women and girls Evidence Reviews Paper 3. WhatWorks, DFID.

Jewkes, R. \& Morrell, R. 2012. Sexuality and the limits of agency among South African teenage women: theorising femininities and their connections to HIV risk practises. Social Science and Medicine, 74:1729-1737.

Jewkes, R., Nduna, M., Levin, J., Jama, N., Dunkle, K., Khuzwayo, N., Koss, M., Puren, A., Wood, K. \& Duvvury, N. 2006. A cluster randomized-controlled trial to determine the effectiveness of Stepping Stones in preventing HIV infection and promoting safer sexual behaviour amongst youth in the rural Eastern Cape, South Africa: trial design, methods and baseline findings. Tropical Medicine and International Health, 11(1):3-16.

Jewkes, R., Nduna, M., Levin, J., Jama, N., Dunkle, K., Wood, K., Koss, M., Puren, A. \& Duvvury, N. 2007. Evaluation of Stepping Stones: A gender transformative HIV prevention intervention - Policy Brief. Pretoria: MRC.

Jewkes, R., Sikweyiya, Y., Morrell, R. \& Dunkle, K. 2009. Understanding men's health and use of violence: Interface of rape and HIV in South Africa. Pretoria: MRC.

Jewkes, R., Wood, K. \& Duvvury, N. 2010. 'I woke up after I joined Stepping Stones': meanings of an HIV behavioural intervention in rural South African young people's lives. Health Education Research, 25(6):1074-1084.

Jones, A. 2000. Gendercide and genocide. Journal of Genocide Research, 2(2):185-211. Jules-Macquet, R. 2014. The state of South African prisons. NICRO Public Education Series, 1.

Kamberelis, G. \& Dimitriadis, G. 2005. Qualitative Inquiry - Approaches to language and literacy. New York, London: Teachers College Press.

Kandirikirira, N. 2002. Deconstructing domination: gender disempowerment and the legacy of colonialism and apartheid in Omahehe, Namibia, in F. Cleaver (ed) Masculinities Matter! Men, gender and development. Cape Town: David Philip. 
Karp, D.R. 2010. Unlocking men, unmasking masculinities: Doing men's work in prison. Journal of Men's Studies, 18(1):63-83.

Kaufman, M. 2012. Sexual violence in conflict and post-conflict: engaging men and boys Advocacy Brief. Johannesburg: MenEngage, UNFPA, Sonke Gender Justice Network, Promundo.

Kelly, K. 2002. From encounter to text: collecting qualitative data for interpretive research, in M. Terre Blanche \& K. Durrheim (eds) Research in practice: Applied methods for the social sciences. Cape Town: University of Cape Town Press.

Kim, J., Ferrari, G., Abramsky, T., Watts, C., Hargreaves, J., Morison, L., Phetla, G., Porter, J. \& Pronyk, P. 2009. Assessing the incremental effects of combining economic and health interventions: the IMAGE study in South Africa. Bulletin of the World Health Organisation, 87:824-832.

Kim, J. \& Motsei, M. 2002. "Women enjoy punishment": attitudes and experiences of genderbased violence among PHC nurses in rural South Africa. Social Science and Medicine, 54:1243-1254.

Kim, J., Watts, C., Hargreaves, J., Ndhlovu, L., Phetla, G., Morison, L., Busza, J., Porter, J. \& Pronyk, P. 2007. Understanding the impact of a microfinance-based intervention on women's empowerment and the reduction of intimate partner violence in South Africa. American Journal of Public Health, 97(10):1794-1802.

Kimmel, M.S. 2006. The masculine mystique, in M.S. Kimmel (ed) Manhood in America: A cultural history. New York: Oxford University Press.

Kubany, E.S., Hill, E.E., Owens, J.A., lannce-Spencer, C., McCaig, M.A., Tremayne, K.J. \& Williams, P.L. 2004. Cognitive trauma therapy for battered women with PTSD (CCT-BW). Journal of Consulting and Clinical Psychology, 72(1):3-18.

Lahelma, E. 2000. Lack of male teachers: a problem for students or teachers? Pedagogy, Culture and Society, 8(2):173-185.

Landau, P.S. 2012. The ANC, MK and 'The turn to violence'. South African Historical Journal, 64(3):538-563.

Langa, M. \& Eagle, G. 2008. The intractability of militarised masculinity: A case study of former Self-Defence Unit members in the Kathorus area, South Africa. South African Journal of Psychology, 38(1):152-175. 
Lau, L. 2009. Intimate partner violence Fact Sheet. South Africa: Institute for Social and Health Sciences, MRC.

Lehmann, H. 2013. Introductory guide. Preventing violence against women and girls: Engaging Men through Accountable Practice 1. New York: International Rescue Committee. Lerche, C. 2000. Peace building through reconciliation, International Journal of Peace Studies 5(2): 61-76.

Levy, A. 2011. South Africa's strike season. Moneyweb [online] http://www.moneyweb.co.za/archive/south-africas-strike-season/ [12.07.2016].

Liebschutz, J., Savetsky, J., Saitz, R., Horton, N., Lloyd-Travaglini, C. \& Samet, J. 2002. The relationship between sexual and physical abuse and substance abuse consequences. Journal of Substance Abuse Treatment, 22:121-128.

Lindegger, G. 2002. Research methods in clinical research, in M. Terre Blanche \& K. Durrheim (eds) Research in practice: Applied methods for the social sciences. Cape Town: University of Cape Town Press.

Lindegger, G. \& Maxwell, J. 2007. Teenage masculinity: the double bind of conformity to hegemonic standards, in T. Shefer, K. Ratele, A. Strebel, N. Shabalala \& R. Buikema (eds) From boys to men: Social constructions of masculinity in contemporary society. South Africa: UCT Press.

Lopes, H. 2011. Background paper: Militarized masculinity in peacekeeping operations: An obstacle to gender mainstreaming. Peacebuilding and Conflict Prevention Consultation Series. Ottawa, Canada: Peacebuild/Paixdurable.

Lorber, W. \& Garcia, H.A. 2010. Not supposed to feel this: traditional masculinity in psychotherapy with male veterans returning from Afghanistan and Iraq. Psychology, Theory, Research, Practice, Training, 47(3):296-305.

Lwambo, D. 2011. Before the war I was a man: Men and Masculinities in Eastern DR Congo. Goma: DRC, HEAL Africa.

Mac an Ghaill, M. 1996. What about the boys - schooling, class and crisis masculinity. Sociological Review, 44(3):381-397.

Machisa, M. 2010. When violence becomes normal. 16 Days of Activism Gender Links Opinion and Commentary Service. Johannesburg: GenderLinks. 
Magadla, S. 2013. EFF and the return of the warrior citizen, Mail \& Guardian, http://www.thoughtleader.co.za/siphokazimagadla/2013/11/06/eff-and-the-return-of-thewarrior-citizen/ [14.06.2014].

Malinosky-Rummell, R. \& Hansen, D.J. 1993. Long-term consequences of childhood physical abuse. Psychological Bulletin, 114(1):68-79.

Mankayi, N. 2008. Morality and sexual rights: constructions of masculinity, femininity and sexuality among a group of South African soldiers. Culture, Health \& Sexuality, 10(6):625634.

Martin, A.J. \& Marsh, H. 2005. Motivating boys and motivating girls: does teacher gender really make a difference? Australian Journal of Education, 49(3):320-334.

Martino, W. 2008. Male teachers as role models: addressing issues of masculinity, pedagogy and the re-masculinization of schooling. Curriculum Inquiry, 38(2):189-223.

Martino, W. \& Kehler, M. 2006. Male teachers and the "boy problem": An issue of recuperative masculinity politics. McGill Journal of Education, 41(2):113-131.

Mathews, S. \& Abrahams, N. 2001. Combining stories and numbers: An analysis of the impact of the Domestic Violence Act (No. 116 of 1998) on women. Cape Town: Gender Advocacy Programme, MRC.

Mathews, S., Abrahams, N., Martin, L.J., Vetten, L., van der Merwe, L. \& Jewkes, R. 2004. 'Every six hours a woman is killed by her intimate partner': A national study of female homicide in South Africa. MRC Policy Brief, 5.

McDowell, L. 2000. The trouble with men? Young people, gender transformation and the crisis of masculinity. International Journal of Urban and Regional Research, 24(1):201-209.

McGinley, A.C. \& Cooper, F.R. 2013. Identities cubed: Perspectives on multidimensional masculinities theory. Nevada Law Journal, 13(2):326.

Messerschmidt, J.W. 1993. Masculinities and crime - critique and reconceptualization of theory. USA: Rowman \& Littlefield Publishers.

Messerschmidt, J.W. 2001. Masculinities, crime and prison, in D. Sabo, T.A. Kupers \& W. London (eds) Prison Masculinities. Philadelphia: Temple University Press.

Messner, M.A. 1997. Politics of masculinities: Men in social movements. Thousand Oaks, London, New Delhi: Sage Publications. 
Messner, M.A. 1998. The limits of "The Male Sex Role": An analysis of the Men's Liberation and Men's Rights Movements' Discourse. Gender and Society, 12(3):255-276.

Ministerial Advisory Task Team on the Adjudication of Sexual Offence Matters [MATTSO]. 2013. Report on the re-establishment of sexual offences courts. Department of Justice, Department of Constitutional Development.

Moffett, H. 2006. "These women, they force us to rape them": Rape as narrative of social control in post-Apartheid South Africa. Journal of Southern African Studies, 32(1):129-144.

Mofokeng, T. 2016. Are the Sexual Offences Courts in South Africa serving their purpose? CapeTalk [online] http://www.capetalk.co.za/articles/13856/are-the-sexual-offences-courtsin-south-africa-serving-their-purpose [18.07.2016].

Moleketi, T. \& Motsoane, K. 2013. Young men and fathers must challenge 'manhood'. Gender Links Opinion and Commentary Service. Johannesburg: GenderLinks.

Mooney, K. 1998. "Ducktails, flick-knives and pugnacity": Subcultural and hegemonic masculinities in South Africa, 1948-1960. Journal of Southern African Studies, 24(4):753744.

Morrell, R. 1998. Of boys and men: Masculinity and gender in Southern African studies. Journal of Southern African Studies, 24(4):605-630.

Morrell, R., Jewkes, R. \& Lindegger, G. 2012. Hegemonic masculinity/masculinities in South Africa: Culture, power and gender politics. Men and Masculinities, 15(1):11.

Mortimer, J.T. \& Simmons, R.G. 1978. Adult socialization. Annual Review of Sociology, $4: 421-454$.

Mosher, D.L. \& Sirkin, M. 1984. Measuring a macho personality constellation. Journal of Research in Personality, 18(2):150-163.

Muggah, R. 2006. Reflections on disarmament, demobilisation and reintegration in Sudan. Humanitarian Exchange, 23(March):32-34.

Muntingh, L. \& Gould, C. 2010. Towards an understanding of repeat violent offending: A review of the literature. ISS Paper, 213.

Mutua, A.D. 2012/2013. Multidimensionality is to masculinities what intersectionality is to feminism. Nevada Law Journal, 13:341-367. 
Myrttinen, H. 2009. Violent islands - notes on masculinities and security sector reform processes in Haiti, Solomon Islands and Timor Lester, in M. Jacob, D. Bendix \& R. Stanley (eds) Engendering security sector reform: A workshop report. Berlin: Free University Berlin. Nagel, J. 1998. Masculinity and nationalism: gender and sexuality in the making of nations. Ethnic and Racial Studies, 21(2):242-269.

Nath, D. 2011. "We'll show you you're a woman": Violence and discrimination against black lesbians and transgender men in South Africa. South Africa: Human Rights Watch.

News24. 2013. SA braces for 'strike season', http://www.news24.com/SouthAfrica/News/SAbraces-for-strike-season-20130505, [12.07.2016].

Oakley, A. 1972. Sex, gender and society. London: Temple Smith.

Organisation for Economic Co-operation and Development (OECD). 2012. Closing the gender gap. Act Now, OECD.

Overlien, C., Aronsson, K. \& Hyden, M. 2005. The focus group interview as an in-depth method? Young women talking about sexuality. International Journal of Social Research Methodology, 8(4):331-344.

Paine, T., Khanyile, N.J., Herstad, M. \& Nkurunziza, J-M. 2011/2012. Study on involving men and boys in preventing and responding to gender-based violence in conflict, postconflict and humanitarian settings. Johannesburg: UNFPA, Sonke Gender Justice Network.

Paolucci, E.O., Genuis, M.L. \& Violato, C. 2001. A meta-analysis of the published research on the effects of child sexual abuse. The Journal of Psychology: Interdisciplinary and Applied, 135(1):17-36.

Patel, P. \& Tripodi, P. 2007. Peacekeepers, HIV and the role of masculinity in military behaviour. International Peacekeeping, 14(5):584-598.

Peacock, D. 2012. Engaging men and boys in efforts to end gender based violence in conflict and post-conflict settings, in When men stop fighting: Masculinities in post-conflict series. Vienna: Vienna Institute for International Dialogue and Cooperation (VIDC).

Peacock, D. 2013. Profile: South Africa's Sonke Gender Justice Network: Educating men for gender equality. Agenda, 27(1):128-140.

Peacock, D. \& Levack, A. 2004. The Men as Partners program: reaching men to end gender-based violence and promote sexual and reproductive health. International Journal of Men's Health, 3(3):173-188. 
Pease, B. 2008. Engaging men in men's violence prevention exploring the tensions, dilemmas and possibilities. Australian Domestic and Family Violence Clearinghouse, 17(August).

Pedwell, C. 2007. Gender, embodiment and cultural practice: Towards a relational feminist approach. Unpublished doctoral thesis. London: London School of Economics.

Peralta, R.L. \& Tuttle, L.A. 2013. Male perpetrators of heterosexual-partner-violence: The role of threats to masculinity. The journal of men's studies, 21(3):255-276.

Petitfor, A., Lippman, S.A., Selin, A.M., Peacock, D., Gottert, A., Maman, S., Rebombo, D., Suchindran, C.M., Twine, R., Lancaster, K., Daniel, T., Gómez-Olivé, F., Khan, K. \& MacPhail, C. 2015. A cluster randomized-controlled trial of a community mobilization intervention to change gender norms and reduce HIV risk in rural South Africa: study design and intervention. BMC Public Health, 15:752-758.

Pulerwitz, J., Barker, G. \& Segundo, M. 2004. Promoting healthy relationships and HIV/STI prevention for young men: positive findings from an intervention study in Brazil. Washington DC: USAID.

RAPCAN. 2007. Crime prevention interventions with boys: $A$ review of programmes and exploring what works in the South African context: Seminar report. Cape Town: RAPCAN.

RAPCAN. 2008. Assessing current approaches to the construction of masculinities: A focus on crime and violence prevention with reference to work with boys: Seminar report. Cape Town: RAPCAN.

RapeCrisis. N.d. About Rape. http://rapecrisis.org.za/rape-in-south-africa/ [14.06.2014].

Rasool, S., Vermaak, K., Pharoah, R., Louw, A. \& Stavrou, A. 2002. Violence against women - a national survey. Pretoria: Institute for Security Studies.

Ratele, K. 2012. Violence, militarised masculinity and positive peace. Gender, Peace and Security Occasional Paper, 6.

Remme, M., Michaels-Igbokwe, C. \& Watts, C. 2015. Approaches to scale-up and assessing cost-effectiveness of programmes to prevent violence against women and girls. What works to prevent violence against women and girls evidence reviews Paper 4. WhatWorks, DFID.

Republic of South Africa. 1996. Constitution of the Republic of South Africa Act 108 of 1996. Pretoria: Government Printer.

Republic of South Africa. 1998. Domestic Violence Act 116 of 1998. Pretoria: Government Printer. 
Republic of South Africa. 2007. Criminal Law (Sexual Offences and Related Matters) Amendment Act 32 of 2007. Pretoria: Government Printer.

Rhodes, J.E. \& DuBois, D.L. 2008. Mentoring relationships and programs for youth. Current Directions in Psychological Science, 17(4):254-258.

Ricardo, C. \& Verani, F. 2010. Engaging men and boys in gender equality and health - $A$ global toolkit for action. Brazil: Promundo, UNFPA, MenEngage Alliance.

Roberts, D.E. 1993/94. Rape, violence and women's autonomy. Chicago Kent Law Review, 69:359-388.

Rosenfeld, B.D. 1992. Court-ordered treatment of spouse abuse. Clinical Psychology Review, 12:205-226.

Ross, R. 1999. A concise history of South Africa. Cambridge: Cambridge University Press. Roy, A. \& Das, A. 2014. Are masculinities changing? Ethnographic exploration of a gender intervention with men in rural Maharashtra, India. IDS Bulletin, 45(1):29-38.

Saffitz, J. 2010. Understanding gender-based violence: Evidence from Kilimanjaro Assessment of Rombo and Moshi Rural. African Sociological Review, 14(1):84-101.

Salo, E. 2007. Social construction of masculinity on the racial and gendered margins of Cape Town, in T. Shefer, K. Ratele, A. Strebel, N. Shabalala \& R. Buikema (eds) From boys to men: Social constructions of masculinity in contemporary society. South Africa: UCT Press.

Sartin, R.M., Hansen, D.J. \& Huss, M.T. 2006. Domestic violence treatment response and recidivism: A review and implications for the study of family violence. Aggression and Violent Behavior, 11:425-440.

Schoeman, M. \& Naude, Z. 2007. Add in or add on: The role of gender and the position of women in PCRD, in Implementation of the post-conflict reconstruction and development policy and decision. Lusaka: African Union.

Scott, S. 2010. Revising the total institution: Performative regulation in the reinventive institution. Sociology, 44(2):213-231.

Scott, K.L. \& Wolfe, D.A. 2000. Change among batterers: examining men's success stories. Journal of Interpersonal Violence, 15(8):827-842.

Seedat, M., Van Niekerk, A., Jewkes, R., Suffla, S. \& Ratele, K. 2009. Violence and injuries in South Africa: prioritising an agenda for prevention. The Lancet, 374(August):1011-1022. 
Segal, L. 1993. Changing men: Masculinities in context. Theory and Society, 22(5):625-641.

Shrock, D.P. \& Padavic, I. 2007. Negotiating hegemonic masculinity in a batterer intervention program. Gender \& Society, 21(5):625-649.

Sideris, T. 2004. "You have to change and you don't know how!": Contesting what it means to be a man in a rural area of South Africa. African Studies, 63(1):29-49.

Silvergleid, C.S. \& Mankowski, E.S. 2006. How batterer intervention programs work: Participant and facilitator accounts of processes of change. Journal of Interpersonal Violence, 21(1):139-159.

Simpson, S.S. 1989. Feminist theory, crime and justice. Criminology, 27(4):605-631.

Simpson, T. 2009. "Umkhonto we Sizwe, we are waiting for you": The ANC and the township uprising, September 1984-September 1985. South African Historical Journal, 61(1):158-177.

Sims, J. 1998. Collecting and analysing qualitative data: issues raised by the focus group. Journal of Advanced Nursing, 28(2):345-352.

Slegh, H., Barker, G., Ruratotoye, B. \& Shand, T. 2012. Gender relations, sexual violence and the effects of conflict on women and men in North Kivu, Eastern Democratic Republic of Congo: Preliminary results. Cape Town, Washington DC: Sonke Gender Justice Network, Promundo.

Smeaton, G. \& Byrne, D. 1987. The effects of R-rated violence and erotica, individual differences, and victim characteristics on acquaintance rape proclivity. Journal of Research in Personality, 21(2):171-184.

Sonke Gender Justice. 2006. One Man Can, http://www.genderjustice.org.za/news-item/one$\underline{\text { man-can/ [17.02.2015]. }}$

Sonke Gender Justice. 2007. Prisons Transformation,

http://www.genderjustice.org.za/community-education-mobilisation/prisons-transformation/ [20.10.2015].

Sonke Gender Justice Network. 2008. End of Project report. Cape Town: Sonke Gender Justice.

Sonke Gender Justice. 2015. Digital Stories, http://www.genderjustice.org.za/digital-story/ [02.11.2015]

Sonke Gender Justice. 2015. Vision and Mission, http://www.genderjustice.org.za/aboutus/vision-mission/ [29.10.2015]. 
Sonke Gender Justice Network. 2008. Workshop activities: Talking to men about gender, domestic and sexual violence and HIVIAIDS. Cape Town: Sonke Gender Justice Network.

South African Government. N.d. Violence against women and children, http://www.gov.za/issues/violence-against-women-and-children-0 [14.09.2016].

Statistics South Africa. 2013. Mid-year population estimates. Pretoria: Statistics South Africa. Stith, S.M., Rosen, K.H., Middleton, K.A., Busch, A.L., Lundenberg, K. \& Carlton, R.P. 2000. The intergenerational transmission of spouse abuse: A meta-analysis. Journal of Marriage and Family, 62(3):640-654.

Strebel, A. 1995. Focus groups in AIDS research. Journal of Community and Health Services, 2(2):59-69.

Stuart, G.L., Temple, J.R. \& Moore, T.M. 2007. Improving batterer intervention programs through theory-based research. JAMA, 298(5):560-562.

Suarez, E. \& Gadalla, T.M. 2010. Stop blaming the victim: A meta-analysis on rape myths. Journal of Interpersonal Violence, 25(11):2010-2035.

Suttner, R. 2007. Masculinities in the ANC-led liberation movement, in T. Shefer, K. Ratele, A. Strebel, N. Shabalala \& R. Buikema (eds) From boys to men: Social constructions of masculinity in contemporary society. South Africa: UCT Press.

Suttner, R. 2009. The Jacob Zuma rape trial: Power and African National Congress (ANC) masculinities. NORA - Nordic Journal of Feminist and Gender Research, 17(3):222-236.

Swart, S. 1998. "A boer and his gun and his wife are three things always together": Republican masculinity and the 1914 rebellion. Journal of Southern African Studies, 24(4):737-751.

Taylor, B.G., Davis, R.C. \& Maxwell, C.D. 2001. The effects of a group batterer treatment program: a randomized experiment in Brooklyn. Justice Quarterly, 18(1):172-201.

Terre Blanche, M. \& Kelly, K. 2002. Interpretive methods, in M. Terre Blanche \& K. Durrheim (eds) Research in Practice: Applied methods for the Social Sciences. Cape Town: University of Cape Town Press.

Theidon, K. 2009. Reconstructing masculinities: the disarmament, demobilization and reintegration of former combatants in Colombia. Human Rights Quarterly, 31(1):1-34.

Thomson, M. 2002. Boys will be boys: addressing the social construction of gender, in F. Cleaver (ed) Masculinities Matter! Men, gender and development. Cape Town: David Philip. 
Tshwaranang Legal Advocacy Centre. 2012. Violence against women in South Africa fact sheet. Johannesburg: Tshwaranang Legal Advocacy Centre.

United Nations Inter-Agency Working Group on DDR (UN-IAWG). 2006. Glossary: Terms and Definitions, in Integrated Disarmament, Demobilisation and Reintegration Standards (IDDRS). UN-IAWG.

UN-IAWG. 2012. Blame it on the war? The gender dimensions of violence in disarmament, demobilization and reintegration - report and recommendations for action. Geneva: UNIAWG.

United Nations International Children's Emergency Fund (UNICEF)

United Nations Office on Drugs and Crime (UNODC). 2013. Global study on homicide 2013: Trends, context, data. Vienna: UNODC.

Usdin, S., Scheepers, E., Goldstein, S. \& Japhet, G. 2005. Achieving social change on gender-based violence: A report on the impact evaluation of Soul City's fourth series. Social Science and Medicine, 61:2434-2445.

Van der Keur, D., Vrethen, K., Titley, G. \& Toth, G. 2007. Gender matters: A manual on addressing gender-based violence affecting young people. Budapest: Council of Europe, Directorate of Youth and Sport.

Van Kessel, I. 2000. Beyond our wildest dreams. London: University Press of Virginia. Valasek, K. 2008. Security Sector Reform and Gender, in M. Bastick \& K. Valasek (eds) Gender and Security Sector Reform Toolkit. Geneva: DCAF, OSCE/ODIHR, UN-INSTRAW.

Viitanen, A.P. \& Colvin, C.J. 2015. Lessons learned: program messaging in gendertransformative work with men and boys in South Africa. Global Health Action, 8:27860.

Walby, S. 1990. Theorizing Patriarchy. Oxford: Basil Blackwell.

Wekwete, N.N., Sanhokwe, H., Murenjekwa, W., Takavarasha, F. \& Madzingira, N. 2014. The association between spousal gender based violence and women's empowerment among currently married women age 15-49 in Zimbabwe: Evidence from the 2010-11 Zimbabwe Demographic and Health Survey. African Population Studies, 28(3):1413-1431.

What Works. 2014. Home Page, http://www.whatworks.co.za/ [11.02.2015].

Willig, C. 2000. A discourse-dynamic approach to the study of subjectivity in health psychology. Theory and Psychology, 10(4):547-570. 
Wong, F.Y., Huang, Z.J., DiGangi, J.A., Thompson, E.E. \& Smith, B.D. 2008. Gender differences in intimate partner violence on substance abuse, sexual risks, and depression among a sample of South Africans in Cape Town, South Africa. AIDS Education and Prevention, 20(1):56-64.

World Bank Report. 1996. Demobilisation and reintegration of military personnel in Africa: Evidence from seven country case studies, http://siteresources.worldbank.org/INTCPR/882635-1120216203830/20626336/IDP0130.pdf [15.09.2016].

WHO. 2010. Engaging men and boys in changing gender-inequity in health: evidence from programme interventions. Geneva: WHO.

WHO. 2013. Responding to intimate partner violence and sexual violence against womenWHO clinical and policy guidelines. Geneva: WHO.

Zuckerman, E. \& Greenberg, M. 2004. The gender dimensions of post-conflict reconstruction: an analytical framework for policymakers. Gender \& Development, 12(3):7082. 


\section{APPENDIX A Interview schedules}

\section{$\underline{\text { One Man Can facilitator interview schedule }}$}

* process of developing the workshops - why a masculinities-focused approach? Why focus on GBV and gender inequality? Why not workshops focused on women? Why using workshops?

* aims of workshops - what do the workshops hope to achieve? How are the workshops designed to achieve this? Workshops as stand-alone intervention, or part of broader process? Expected/hoped for outcomes in terms of behaviour and attitudes of participants? What behaviour/attitudes being targeted?

* space for workshops in SA context - what needs to be addressed? What contributes to high rates of GBV in SA? How do workshops aim to address that?

* follow up of participants - any ongoing support for participants? How do they experience the post-workshop period? Ways to keep them involved or engaged? Response from communities - positive/negative? Response from families? Ways to involve families?

* who gets involved? Who needs to get involved? Ways to target those people?

\section{Academic/practitioner interview schedule}

* GBV in SA - causes? Ways to address, and why these should be used?

* masculinities in SA - what causes? Who enforces?

* who should be helping to address? (academics, NGOs, government, churches, media etc.) How? Why? 


\section{Focus groups interview schedule}

* reasons for joining workshops - where did you hear about it? (through others who had participated? If yes, what was their impression/experience?) What kind of information is available about these workshops in your community? What interested you in the workshops, and specifically in a masculinities-focused workshop? Were there any factors that made you feel unwilling to be involved in the workshops? Were others supportive of your decision? * what kinds of people should be attending these workshops? Are they present? If not, why not? If yes, how do you think it affected them? How to bring in the people who need to be there?

* expectations of content and process - what were you expecting the workshops to be about? How were you expecting the workshops to deal with these topics?

* expectations met - were the workshops carried out as you expected? Did they cover the information that you thought they would? What did you think of the content/the way that the workshops were carried out? Do you think it could be done better - why/why not?

* understandings of masculinities in own communities - what does it mean to be a man? What is important to do (and be seen to do) or not to do? How is this enforced/encouraged? Who passes these messages on? Where do these understandings come from? (Family, media, partners, schools, workplaces, churches etc.).

* relations between men and women - who does what in the household or a relationship? What happens if one person does the other's job? Why are these roles in place? Who decides these roles? 


\section{$\underline{\text { Participant interview schedule }}$}

[Questions may be amended depending on the content of the focus groups, and participant's responses. The follow-up interviews will likely focus more on the societal responses, and ways that this can help or hinder the participant to maintain any changes that they feel they have made.]

* impact of workshop on behaviour/attitudes - have they changed? If so, how do you feel your behaviour or attitudes have changed because of the workshops?

* [if not discussed in focus groups] - did the workshops meet your expectations? Why/why not? What was or was not met? Were these differences good or bad? Would you recommend the workshops to others? Why/why not?

* what in workshops made the impact? Which aspects did you feel strongly about? Were there tools to help you keep working on the aspects covered in the workshops?

* societal responses to perceived changes - how have people responded to hearing that you went through the workshops? Have there been positive or negative responses? Who have you spoken to about it? Is there anyone you would not want to discuss it with?

* what helps/makes it hard to maintain any positive changes - is there anyone who has been very supportive of your experience, or helped you since? How? Has there been support from Sonke, or ways to remain involved if you want to? Is there anyone who has not been supportive? In what ways?

* impact of being involved in Community Action Team - does it help to maintain impacts?

Does it create pressure/expectations? How do people respond to your involvement in it?

* why are workshops like this important in your community? Is there violence in the community? If yes, where is the violence coming from? What are ways to start responding to it?

* examples: if a man is hitting his partner, what are possible reasons? (alcohol, it's his right, absent families/fathers) 